


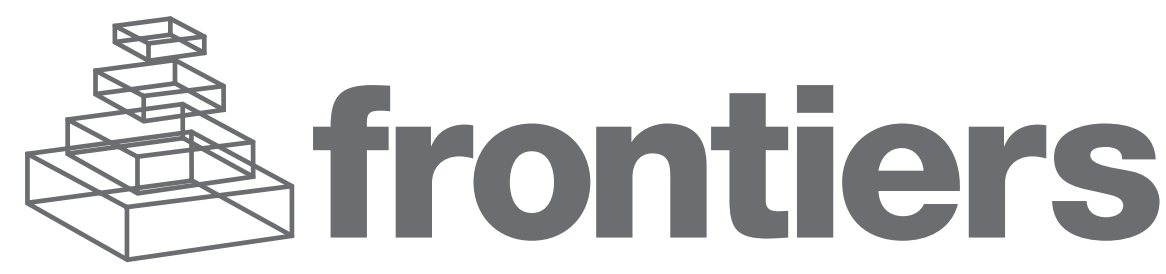

\section{FRONTIERS COPYRIGHT STATEMENT}

C Copyright 2007-2015

Frontiers Media SA.

All rights reserved.

All content included on this site, such as text, graphics, logos, button icons, images, video/audio clips, downloads, data compilations and software, is the property of or is licensed to Frontiers Media SA

("Frontiers") or its licensees and/or subcontractors. The copyright in the text of individual articles is the property of their respective authors, subject to a license granted to Frontiers.

The compilation of articles constituting this e-book, wherever published, as well as the compilation of all other content on this site, is the exclusive property of Frontiers. For the conditions for

downloading and copying of e-books from Frontiers' website, please see the Terms for Website Use. If purchasing Frontiers e-books from other websites or sources, the conditions of the website concerned apply.

Images and graphics not forming part of user-contributed materials may not be downloaded or copied without permission.

Individual articles may be downloaded and reproduced in accordance with the principles of the CC-BY licence subject to any copyright or other notices. They may not be re-sold as an e-book.

As author or other contributor you grant a CC-BY licence to others to reproduce your articles, including any graphics and third-party materials supplied by you, in accordance with the Conditions for Website Use and subject to any copyright notices which you include in connection with your articles and materials.

All copyright, and all rights therein, are protected by national and international copyright laws.

The above represents a summary only. For the full conditions see the Conditions

for Authors and the Conditions for Website Use.

Cover image provided by lbbl sarl Lausanne $\mathrm{CH}$

\section{ABOUT FRONTIERS}

Frontiers is more than just an open-access publisher of scholarly articles: it is a pioneering approach to the world of academia, radically improving the way scholarly research is managed. The grand vision of Frontiers is a world where all people have an equal opportunity to seek, share and generate knowledge. Frontiers provides immediate and permanent online open access to all its publications, but this alone is not enough to realize our grand goals.

\section{FRONTIERS JOURNAL SERIES}

The Frontiers Journal Series is a multi-tier and interdisciplinary set of open-access, online journals, promising a paradigm shift from the current review, selection and dissemination processes in academic publishing.

All Frontiers journals are driven by researchers for researchers; therefore, they constitute a service to the scholarly community. At the same time, the Frontiers Journal Series operates on a revolutionary invention, the tiered publishing system, initially addressing specific communities of scholars, and gradually climbing up to broader public understanding, thus serving the interests of the lay society, too.

\section{DEDICATIONTO QUALITY}

Each Frontiers article is a landmark of the highest quality, thanks to genuinely collaborative interactions between authors and review editors, who include some of the world's best academicians. Research must be certified by peers before entering a stream of knowledge that may eventually reach the public - and shape society; therefore, Frontiers only applies the most rigorous and unbiased reviews.

Frontiers revolutionizes research publishing by freely delivering the most outstanding research, evaluated with no bias from both the academic and social point of view.

By applying the most advanced information technologies, Frontiers is catapulting scholarly publishing into a new generation.

\section{WHAT ARE FRONTIERS RESEARCHTOPICS?}

Frontiers Research Topics are very popular trademarks of the Frontiers Journals Series: they are collections of at least ten articles, all centered on a particular subject. With their unique mix of varied contributions from Original Research to Review Articles, Frontiers Research Topics unify the most influential researchers, the latest key findings and historical advances in a hot research area!

Find out more on how to host your own Frontiers Research Topic or contribute to one as an author by contacting the Frontiers Editorial Office: researchtopics@frontiersin.org 


\section{ATTACHMENT ASSESSMENT IN TREATMENTS, PREVENTION AND INTERVENTION PROGRAMS}

Topic Editor:

Silvia Salcuni, Dipartimento di Psicologia dello Sviluppo e della Socializzazione - DPSS Università degli Studi di Padova, Padova, Italy

Attachment theory, assessment and research offers a broad, far-reaching view of human functioning, and it can enrich a psychologist's understanding of subjects and their relational adjustment, both in clinical and non-clinical settings.

Ongoing research in attachment has led to a number of individual treatments and prevention and intervention programs. The assessment of an individual's attachment organization, can play a crucial role in explaining and previewing the unfolding treatment, the relational adjustments or concerns, and the psychological wellbeing.

We hope to receive empirical papers that give evidence for the usefulness of attachment assessment in both clinical (e.g., patients with Eating Disorder; or Axis-II; psychotherapy patients ...) or not clinical population (e.g. Adoptive and/or foster families or couples, Mother-infant assessment in prevention field ...). These papers should include methodological issues and information about the participants, the methods used to assess attachment, the process of scorer training and the availability of the manual used to obtain inter-scorer reliability. Case studies may be of interest to the extent that they demonstrate the value of a systematic approach to attachment material. A range of theoretical perspectives is welcome as well presentation of new emergent tools on attachment.

Because Frontiers in Psychology is an international journal, each empirical paper should comment on the international implications of the findings and discuss its cross-cultural use. Such comments may include, for example, its linguistic specificity, its robustness in translation, and the cross-cultural generalizability of the constructs and behaviors of the measure and its usual correlates. Cross-cultural generalizability is not, however, a requirement. 


\section{Table of Contents}

04 New Frontiers and Applications of Attachment Theory

Silvia Salcuni

07 Early Interpersonal Neurobiological Assessment of Attachment and Autistic Spectrum Disorders

Allan N. Schore

20 Unresolved Trauma in Mothers: Intergenerational Effects and the Role of Reorganization

Udita lyengar, Sohye Kim, Sheila Martinez, Peter Fonagy and Lane Strathearn

29 Predictors of Mother-Child Interaction Quality and Child Attachment Security in At-Risk Families

Simona De Falco, Alessandra Emer, Laura Martini, Paola Rigo, Sonia Pruner and Paola Venuti

39 Parenting Quality in Drug-Addicted Mothers in a Therapeutic Mother-Child Community: The Contribution of Attachment and Personality Assessment

Francesca De Palo, Nicoletta Capra, Alessandra Simonelli, Silvia Salcuni and Daniela Di Riso

52 Anorexia and Attachment: Dysregulated Defense and Pathological Mourning Elisa Delvecchio, Daniela Di Riso, Silvia Salcuni, Adriana Lis and Carol George

60 The Role of Both Parents' Attachment Pattern in Understanding Childhood Obesity

Claudia Mazzeschi, Chiara Pazzagli, Loredana Laghezza, Giulia Radi, Dalila Battistini and Pierpaolo De Feo

69 The Circle of Security Parenting and Parental Conflict: A Single Case Study Chiara Pazzagli, Loredana Laghezza, Francesca Manaresi, Claudia Mazzeschi and Bert Powell

79 Use of the Adult Attachment Projective Picture System in Psychodynamic Psychotherapy with a Severely Traumatized Patient

Carol George and Anna Buchheim

88 "Achild's Nightmare. Mum Comes and Comforts Her Child." Attachment Evaluation as a Guide in the Assessment and Treatment in a Clinical Case Study Silvia Salcuni, Daniela Di Riso and Adriana Lis

101 Assessing Attachment Representations Among Adoptees During Middle Childhood and Adolescence with the Friend and Familyinterview (FFI): Clinical and Research Perspectives

Cecilia Serena Pace 


\title{
New frontiers and applications of attachment theory
}

\author{
Silvia Salcuni * \\ Dipartimento di Psicologia dello Sviluppo e della Socializzazione, Università degli Studi di Padova, Padova, Italy
}

Keywords: attachment, prevention, intervention, neuroscience, AAP, addiction, trauma, autism

Attachment is a deep and enduring emotional bond that connects one person to another across time and space (Bowlby, 1969; Ainsworth, 1973). Bowlby considered the importance of children's relationship with their mothers in terms of their social, emotional and cognitive development. Specifically, he emphasized the importance of the link between early infant separations from their mothers and related traumatic experiences and later maladjustment. His attachment theory provides a framework able to explain how the parent-child relationship emerges and influences subsequent development, becoming the key determinant of child's social emotional adaptation and cognitive growth (Belski and Fearon, 2002; Bernier and Meins, 2008).

During the last 20 years, attachment theory played an important role in the field of assessment, interventions and psychotherapy, representing the foundation of a wide range of perspectives and practices. Among others, some of such perspectives and practices stand out for their relevant consequences and effects, such as (1) the role of traumatic or neglectful bonds with early caregivers; (2) the importance of assessing patient's attachment pattern, attachment defenses and quality of affect regulation as to plan both individual therapies and dyadic/triadic interventions aimed to promote psychological development and wellbeing in children and adults; (3) the importance of giving the patient a close, intense, emotional and consistent therapeutic relationship (Wallin, 2007). Working within the framework of attachment theory has the ultimate goal of recreating in interventions or in psychotherapeutic treatment an attachment experience "that makes up, at least to some degree, for what the client missed the first time around" (Wylie and Turner, 2011, p.1). In the last years, integration between attachment and neuroscience underlined how "the art of a certain specialized form of relationship and attuned connection, isn't just helping people feel better, but deeply changing the physical function and structure of their brains as well" (Schore and Schore, 2008, 2010; Wylie and Turner, 2011, p. 17; Schore and Newton, 2012).

The present E-book is an interesting collection of original theoretical models, empirical papers in both clinical and non-clinical populations, and single case studies, which provide evidence for the need to move psychological comprehension toward the framework of the attachment theory. All papers share some common issues: first of all, the importance of assessing attachment to improve knowledge about patient's deep and inner relational functioning, emotional regulation and adjustment; second, the main aim is always to use these attachment notions within a multi-method assessment, able to strengthen incremental validity of results and interpretations; and, last but not least, the need to consider not just global attachment classifications (secure, dismissing, preoccupied, and disorganized), but also the implicit dimensions which lead to such general classification, such as coherence of mind, reflective function, evidence of secure base, capacity to act, defensive mechanisms: all these dimensions can offer more relevant information about the patient's inner world. Since each attachment pattern occurs in a unique way, a deeper knowledge about its functioning could provide clinicians with a personalized key of interpretation for each single patient, helping to establish a synchronized and responsive connection, in order to offer a second chance for the construction of a secure base (Wylie and Turner, 2011). 
The E-book starts with an interesting paper written by Schore (2014), in which the author proposes an interpersonal neurobiological theoretical model of early socio-emotional development both for typical and a-typical (autistic) child development. The manuscript is an original work in line with Schore's contributions to affective interactive regulation and neuroscience, and suggests how recent literature on social and emotional functions of the early developing right brain may not only bridge the separate worlds of attachment and autism, but also facilitate more effective attachment and autism models of early intervention.

A series of original studies on mother-child interaction come next: these papers focus on the exploration of mother-child interaction effects in at-risk families (De Falco et al., 2014), in mothers who presented an unresolved trauma (Iyengar et al., 2014), and in drug addicted mothers who were hosted in a therapeutic community with their children (De Palo et al., 2014). Within a multimethod assessment framework, these papers provide insightful indications both of inclusion criteria for intervention programs and of treatment planning to support parenting skills in these specific mother-child dyads.

Other two papers present original research, which focuses on the assessment of attachment in people with eating dysregulation or disorder, using the Adult Attachment Projective Picture System (George and West, 2012). Delvecchio et al. (2014) paper describes a new conceptual model of attachment to understand the role of defensive exclusion in the development of early relationships. Such model is related to subsequent manifestations of symptoms of anorexia. Mazzeschi et al. (2014) manuscript demonstrated the role of paternal and maternal attachment status in the genesis and in the maintenance of childhood obesity. In line with the previous papers, these two contributions propose insightful implications for prevention and clinical intervention too.

A series of really interesting clinical case studies, mostly based on the use of the Adult Attachment Projective Picture System, together with other validated and powerful tools, follow this section and propose important attachment-based recommendations for intervention. First of all, George and Buchheim's (2014) manuscript demonstrates the advantages of using the AAP for the

\section{References}

Ainsworth, M. D. S. (1973). "The development of infant-mother attachment," in Review of Child Development Research, eds B. Cardwell and H. Ricciuti (Chicago, IL: University of Chicago Press), 1-94.

Belski, J., and Fearon, R. M. (2002). Infant-mother attachment security, contextual risk, and early development: a moderational analysis. Dev. Psychopathol. 14, 293-310. doi: 10.1017/S0954579402 002067

Bernier, A., and Meins, E. (2008). A threshold approach to understanding the origins of attachment disorganization. Dev. Psychol. 44, 969-982. doi: 10.1037/0012-1649.44.4.969

Bowlby, J. (1969). Attachment. Attachment and Loss: Vol. 1. Loss. New York, NY: Basic Books.

De Falco, S., Emer, A., Martini, L., Rigo, P., Pruner, S., and Venuti, P. (2014). Predictors of mother-child interaction quality and child attachment security in at-risk families. Front. Psychol. 5:898. doi: 10.3389/fpsyg.2014. 00898 assessment of a traumatized patient in an inpatient setting. They present a case study to illustrate those AAP components that are particularly relevant to a psychodynamic conceptualization. A case reporting a high level of parental conflict is presented by Pazzagli et al. (2014), through the use of the AAP and the Circle of Security Parenting (COS-P); the authors offer specific clinical and contextual indications for the application of COS-P. In the paper devised by Salcuni et al. (2014), a clinical battery composed of AAP, Symptom Check List 90 Revised (SCL-90-R) and ShedlerWesten Assessment Procedure (SWAP-200) was administered in the pre and post assessment phases of a young adult panic disorder patient's psychotherapy; the authors outlined the reasons why they adopted an approach within a psycho-dynamic framework with specific attention to an "attachment theory stance" considered as the treatment of choice for this patient. An original interpretation of change in psychotherapy using the Psychodynamic Diagnostic Manual (PDM) was also included.

As a conclusion, an Opinion paper by Pace (2014) sheds light on the clinical and research perspectives of the Friend and Family Interview (FFI; Steele and Steele, 2005; Steele et al. unpublished manuscript), a novel method developed to assess the IWMs of young individuals, often used with adopted samples, pointing out to the necessity of considering not just the global attachment classifications (secure, dismissing, preoccupied and disorganized), but also other important FFI dimensions (coherence, reflective function, evidence of secure base, etc.) that could offer more relevant information about adoptees' inner world.

\section{Acknowledgments}

At the very end of this Editorial I would like to thank Frontiers staff and Dr. Castelnuovo for the opportunity they gave to me. A special remark goes to all the authors who agreed to participate in this Topic with their original contributions, and to all the reviewers who promoted the quality of research and manuscripts with their punctual comments. Finally, a very special thanks goes to Dr. Diana Miconi and Dr. Gea Calcagno for their precious work and their kind and professional collaboration in the present special issue on attachment.
Delvecchio, E., Di Riso, D., Salcuni, S., Lis, A., and George, C. (2014). Anorexia and attachment: dysregulated defense and pathological mourning. Front. Psychol. 5:1218. doi: 10.3389/fpsyg.2014.01218

De Palo, F., Capra, N., Simonelli, A., Salcuni, S., and Di Riso, D. (2014). Parenting quality in drug-addicted mothers in a therapeutic mother-child community: the contribution of attachment and personality assessment. Front. Psychol. 5:1009. doi: 10.3389/fpsyg.2014.01009

George, C., and Buchheim, A. (2014). Use of the adult attachment projective picture system in psychodynamic psychotherapy with a severely traumatized patient. Front. Psychol. 5:865. doi: 10.3389/fpsyg.2014.00865

George, C., and West, M. (2012). The Adult Attachment Projective Picture System. New York, NY: Guilford Press.

Iyengar, U., Kim, S., Martinez, S., Fonagy, P., and Strathearn, L. (2014). Unresolved trauma in mothers: intergenerational effects and the role of reorganization. Front. Psychol. 5:966. doi: 10.3389/fpsyg.2014.00966

Mazzeschi, C., Pazzagli, C., Laghezza, L., Radi, G., Battistini, D., and De Feo, P. (2014). The role of both parents' attachment pattern in understanding childhood obesity. Front. Psychol. 5:791. doi: 10.3389/fpsyg.2014.00791 
Pace, C. S. (2014). Assessing attachment representations among adoptees during middle childhood and adolescence with the Friend and Family Interview (FFI): clinical and research perspectives. Front. Psychol. 5:1114. doi: 10.3389/fpsyg.2014.01114

Pazzagli, C., Laghezza, L., Manaresi, F., Mazzeschi, C., and Powell, B. (2014). The circle of security parenting and parental conflict: a single case study. Front. Psychol. 5:887. doi: 10.3389/fpsyg.2014.00887

Salcuni, S., Di Riso, D., and Lis, A. (2014). "A child's nightmare. Mum comes and comforts her child." Attachment evaluation as a guide in the assessment and treatment in a clinical case study. Front. Psychol. 5:912. doi: 10.3389/fpsyg.2014.00912

Schore, A. N. (2014). Early interpersonal neurobiological assessment of attachment and autistic spectrum disorders. Front. Psychol. 5:1049. doi: 10.3389/fpsyg.2014.01049

Schore, A. N., and Newton, R. P. (2012). "Using modern attachment theory to guide clinical assessments of early attachment relationships," in Attachment-Based Clinical Work with Children and Adolescents, eds J. E. Bettmann and D. Friedman (New York, NY: Springer), 61-96.

Schore, J. R., and Schore, A. N. (2008). Modern attachment theory: the central role of affect regulation in development and treatment. Clin. Soc. Work J. 36, 9-20. doi: 10.1007/s10615-007-0111-7
Schore, J. R., and Schore, A. N. (2010). "Clinical social work and regulation theory: Implications of neurobiological models of attachment," in Adult Attachment in Clinical Social Work, eds S. Bennett and J. K. Nelson (New York, NY: Springer), 57-75.

Steele, H., and Steele, M. (2005). "The construct of coherence as an indicator of attachment security in middle childhood: the friends and family interview," in Attachment in Middle Childhood, eds K. Kerns and R. Richardson (New York, NY: Guilford Press), 137-160.

Wallin, D. J. (2007). Attachment in Psychotherapy. New York, NY: Guilford Press. Wylie, W. S., and Turner, L. (2011). The attuned therapist: does Attachment theory really matter? Psychoth. Net. 35, 1-19.

Conflict of Interest Statement: The author declares that the research was conducted in the absence of any commercial or financial relationships that could be construed as a potential conflict of interest.

Copyright (C) 2015 Salcuni. This is an open-access article distributed under the terms of the Creative Commons Attribution License (CC BY). The use, distribution or reproduction in other forums is permitted, provided the original author (s) or licensor are credited and that the original publication in this journal is cited, in accordance with accepted academic practice. No use, distribution or reproduction is permitted which does not comply with these terms. 


\title{
Early interpersonal neurobiological assessment of attachment and autistic spectrum disorders
}

\author{
Allan N. Schore* \\ David Geffen School of Medicine, University of California Los Angeles, Northridge, CA, USA
}

\section{Edited by:}

Silvia Salcuni, Università degli Studi di

Padova, Italy

\section{Reviewed by:}

Gabriele Roberto Cassullo, Università degli Studi di Torino, Italy

Alessandra Simonelli, University of

Padova, Italy

\section{*Correspondence:}

Allan N. Schore, David Geffen School of Medicine, University of California Los Angeles, 9817 Sylvia Avenue,

Northridge, CA, USA

e-mail: anschore@aol.com

There is now a strong if not urgent call in both the attachment and autism literatures for updated, research informed, clinically relevant interventions that can more effectively assess the mother infant dyad during early periods of brain plasticity. In this contribution I describe my work in regulation theory, an overarching interpersonal neurobiological model of the development, psychopathogenesis, and treatment of the early forming subjective self system. The theory models the psychoneurobiological mechanisms by which early rapid, spontaneous and thereby implicit emotionally laden attachment communications indelibly impact the experience-dependent maturation of the right brain, the "emotional brain." Reciprocal right-lateralized visual-facial, auditory-prosodic, and tactile-gestural nonverbal communications lie at the psychobiological core of the emotional attachment bond between the infant and primary caregiver. These affective communications can in turn be interactively regulated by the primary caregiver, thereby expanding the infant's developing right brain regulatory systems. Regulated and dysregulated bodily based communications can be assessed in order to determine the ongoing status of both the infant's emotional and social development as well as the quality and efficiency of the infant-mother attachment relationship. I then apply the model to the assessment of early stages of autism. Developmental neurobiological research documents significant alterations of the early developing right brain in autistic infants and toddlers, as well profound attachment failures and intersubjective deficits in autistic infant-mother dyads. Throughout I offer implications of the theory for clinical assessment models. This work suggests that recent knowledge of the social and emotional functions of the early developing right brain may not only bridge the attachment and autism worlds, but facilitate more effective attachment and autism models of early intervention.

\section{Keywords: attachment, autism, interpersonal neurobiology, early intervention, right brain}

\section{INTRODUCTION}

In a recent study on the developmental neurobiological basis of attachment in the journal Neuropsychopharmacology, researchers are boldly asserting, "Understanding the motivational basis of healthy and at-risk parenting may open new theoretical vistas and clinical opportunities and may lead to the construction of more specific interventions that can target disruptions to maternal-infant bonding at an earlier stage and in a more accurate manner" (Atzil etal., 2011, p. 11). And in a concurrent editorial in the Journal of Child and Psychiatry "Developmental neuroscience comes of age," Leckman and March (2011) are articulating the well-established developmental principle that underlies the current intense interest in early assessment: "A scientific consensus is emerging that the origins of adult disease are often found among developmental and biological disruptions occurring during the early years of life" ( $p$. 333). Researchers as well as clinicians are now eagerly looking for clinical applications of current knowledge about the critical biological and psychological aspects of early attachment experiences, both in optimal and non-optimal relational contexts.
Toward that end I have recently offered my own contributions. Over the past two decades I have articulated and expanded regulation theory in order to model how early emotionally laden attachment experiences indelibly impact and alter the early developing right brain, which for the rest of the lifespan is dominant for the non-verbal, holistic, spontaneous (unconscious) processing of emotional information and social interactions, for enabling the organism to regulate affect and cope with stresses and challenges, and thereby for emotional resilience and emotional well-being in later stages of life (Schore, 1994, 2003a,b, 2012a). Modern attachment theory (Schore and Schore, 2008, 2010) represents a neurobiological update of John Bowlby's seminal work. The more comprehensive model, regulation theory offers an overarching interpersonal neurobiological model of the development, psychopathogenesis, and treatment of the early forming subjective self system. In a number of current publications in the clinical literature I am using my work on regulation theory as a guide for formulating early assessments of mother-infant attachment relationships (Schore, 2012a, 2013; Schore and Newton, 2012). In this work I describe my ongoing attempts to apply the theory to clinical practice in order to generate more effective evidence-based models of early assessment, intervention, and prevention. 
The assessment model of regulation theory emerges from a foundation of three organizing principles. First, the construct of interpersonal neurobiology, that the structure and function of the mind and brain are shaped by social experiences, especially those involving emotional relationships. The fundamental core principle of the body of my work dictates that, "the selforganization of the developing brain occurs in the context of a relationship with another self, another brain" (Schore, 1996, p. 60). A number of research and clinical disciplines are now emphasizing the "relational" or "intersubjective" principle in models of human development, over the life span (Schore, 2014). Regulation theory describes the interpersonal neurobiology of attachment and the development of intersubjectivity. This clearly implies that a central focus of an early assessment is on the dynamics of the attachment relationship, and on the developing infant's evolving capacity for intersubjectivity (Schore, 2012a; Ammaniti and Gallese, 2014).

Second, recent advances in our understanding of the ontogeny of brain lateralization now indicate that a critical period of growth in the right hemisphere precedes that in the left in human infancy. Two decades ago I proposed that attachment experiences specifically impact the early developing right brain (Schore, 1994). I also presented extant studies which reported that the infant's right hemisphere begins a growth spurt in the last trimester of pregnancy and ends in the middle/end of the second year, when the left hemisphere begins its own, a period that also marks the end of the human brain growth spurt. A number of anatomical and imaging studies now document earlier maturation of the right hemisphere in prenatal and postnatal stages of human development (Gupta et al., 2005; Sun et al., 2005; Mento et al., 2010). This body of research clearly indicates that attachment transactions influence the "early life programming of hemispheric lateralization" (Stevenson et al., 2008) that underlies the dominance of the right hemisphere in the first year of life (Chiron et al., 1997).

In addition to laterality research on the developing brain, studies on the adult brain are now shifting the classical "single brain" paradigm to a "dual brain" paradigm, and exploring precisely how the two cerebral hemispheres mediate different modes of experiencing and coping with the external world. In his monumental overview of current brain asymmetry research, neuropsychiatrist Iain McGilchrist puts forth the argument that the difference between the two brain hemispheres is profound. The right and left hemispheres create coherent, utterly different, and often incompatible versions of the world with competing priorities and values, and indeed two modes of being. He concludes, when the right hemispheric mode is dominant, "we experience - the live, complex, embodied world of individual, always unique beings, forever in flux, a net of interdependencies, forming and reforming wholes, a world with which we are deeply connected" (2009, p. 31). Hecht (2014) cites even more recent lateralization research which indicates that the right hemisphere is the primary driver of the innate psychobiological need for affiliation and social connection, and thereby for emotion regulation and personal growth. The essential adaptive right brain functions of interdependence, social connection, and emotion regulation emerge out of early attachment experiences, and they need to be assessed during the critical period.
Third, on the basis of the principle of hierarchical brain organization I have offered a model of the ontogeny of the emotion processing limbic system, which is shaped by the mother-infant attachment relationship (Schore, 2000, 2005). It is well-established that the right cortical hemisphere, more so than the left, is particularly well reciprocally connected with limbic and subcortical regions, and that the functional maturation of cortical-limbic circuits is significantly influenced by early socio-emotional experience. In his classic volume Bowlby's (1969) speculated about an attachment "biological control system" that regulates the limbic system and is structured as a "hierarchical mode of organization." Following this idea in a pair of articles in the 2001 issue of the Infant Mental Health Journal I articulated a model of the pre- and postnatal ontogeny of the hierarchically organized limbic system, which suggests that a number of discrete limbic components come online and develop connectivity in a defined sequence in the first year (Schore, 2001a,b). The model proposes that the neuroanatomy of the emotion processing limbic system is characterized as series of hierarchically organized "control systems" or "hubs" in the right amygdala, right anterior cingulate, and right orbitofrontal cortex, (Schore, 2003a, 2012a,b, 2013).

In line with the morphogenetic principle of caudal to rostral brain development, regulation theory proscribes a maturational sequence over prenatal to postnatal stages of more complex rightlateralized control (regulatory) systems in the amygdala, then anterior cingulate, then orbitofrontal cortex. This hierarchical circuit of emotion regulation is imprinted in affective attachment transactions over the course of first year, bottom-up, that is, subcortical to cortical, amygdala at the beginning of the first year to orbital prefrontal cortical at the end of infancy. Research now demonstrates subcortical components of the limbic system (e.g., amygdala) mature earlier than the cortical components, and that their maturation is influenced by attachment experiences. It is often overlooked that the first year is a time of tremendous expansion of subcortical brain areas. Knickmeyer et al. (2008) report that the volume of the human subcortical area (including brainstem) increased by $130 \%$ in the first year of human life. Early assessments need to shift from later maturing cortical executive functions to earlier-developing subcortical functions.

Integrating the preceding three developmental organizing principles of interpersonal neurobiology, right brain lateralization, and ontogenetic progression of hierarchical regulatory systems, I offer a psychoneurobiological model that can be used to evaluate the burgeoning attachment system, as it is evolving in real developmental time. This interpersonal neurobiological assessment of social-emotional development attempts to observe and document, in any specific case, the dynamic impact of the right brain emotion transacting attachment relationship on the infant's developing right-lateralized limbic system. Modern attachment theory also offers an heuristic model of both optimal and less than optimal early right brain development. The model suggests that optimal development in infancy reflects a growth-facilitating relational context that promotes the progression of more complex limbic control systems in the right brain that support a foundation of later emotional-wellbeing. On the other hand, less than optimal right brain development is associated with various growth-inhibiting relational contexts that generate altered 
subcortical-cortical patterns of limbic-autonomic connectivity, or even structural and neuropathological alterations within the regulatory hubs themselves, and thereby inefficient control functions. Interpersonal neurobiological assessments of both the infantmother relationship and the infant's social-emotional development should be done over the course of the first year, during the critical periods of maturation of right-lateralized amygdala, anterior cingulate, and orbitofrontal limbic regulating control systems.

But how can an individual infant's right brain socialemotional development be compared to a psychobiological standard of optimal normative versus non-optimal "high-risk" social-emotional development? In my pair of Infant Mental Health Journal articles I contrasted optimal right brain development in secure attachments with non-optimal right brain development in contexts of relational trauma (abuse and/or neglect) associated with disorganized-disoriented insecure attachments. In subsequent work I utilized the perspective of regulation theory and the construct of "relational trauma" to model the role of right brain attachment trauma in the psychopathogenesis of a DSM Axis 1 disorder (post-traumatic stress disorder, Schore, 2003b) as well as Axis 11 disorders (borderline personality disorder and antisocial personality disorder; Schore, 2002, 2003a, Meares et al., 2011).

In this paper I apply the regulation model of early assessment to another Axis 1 "developmental disturbance," autistic spectrum disorders, which manifest both early appearing neurobiological disturbances and severe developmental psychopathology. In light of the longstanding gap, indeed disconnect between the attachment and autism worlds, it may seem surprising that attachment theory can make important contributions to a deeper understanding of autism. This work bears directly upon the clinical need for the early identification of what has previously been called "infantile autism."

Indeed, echoing the call for early interventions by attachment scientists cited above, autism researchers studying "the very early autism phenotype" are now asserting, "One purpose of the earlier identification is that treatments delivered at very young ages, when the brain is most plastic, may ultimately lessen or prevent the lifelong challenges associated with autism" (Yirmiya and Ozonoff, 2007, p. 9). The fact that both fields are intensely focused on social-emotional development in the prenatal, perinatal, and postnatal stages of human infancy highlights the problem of the early differential diagnosis of these developmental disorders. In classic writings on childhood autism Rutter (1978, pp. 146-147) observed, "there is a lack of attachment behavior and a relative failure of bonding," but also noted that "a failure of bonding is also seen in conditions other than autism" which show a different "style of social interaction." At present there is agreement that most children who experience attachment disorders do not develop autistic spectrum disorders, and that attachment disorders are much more common than autism. That said, both fields have now embraced an epigenetic perspective, which suggests that they may share at least some common psychoneurobiological etiological factors.
In the upcoming first section of this work I describe how the first 2 years of life represents a sequence of critical periods for the relationally driven maturation of the right brain, the "emotional brain." More and more complex rapid, spontaneous, and thereby implicit right-lateralized visual-facial, auditoryprosodic, and tactile-gestural communications lie at the psychobiological core of the emotional attachment bond between the infant and primary caregiver. These affective communications can in turn be interactively regulated by the primary caregiver, thereby expanding the infant's developing right brain regulatory systems. Regulated and dysregulated bodily based communications can be assessed in order to determine the ongoing status of both the infant's emotional and social development and the quality and efficiency of the infant-mother attachment relationship. In the second section I offer an overview of current research from developmental neuroscience on the early stages of autism. I also report recent studies on alterations of right brain limbic structures in developing autistic brains, as well as a growing body of research demonstrating early appearing deficits in intersubjective behavior in autistic mother-infant dyads. This work suggests that the emotion-processing limbic system and the "emotional" right brain may bridge not only attachment and autism neurobiology, but attachment and autism models of early intervention.

\section{CLINICAL IMPLICATIONS OF REGULATION THEORY FOR EARLY ATTACHMENT ASSESSMENTS}

Neurobiologically informed models of modern attachment theory advance Bowlby's (1969) basic tenet that attachment is biological in nature, and underscore the morphogenetic role of the attachment relationship in the structural connectivity of the right brain, the emergence of emotional regulation, and the development of the implicit subjective self. J. R. Schore and I have suggested that the current expansion of Bowlby's seminal ideas allows for "new understandings in clinical assessments, shaping therapeutic interventions from relevant theory" (Schore and Schore, 2008, p. 17, authors italics). Toward that end regulation theory can be used to guide the assessment of attachment episodes of rapid, spontaneous, implicit visual-facial, auditory-prosodic, and tactile-gestural affective communications, in which the primary caregiver interactively regulates the infant's internal states of peripheral and central arousal. In this section I describe current developmental neuroscience findings on the infant and maternal processing of these sensoriaffective communications. These studies are organized as a temporal sequence over the course of the first year. I also offer clinical implications of the research studies for assessments of social-emotional development. Due to space limitations I refer the reader to Schore (2012a, 2013) for specific references to the following.

With respect to visual-facial attachment communications, it is now established that mutual gaze is critical to early social development. The emergence of the capacity to efficiently process information from faces requires visual input to the right (and not left) hemisphere during infancy. At 2 months of age, the onset of a critical period during which synaptic connections in the developing occipital cortex are modified by visual experience, infants show right hemispheric activation when exposed to a 
woman's face. Using electroencephalography (EEG) methodology, Grossmann etal. (2007) report that 4-month-old infants presented with images of a female face gazing directly ahead show enhanced gamma electrical activity over right prefrontal areas. Recent near-infrared spectroscopy (NIRS) research (perhaps the most suitable of all neuroscience techniques applicable to human infants) reveals that specifically the 5-month-old's right hemisphere responds to images of adult female faces. By 6 months infants show a right-lateralized, left gaze bias when viewing faces, right temporal activation when looking at angry faces, and significantly greater right frontotemporal activation when viewing their own mother's (as opposed to a stranger's) face.

Note the developmental progression over the first year to more complex visual-affective functions. These research data indicate that the future capacity to process the essential social information expressed in face-to-face communications, a central aspect of all later intimate relationships, is dependent upon caregiverinfant eye contact and visual gazing during early critical periods. Thus, how often and in what contexts the mother and infant spontaneously look (and not look) directly at each other is of key importance to a clinician when evaluating both an infant's development and the health of the dyadic relationship. When there is mutual infant-caregiver visual gazing that looks and feels natural, the clinician implicitly knows that the infant's brain is likely developing well in this area.

Ongoing studies of prenatal, perinatal, and postnatal auditoryprosodic attachment communications also highlight the role of the right brain. In an EEG study of auditory pitch processing in preterm infants born at 30 gestational weeks, Mento et al. (2010) conclude, "the earlier right structural maturation in fetal epochs seems to be paralleled by a right functional development" ( $p$. 1). A functional magnetic resonance imaging (MRI) study of 1- to 3-day-old newborns reports that music evokes right hemispheric activation in the auditory cortex. Using NIRS with 2- to 6-day-old neonates, Telkemeyer et al. (2009) observe, "responses to slow acoustic modulations are lateralized to the right hemisphere" (p. 14726). This same optical brain imaging technology reveals that prosodic processing of emotional voices in 3-monthold and 4-month-old infants activates the right temporoparietal region. Grossmann et al. (2010) report that 7-month-old infants respond to emotional voices in a voice-sensitive region of the right superior temporal sulcus, and happy prosody specifically activates the right inferior frontal cortex. These authors conclude, "The pattern of findings suggests that temporal regions specialize in processing voices very early in development and that, already in infancy, emotions differentially modulate voice processing in the right hemisphere" (p. 852). At 11-months the voice of a woman's child-directed speech (i.e., with somewhat exaggerated prosody), elicits a right-lateralized event-related potential.

Furthermore, neuroscience now supports the principle that the caregiver's use of infant-directed speech ("motherese") is critical for the development of the posterior areas of the right hemisphere that process prosodic-emotional functions. Independent of culture infant-directed speech is preferred over adult-directed speech as early as a few weeks after birth. Compared to adultdirected speech, motherese, the vocal expression of emotion to infants, is higher in pitch, has a wider pitch range, and exhibits exaggerated pitch contours. In addition, it is shorter, slower, and separated by longer pauses than adult speech. Developmental neurobiological research demonstrates that maternal infant directed speech activates the right temporal area of 4to 6-month-old infants, and that this activation is even greater in 7- to 9-month-old infants. In 11-month-old infants, the voice of a woman's infant-directed speech (i.e., with somewhat exaggerated prosody) elicits a right-lateralized event-related potential.

Again, note the developmental progression of auditory affective functions that allow for more complex communication. The emotional quality of what infants hear in the early stages of infancy affects the development of the voice processing areas of the right hemisphere, especially the temporal voice areas in the upper banks of the right superior temporal sulcus. Clinically, these studies indicate the importance of assessing not the verbal content but the melody of the mother's voice, and whether or not she's using infant-directed versus adult-directed speech in her interactions with her child, especially in both arousal reducing calming-soothing and arousal amplifying playful contexts. This use of infant-directed speech is essential to the development of the infant's right temporal areas, and the burgeoning ability of reading the emotional tone of the voice of others, is an essential element of all later social relationships.

In terms of tactile-gestural attachment communications, Sieratzki and Woll (1996) describe the effects of touch on the developing right hemisphere, and assert that the emotional impact of touch is more direct and immediate if an infant is held to the left side of the body ("left sided cradling"). Clinical research demonstrates the essential role of maternal "affective touch" on human infant development in the first year of life. This allows the infant and mother to create a system of "touch synchrony" in order to alter vagal tone and cortisol reactivity. The dyad thus uses "interpersonal touch" as a communication system, especially for the communication and regulation of emotional information. Other studies report high levels of tactile stimulation and mutual touch occur in breastfeeding, and an increase in EEG amplitude in right posterior cortical areas in 6-month-old infants during the intense somatosensory tactile contact of breastfeeding.

This research supports the infant's need for affectionate touch for healthy right hemisphere development, which can be observed in an infant-caregiver assessment. Clinicians need to appraise not only the quality and amount of spontaneous caregiver-infant direct pupil-focused eye gazing and auditory communications but also the quality and amount of sensitive interpersonal touch the infant is receiving and expressing. Left versus right sided cradling should be assessed, since right cradling has been associated with maternal depression and maternal stress. The finding that adults who cradle on the right are more detached and less responsive to their infants than those who cradle on the left can also be used diagnostically (see Schore, 2013).

As the securely attached infant enters toddlerhood, his or her interactively regulated right brain visual-facial, auditory-prosodic, and tactile-gestural communications become holistically integrated, allowing for the emergence of a coherent right brain emotional and corporeal subjective sense of self. Confirming 
this model of the critical importance of right brain-to-right attachment communications in the progressive social experiencedependent lateralization of the right brain, neuroscientists now document that the right brain hemisphere is dominant in human infants, that the strong and consistent predominance for the right hemisphere emerges postnatally, and that the mother's right hemisphere is more involved than the left in emotional processing and mothering. Studying structural connectivity asymmetry in the perinatal brain with newborn infants at the beginning of the first year, Michael Meaney and his colleagues conclude,

[I]n early life the right cerebral hemisphere could be better able to process ... emotion (Wada and Davis, 1977; Schore, 2000). This idea appears consistent with our findings of rightward asymmetry in ... limbic structures ... These neural substrates function as hubs in the right hemisphere for emotion processes and mother and child interaction (Ratnarajah et al., 2013, p. 193, my italics)

Tronick's recent research on infants in the middle of the first year reports 6-month-old infants use left sided gestures generated by the right hemisphere in order to cope with the stressful face-to-face- still face paradigm. They interpret this data as being "consistent with Schore's (2005) hypotheses of hemispheric right-sided activation of emotions and their regulation during infant-mother interactions" (Montirosso et al., 2012, p. 826). Using NIRS Minagawa-Kawai's etal. (2009, p. 289) study of infant mother attachment at the end of the first year observe, "Our results are in agreement with that of Schore (2000) who addressed the importance of the right hemisphere in the attachment system".

Consonant with Bowlby's deduction that the hierarchically organized attachment control system is centrally involved in the organism's states of arousal, my work indicates that at the most fundamental level, the attachment mechanism is expressed as right brain-to-right brain interactive regulation of affective arousal, and thereby the regulation of biological synchronicity between and within organisms. Bowlby (1969, p. 156) speculated, the "upgrading of control during individual development from simple to more sophisticated is no doubt in large part a result of the growth of the central nervous system." Earlier I described the emergence of a hierarchical sequence of interconnected limbic "control systems" or "hubs" in the right amygdala, right anterior cingulate, and right orbitofrontal cortex. These three systems interconnect with each other and with arousal regulating bioaminergic neuromodulatory dopaminergic, noradrenergic, and serotonergic nuclei in the brainstem and midbrain, as well as with neuroendocrine nuclei in the hypothalamus, the "head ganglion" of the autonomic nervous system, and therefore each inputs the stress regulating hypothalamic-pituitary-adrenocortical (HPA) axis.

Each hierarchical level of the three tiered limbic system processes and imprints a positive or negative hedonic charge on current exteroceptive information about changes in the external social environment and then integrates it with interoceptive information about concurrent alterations in internal bodily states. Although all process exteroceptive and interoceptive information, the later maturing systems in the cortex process this information in a more complex fashion than the earlier subcortical components. The output of the lowest level limbic levels is expressed as automatic innate reflexes, while higher processing produces more flexible intuitive responses that allow fine adjustment to environmental circumstances. In three dimensions, the attachment control system is hierarchically structured as an outerlater developing orbitofrontal-limbic regulated core, an inner earlier-developing cingulate-limbic regulating core, and an earliest evolving amygdala-regulated core, like nested Russian dolls.

In my most recent articulation of this model of the ontogenetic progression of hierarchical limbic-autonomic regulatory centers, I offer evidence showing that the amygdala (especially the central nucleus), the paraventricular areas of the hypothalamus that produce the stress reducing neuropeptide oxytocin and the stress intensifying neuropeptide corticotropin releasing factor, and the insula, involved in stress-responsive visceroautonomic functions, begin their maturation prenatally and are functional at birth and over the ensuing perinatal stage (Schore, 2012a). In light of the fact that the emotional state of the mother influences the fetus, assessing the emotional well-being of the mother-to-be in pregnancy is critical.

At 2-3 months the right basolateral amygdala, which densely connects with higher cortical areas, begins a critical period of growth, initiating the infant's burgeoning intersubjective functions. From 3 to 9 months, the anterior cingulate, a cortical-limbic structure associated with responsivity to social cues comes online, giving the infant even greater capacities for intersubjectivity and for receiving non-verbal communications of "good-enough" caregiver interactive regulation. From 10 to 12 months of age the regulatory center in the orbitofrontal cortex, the attachment executive control system, begins its developmental growth period, which spans until the end of the second year (Schore, 2000). With optimal relational attachment experiences, the vertical axis that connects the right orbitofrontal cortex with subcortical areas is well developed, allowing the right orbitofrontal cortex to regulate the right amygdala.

Indeed, developmental neurobiological research reveals that the most rapid change in brain maturation occurs in the first 3-6 months of life, followed by slower change until 24 months, and relative stability after 24 months (Hermoye et al., 2006). Other studies demonstrate that amygdala function contributes to human attachment security (Lemche et al., 2006), and that the process of coping with early life stress increases the myelination of the orbitofrontal cortex that controls arousal regulation and thereby promotes emotional resilience (Katz et al., 2009). For the rest of the life span the right, and not left lateralized prefrontal regions are responsible for the most complex regulation of affect and stress (Schore, 1994; Sullivan and Gratton, 2002; Cerqueira et al., 2008; Czeh et al., 2008; Quirin et al., 2013). The right orbitofrontal cortex imprints internal representations of attachment experiences in implicit-procedural memory, thereby generating an internal working model that encodes non-conscious strategies of affect regulation. This regulatory system, the hierarchical the apex of the limbic system, is responsible for the adaptive capacities of emotional communication and regulation that is found in secure children. On the other hand functional limitations of the orbitofrontal system are seen in insecure attachment and a wide variety of psychiatric disorders (see Schore, 2003a,b, 2012a). 
This ontogenetic hierarchical model suggests that right brain assessments need to be timed to crucial period transitions of the three regulatory systems (2-3, 10-12, 18-24 months), periods of complex reorganizations of the emotion processing limbic system. As the securely attached infant moves through infancy and toddlerhood, his or her interactively regulated intersubjective right brain visual-facial, auditory-prosodic, and tactile-gestural attachment communications become holistically integrated, allowing for the emergence of a right brain coherent emotional and corporeal subjective sense of self and a background state of wellbeing. The non-verbal implicit social-emotional capacities and deficits of both the infant's and the mother's right-lateralized self system are a central focus of attachment assessments. Left hemispheric verbal explicit measures cannot tap into these implicit psychoneurobiological mechanisms. In addition to ongoing clinical intersubjective evaluations, clinicians should investigate the use of current research methodologies as a potential source of developmental neuropsychological assessment tools.

\section{CLINICAL IMPLICATIONS OF REGULATION THEORY FOR THE EARLY ASSESSMENT OF AUTISTIC SPECTRUM DISORDERS}

As previously mentioned, there is now intense interest in the problem of early intervention and assessment of not only burgeoning attachment disorders but also the earliest expression of autistic spectrum disorders, infantile autism. Autism is now viewed as a lifelong, complex neurodevelopmental disorder that severely impairs social interaction. Core symptoms include abnormal or unreciprocated interpersonal and emotional interactions, disordered social communication, and repetitive and stereotypic behaviors and restricted interests. At present it is thought that its onset most likely occurs in the latter part of the first year of life (Hazlett etal., 2005), although the field is now searching for neurobiological expressions of autism in even earlier periods of development. In a recent review Yirmaya and Charman (2010) highlight the importance of "brain development and the prodrome of autism spectrum disorders," noting that the finding of abnormal brain growth has "attracted enormous interest."

A large body of neurobiological studies reveals gross, widespread abnormalities in multiple areas of the autistic brain, including larger global brain volume in the first year (Courchesne et al., 2003). Autism is now characterized as a disorder of aberrant neural circuitry, and very recent research with infants at 6 months shows atypical patterns of connectivity of a number of white matter fiber tracts "not specific to any single brain region or behavioral domain" (Wolff et al., 2012, p. 596). These authors note that the earliest stages of infancy represent periods when "dramatic changes in behavior are paralleled by dramatic changes in the brain" (p. 590), and so "Extending neuroimaging downward to infants younger than 6 months would help clarify the temporal origin of diverging trajectories" (p. 597). The field is presently poised to begin more comprehensive studies of the prenatal, perinatal and early postnatal periods. Yirmaya and Charman (2010) assert, "Prenatal and perinatal environmental challenges during the course of pregnancy are likely causes of deleterious epigenetic modifications to the fetal brain with long-term developmental consequences, including risk and to autistic spectrum disorders" (p. 446).

Recall Kanner (1943) originally suggested that autistic individuals "come into the world with an innate inability to form the usually biologically provided affective contact with other people" (p. 250, my italics). Although the past two decades of autism research has been influenced almost exclusively by cognitive developmental psychology and cognitive neuroscience, there is currently a growing interest in altered development within autistic emotion processing "limbic circuitry" (Haznedar et al., 2000). Yirmaya and Charman (2010) observe,

\begin{abstract}
The window of this abnormal brain growth coincides with the period of synaptogenesis and subsequent pruning when cortical connections are developed, refined and stabilized. This process is interactive with the infant's experience of the environment .... and the consequences of a developing brain whose connections are not undergoing the usual refinement on information processing ... may result in ... the emergence of the ASD phenotype (p. 443, my italics)
\end{abstract}

This clearly implies that updated models of autistic etiology are now shifting into the interactive relational model used in other developmental neuropsychiatric disorders, that is, the infant's interactions with the social-emotional environment (the attachment relationship) directly influence the development of the autistic infant brain.

In their overview of the field Yirmaya and Charman (2010) refer to "an intriguing finding" that by the age of 2 years children with autism had "enlarged amygdala, particularly in the right hemisphere" (p. 443). Indeed six studies now document a "pathological enlargement of the amygdala" in autistic infants, toddlers, and young children (Sparks et al., 2002; Munson et al., 2006; Mosconi et al., 2009; Schumann et al., 2009; Kim et al., 2010; Nordahl et al., 2012). Mosconi et al. (2009) suggest "failure to orient to faces and, more specifically, the eye region of the face is inherent in multiple aspects of social impairment unique to autism (e.g., joint attention, facial emotion processing) ... may be linked to amygdala abnormalities" (p. 510).

Studying children as young as 18 months Munson et al. (2006) report an association between enlarged right (and not left) amygdala volume with poorer socialization and communication development as measured on the Autism Diagnostic Interview and Vineland Scale. They speculate right amygdala enlargement may reflect "right-sided amygdala activation in response to conditioned fear" (p. 690). Commenting on this amygdala enlargement in 18-months-old toddlers Schumann et al. (2009) state, "The amygdala has long been a site of intense interest in the search for neuropathologic markers for autism, given its well-established role in the production and recognition of emotions and modulatory role in social behavior. Initial signs of autism in toddlers include unusual affective behavior, reduced social interest, and poor eye contact, which are all suggestive of aberrant amygdalar function." (p. 942). The problem of diminished attention to faces early on "may be the first in a cascade of problems that lead to later emotional and social impairments" (p. 947). Furthermore, they conclude that the autistic toddler's dysfunctional hyperaroused amygdala "suggests a heightened emotional, or even 
fearful, response when autistic individuals look at another person's eyes, regardless of whether they are familiar or a stranger" (p. 947).

This body of research clearly implies that autistic infants and toddlers experience a chronic intense fear state in the first 2 years of infancy, and that this needs to be assessed. The finding that early developing right basolateral amygdalar enlargement, associated with amygdalar hyperreactivity and abnormal fear conditioning persists in 6-to 7-year old children (Kim et al., 2010) strongly suggest that a chronic fear-based subjectivity continues in the autistic child's mind. My own studies on early relational trauma, disorganized attachment, and the origins of post-traumatic stress disorder implicate the right amygdala in states of fear conditioning (Baker and Kim, 2004) and "unseen fear" (Morris et al., 1999), in both hyperaroused amygdala terror states and hypoaroused amygdala dissociative, detached states of emotional withdrawal (Schore, 2001b, 2002, 2009, 2012a). This work describes not only attachment experiences of traumatic affective arousal, but the unique defenses that the infant (and mother) use to counteract traumatic hyperarousal, dissociation, "the escape when there is no escape," "the last resort defensive strategy," "detachment from an unbearable situation" (Schore, 2001a).

In the infant mental health and infant psychiatry literatures Guedeney and Fermanian (2001) describe the "sustained withdrawal" of the disorganized infant, manifested in frozen, absent facial expression; total avoidance of eye contact; immobile level of activity; absence of vocalization; absence of relationship to others; and the impression that the child is beyond reach. In a subsequent study Guedeney et al. (2008) observe withdrawn social behavior from as early as 2 months in "autism, chronic or severe pain, failure to thrive, or post-traumatic stress disorder” (p. 151, my italics). Other research reports hyporesponsivesness to social stimuli (e.g., lack of orienting to novel sounds and attention disengagement) in 6-month-old autistic infants (Baranek et al., 2013). Indeed in a case study Dawson et al. (2000) documents an infant with autism's "checking out" after over-stimulation at 2.5 months, and presenting a "transfixed stare" during eye contact at 9 months. The right amygdala findings in autistic toddlers indicate that pathological dissociation needs to be recognized and studied by autism researchers.

Developmental neuroscience also implicates another component of limbic circuitry, the right anterior cingulate (that is strongly connected with the right amygdala) in autism. Allman et al. (2006) describe Von Economo neurons (VENs) in the anterior cingulate and fronto-insular cortex of humans that are part of the circuitry supporting social bonding. They observe that the VEN number is low at birth but increase in early development, that they are $30 \%$ more numerous in the right hemisphere than the left, and that this ratio develops in the early postnatal period. These authors state the strong and consistent predominance for the right hemisphere emerges postnatally, that this right hemisphere VEN predominance may be related to the right hemispheric specialization for the social-emotions and therefore important for normal functioning, and therefore deviations from this ratio could be dysfunctional. Thus "their emergence might be disrupted during postnatal development with dysfunctional consequences related to neuropsychiatric disorders" (p. 367). Functionally this right anterior cingulate system is involved in the fast intuitive assessment of complex social situations. Allman et al. (2006) propose, "in autism spectrum disorders the VENs fail to develop normally and that this failure could be partially responsible for the social disabilities in these disorders as a result of faulty intuition. Our theory predicts that autistic subjects will be abnormal in making intuitive decisions under conditions involving a high degree of uncertainty" (p. 372). Supporting this model they cite an MRI study of autistic individuals that reports the area of the anterior cingulate in the right hemisphere that contains the VENs is reduced in volume (Haznedar et al., 2000). I suggest that during the critical period of development of these VEN neurons some autistic infants may experience stressful levels of allostatic overload (McEwen, 2007) that induces an apoptotic destruction of these neurons of the developing anterior cingulate, an essential subsystem of right lateralized limbic circuits that evolve in the first year. This psychoneurobiological mechanism may underlie early autistic "regressive" phenomena (Yirmaya and Charman, 2010).

Von Economo neurons are also found in the human frontoinsular cortex. The right insula, a limbic structure that has extensive connections with the amygdala (Hoistad and Barbas, 2008), is involved in emotional and facial processing (Berthier etal., 1987), in integrating tonal structure with a speaker's emotions and attitudes (Riecker et al., 2000), and in visceral and autonomic functions that mediate the generation of an image of one's physical state (Craig, 2011). This limbic structure is activated by perceptual awareness of threat (Critchley et al., 2002), and harm avoidance (Paulus et al., 2003). It is also implicated in pain processing and serves as an alarm center, "alerting the individual to potentially distressing interoceptive stimuli, investing them with negative emotional significance" (Banzett et al., 2000, p. 2120). These functions may be severely altered in the autistic brain. Research documents that at 2 years a group of autistic toddlers exhibit sensory abnormalities, hyperesthesia or hypoesthesia to pain and touch, and hyperactivity in the somatosensory (parietal) areas of the right (and not left) hemisphere (Miyazaki et al., 2007).

Along with the right anterior cingulate, the right insula is a "hub" of a "salience network" that integrates external sensory stimuli with internal states, and thereby is implicated in subjective awareness and interoception (Craig, 2011). Autistic children show alterations in connectivity between the insula and anterior cingulate (Uddin and Menon, 2009), reflecting disturbances in affective processes and difficulty with adapting to change, restrictive and repetitive behavior, and increased sensitivity to visual, auditory, and tactile stimuli (Uddin et al., 2013). These latter authors conclude that altered connectivity between the insula and anterior cingulate underlies a dysfunction in identifying relevant internal and extrapersonal stimuli to guide behavior, and therefore "dysfunction of the system may be part of the neurobiology of autism." Other studies of emotional face processing deficits in autism that show increased activity in salience detection in the right amygdala and insula (Monk et al., 2010). The insular dysfunction of autism thus reflects an impairment in what Craig (2010) calls "a sentient self." 
With regard to the highest level of the hierarchical emotion processing limbic circuit, Sabbagh (2004) asserts that the ability to decode others' mental states from facial expressions is mediated by the orbitofrontal/medial temporal circuit within the right hemisphere. Offering a neurobiological model of autism he describes a "core deficit" and concludes, "The developmental roots of autism might lie in abnormal functioning of the orbitofrontal/medial temporal circuit which may, in turn, underlie the abnormal development of social-cognitive skills among individuals with autism." Baron-Cohen, whose group first proposed the amygdala theory of autism (Baron-Cohen et al., 2000), now postulates an atypical selfrepresentation in autism, involving dysfunctional processing in the cingulate and ventromedial (orbitofrontal) cortex (Lombardo et al., 2010).

Indeed for over two decades I have offered interdisciplinary data indicating that the right hemispheric orbitofrontal cortex and its cortical and subcortical connections support the adaptive functions of the implicit self system (see Schore, 2012a, pp. 295-296 for a large body of research confirming right hemispheric activity in generating self-awareness and self-recognition). The term "autism" is derived from the Greek word "autos," meaning self, and since Kanner's groundbreaking work autism has been associated with an atypical sense of self. In an extensive neurobiological overview of atypical development of self-related processes in autism spectrum disorders Lyons and Fitzgerald (2013) cite my work and others and conclude,

[T]here is substantial evidence that the main components of selfawareness including self-recognition, self-other differentiation, body awareness, theory of mind, intersubjectivity, emotion processing, language (pronoun reversal, inner speech, third person perspective), autobiographical memory and narrative self are impaired in ASD. Our review of neural substrates underlying these processes has highlighted the significance of the Right Hemisphere. (p. 753)

These authors contend that the developmental organization of the early developing self depends on relations with others, and that these early experiences are vital to right brain maturation. They conclude that "right hemisphere impairment leads to a dysfunctional self-development in autism spectrum disorders" ( $p, 754)$, and that "substantial behavioral evidence of infants who later developed autism is supporting the theory of disrupted intersubjective behavior" (p. 755, my italics).

In fact, a small but extremely important group of recent studies are now exploring very early deficits in "intersubjective communication" and "emotional attachment" in autistic infants. In groundbreaking clinical research using micro-analytic analysis of home videos Trevarthen and Daniel (2005) report disorganized rhythm and synchrony in the dyadic play of an 11-month-old autistic infant and her father. Their interactional analysis also reveal reduced motor capacities, as well as "abnormal withdrawal or detachment," specifically documenting that the interaction was characterized by "long blank periods lacking in shared experience" (p. S29), clearly describing dissociative withdrawal. The authors assert that these deficits in infant intersubjectivity and mutual reciprocity that underlie "asynchronous social behavior" reflect alterations in "both brain growth and early development of skills and sociability" (p. S25).
Expanding upon this work Muratori's etal. (2011) laboratory has offered the most productive studies of the very earliest manifestations of autism. Analyzing home videos of spontaneous interactions of autistic infants and their caregiver over three trimesters of the first 18 months ( $0-6,6-12$, and over 12 months), their video coding of interactions within a time window of $3 \mathrm{~s}$ includes "maintain social engagement" (operationally defined as "The infant takes up an active role within a two-way interaction in order to keep the caregiver involved. The infant interacts, vocalizes and maintains turn taking"), as well as "regulation" ["The caregiver modulates the infant's arousal and mood; the caregiver may act to either excite (up-regulation) or calm-down (down-regulation) the infant"]. They document that autistic infants show, in the first semester, a reduction in the duration of spontaneous social behavior "such as enjoying with people and maintaining social engagement," and "the capacity on the one hand to express and to repeat affective states, and on the other hand to be attentive and to read the affective states of the other" (p. 413). In the second semester they observe further difficulties in the development of intersubjectivity, expressed in a decreased tendency to orient to their own name, typically seen at 9 months. They conclude,

[D]ifferent intersubjective abnormalities operate during the first year to impede its development. These abnormalities reduce the typical propensity of infants and toddlers to be active in seeking interactive experiences and in sympathizing intentions and feelings of others. Sideby-side, primary caregiver-infant interactions are shaped by the lack of infant intersubjectivity (Muratori et al., 2011, p. 409, my italics).

In a subsequent study these researchers used more complex computational methods to analyze interaction synchrony from home movies in order to differentiate autism from intellectual disability and typical development over the first three trimesters (Saint-Georges et al., 2011). Summarizing caregiver-infant interactions in typically developing babies, they assert,

[V]ocalizations are predominant from birth ... While seeking people peaks significantly at second semester ... intersubjective behavior continues to grow significantly over the semesters. Thus in the second semester, a typical child is rather seeking and attending to his caregiver and little by little turns to objects ... This pattern describes the typical development of shared or joint attention. (p. 10)

Describing typical caregiver behavior in these same two periods of the first year they state,

(Caregiver) vocalizations are predominant from birth. We can assume that this type of stimulation which has its roots in animal communication is the more powerful way to strengthen child attention and affective communication. Probably it happens thanks to prosodic cues specific to infant directed speech ... caregiver gestural solicitations increase during the first year. (p. 10)

Note this description echoes my studies of right brain prosody and gestures.

In contrast, "autistic children show less orienting toward people in the first semester, and thereafter they exhibit a much smaller increase of seeking people behaviors" (p. 10). Importantly, orienting and being receptive toward people is not active, but passive. They conclude,

Thus, it seems that the real marker for atypical social development is the weakness in initiating a social interaction: without the increase 
in social initiative the ability to be receptive and responding to others also become more severe ... All these results are consistent with the hypothesis of a growing deviant development in autistic disorders. (p. 10, my italics)

On the caregiver side, they observe that in response to a socially under-active autistic infant (lack of initiative, inability to provoke or to anticipate other's aims, hypo-activity), the parent assumes that the infant needs to be more stimulated, and by the second trimester a parent adopts a hyper-stimulating style. Doussard-Roosevelt et al. (2003) and Trevarthen and Daniel (2005) also report parents of autistic children overstimulate their infants as a result of their inactivity. (I'd suggest this could be a relational context that increases infant dissociative withdrawal). On the basis of these data Saint-Georges et al. (2011) recommend assessment/screening in the first 6 months and parent-infant training in the second trimester.

In the most recent publication of this group Apicella et al. (2013) again report less infant motor activity in the first trimester and lower amounts of vocalizations in the second. They cite Grossmann et al.'s (2010) study on right-lateralized voice processing in 4 and 7 month infants (described in the first section of this paper), and propose, "The reduced use of vocalizations to respond could suggest that, in infants with autistic spectrum disorders, the original vocalizations do not develop into a vocal communication able to respond, engage in dialog" (p. 8). As for caregivers' behaviors, they document a reduction in affectionate touch (less caressing or kissing) in the second trimester, suggesting that it represents a response to the infant's atypically reduced motor and vocal development, and that this non-synchronic motor-vocal pattern may interfere with the development of reciprocity. On the other hand they also report an increase in caregiver's stimulating gestures (gesticulating, tickling, making faces, or presenting objects to the infant), which also may be "the way parents infants with ASD adapt to their less responsive child" (p. 9).

It is interesting to note that the primary caregiver's reduction in affectionate, loving touch may be understood as a maternal coping mechanism of defensive withdrawal in response to the intense stressor of an increasingly emotionally unresponsive autistic infant, one who is becoming more and more unable to respond to the love of the mother. In other words the intensely stressful interpersonal neurobiological context of the autistic infant-mother interaction may in some cases dyadically generate a detached "refrigerator mother." It is frequently forgotten that a dysregulated infant may be a source of relational stress for the mother.

These studies that directly assess real-life, real-time reciprocal social interactions represent a potential paradigm shift in autism research, assessment, and treatment. Saint-Georges et al. (2011) assert that the use of engineering methods related to detecting spontaneous social signal processing allows "focusing on dynamic parent-infant interaction instead of single behaviors of the baby or of the parent" (p. 9). This methodology of studying interactions rather than discrete behaviors of each member of the dyad mirrors the theoretical perspective of my interpersonal neurobiological work on right brain-to-right brain intersubjective emotional communications. Trevarthen and Daniel (2005) state that the "modern diagnosis of autism" reflects the prevailing view of psychological growth as "the development of cognition," and that to date it has ignored "the special significance of interpersonal factors" such as "infant subjectivity." They conclude autism fundamentally represents "a failure in the integration of motives to move in purposeful ways with self awareness, and also to difficulties with intuitive awareness of other persons' motives and states of mind. The processes that make these functions possible are not explained by cognitive neuroscience" (p. S26). For some time now both autism research and treatment have been dominated by cognitive science, cognitive neuroscience, and cognitive developmental psychology. But with a renewed interdisciplinary focus on the very early development of not left brain cognitive but right brain socialemotional survival functions and the emergence of the implicit self there is now a possibility of reforging a bridge between autism and attachment-informed treatment models, including models of early assessment and intervention.

In light of the fact that the primordial etiology of autism, attachment disorders, and indeed all early forming psychiatric disorders takes place in universally shared prenatal, perinatal, and postnatal stages of human brain development, developmental neuroscience may play a key role in this rapprochement. According to regulation theory all human infants, with whatever early genetic endowments and in both positive growth-facilitating or growth-inhibiting relational contexts, progress through the same critical periods of attachment-influenced right brain development and stages of selforganization. Both the significant degree of brain dysfunction and level of psychopathology of autistic disorders, which are essentially relational, intersubjective, social-emotional and not merely cognitive disturbances, are clearly more widespread than attachment disorders or early forming personality disorders.

The neurobiological alterations of organized insecure attachments are mainly focal alterations of cortical limbic-autonomic circuitry, while disorganized attachments show more subcortical right amygdala dysfunction. Autistic disorders involve more global alterations of various brain circuits, both subcortical and cortical. Although the right amygdala is functionally deficient in both disorganized attachment disorders and autism, early amygdala pathological enlargement and brain hypertrophy are unique to autism. It is now thought that "the processes that lead to autistic spectrum disorders probably begin during fetal development" (Abel etal., 2013, p. 391). A very recent study of RNA in situ hybridization of the brains of autistic children reports patches of pathological disorganization in regions mediating social and emotional functions. The authors conclude, "Our data are consistent with an early prenatal origin of autism or at least prenatal processes that may confer a predisposition to autism" (Stoner et al., 2014, p. 1216).

Based on these data I would speculate that in autism stressful alterations of the right amygdala occur prenatally due to untoward intrauterine influences of the social and physical environment that substantially compromise the very early development of the midbrain reticular formation - bioaminergic (dopaminergic, noradrenergic, serotonergic) nuclei that innervate the fetal amygdala. These bioamines, central to emotional functioning, have energy regulating, arousal generating, and trophic functions. For example, in utero early pathological mechanisms within 
midbrain ventral tegmental dopaminergic subnuclei could alter dopamine's trophic functions and impair mesolimbic dopaminergic innervation of the central (and then basolateral amygdala). These systems may also be sensitive to gestational neurotoxic pesticide exposure, which has also been implicated in autism (Shelton et al., 2012).

On the other hand right amygdala alterations in disorganized attachments may result from epigenetic mechanisms associated with stressful perinatal and postnatal social environments. Attachment disorders reflect delayed connectivity or "immaturity" of the limbic-autonomic circuits of the right brain, whereas the "complex neurodevelopmental" autistic disorders reflect altered connectivity and "developmental derangement" of the right brain. The biological mechanisms that underlie the neuropathology of the "growing deviant development in autistic disorders" are now thought to produce an individual deviation from normative developmental processes (Jones and Klin, 2013). In autism developmental neuropathology is expressed not only in the right amygdala but in all three regulatory control systems, again suggesting a progressive metabolic failure of bioaminergic innervation, even in postnatal critical periods. Research strongly suggests that during prenatal and postnatal critical periods, aberrant DNA methylation, excessive oxidative cell damage, apoptosis, and mitochondrial dysfunction may underlie the metabolic pathology of the developing autistic brain (e.g., Melnyk et al., 2012). In any event, the earlier described progression of right brain subcortical and cortical attachment functions and structures also apply to early assessments of the ontogeny of autism.

\section{CONCLUSION}

At the outset of this work I described a major goal of autism researchers - to create "treatments delivered at very young ages, when the brain is most plastic, may ultimately lessen or prevent the lifelong challenge associated with autism" (Yirmiya and Ozonoff, 2007, p. 9, my italics). The importance of early intervention in not just autism but in all developmental disorders is stressed in a number of disciplines: infant mental health, child psychology and psychiatry, pediatrics, clinical social work, and developmental neuroscience. Authors in this latter field assert, "Although the first year of life may be a period of developmental vulnerability, it may also be a period in which therapeutic interventions would have the greatest positive affect (Knickmeyer et al., 2008, pp. 12179-12180, my italics)."

Regulation theory highlights the potentially optimizing effects of early interventions within prenatal, perinatal, and postnatal critical periods of brain development. The theory has recently been applied to using maternal-infant interactions as a mechanism for reducing the effects of allostatic load on premature infant neurodevelopment in neonatal intensive care units (Weber et al., 2012), for differentially diagnosing attachment disorders from infantile autism in the first year (Schore, 2013; Voran, 2013), and for generating an evidence-based interpersonal neurobiological model of attachment assessments and interventions (see Schore and Newton, 2012 for applications to a clinical case, the assessment and treatment of a 7-month-old infant and his mother).

Although left hemispheric language disturbances appear later in the second and third year, the common underlying social impairment symptoms of autism spectrum disorders, abnormal or unreciprocated interpersonal and emotional interactions and disordered social communication present in the first year. In human infancy "communication" is not verbal but non-verbal communication, a specialization of the right hemisphere. The early evolving core symptomatology of infantile autism describes a developmental neuropathology and developmental psychopathology of the early developing right hemisphere, which for the rest of the lifespan is dominant for the implicit non-verbal, holistic processing of rapidly communicated emotional information and spontaneous social interactions (Decety and Lamm, 2007; Semrud-Clikeman et al., 2011; Schore, 2012a). Very recent research reveals decreased spontaneous attention to social stimuli in 6 month-old infants later diagnosed with autism spectrum disorders (Chawarska et al., 2013). A developmental neuropsychological study of these implicit spontaneous functions demonstrates that "the social choices of children with autism were influenced less by emotional information presented subconsciously and suggest a subcortical contribution to the social/emotional processing deficits observed with autism" (Hall et al., 2007, p. 100). Although both the analytic left hemisphere and holistic right hemisphere are impacted by a common neuropathological process, at the core, autism represents a severe impairment of the right-lateralized implicit cortical-subcortical implicit self system that acts unconsciously, beneath levels of conscious awareness (Schore, 1994, 2003b, 2012a).

Developmental assessments of human social-emotional (as opposed to cognitive) development need to focus attention on rapid dyadic right brain-to-right brain visual, auditory, tactile (and olfactory) attachment communications that can either facilitate or inhibit the experience-dependent maturation of the infant's developing right brain. Modern attachment theory can be used as a guide for assessing a misattuned infant/caregiver relationship by observing, experiencing and evaluating the intersubjective communication of affects and the interactive regulation of affective arousal between the infant's and mother's right brains (see Schore, 2012a, pp. 389-393, for schematics of regulated and dysregulated right brain attachment communications). Early chronic failures of interactive arousal regulation are expressed not only in intersubjective deficits but also in dysregulated fear-driven subjective states of consciousness in the infantile autistic brain. Regulation theory dictates that assessments of infant mental health (Schore, 2001b) in the first and second year must be relational, and need to utilize non-verbal, bodily based measures of early forming right brain intersubjective relational affectivity (implicit affect regulation), and not later forming left brain verbal language-based measures (explicit mentalization).

Early assessments of "high-risk dyads" can easily transition into clinical interventions that potentially are able to expand the mother's implicit capacities for interactive affect regulation, the core of the attachment dynamic, thereby creating a growth-facilitating environment for infant right brain development. This work suggests that modern attachment theory can act as a catalyst for the potential cross-fertilization of the attachment and autism worlds, one that can lead to more effective 
clinical intervention models. In the case of infantile autism timely neurochemical interventions may also be used to prevent oxidative damage of the developing brain (e.g., Main et al., 2012) and to enhance psychological interventions (Gordon et al., 2013).

The interpersonal neurobiological perspective of regulation theory supports the clinical principle that effective early intervention during critical periods of heightened brain plasticity can facilitate the expansion of the right brain not only in infancy, but over the course of the rest of the life span. A large body of developmental psychiatric research confirms the idea that "Most mental illnesses... begin far earlier in life than was previously believed" (Insel and Fenton, 2005, p. 590). Neurobiologically informed programs of early intervention could thus bring us closer to a common goal of psychology and psychiatry, the optimization of emotional well-being and the prevention of emotional disorders.

\section{REFERENCES}

Abel, K. M., Dalman, C., Svensson, A. C., Susser, E., Dal, H., Idring, S., et al. (2013). Deviance in fetal growth and risk of autism spectrum disorder. Am. J. Psychiatry 170, 391-398. doi: 10.1176/appi.ajp.2012.12040543

Allman, J. M., Watson, K. K., Tetreault, N. A., and Hakeem, A. Y. (2006). Intuition and autism: a possible role for Von Economo neurons. Trends Cogn. Sci. 9, 367373. doi: 10.1016/j.tics.2005.06.008

Ammaniti, M., and Gallese, V. (2014). The Birth of Intersubjectivity. New York: W. W. Norton \& Company, Inc.

Apicella, F., Chericoni, N., Costanzo, V., Baldini, S., Billeci, L., Cohen, D., et al. (2013). Reciprocity in interaction: a window on the first year of life in autism. Autism Res. Treat. 2013:705895. doi: 10.1155/2013/705895

Atzil, S., Hendler, T., and Feldman, R. (2011). Specifying the neurobiological basis of human attachment: brain, hormones, and behavior in synchronous and intrusive mothers. Neuropsychopharmacology 36, 2603-2615. doi: 10.1038/npp.2011.172

Baker, K. B., and Kim, J. J. (2004). Amygdalar lateralization in fear conditioning: evidence for greater involvement of the right amygdala. Behav. Neurosci. 118, 15-23. doi: 10.1037/0735-7044.118.1.15

Banzett, R. B., Mulnier, H. E., Murphy, K., Rosen, S. D., Wise, R. J. S., and Adams, L. (2000). Breathlessness in humans activates insular cortex. Neuroreport 11, 2117-2120. doi: 10.1097/00001756-200007140-00012

Baranek, G. T., Watson, L. R., Boyd, B. A., Poe, M. D., David, F. J., and McGuire, L. (2013). Hyporesponsiveness to social and nonsocial sensory stimuli in children with autism, children with developmental delays, and typically developing children. Dev. Psychopathol. 25, 307-320. doi: 10.1017/S0954579412001071

Baron-Cohen, S., Ring, H. A., Bullmore, E. T., Wheelwright, S., Ashwin, C., and Williams, S. C. (2000). The amygdala theory of autism. Neurosci. Biobehav. Rev. 24, 355-364. doi: 10.1016/S0149-7634(00)00011-7

Berthier, M., Starkstein, S., and Leiguarda, R. (1987). Behavioral effects of damage to the right insula and surrounding regions. Cortex 23, 673-678. doi: 10.1016/S00109452(87)80057-6

Bowlby, J. (1969). Attachment and Loss: Attachment, Vol. 1. New York: Basic Books.

Cerqueira, J., Almeida, O. F. X., and Sousa, N. (2008). The stressed prefrontal cortex. Left? Right! Brain Behav. Immun. 22, 630-638. doi: 10.1016/j.bbi.2008. 01.005

Chawarska, K., Macari, S., and Shic, F. (2013). Decreased spontaneous attention to social scenes in 6-month-old infants later diagnosed with autism spectrum disorders. Biol. Psychiatry 74, 195-203. doi: 10.1016/j.biopsych.2012. 11.022

Chiron, C., Jambaque, I., Nabbout, R., Lounes, R., Syrota, A., and Dulac, O. (1997). The right brain hemisphere is dominant in human infants. Brain 120, 1057-1065. doi: 10.1093/brain/120.6.1057

Courchesne, E., Carper, R., and Akshoomoff, N. (2003). Evidence of brain overgrowth in the first year of life in autism. JAMA 290, 337-344. doi: 10.1001/jama.290.3.337

Craig, A. D. (2010). The sentient self. Brain Struct. Funct. 214, 563-577. doi: $10.1007 /$ s00429-010-0248-y
Craig, A. D. (2011). Significance of the insula for the evolution of human awareness of feelings from the body. Ann. N. Y. Acad. Sci. 1225, 72-82. doi: 10.1111/j.17496632.2011.05990.x

Critchley, H. D., Mathias, C. J., and Dolan, R. J. (2002). Fear conditioning in humans: the influence of awareness and autonomic arousal on functional neuroanatomy. Neuron 33, 653-663. doi: 10.1016/S0896-6273(02)00588-3

Czeh, B., Perez-Cruz, C., Fuchs, E., and Flugge, G. (2008). Chronic stress-induced cellular changes in the medial prefrontal cortex and their potential clinical implications: does hemisphere location matter? Behav. Brain Res. 190, 1-13. doi: 10.1016/j.bbr.2008.02.031

Dawson, G., Osterling, J., Meltzoff, A. N., and Kuhl, P. (2000). Case study of the development of an infant with autism from birth to two years of age. J. Appl. Dev. Psychol. 21, 299-313. doi: 10.1016/S0193-3973(99)00042-8

Decety, J., and Lamm, C. (2007). The role of the right temporoparietal junction in social interaction: how low-level computational processes contribute to metacognition. Neuroscientist 13, 580-593. doi: 10.1177/1073858407304654

Doussard-Roosevelt, J. A., Joe, C. M., Bazhenova, O. V., and Porges, S. W. (2003). Mother-child interaction in autistic and nonautisitic children: characteristics of maternal approach behaviors and child social responses. Dev. Psychopathol. 15, 277-295. doi: 10.1017/S0954579403000154

Gordon, I., Vender Wyk, B. C., Bennett, R. H., Cordeaux, C., Lucas, M. V., Eilbott, J. A., et al. (2013). Oxytocin enhances brain function in children with autism. Proc. Natl. Acad. Sci. U.S.A. 110, 20953-20958. doi: 10.1073/pnas. 1312857110

Grossmann, T., Johnson, M. H., Farroni, T., and Csibra, G. (2007). Social perception in the infant brain: gamma oscillatory activity in response to eye gaze. Soc. Cogn. Affect. Neurosci. 2, 284-291. doi: 10.1093/scan/nsm025

Grossmann, T., Oberecker, R., Koch, S. P., and Friederici, A. D. (2010). The developmental origins of voice processing in the human brain. Neuron 65, 852-858. doi: 10.1016/j.neuron.2010.03.001

Guedeney, A., and Fermanian, J. (2001). A validity and reliability study of assessment and screening for sustained withdrawal in infancy: the alarm distress scale. Infant Ment. Health J. 22, 559-575. doi: 10.1002/imhj.1018

Guedeney, A., Foucault, C., Bougen, E., Larroque, B., and Mentre, F. (2008). Screening for risk factors of relational withdrawal behavior in infants aged 14-18 months. Eur. Psychiatry 23, 150-155. doi: 10.1016/j.eurpsy.2007.07.008

Gupta, R. K., Hasan, K. M., Trivedi, R., Pradhan, M., Das, V., Parikh, N. A., et al. (2005). Diffusion tensor imaging of the developing human cerebrum. J. Neurosci. Res. 81, 172-178. doi: 10.1002/jnr.20547

Hall, G. B. C., West, C. D., and Szatmari, P. (2007). Backward masking of reduced subcortical amygdala engagement in autism. Brain Cogn. 65, 100-106. doi: 10.1016/j.bandc.2007.01.010

Hazlett, H., Poe, M., Gerig, G., Smith, R., Provenzale, J., Ross, A., et al. (2005). Magnetic resonance iomaging and head circumference study of brain size in autism birth through 2 years. JAMA 62, 1366-1376.

Haznedar, M. M., Buchsbaum, M. S., Wei, T.-C., Hof, P. R., Cartwright, C., Bienstock, C. A., et al. (2000). Limbic circuitry in patients with autism spectrum disorders studied with positron emission tomography and magnetic resonance imaging. Am. J. Psychiatry 157, 1994-2001. doi: 10.1176/appi.ajp.157.12.1994

Hecht, D. (2014). Cerebral lateralization of pro- and anti-social tendencies. Exp. Neurobiol. 23, 1-27. doi: 10.5607/en.2014.23.1.1

Hermoye, L., Saint-Martin, C., Cosnard, G., Lee, S.-K., Kim, J., Nassogne, M.-C., et al. (2006). Pediatric diffusion tensor imaging: normal database and observation of the white matter maturation in early childhood. Neuroimage 29, 493-504. doi: 10.1016/j.neuroimage.2005.08.017

Hoistad, M., and Barbas, H. (2008). Sequence of information processing for emotions through pathways linking temporal and insular cortices with the amygdala. Neuroimage 40, 1016-1033. doi: 10.1016/j.neuroimage.2007.12.043

Insel, T. R., and Fenton, W. S. (2005). Psychiatric epidemiology. It's not just about counting anymore. Arch. Gen. Psychiatry 62, 590-592. doi: 10.1001/archpsyc.62.6.590

Jones, W., and Klin, A. (2013). Attention to eyes is present but in decline in 26-month-old infants later diagnosed with autism. Nature 504, 427-431. doi: 10.1038 /nature 12715

Kanner, L. (1943). Autistic disturbances in affective contact. Nerv. Child 2, 217-250. Katz, M., Liu, C., Schaer, M., Parker, K. J., Ottet, M.-C., Epps, A., et al. (2009). Prefrontal plasticity and stress inoculation-induced resilience. Dev. Neurosci. 31, 293-299. doi: 10.1159/000216540 
Kim, J., Lyoo, I. K., Estes, A. M., Renshaw, P. F., Shaw, D. W., Friedman, S. D., et al. (2010). Laterobasal amygdalar enlargement in 6- to 7-year-old children with autism spectrum disorder. Arch. Gen. Psychiatry 67, 1187-1197. doi: 10.1001/archgenpsychiatry.2010.148

Knickmeyer, R. C., Gouttard, S., Kang, C., Evans, D., Wilber, K., Smith, J. K., et al (2008). A structural MRI study of human brain development from birth to 2 years. J. Neurosci. 28, 12176-12182. doi: 10.1523/JNEUROSCI.3479-08.2008

Leckman, J. F., and March, J. S. (2011). Editorial: developmental neuroscience comes of age. J. Child Psychol. Psychiatry 52, 333-338. doi: 10.1111/j.14697610.2011.02378.x

Lemche, E., Giampietro, V. P., Surguladze, S. A., Amaro, E. J., Andrew, C. M., Williams, S. C. R., et al. (2006). Human attachment security is mediated by the amygdala: evidence from combined $\mathrm{fMRI}$ and psychophysiological measures. Hum. Brain Mapp. 27, 623-635. doi: 10.1002/hbm.20206

Lombardo, M. V., Chakrabarti, B., Bullmore, E. T., Sadek, S. A., Pasco, G., Wheelwright, S. J., et al. (2010). Atypical neural self-representation in autism. Brain 133, 611-624. doi: 10.1093/brain/awp306

Lyons, T., and Fitzgerald, M. (2013). Recent Advances in Autism Spectrum Disorders, Vol. 1. Rijeka: In Tech.

Main, P. A. E., Angley, M. T., O’Doherty, C. E., Thomas, P., and Fenech, M. (2012). The potential role of the antioxidant and detoxification properties of glutathione in autism spectrum disorders: a systematic review and meta-analysis. Nutr. Metab. (Lond.) 9:35. doi: 10.1186/1743-7075-9-35

McEwen, B. S. (2007). Physiology and neurobiology of stress and adaptation: central role of the brain. Physiol. Rev. 87, 873-904. doi: 10.1152/physrev.00041.2006

Meares, R., Schore, A. N., and Melkonian, D. (2011). Is borderline personality disorder s particularly right hemispheric disorder? A study of P3a using single trial analysis. Aust. N. Z. J. Psychiatry 45, 131-139. doi: 10.3109/00048674.2010. 497476

Melnyk, S., Fuchs, G. J., Schulz, E., Lopez, M., Kahler, S. G., Fussell, J. J., et al. (2012). Metabolic imbalance associated with methylation dysregulation and oxidative damage in children with autism. J. Autism Dev. Disord. 42, 367-377. doi: 10.1007/s10803-011-1260-7

Mento, G., Suppiej, A., Altoe, G., and Bisiacchi, P. S. (2010). Functional hemispheric asymmetries in humans: electrophysiological evidence from preterm infants. Eur J. Neurosci. 31, 565-574. doi: 10.1111/j.1460-9568.2010.07076.x

Minagawa-Kawai, Y., Matsuoka, S., Dan, I., Naoi, N., Nakamura, K., and Kojima, S. (2009). Prefrontal activation associated with social attachment: facialemotion recognition in mothers and infants. Cereb. Cortex 19, 284-292. doi: 10.1093/cercor/bhn081

Miyazaki, M., Fujii, E., Saijo, T., Mori, K., Hashimoto, T., Kagami, S., et al. (2007). Short-latency somatosensory evoked potentials in infantile autism: evidence of hyperactivity in the right primary somatosensory area. Dev. Med. Child Neurol. 49, 13-17. doi: 10.1017/S0012162207000059.x

Monk, C. S., Weng, S. J., Wiggins, J. L., Kurpati, N., Louro, H. M. C., Carrasco, M., et al. (2010). Neural circuitry of emotional face processing in autism spectrum disorders. J. Psychiatry Neurosci. 35, 105-114. doi: 10.1503/jpn. 090085

Montirosso, R., Cozzi, P., Tronick, E., and Borgatti, R. (2012). Differential distribution and lateralization of infant gestures and their relation to maternal gestures in the Face-to-Face Still-Face paradigm. Infant Behav. Dev. 35, 819-828. doi: 10.1016/j.infbeh.2012.07.005

Morris, J. S., Ohman, A., and Dolan, R. J. (1999). A subcortical pathway to the right amygdala mediating "unseen" fear. Proc. Natl. Acad. Sci. U.S.A. 96, 1680-1685 doi: $10.1073 /$ pnas.96.4.1680

Mosconi, M. W., Cody-Hazlett, H., Poe, M. D., Gerig, G., Gimpel-Smith, B. A., and Piven, J. (2009). Longitudinal study of amygdala volume and joint attention in 2- to 4-year-old children with autism. Arch. Gen. Psychiatry 66, 509-516. doi: 10.1001/archgenpsychiatry.2009.19

Munson, J., Dawson, G., Abbott, R., Faja, S., Webb, S. J., Friedman, S. D., et al. (2006). Amygdalar volume and behavioral development in autism. Arch. Gen. Psychiatry 63, 686-693. doi: 10.1001/archpsyc.63. 6.686

Muratori, F., Apicella, F., Muratori, P., and Maestro, S. (2011). Intersubjective disruptions and caregiver-infant interactions in early autistic disorder. Res. Autism Spectr. Disord. 5, 408-417. doi: 10.1016/j.rasd.2010.06.003

Nordahl, C. W., Scholz, R., Yang, X., Buonocore, M. H., Simon, T., Rogers, S., et al. (2012). Increased rate of amygdala growth in children aged 2 to 4 years with autism spectrum disorders. Arch. Gen. Psychiatry 69, 53-61. doi: 10.1001/archgenpsychiatry.2011.145

Paulus, M. P., Rogalsky, C., Simmons, A., Feinstein, J. S., and Stein, M. B. (2003). Increased activation in the right insula during risk-taking decision making is related to harm avoidance and neuroticism. Neuroimage 19, 1439-1448. doi: 10.1016/S1053-8119(03)00251-9

Quirin, M., Gruber, T., Kuhl, J., and Düsing, R. (2013). Is love right? Prefrontal resting brain asymmetry is related to the affiliation motive. Front. Hum. Neurosci. 7, 1-11. doi: 10.3389/fnhum.2013.00902

Ratnarajah, N., Rifkin-Graboi, A., Fortier, M. V., Chong, Y. S., Kwek, K., Saw, S.M., et al. (2013). Structural connectivity in the neonatal brain. Neuroimage 75, 187-194. doi: 10.1016/j.neuroimage.2013.02.052

Riecker, A., Ackermann, H., Wildgruber, D., Dogil, G., and Grodd, W. (2000). Opposite hemispheric lateralization effects during speaking and singing at motor cortex insula and cerebellum. Neuroreport 11, 1997-2000. doi: 10.1097/00001756200006260-00038

Rutter, M. (1978). Diagnosis and definition of childhood autism. J. Autism Child. Schizophr. 8, 139-161. doi: 10.1007/BF01537863

Sabbagh, M. A. (2004). Understanding orbitofrontal contributions to theoryof-mind reasoning: implications for autism. Brain Cogn. 55, 209-219. doi: 10.1016/j.bandc.2003.04.002

Saint-Georges, C., Mahdhaoui, A., Chetouani, M., Cassel, R. S., Laznik, M.-C., Apicella, F., et al. (2011). Do parents recognize autistic deviant behavior long before diagnosis? Taking into account interaction using computational methods. PLoS ONE 6:e22393. doi: 10.1371/journal.pone.0022393

Schore, A. N. (1994). Affect Regulation and the Origin of the Self. The Neurobiology of Emotional Development. Mahwah, NJ: Erlbaum.

Schore, A. N. (1996). The experience-dependent maturation of a regulatory system in the orbital prefrontal cortex and the origin of developmental psychopathology. Dev. Psychopathol. 8, 59-87. doi: 10.1017/S0954579400006970

Schore, A. N. (2000). Attachment and the regulation of the right brain. Attach. Hum Dev. 2, 23-47. doi: 10.1080/146167300361309

Schore, A. N. (2001a). The effects of a secure attachment relationship on right brain development, affect regulation, and infant mental health. Infant Ment. Health J. 22, 7-66. doi: 10.1002/1097-0355(200101/04)22:1<7::AID-IMHJ2>3.0.CO;2-N

Schore, A. N. (2001b). The effects of relational trauma on right brain development, affect regulation, and infant mental health. Infant Ment. Health J. 22, 201-269. doi: 10.1002/1097-0355(200101/04)22:1<201::AID-IMHJ8>3.0.CO;2-9

Schore, A. N. (2002). Dysregulation of the right brain: a fundamental mechanism of traumatic attachment and the psychopathogenesis of posttraumatic stress disorder. Aust. N. Z. J. Psychiatry 36, 9-30. doi: 10.1046/j.1440-1614.2002.00996.x

Schore, A. N. (2003a). Affect Regulation and the Repair of the Self. New York: W. W. Norton \& Company, Inc.

Schore, A. N. (2003b). Affect Dysregulation and Disorders of the Self. New York: W. W. Norton \& Company, Inc.

Schore, A. N. (2005). Attachment, affect regulation, and the developing right brain: linking developmental neuroscience to pediatrics. Pediatr. Rev. 26, 204-212. doi: 10.1542/pir.26-6-204

Schore, A. N. (2009). Relational trauma and the developing right brain. An interface of psychoanalytic self psychology and neuroscience. Ann. N. Y. Acad. Sci. 1159, 189-203. doi: 10.1111/j.1749-6632.2009.04474.x

Schore, A. N. (2012a). The Science of the Art of Psychotherapy. New York: W. W. Norton \& Company, Inc.

Schore, A. N. (2012b). "Bowlby's 'environment of evolutionary adaptedness.' Recent studies on the interpersonal neurobiology of attachment and emotional development," in Evolution, Early Experience and Human Development. From Research to Practice, eds D. Narvaez, J. Panksepp, A. N. Schore, and T. R. Gleason (New York: Oxford University Press), 31-73. doi: 10.1093/acprof:oso/9780199755059.003.0002

Schore, A. N. (2013). Regulation theory and the early assessment of attachment and autistic spectrum disorders: a response to Voran's clinical case. J. Infant Child Adolesc. Psychother. 12, 164-189. doi: 10.1080/15289168.2013.822741

Schore, A. N. (2014). The right brain is dominant in psychotherapy. Psychotherapy 51, 388-397. doi: 10.1037/a0037083

Schore, A. N., and Newton, R. P. (2012). "Using modern attachment theory to guide clinical assessments of early attachment relationships," in Attachment-Based Clinical Work with Children and Adolescents, eds J. E. Bettmann and D. Friedman (New York: Springer), 61-96. 
Schore, J. R., and Schore, A. N. (2008). Modern attachment theory: the central role of affect regulation in development and treatment. Clin. Soc. Work J. 36, 9-20. doi: 10.1007/s10615-007-0111-7

Schore, J. R., and Schore, A. N. (2010). "Clinical social work and regulation theory: implications of neurobiological models of attachment," in Adult Attachment in Clinical Social Work, eds S. Bennett and J. K. Nelson (New York: Springer), $57-75$.

Schumann, C. M., Barnes, C. C., Lord, C., and Courchesne, E. (2009). Amygdala enlargement in toddlers with autism related to severity of social communication impairments. Biol. Psychiatry 66, 942-949. doi: 10.1016/j.biopsych.2009.07.007

Semrud-Clikeman, M., Fine, J. G., and Zhu, D. C. (2011). The role of the right hemisphere for processing of social interactions in normal adults using functional magnetic resonance imaging. Neuropsychobiology 64, 47-51. doi: $10.1159 / 000325075$

Shelton, J. F., Hertz-Picciotto, I., and Pessah, I. N. (2012). Tipping the balance of autism risk: potential mechanisms linking pesticides with autism. Environ. Health Perspect. 120, 944-951. doi: 10.1289/ehp.1104553

Sieratzki, J. S., and Woll, B. (1996). Why do mothers cradle their babies on the left? Lancet 347, 1746-1748. doi: 10.1016/S0140-6736(96)90813-2

Sparks, B. F., Friedman, S. D., Shaw, D. W., Aylward, E. H., Echelard, D., Artru, A. A., et al. (2002). Brain structural abnormalities in young children with autism spectrum disorder. Neurology 59, 184-192. doi: 10.1212/WNL.59.2.184

Stevenson, C. W., Halliday, D. M., Marsden, C. A., and Mason, R. (2008). Early life programming of hemispheric lateralization and synchronization in the adult medial prefrontal cortex. Neuroscience 155, 852-863. doi 10.1016/j.neuroscience.2008.06.013

Stoner, R., Chow, M. L., Boyle, M. P., Sunkin, S. M., Mouton, P. R., Roy, S., et al. (2014). Patches of disorganization in the neocortex of children with autism. N. Engl. J. Med. 370, 1209-1219. doi: 10.1056/NEJMoa13 07491

Sullivan, R. M., and Gratton, A. (2002). Prefrontal cortical regulation of hypothalamic-pituitary-adrenal function in the rat and implications for psychopathology: side matters. Psychoneuroendocrinology 27, 99-114. doi: 10.1016/S0306-4530(01)00038-5

Sun, T., Patoine, C., Abu-Khalil, A., Visvader, J., Sum, E., Cherry, T. J., et al. (2005). Early asymmetry of gene transcription in embryonic human left and right cerebral cortex. Science 308, 1794-1798. doi: 10.1126/science.1110324

Telkemeyer, S., Rossi, S., Koch, S. P., Nierhaus, T., Steinbrink, J., Poeppel, D., et al. (2009). Sensitivity of newborn auditory cortex to the temporal structure of sounds. J. Neurosci. 29, 14726-14733. doi: 10.1523/JNEUROSCI.1246-09.2009

Trevarthen, C., and Daniel, S. (2005). Disorganized rhythm and synchrony: early signs of autism and Rett syndrome. Brain Dev. 27, S25-S34. doi: 10.1016/j.braindev.2005.03.016
Uddin, L. Q., and Menon, V. (2009). The anterior insula in autism: underconnected and under-examined. Neurosci. Biobehav. Rev. 33, 1198-1203. doi 10.1016/j.neubiorev.2009.06.002

Uddin, L. Q., Supekar, K., Lynch, C. J., Khouzam, A., Phillips, J., Feinstein, C., et al. (2013). Salience netwok-based classification and prediction of symptom severity in children with autism. JAMA Psychiatry 70, 869-879. doi: 10.1001/jamapsychiatry.2013.104

Voran, M. (2013). The protest of a 6-month-old girl: Is this a prodrome of autism? J. Infant Child Adolesc. Psychother. 12, 139-155. doi: 10.1080/15289168.2013.821848

Wada, J. A., and Davis, A. E. (1977). Fundamental nature of human infant's brain asymmetry. Can. J. Neurol. Sci. 4, 203-207.

Weber, A. M., Harrison, T. M., and Steward, D. K. (2012). Schore's regulation theory: maternal-infant interaction in the NICU as a mechanism for reducing the effects of allostatic load on neurodevelopment in premature infants. Biol. Res. Nurs. 14, 375-386. doi: 10.1177/1099800412453760

Wolff, J. J., Gu, H., Gerrig, G., Elison, J. T., Styner, M., Gouttasrd, S., et al. (2012). Differences in white matter fiber tract development presente from 6 to 24 months in infants with autismo. Am. J. Psychiatry 169, 589-600. doi: 10.1176/appi.ajp.2011.11091447

Yirmaya, N., and Charman, T. (2010). The prodrome of autism: early behavioral and biological signs, regression, peri-and pos-natal development and genetics. $J$. Child Psychol. Psychiatry 51, 432-458. doi: 10.1111/j.1469-7610.2010.02214.x

Yirmiya, N., and Ozonoff, S. (2007). The very early autism phenotype. J. Autism Dev. Disord. 37, 1-11. doi: 10.1007/s10803-006-0329-1

Conflict of Interest Statement: The author declares that the research was conducted in the absence of any commercial or financial relationships that could be construed as a potential conflict of interest.

Received: 16 June 2014; accepted: 02 September 2014; published online: 23 September 2014.

Citation: Schore AN (2014) Early interpersonal neurobiological assessment of attachment and autistic spectrum disorders. Front. Psychol. 5:1049. doi: 10.3389/fpsyg.2014.01049

This article was submitted to Psychology for Clinical Settings, a section of the journal Frontiers in Psychology.

Copyright $($ C 2014 Schore. This is an open-access article distributed under the terms of the Creative Commons Attribution License (CC BY). The use, distribution or reproduction in other forums is permitted, provided the original author(s) or licensor are credited and that the original publication in this journal is cited, in accordance with accepted academic practice. No use, distribution or reproduction is permitted which does not comply with these terms. 


\title{
Unresolved trauma in mothers: intergenerational effects and the role of reorganization
}

\author{
Udita lyengar $^{1,2,3}$, Sohye Kim ${ }^{1,2,4}$, Sheila Martinez ${ }^{1,2}$, Peter Fonagy ${ }^{2,3,4}$ and Lane Strathearn ${ }^{1,2,3,4,5 *}$ \\ 1 Department of Pediatrics, Children's Nutrition Research Center, Baylor College of Medicine, Houston, TX, USA \\ ${ }^{2}$ Attachment and Neurodevelopment Laboratory, Children's Nutrition Research Center, Baylor College of Medicine, Houston, TX, USA \\ ${ }^{3}$ Research Department of Clinical, Educational, and Health Psychology, University College London, London, UK \\ ${ }^{4}$ Menninger Department of Psychiatry and Behavioral Sciences, Baylor College of Medicine, Houston, TX, USA \\ ${ }^{5}$ The Meyer Center for Developmental Pediatrics, Texas Children's Hospital, Houston, TX, USA
}

\section{Edited by:}

Silvia Salcuni, Università degli Studi di Padova, Italy

\section{Reviewed by:}

Aldo Lucion, Universidade Federal do Rio Grande do Sul, Brazil

Silvia Salcuni, Università degli Studi

di Padova, Italy

Alessandra Simonelli, Università

degli Studi di Padova, Italy

${ }^{*}$ Correspondence:

Lane Strathearn, Attachment and Neurodevelopment Laboratory,

Children's Nutrition Research Center, Baylor College of Medicine, 1100 Bates Street, Suite 4004, Houston, TX 77030, USA

e-mail: lanes@bcm.edu
A mother's unresolved trauma may interfere with her ability to sensitively respond to her infant, thus affecting the development of attachment in her own child, and potentially contributing to the intergenerational transmission of trauma. One novel construct within the Dynamic Maturational Model of Attachment and Adaptation (DMM) coding of the Adult Attachment Interview (AAI) is "reorganization," a process whereby speakers are actively changing their understanding of past and present experiences and moving toward attachment security. We conducted a study of mothers with unresolved trauma, exploring their own attachment classification, attachment outcomes of their children, and the potential effects of reorganization on child attachment. Forty-seven first-time mothers participated in the AAI during pregnancy, and returned with their child at 11 months to assess child attachment using the Strange Situation Procedure. Mothers with and without unresolved trauma were compared. We found that mothers with unresolved trauma had insecure attachment themselves and were more likely to have infants with insecure attachment. However, the one exception was that all of the mothers with unresolved trauma who were reorganizing toward secure attachment had infants with secure attachment. These preliminary findings suggest that mothers who are reorganizing may be able to more sensitively respond to their child's cues, contributing to the development of secure attachment. While our results need to be replicated in a larger cohort, this study is the first to explore the construct of reorganization and its potential relationship with child attachment. If confirmed in future studies, it may provide clinical insight into the intergenerational transmission of insecure attachment within the context of unresolved trauma.

Keywords: unresolved trauma, intergenerational transmission, attachment, mother-infant, reorganization

\section{INTRODUCTION}

Attachment theory emphasizes the quality of one's early relationships and how this affects aspects of later functioning, wherein the attachment relationship between mother and infant ensures infant survival, as well as optimal social, emotional, and cognitive development (Insel and Young, 2001; Sroufe, 2005). Mothers who are sensitive to their children's signals, who are emotionally available, perceptive, and responsive to their infants' needs and mental states, have infants who are more likely to be securely attached (Siegel, 1999). Empirical research has documented patterns of sensitive responsiveness leading to secure attachment across generations, as observed in numerous studies utilizing the Adult Attachment Interview (AAI; George et al., unpublished manuscript), and measures of infant attachment, such as the Strange Situation Procedure (Ainsworth et al., 1978). From both cross-sectional and prospective longitudinal studies, the AAI has been widely used and shown to reliably predict maternal behavior patterns, development of infant attachment (van IJzendoorn,
1995; van IJzendoorn and Bakermans-Kranenburg, 2009), and infant social and emotional development (Sroufe, 2005). For instance, a meta-analysis of 13 studies examined the correspondence between mother and infant attachment, indicating a high concordance rate $(75 \%)$ between secure attachment in mothers and infants (van IJzendoorn, 1995). Our previous study suggested a similar pattern of transmission between mothers and infants, with secure attachment classifications between mother and child matching $73.4 \%$ of the time (Fonagy et al., 1991; Shah et al., 2010). Whether the data are examined prospectively, retrospectively, or concurrently, these studies have provided evidence for the validity and cross-generational stability of secure attachment.

Patterns of insecure attachment across generations have also been widely substantiated, particularly when exploring the impact of unresolved trauma of parents in relation to their children. Main and Hesse (1990) first found an association between the adult attachment pattern of an adult who lost her parent in childhood, and the subsequent transmission of insecure 
(specifically, disorganized) attachment to the infant, based on AAI and SSP. A follow-up study by Ainsworth and Eichberg (1991) found that in the AAI, a mother's discourse regarding a loss that she faced in her childhood was also related to infant disorganization. Schuengel et al. (1999) similarly found that mothers with insecure attachment who had an unresolved trauma or loss of an attachment figure tended to have children with insecure attachment themselves, more so than if the mother had an unresolved trauma or loss with secure attachment. Infants of traumatized mothers also appear to find it difficult to seek comfort when distressed, and demonstrate frightened and alarmed behavior when in the presence of their traumatized mothers (Hesse and Main, 1999; Lyons-Ruth et al., 1999; Madigan et al., 2006). The occurrence of an unresolved trauma or loss may therefore impair a mother's ability to respond sensitively and effectively to her infant's needs, possibly intensifying the behavior of her child when frightened or alarmed, and increasing the risk of insecure attachment.

Schwerdtfeger and Goff (2007) explored the relationship between trauma history and symptomatology in expectant mothers, and subsequent development of attachment and bonding to their unborn children, in an effort to understand the possible intergenerational transmission of trauma. They found that interpersonal trauma had negative effects on prenatal attachment, such that disturbances in the caregiver-child relationship were associated with the maternal perception of the "child as threat" (Schechter et al., 2004, p. 321). Unresolved trauma or loss may interfere with a mother's expectations and perceptions of her child, as well as her ability to sensitively respond, thus compromising the development of secure attachment in her infant.

On a neurobiological level, our other recent study utilizing functional magnetic resonance imaging ( $\mathrm{fMRI}$ ) demonstrated the impact of unresolved trauma on brain response when mothers viewed sad face images of their infants (Kim et al., 2014). In this sample, mothers who were classified as having unresolved trauma or loss displayed reduced activation in the amygdala, a key neural structure involved in emotion processing (Sander et al., 2003; Ewbank et al., 2009; Adolphs, 2010) which is susceptible to both structural (Rauch et al., 2000) and functional change (Rauch et al., 2000; Protopopescu et al., 2005; Williams et al., 2006a,b) in response to trauma. This blunted amygdala response was seen only when these mothers viewed their own infant's distressed face, and not that of unknown infants. This may reflect traumatized mothers' disengagement from their infants' distress, and could contribute to the transgenerational transmission of trauma. Unresolved trauma may therefore interfere with a mother's expectations and perceptions of her child, her ability to sensitively respond to her infant, and associated neural responses to infant emotional cues, thus compromising the development of secure attachment in her infant.

While the intergenerational transmission of secure and insecure attachment has been well established, our previous study (Shah et al., 2010) also found an interesting reversal of attachment strategies within insecure attachment across generations, whereby mothers with preoccupied attachment tended to have infants who used an avoidant strategy, and vice-versa. This pattern of attachment strategy reversal between parent and child has also been observed in other normative samples (Hautamaki et al., 2010), as well as in families with a history of maltreatment who are at high risk for insecure attachment (Crittenden et al., 1991; Farnfield et al., 2010). To further understand the transmission of insecure attachment being transmitted across generations, with an emphasis on unresolved trauma, we chose to utilize the Dynamic Maturational Model of Attachment and Adaptation (DMM) (see Farnfield et al. (2010) for a detailed description of the various DMM measures). The DMM views attachment as an array of self-protective strategies organized around danger (Crittenden, 1992, 1995, 1997, 2000). In the DMM, patterns of attachment vary dimensionally (rather than categorically) to encompass a broader scope of attachment-related characteristics, or strategies. According to the DMM, an individual with balanced or secure attachment uses cause and effect contingencies learned from previous experiences (defined here as "cognition") and a range of positive and negative emotions (defined here as "affect"), while taking a variety of perspectives when drawing conclusions (one's own and others'), and demonstrating thoughtful and reflective integration when recalling childhood experiences and relationships. When faced with adversity or situations in which attachment figures fail to protect or comfort, an individual may develop self-protective strategies leading to non-balanced, or insecure attachment.

At times, a life event or circumstance can be psychologically traumatic for an individual, such as instances of abuse or loss of an attachment figure. Exposure to danger or loss may lead to several possible outcomes. One is that an individual may garner new information from the situation and context to integrate the experience, resulting in adaptation and a newfound understanding that helps the individual to avoid future danger. These individuals would be considered "resolved" with regard to the trauma or loss. In another scenario, individuals experiencing trauma or loss may either retain too much information about the traumatic event or dismiss the importance of it, in ways that are maladaptive to future processing of information (Crittenden and Landini, 2011). For example, an adolescent girl may experience a hypervigilant fearful response when in close contact with a male schoolteacher who reminds her of a childhood sexual predator. Alternately, this same adolescent may ignore relevant information and memories to place herself at increased risk of further sexual abuse. A lack of resolution of trauma suggests that the event has not been adequately integrated or reflected upon, leaving potential for future risk. These individuals will be classified, on the basis of their AAI, as having unresolved trauma or loss, may be at risk for developing later psychosocial problems (Cicchetti and Toth, 1999; Easterbrooks et al., 2000), and most relevant to our study, may be more likely to propagate the cycle of insecure attachment to include their own offspring.

Despite evidence of the continuity of both secure and insecure attachment across generations, this is not always the case. Bowlby (1973) himself understood that change in attachment strategy is possible, and can be associated with major life changes or a series of events across the lifespan. Some individuals with patterns of insecure attachment (transmitted across generations), who have experienced harsh parenting or adverse life events, are able to overcome the effects of these experiences and demonstrate 
balanced integration. These individuals are labeled as "earned secure" by some theorists (Pearson et al., 1994; Roisman et al., 2002). Earned secure individuals are thought to have interrupted the intergenerational cycle by demonstrating emotional resilience (Fearon et al., 2010).

Less explored is the process by which those with insecure attachment actively change their understanding of past and present experiences, often in the direction of greater balance and resolution (Crittenden and Landini, 2011). This construct is referred to as "reorganization" in the DMM, and is based on clinical observations from within AAIs (Crittenden, 1990, 1995). Whilst it is not necessary for an individual to experience danger or trauma before undergoing reorganization, the experience and resolution of danger can at times in an alteration in mental processing and behavior, leading to a change in attachment strategy (Crittenden, 2008). The modified AAI coding scheme aims, through the process of discourse analysis, to identify individuals who are undergoing reorganization. Although not fully secure or balanced in attachment terms, reorganizing individuals may exhibit mental resilience to buffer the effects of adversity or unresolved trauma as a result of maturation or changing circumstances (Landa and Duschinsky, 2013), which may have positive effects on the security of their progeny. Little is known about those individuals who have unresolved trauma or loss but who are in the dynamic process of altering their attachment strategy toward security. The process of reorganizing may alter the transmission of insecure attachment from one generation to the next, an idea that has important clinical implications but has received little attention in the literature.

The transmission of secure and insecure attachment across generations, as well as the contribution of earned security in this process, has been previously explored and established (Fonagy et al., 1991; van IJzendoorn, 1995; Hesse and Main, 1999; Schuengel et al., 1999; Lyons-Ruth et al., 2005; Shah et al., 2010). In the present study, we sought to understand how the process of reorganization might positively impact the transmission of attachment across generations. This is the first paper to explore the concept of reorganization within the context of the intergenerational transmission of attachment, thereby adding to the validity of a novel and clinically relevant attachment-related construct. The goal of this study was to examine associations between unresolved trauma and mother and child attachment, while testing whether reorganization is associated with more secure child attachment. Consistent with previous studies (van IJzendoorn, 1995; Hesse and Main, 1999; Schuengel et al., 1999; Lyons-Ruth et al., 2005), we hypothesized that mothers with unresolved trauma would be more likely to have insecure attachment (hypothesis 1), as well as children with insecure attachment (hypothesis 2). In addition, we tested two hypotheses relating to change in attachment style. We predicted that mothers with unresolved trauma (Utr) who were reorganizing toward security would be more likely to have securely attached children (hypothesis 3). We also predicted that maternal reorganization would explain incremental variance in child attachment security above and beyond that accounted for by maternal Utr (hypothesis 4). While predicting that unresolved trauma would be associated with insecure child attachment, we further hypothesized that maternal reorganization would add to this model to better predict the outcome.

\section{MATERIALS AND METHODS PARTICIPANTS}

Sixty-seven first time mothers were recruited during their third trimester of pregnancy and followed-up 11 months postnatally, with 47 mothers completing both the AAI and the SSP. Mothers were recruited through advertisements posted in prenatal clinics, magazines, on billboards and via the Internet. Potential subjects were excluded if they were on psychotropic medications, were using cigarettes during pregnancy, or were left-handed (due to the neuroimaging component of the study). The Institutional Review Board at Baylor College of Medicine approved the research protocol, and all subjects provided written informed consent.

\section{THE ADULT ATTACHMENT INTERVIEW}

The Adult Attachment Interview (AAI; Crittenden and Landini, 2011; George et al., unpublished manuscript) is a semi-structured $1 \frac{1}{2}-2 \mathrm{~h}$-long interview comprised of questions which highlight childhood relationships with attachment figures, usually parents. A modified version of the AAI was chosen because of its expanded questions that contain more direct probes into potential life traumas and losses (Shah and Strathearn, 2014), and validation from previously published data (Strathearn et al., 2009). Through analysis of the discourse, an overall attachment strategy is determined [labeled in the Crittenden model as A, $\mathrm{B}$, or $\mathrm{C}$, paralleling the infancy model of attachment from the Strange Situation Procedure (SSP)], along with discourse modifiers, including "unresolved trauma or loss," and those meeting the classification of "reorganization."

We chose to measure attachment during pregnancy using a longitudinal design to exclude the possibility that the infant's temperament or mother-infant interaction patterns might influence the way the mother describes her own attachment experiences. Each interview was digitally recorded and transcribed. In order to maintain confidentiality, all identifying information was changed. To categorize the mothers' adult attachment strategies, the transcripts were coded blindly by reliable raters according to the Dynamic Maturational Model (DMM) of Attachment and Adaptation. Adult classifications were not revealed until the completion of the study, and $50 \%$ of the transcripts were double coded to ensure reliability. Discrepancies were resolved through conferencing between coders, and the intraclass correlation for the unresolved trauma classification was 0.86 .

\section{Coding unresolved trauma}

As conceptualized by Bowlby (1982) and Crittenden and Landini (2011), the notion of unresolved loss was considered to be a subcategory of trauma, and is hereafter referred to under the term "unresolved trauma." Utr was coded when examining especially frightening or dangerous experiences that continued to affect the speaker's thoughts, feelings, or behavior. The coding of Utr may include how the incident was mentioned (for example, if omitted when relevant, or introduced more often than necessary in a preoccupying way, etc.), changes in discourse during discussion of 
the trauma or loss (such as errors in tense or lapses in grammar), as well as the overall consideration of relationships and effects of the traumatic incident.

\section{Coding reorganization}

In the coding process, a reorganizing speaker is identified as actively changing their perception and understanding of their experiences, both past and present. Reorganizing speakers make reflective and evaluative statements indicative of mental balance, incorporate new information to achieve a new understanding of situations, consider alternate perspectives, and achieve a cooperative relationship with the interviewer to find meaning in their history (Crittenden and Landini, 2011). There are slips into the dominant pattern of insecure attachment, and some level of unresolved incoherence noted in the discourse, but the reorganizing speaker attempts to reach an integrative conclusion about their situation. The coding of reorganization includes a list of hallmark features, with a specific number of criteria needed before reaching this classification. For a complete list of reorganizing criteria, see Supplementary material.

\section{STRANGE SITUATION PROCEDURE}

The SSP (Ainsworth et al., 1978) is a standard procedure used to classify infant attachment between 11 and 15 months of age (Farnfield et al., 2010). Three reliable coders blindly coded the SSP videos, using DMM coding criteria. The kappa on a 4way classification of SSPs ranged from 0.47 to 0.59 (Shah et al., 2010) and where discrepancies existed, the final classification was determined through conferencing.

\section{SELF-REPORT OUESTIONNAIRES}

Mothers completed a battery of questionnaires, including the Adult Temperament Questionnaire (ATQ; Rothbart et al., 2000), Personality Development Questionnaire (PDQ; Hyler et al., 1992), Beck Depression Inventory (BDI; Beck et al., 1996), Parenting Stress Index (PSI; Abidin, 1995), and the Infant Behavior Questionnaire-Revised (IBQ; Gartstein and Rothbart, 2003). The ATQ, IBQ, and PSI were completed during a separate visit (approximately 7 months postpartum). The Bayley Scales of Infant and Toddler Development, Screener, Third Edition (Bayley III; Bayley, 2006) was completed when infants were 11 months of age. For the details of all the instruments, please refer to Shah et al. (2010).

\section{PROCEDURES}

In the last trimester of pregnancy, mothers participated in the modified version of the AAI, at which time socio-demographic information and behavioral measures were also collected. The mothers returned with their child at 11 months postpartum, at which time the SSP was conducted, as well as an assessment of infant development using the Bayley-III.

\section{ANALYSIS PLAN}

The two groups of mothers (Utr vs. No Utr) were compared in terms of demographic and questionnaire measures using Chisquare and $t$-tests for categorical and continuous data, respectively. Hypotheses 1-3 were tested using Chi square and Fisher's exact tests, examining associations between maternal attachment security, maternal reorganization, and infant attachment security for mothers with and without Utr. Hypothesis 4 was tested using a likelihood-ratio chi-square test, examining a change in model fit when maternal reorganization was added to the model (which contained maternal Utr as the sole predictor of infant attachment security). All analyses were conducted using SPSS version 21 and STATA/SE version 12.1 .

\section{RESULTS}

\section{STUDY PARTICIPANTS}

Socio-demographic information and self-report measures are presented in Table 1. In addition to the overall AAI classification (secure vs. insecure), the mothers were dichotomized into having unresolved trauma or loss (Utr, $n=18$ ), vs. no unresolved trauma or loss (No Utr, $n=29$ ). Mothers with Utr were significantly older than mothers with no Utr, and $87 \%$ of mothers with Utr identified themselves as white compared to $52 \%$ of mothers with no Utr. The groups did not differ significantly in any other socio-demographic variable, including income level, marital status or IQ. In behavioral measures, mothers with Utr scored their infants lower on the "approach" subscale of the IBQ, but there were no other differences between groups in any measures of adult temperament, personality disorder, parenting stress, depression, or infant development.

\section{Hypothesis 1. Mothers with Utr are more likely to have insecure attachment}

Consistent with our prediction, $100 \%$ of the mothers with Utr had insecure attachment themselves, compared with only $25 \%$ of mothers without Utr (Fisher's exact test: $p<0.001$; Table 2).

\section{Hypothesis 2. Mothers with Utr are more likely to have infants with insecure attachment}

We found that over $75 \%$ of mothers with Utr had insecurely attached infants, compared with only $45 \%$ of mothers without Utr (Fisher's exact test: $p=0.036$; Table 2).

\section{Hypothesis 3. Mothers with Utr who are reorganizing toward security are more likely to have a securely attached infant}

Of the mothers who had unresolved trauma $(n=18)$, four (22\%) were reorganizing toward secure attachment (Table 3A). On examining the possible intergenerational effect of reorganizing attachment, we found that all four of these reorganizing mothers had children with secure attachment, while none of the non-reorganizing mothers had secure children (Fisher's exact test: $p<0.001$; Table 3B).

\section{Hypothesis 4. Maternal reorganization will explain incremental variance in infant attachment security above and beyond that accounted for by maternal Utr}

Compared to the model containing maternal Utr as the sole predictor of infant attachment security $\left[\beta_{\mathrm{Utr}}=0.330\right.$, Model $R^{2}=$ $\left.0.105, F_{(1,45)}=5.28, p=0.026\right]$, adding maternal reorganization led to a significant increase $\left[\operatorname{LR} \chi^{2}(1)=16.93, p<0.0001\right]$ in model fit $\left[\beta_{\text {Reorganization }}=-1\right.$, Model $R^{2}=0.376, F_{(2,44)}=$ $13.24, p<0.001]$. 
Table 1 | Demographic characteristics of mothers with or without unresolved trauma (Utr) $(N=47)$.

\begin{tabular}{|c|c|c|}
\hline Variable & No Utr $(N=29)$ & $\operatorname{Utr}(N=18)$ \\
\hline Age of mother (in years) $\pm S D$ & $27.98 \pm 4.2$ & $30.22 \pm 4.8^{*}$ \\
\hline \multicolumn{3}{|l|}{ Marital status, N (\%) } \\
\hline Married & $20(69)$ & $16(89)$ \\
\hline Not married & $9(31)$ & $2(11)$ \\
\hline \multicolumn{3}{|l|}{ Maternal race, N (\%) } \\
\hline White & $15(52)$ & $15(83)^{*}$ \\
\hline Non-white & $14(48)$ & $3(17)$ \\
\hline \multicolumn{3}{|l|}{ Income, N (\%) } \\
\hline$<\$ 30,000 /$ year & $9(31)$ & $4(22)$ \\
\hline$\$ 30,001-70,000$ & $9(31)$ & $5(28)$ \\
\hline$>\$ 70,000$ & $11(38)$ & $7(39)$ \\
\hline Not reported & 0 & $2(11)$ \\
\hline $\begin{array}{l}\text { Mother-infant separation, } N \\
(\%)\end{array}$ & $(N=26)$ & $(N=18)$ \\
\hline$\leq 20 \mathrm{~h} /$ week & $13(50)$ & $8(44.4)$ \\
\hline$\geq 20 \mathrm{~h} /$ week & $13(50)$ & $10(55.6)$ \\
\hline $\begin{array}{l}\text { Maternal IQ (predicted from } \\
\text { WTAR), } M \pm \text { SDa }^{a}\end{array}$ & $109.56 \pm 9.9$ & $109.72 \pm 7.3$ \\
\hline $\begin{array}{l}\text { Maternal depression (BDI), N } \\
(\%)^{\mathbf{b}}\end{array}$ & $(N=29)$ & $(N=17)$ \\
\hline Minimal & $24(83)$ & $15(88)$ \\
\hline Mild to moderate & $5(17)$ & $2(11)$ \\
\hline $\begin{array}{l}\text { Personality Disorder Screen } \\
\text { (PDQ) }^{c}\end{array}$ & $(N=29)$ & $(N=17)$ \\
\hline Total score, mean \pm SD & $18.9 \pm 10.3$ & $18.5 \pm 10.1$ \\
\hline $\begin{array}{l}\text { Parenting Stress Index } \\
(\mathrm{PSI}), \mathrm{M} \pm \mathrm{SD}^{\mathrm{d}}\end{array}$ & $(N=25)$ & $(N=14)$ \\
\hline Child domain total score & $91.7 \pm 13.1$ & $90.4 \pm 14.7$ \\
\hline Parent domain total score & $111.0 \pm 23.7$ & $112.7 \pm 19.6$ \\
\hline Total stress score & $202.8 \pm 28.7$ & $195.3 \pm 38.7$ \\
\hline $\begin{array}{l}\text { Temperament of Mothers } \\
\text { (ATQ), } M \pm S D\end{array}$ & $(N=28)$ & $(N=17)$ \\
\hline Effortful control & $4.6 \pm 0.6$ & $4.5 \pm 0.8$ \\
\hline Negative affect & $3.9 \pm 0.7$ & $3.9 \pm 0.7$ \\
\hline Extraversion/Surgency & $4.9 \pm 0.6$ & $4.8 \pm 0.6$ \\
\hline Orienting sensitivity & $5.1 \pm 0.7$ & $5.1 \pm 0.6$ \\
\hline $\begin{array}{l}\text { Infant development (Bayley), } \\
\text { mean raw score } \pm \text { SD }\end{array}$ & $(N=29)$ & $(N=17)$ \\
\hline Cognitive & $17.6 \pm 1.5$ & $17.4 \pm 2.0$ \\
\hline Receptive communication & $14.7 \pm 2.2$ & $14.0 \pm 2.1$ \\
\hline Expressive communication & $13.9 \pm 1.9$ & $13.5 \pm 1.9$ \\
\hline Fine motor & $15.7 \pm 1.8$ & $15.9 \pm 2.0$ \\
\hline Gross motor & $18.2 \pm 1.3$ & $17.3 \pm 1.9$ \\
\hline $\begin{array}{l}\text { Infant temperament (IBQ), } \\
M \pm S D\end{array}$ & $(N=27)$ & $(N=17)$ \\
\hline Approach & $5.8 \pm 0.8$ & $4.9 \pm 1.5^{*}$ \\
\hline Vocal reactivity & $5.2 \pm 0.8$ & $5.0 \pm 0.9$ \\
\hline High intensity pleasure & $6.0 \pm 0.5$ & $6.1 \pm 0.7$ \\
\hline Activity level & $4.9 \pm 0.8$ & $4.7 \pm 0.9$ \\
\hline Perceptual sensitivity & $4.8 \pm 1.2$ & $4.3 \pm 1.0$ \\
\hline Distress to limitations & $3.9 \pm 0.6$ & $3.8 \pm 0.8$ \\
\hline Fear & $2.5 \pm 0.8$ & $2.8 \pm 1.5$ \\
\hline
\end{tabular}

Table 1 | Continued

\begin{tabular}{lcc}
\hline Variable & No Utr $(\boldsymbol{N}=\mathbf{2 9})$ & Utr $(\boldsymbol{N}=\mathbf{1 8})$ \\
\hline Low intensity pleasure & $5.0 \pm 1.3$ & $5.5 \pm 0.9$ \\
Cuddliness & $5.5 \pm 0.6$ & $5.8 \pm 0.7$ \\
Duration of orienting & $4.4 \pm 1.0$ & $3.9 \pm 1.1$ \\
\hline
\end{tabular}

${ }^{*} p<0.05$.

$B D I$, Beck Depression Inventory-II; PDQ, Personality Disorder Questionnaire4+; PSI, Parenting Stress Index; ATQ, Adult Temperament Questionnaire-Short Form; IBQ, Infant Behavior Questionnaire.

a Maternal Full Scale 10 was estimated from the Wechsler Test of Adult Reading (WTAR).

${ }^{b} B D I-I /$ score of 0-13 indicates minimal depression, 14-19 indicates mild depression, and 20-28 indicates moderate depression.

c PDQ-4+ total score of $\geq 50$ is highly suggestive of DSM-IV personality disorder. ${ }^{d}$ PSI Total Stress Score of $<260$ is considered normal range.

Table 2 | Adult and infant attachment classifications in mothers with and without unresolved trauma (Utr).

\begin{tabular}{lcclcc}
\hline Mothers with Utr & \multicolumn{2}{l}{ Mother attachment } & & \multicolumn{2}{l}{ Infant attachment ${ }^{\mathbf{b}}$} \\
\cline { 2 - 3 } & Secure & Insecure & & Secure & Insecure \\
\hline Yes, N (\%) & $0(0)$ & $18(100)$ & & $4(22)$ & $14(78)$ \\
Adjusted residual & -5.1 & -5.1 & & -2.2 & 2.2 \\
No, $N(\%)$ & $22(76)$ & $7(24)$ & $16(55)$ & $13(45)$ \\
Adjusted residual & 5.1 & -5.1 & & 2.2 & -2.2 \\
\hline${ }^{a} \chi^{2}=25.672, d f=1, p<0.001, K=0.707 ;{ }^{b} \chi^{2}=4.933, d f=1, p=0.026$ \\
$K=0.301$.
\end{tabular}

\section{DISCUSSION}

This is the first study to examine the construct of "attachment reorganization" as measured by the DMM and its effect on children's attachment security within the context of intergenerational transmission of trauma and attachment. As expected, mothers with unresolved trauma were universally classified as having insecure attachment themselves, and were less likely to have children who were securely attached when compared to mothers with no unresolved trauma. Using the Crittenden's Dynamic Maturational Model of Attachment and Adaptation, these results reaffirm the role of unresolved trauma in the intergenerational transmission of insecure attachment (van IJzendoorn, 1995; Hesse and Main, 1999; Schuengel et al., 1999; Lyons-Ruth et al., 2005). Most importantly, individuals who were identified as reorganizing toward secure attachment before the birth of their child were more likely to have securely attached children at 11 months postpartum. Although preliminary, this study suggests that the construct of "reorganization" may help us better predict attachment outcomes in the children of mothers with unresolved trauma.

Except for maternal age and race variables, mothers with and without Utr could not be readily distinguished by other socio-demographic factors, self-report measures of temperament, personality traits, psychopathology risk, or infant development. It was interesting to note that, in the Infant Behavior 
Table 3 | Infant attachment security predicted by reorganization in mothers with unresolved trauma (Utr).

\begin{tabular}{|c|c|c|c|}
\hline \\
\hline \multirow[t]{2}{*}{ Utr status } & \multicolumn{2}{|c|}{ Reorganization status } & \multirow[t]{2}{*}{ Total } \\
\hline & Reorganizing & Not reorganizing & \\
\hline Utr, N (\%) & $4(22)$ & $14(78)$ & $18(100)$ \\
\hline No Utr, N (\%) & $0(0)$ & $29(100)$ & $29(100)$ \\
\hline \multicolumn{4}{|c|}{$\chi^{2}=7.044, d f=1, p=0.008, K=0.261$} \\
\hline \multicolumn{4}{|l|}{ (B) } \\
\hline \multirow{2}{*}{\multicolumn{2}{|c|}{ Reorganizing status of Utr mothers }} & \multicolumn{2}{|c|}{ Infant attachment } \\
\hline & & Secure & Insecure \\
\hline \multicolumn{2}{|c|}{ Reorganizing, N (\%) } & $4(100)$ & $0(0)$ \\
\hline \multicolumn{2}{|c|}{ Adjusted residual } & 4.2 & -4.2 \\
\hline \multicolumn{2}{|c|}{ Nor reorganizing, $\mathrm{N}(\%)$} & $0(0)$ & $14(100)$ \\
\hline \multicolumn{2}{|c|}{ Adjusted residual } & -4.2 & 4.2 \\
\hline
\end{tabular}

$\chi^{2}=18.000, d f=1, p<0.001, K=-0.528$.

Questionnaire, mothers with Utr rated their infants as having less "approach" behavior, which subscale included infant "excitement" and "positive anticipation of pleasurable activities" (Gartstein and Rothbart, 2003). The diminished approach behavior in infants of mothers with Utr is consistent with literature showing that infants of traumatized mothers tend to be more inhibited or even fearful in their mother's presence (Hesse and Main, 1999; Lyons-Ruth et al., 1999).

\section{UNRESOLVED TRAUMA AND REORGANIZATION}

In considering the implications of our findings, it is important to note that coding unresolved trauma from the AAI transcript is based less on the description of the traumatic event and more on how the experience impacts the individual's current functioning and evaluation of the event (Crittenden and Landini, 2011). In the DMM coding of the AAI, the presence of Utr in an individual suggests maladaptive information processing. Yet, what is it about reorganizing mothers in particular that could positively impact their children's attachment status when mothers themselves have unresolved trauma? One way to differentiate a reorganizing and a non-reorganizing speaker, both of whom have a classification of unresolved trauma, is to explore the discourse surrounding the event, as well as their integration of the event with respect to current functioning, based on their AAIs. To illustrate the difference, Nina and Marlene (names have been changed) are examples of speakers in our sample with similar cognitive-driven attachment strategies as well as unresolved trauma. Both also presented with unresolved traumas regarding frightening incidents with their parents, specifically their fathers. Marlene was classified as having insecure attachment but was in the process of reorganizing toward security, and had a child with secure or balanced attachment, while Nina and her child both had insecure attachment.

\section{Example 1. Marlene describes her father as "frightening," and relates an experience in which her father caused a second-degree burn in teaching her a lesson about overcoming her fears}

... the water started to boil and I, the steam was coming out from the sides of the, top of the, the pot, and I was scared of the steam. I was scared to take the top off. . . My dad said in his very slow, methodical way "just take the top off." "No, but there's steam ah ah." ... and very slowly walking over to me and taking his hand over my hand and, you know, ... slowly, deliberately, on purpose, and unknowingly, he pressed the tips of my fingertips down on the top of, of the pot top (nervous laugh), which was metal um, and I started screaming as my finger tips are being burned off ....... Not that he would ever intentionally hurt me...

\section{Example 2. Nina describing her father as being "volatile," and provided two separate examples of her frightening experiences}

\begin{abstract}
Nina: ... I'd run as far as I could go thinking I was going to get away with, get away from them, which probably wasn't very far, and then as far as, and then I could get as far as I could go, I would drop to the ground so the butt was close to the ground, but you know like they do in a tornado drill for a little kid? Run as far as away, realize they were catching me, drop to the ground so that the butt's covered, cover the head up, so the only thing out is the back. So if they're going to spank me, they have to spank my back (chuckle). That's... so.. and then uhhhh... you know, I don't really remember ever being really... hurt. I never really got.. seriously hurt."
\end{abstract}

Interviewer: Well, did you ever feel very frightened or unsure that you were safe?

Nina: The teeth pulling thing for sure. That terrified me for some reason. So... He, he... you know I still think the dentist must have told him to do it for some reason. I don't really know why he did it. Two people had to hold me to make it possible. So, uh, like my mom and my dad and, you know, he's got these pliers (chuckle). So I remember. . being. . . uh... you know, they, they came in and woke me up... to.... so... I mean ultimately, all that happened was a loose tooth got pulled. You know, not a big deal.

When describing the traumas, there are similar features of Marlene and Nina's discourse that rendered them as unresolved, particularly the slips into present tense (e.g., "and very slowly walking over to me and taking his hand over my hand"; "I started screaming as my finger tips are being burned off"; and "run as far away realize they were catching me, drop to the ground... cover the head up), and false positive laughter intended to minimize the severity of the trauma ("he pressed the tips of my fingertips down on the top of, of the pot top [nervous laughter]," "so if they are going to spank me, they have to spank my back [chuckle]"). These discourse markers indicate a preoccupying unresolved trauma, whereby the present tense brings the threatening event closer in time and space, possibly distorting when and where they may be in danger (Crittenden and Landini, 2011), and allowing the speaker to maintain a vigilant awareness of all the details. The false positive laughter after the dangerous event serves to minimize discomfort. At the same time, there is a dismissing component to the traumas, with both speakers suggesting that the events were 
unimportant, and that the parents were not responsible for any harm (e.g., "not that he would ever intentionally hurt me"; "you know I don't really remember ever being really... hurt. I never really got... seriously hurt"; and "so... I mean ultimately, all that happened was a loose tooth got pulled. You know, not a big deal”). This discourse may result in decreased accuracy in predicting future danger, thus placing speakers at greater risk of misinterpreting or omitting future danger cues (Crittenden, 2008). This is relevant when considering decreased maternal attentiveness and sensitivity to infant cues, both at times of safety and danger, which may compromise the quality of parent-child interaction.

\section{Examples of reorganization and non-reorganization in discourse}

When comparing their overall discourse in the interview, we note how Marlene is reorganizing toward secure attachment, while Nina is still maintaining a compulsive cognition-driven insecure attachment strategy that revolves around inhibiting her own feelings and seeking to please others. In the final integrative section of the interview, we note Nina's difficulty in reflecting on how her childhood experiences may have hindered her development:

Nina (non-reorganizing): "I think that my, you know... I, I, I don't know. There's a balance... I mean they kind of just let us, let me particularly I guess, it seems more than even my brother, I'm... make a lot of the decisions for ourselves probably because I was so volatile?"

When asked about what she wished to do differently with her own children:

\begin{abstract}
"Definitely no physical punishment. Like, uh.. I, I'm not saying that a kid doesn't deserve a spanking. I actually still believe in punishing, but you don't ever do it out of anger... I mean, we've actually talked about that, my husband and I because he knows, you know, he knows kind of how things were done at my house and I think. . he probably got slapped once by his mom and deserved it (chuckle)."
\end{abstract}

Nina is unable to articulate the effects that the parental punishment had on her, and instead describes herself as "volatile," the same word she had used to describe her father. She is aware of the impact of her punishment at the hands of her parents, yet she is distancing in the way that she describes it, saying that "you" don't ever do it out of anger, and that her husband knows "kind of how things were done at my house," and then enacts her pattern of chuckling after abuse is mentioned, much like when she described her own circumstances as a child. The final section of the interview is intended to illicit reflective thought and perspective about past experiences, yet Nina is still unable to accurately reflect on how her parent's abuse impacted her.

Marlene, who was reorganizing toward security and whose child had secure attachment, also experienced a very frightening event with her father as a young child. Yet she is able to reflect on the good and the bad, without distancing herself or blaming her parents excessively.

When asked about her experience as an adolescent:

Marlene: "I didn't like how strict (my parents) were and, you know... they wanted to teach us these values and... I didn't see how that was benefitting me at all and, and now I do see how it has benefited me and I, I'm glad for it but, man there were times when I hated them for it."
When asked about what she would do differently from what her parents did:

Marlene: "I probably won't be quite as strict as my mom was, as my parents were. I'm, I hope not but (laugh), I slip into it. I don't know."

Marlene is able to comment openly about an aspect of her parents' behavior that she wishes to change, but with open and fluent discourse, while displaying her ability to self-monitor, noting that she may sometimes slip into her old patterns of behavior. Marlene is reorganizing toward secure attachment based on her discourse, but still retains some aspects of insecure attachment. However, a reorganizing speaker such as Marlene may be more able to integrate the signals given by her infant without distortion, particularly in times of danger, with a balanced overall understanding of the experience. A non-reorganizing speaker with unresolved trauma, such as Nina, is still at risk of falsifying, distorting, or changing the meaning of her infant's signal in times of danger, which may compromise the dyadic interchange between herself and her child. As demonstrated in our recent neuroimaging paper (Kim et al., 2014), mothers with unresolved trauma do show an atypical brain amygdala response when processing their own infant's distress signals, which may result in misattunement during moments of infant distress.

\section{REORGANIZATION AND CLINICAL IMPLICATIONS}

Our preliminary results suggest that reorganization may be associated with child attachment security, despite mothers themselves being insecurely attached. Bowlby himself (1984) believed that current attachment representation is formed on the basis of early attachment experiences, but is also influenced by later relationships or changing circumstances. This concept is particularly important in a therapeutic setting, where therapists are facilitating change in their patients' intrapsychic and interpersonal relationships. While we were not able to determine the precipitating events/people (such as spouse, therapist, birth of a child, etc.) which led to reorganization in our sample, our data suggest that this construct should be further evaluated for its potential role in modifying the cycle of intergenerational transmission of attachment.

\section{LIMITATIONS AND FUTURE DIRECTIONS}

A major limitation of the study the small number of mothers who were identified as having reorganizing attachment: out of the 47 mothers who completed both the AAI and SSP, only 4 mothers had both unresolved trauma and reorganizing attachment. Our findings regarding reorganization reported here are therefore preliminary and need replication in a larger study. Future studies will explore the concepts of unresolved trauma and reorganization within a larger population sample. Furthermore, additional factors such as parental sensitivity and interactive behavior, and infant temperament, may contribute to the development of secure child attachment (van IJzendoorn and BakermansKranenburg, 2004). While our results provide some insight into how a mother with reorganizing attachment may promote the development of secure attachment, the ways in which maternal reorganizing attachment interacts with other factors also remains 
to be explored. We are currently exploring reorganization in a larger population of women with substance abuse disorders, where unresolved trauma is more prevalent.

\section{CONCLUSIONS}

A significant proportion of clinical work revolves around helping patients in the resolution of childhood trauma. Our study reaffirms that unresolved trauma is associated with insecure attachment in both mothers and their offspring, while providing the first preliminary evidence that attachment reorganization may lessen the risk of insecure attachment in the offspring.

While preliminary, this is the first empirical examination of the construct of attachment reorganization, which may ultimately be relevant in clinical settings in which attachment trauma is often a prominent focus of treatment. This study adds to the current literature by providing initial empirical support for the construct of reorganization. With further examination and validation, this construct has the potential to significantly enrich the field's understanding of the intergenerational transmission of attachment.

\section{ACKNOWLEDGMENTS}

Udita Iyengar made substantial contributions to the design, data analysis and interpretation of the work in addition to drafting the manuscript. All remaining authors also contributed in these areas, with a specific focus as follows: Sohye Kim (statistical input, review of results and study design and overall interpretation); Sheila Martinez (data acquisition and interpretation); Peter Fonagy (statistical input, overall interpretation of results, and critical appraisal); Lane Strathearn (conception of study design, overall interpretation, and critical appraisal of the manuscript). This study was supported by the Eunice Kennedy Shriver National Institute of Child Health and Human Development (K23 HD43097, R01 HD065819); the Baylor Child Health Research Center: Pediatrics Mentored Research Program (K12 HD41648); and the National Institute on Drug Abuse (R01 DA026437). The content is solely the responsibility of the authors and does not necessarily represent the official views of these institutes or the National Institutes of Health. The authors declare no competing financial interests.

\section{SUPPLEMENTARY MATERIAL}

The Supplementary Material for this article can be found online at: http://www.frontiersin.org/journal/10.3389/fpsyg. 2014.00966/abstract

\section{REFERENCES}

Abidin, R. R. (1995). Parenting Stress Index, Professional Manual. Lutz, FL: Psychological Assessment Resources.

Adolphs, R. (2010). What does the amygdala contribute to social cognition? Ann. N.Y. Acad. Sci. 1191, 42-61. doi: 10.1111/j.1749-6632.2010.05445.x

Ainsworth, M. D. S., Blehar, M. C., Waters, E., and Wall, S. (1978). Patterns of Attachment: A Psychological Study of the Strange Situation. Hillsdale, NJ: Erlbaum.

Ainsworth, M. D. S., and Eichberg, C. G. (1991). "Effects on infant-mother attachment of mother's unresolved loss of an attachment figure, or other traumatic experience," in Attachment Across the Life Cycle, eds C. M. Parkes, J. Stevenson-Hinde, and P. Marris (New York, NY: Tavistock/Routledge), 307.
Bayley, N. (2006). Bayley Scales of Infant and Toddler Development. San Antonio, TX: Harcourt Assessment.

Beck, A. T., Steer, R. A., and Brown, G. K. (1996). Manual for the Beck Depression Inventory-II. San Antonio, TX: Psychological Corporation.

Bowlby, J. (1973). Attachment and Loss: Vol. 2. Separation. NY: Basic Books. Bowlby, J. (1982). Loss: Sadness and Depression. New York, NY: Basic Books. Bowlby, J. (1984). Attachment and Loss. London: Penguin Books.

Cicchetti, D., and Toth, S. L. (1999). The development of depression in children and adolescents. Am. Psychol. 53, 221-241. doi: 10.1037/0003-066X.53.2.221

Crittenden, P. (2008). Raising Parents. Attachment, Parenting and Child Safety. Devon: Willan Publishing.

Crittenden, P., and Landini, A. (2011). Assessing Adult Attachment: A DynamicMaturational Approach to Disourse Analysis. New York, NY: W. W. Norton and Company.

Crittenden, P. M. (1990). Internal representational models of attachment relationships. Infant Ment. Health J. 11, 259-277.

Crittenden, P. M. (1992). Children's strategies for coping with adverse home environments: an interpretation using attachment theory. Child Abuse Negl. 16, 329-343. doi: 10.1016/0145-2134(92)90043-Q

Crittenden, P. M. (1995). Attachment and risk for psychopathology: the early years. J. Dev. Behav. Pediatr. 16, S12-S16.

Crittenden, P. M. (1997). "Truth, error, omission, distortion, and deception: the application of attachment theory to the assessment and treatment of psychological disorder," in Assessment and Intervention Across the Lifespan, eds S. M. C. Dollinger and L. F. DiLalla (Hillsdale, NJ: Erlbaum), 35-76.

Crittenden, P. M. (2000). "A dynamic-maturational approach to continuity and change in pattern of attachment," in The Organization of Attachment Relationships: Maturation, Culture, and Context, eds P. M. Crittenden and A. H. Claussen. (New York, NY: Cambridge University Press), 343-357.

Crittenden, P. M., Partridge, M. F., and Claussen, A. H. (1991). Family patterns of relationship in normative and dysfunctional families. Dev. Psychopathol. 3, 491-512. doi: 10.1017/S0954579400007653

Easterbrooks, M. A., Biesecker, G., and Lyons-Ruth, K. (2000). Infancy predictors of emotional availability in middle childhood: the roles of attachment security and maternal depressive symptomatology. Attach. Hum. Dev. 2, 170-187. doi: 10.1080/14616730050085545

Ewbank, M. P., Barnard, P. J., Croucher, C. J., Ramponi, C., and Calder, A. J. (2009). The amygdala response to images with impact. Soc. Cogn. Affect. Neurosci. 4, 127-133. doi: 10.1093/scan/nsn048

Farnfield, S., Hautamaki, A., Norbech, P., and Sahhar, N. (2010). DMM assessments of attachment and adaptation: procedures, validity and utility. Clin. Child Psychol. Psychiatry 15, 313-328. doi: 10.1177/1359104510364315

Fearon, R. P., Bakermans-Kranenburg, M. J., van IJzendoorn, M. H., Lapsley, A. M., and Roisman, G. I. (2010). The significance of insecure attachment and disorganization in the development of children's externalizing behavior: a meta-analytic study. Child Dev. 81, 435-456. doi: 10.1111/j.1467-8624.2009. 01405.x

Fonagy, P., Steele, H., and Steele, M. (1991). Maternal representations of attachment during pregnancy predict the organization of infant-mother attachment at one year of age. Child Dev. 62, 891-905. doi: 10.2307/1131141

Gartstein, M. A., and Rothbart, M. K. (2003). Studying infant temperament via the revised infant behavior questionnaire. Infant Behav. Dev. 26, 64-86. doi: 10.1016/S0163-6383(02)00169-8

Hautamaki, A., Hautamaki, L., Neuvonen, L., and Maliniemi-Piispanen, S. (2010). Transmission of attachment across three generations. Eur. J. Dev. Psychol. 7, 618-634. doi: 10.1080/17405620902983519

Hesse, E., and Main, M. (1999). Second-generation effects of unresolved trauma as observed in non-maltreating parents: dissociated, frightened, and threatening parental behavior. Psychoanal. Inq. 19, 481-540. doi: $10.1080 / 07351699909534265$

Hyler, S. E., Skodol, A. E., Oldham, J. M., Kellman, H. D., and Doidge, N. (1992). Validity of the personality diagnostic questionnaire-revised: a replication in an outpatient sample. Compr. Psychiatry 33, 73-77. doi: 10.1016/0010440X(92)90001-7

Insel, T. R., and Young, L. J. (2001). The neurobiology of attachment. Nat. Rev. Neurosci. 2, 129-136. doi: 10.1038/35053579

Kim, S., Fonagy, P., Allen, J., and Strathearn, L. (2014). Mothers' unresolved trauma blunts amygdala response to infant distress. Soc. Neurosci. 9, 352-363. doi: 10.1080/17470919.2014.896287 
Landa, S., and Duschinsky, R. (2013). Crittenden's dynamic-maturational model of attachment and adaptation. Rev. Gen. Psychol. 17, 326-338. doi: 10.1037/a0032102

Lyons-Ruth, K., Bronfman, E., and Parsons, E. (1999). Maternal frightened, frightening, or atypical behavior and disorganized infant attachment patterns. Monogr. Soc. Res. Child Dev. 64, 67-96. doi: 10.1111/1540-5834.00034

Lyons-Ruth, K., Yellin, C., Melnick, S., and Atwood, G. (2005). Expanding the concept of unresolved mental states: hostile/helpless states of mind on the Adult Attachment Interview are associated with disrupted mother-infant communication and infant disorganization. Dev. Psychopathol. 17, 1-23. doi: 10.1017/S0954579405050017

Madigan, S., Bakermans-Kranenburg, M. J., Van Ijzendoorn, M. H., Moran, G., Pederson, D. R., and Benoit, D. (2006). Unresolved states of mind, anomalous parental behavior, and disorganized attachment: a review and meta-analysis of a transmission gap. Attach. Hum. Dev. 8, 89-111. doi: $10.1080 / 14616730600774458$

Main, M., and Hesse, E. (1990). "Parent's unresolved traumatic experiences are related to infant disorganized attachment status: is frightened and/or frightening parental behavior the linking mechanism?" in Attachment in the Preschool Years, eds M. C. Greenberg, D. Cicchetti, and E. M. Cummings (Chicago, IL: University of Chicago Press), 161-182.

Pearson, J. L., Cohn, D. A., Cowan, P. A., and Cowan, C. P. (1994). Earned- and continuous- security in adult attachment: relation to depressive symptomatology and parenting style. Dev. Psychopathol. 6, 359-373. doi: 10.1017/S0954579400004636

Protopopescu, X., Pan, H., Tuescher, O., Cloitre, M., Goldstein, M., Engelien, W., et al. (2005). Differential time courses and specificity of amygdala activity in posttraumatic stress disorder subjects and normal control subjects. Biol. Psychiatry 57, 464-473. doi: 10.1016/j.biopsych.2004.12.026

Rauch, S. L., Whalen, P. J., Shin, L. M., McInerney, S. C., Macklin, M. L., Lasko, N. B., et al. (2000). Exaggerated amygdala response to masked facial stimuli in posttraumatic stress disorder: a functional MRI study. Biol. Psychiatry 47, 769-776. doi: 10.1016/S0006-3223(00)00828-3

Roisman, G. I., Padron, E., Sroufe, L. A., and Egeland, B. (2002). Earned-secure attachment status in retrospect and prospect. Child Dev. 73, 1204-1219. doi: $10.1111 / 1467-8624.00467$

Rothbart, M. K., Ahadi, S. A., and Evans, D. E. (2000). Temperament and personality: origins and outcomes. J. Pers. Soc. Psychol. 78, 122-135. doi: 10.1037/0022-3514.78.1.122

Sander, D., Grafman, J., and Zalla, T. (2003). The human amygdala: an evolved system for relevance detection. Rev. Neurosci. 14, 303-316. doi: 10.1515/REVNEURO.2003.14.4.303

Schechter, D. S., Zeanah, C. H. Jr., Myers, M. M., Brunelli, S. A., Liebowitz, M. R., Marshall, R. D., et al. (2004). Psychobiological dysregulation in violence-exposed mothers: salivary cortisol of mothers with very young children pre-and post-separation stress. Bull. Menninger Clin. 68, 319-336. doi: 10.1521/bumc.68.4.319.56642

Schuengel, C., Bakermans-Kranenburg, M. J., and van IJzendoorn, M. H. (1999). Frightening maternal behavior linking unresolved loss and disorganized infant attachment. J. Consult. Clin. Psychol. 67, 54-63. doi: 10.1037/0022-006X.67.1.54

Schwerdtfeger, K. L., and Goff, B. S. (2007). Intergenerational transmission of trauma: exploring mother-infant prenatal attachment. J. Trauma. Stress 20, 39-51. doi: 10.1002/jts.20179
Shah, P. E., Fonagy, P., and Strathearn, L. (2010). Is attachment transmitted across generations? The Plot Thickens. Clin. Child Psychol. Psychiatry 15, 329-346. doi: $10.1177 / 1359104510365449$

Shah, P. E., and Strathearn, L. (2014). "Similarities and differences of the ABCD model and the DMM classification systems for attachment: a practitioner's guide," in The Guidebook to Attachment Theory and Interventions, eds P. Holmes and S. Farnfield (London: Routledge), 73-88.

Siegel, D. J. (1999). The Developing Mind: How Relationships and the Brain Interact to Shape Who We Are. New York, NY: The Guilford Press.

Sroufe, L. A. (2005). Attachment and development: a prospective, longitudinal study from birth to adulthood. Attach. Hum. Dev. 7, 349-367. doi: $10.1080 / 14616730500365928$

Strathearn, L., Fonagy, P., Amico, J. A., and Montague, P. R. (2009). Adult attachment predicts mother's brain and oxytocin response to infant cues. Neuropsychopharmacology 34, 2655-2666. doi: 10.1038/npp. 2009.103

van IJzendoorn, M. H. (1995). Adult attachment representations, parental responsiveness, and infant attachment: a meta-analysis on the predictive validity of the adult attachment interview. Psychol. Bull. 117, 387-403. doi: 10.1037/00332909.117.3.387

van IJzendoorn, M. H., and Bakermans-Kranenburg, M. J. (2004). "Maternal sensitivity and infant temparement in the formation of attachment," in Theories of Infant Development, eds G. Bremner and A. Slater (London: Blackwell), 223-258.

van IJzendoorn, M. H., and Bakermans-Kranenburg, M. J. (2009). The first 10,000 adult attachment interviews: distributions of adult attachment representations in clinical and non-clinical groups. Attach. Hum. Dev. 11, 223-263. doi: $10.1080 / 14616730902814762$

Williams, L., Kemp, A., Felmingham, K., Barton, M., Olivieri, G., Peduto, A., et al. (2006a). Trauma modulates amygdala and medial prefrontal responses to consciously attended fear. Neuroimage 29, 347-404. doi: 10.1016/j.neuroimage.2005.03.047

Williams, L. M., Liddell, B. J., Kemp, A. H., Bryant, R. A., Meares, R. A., Peduto, A. S., et al. (2006b). Amygdala-prefrontal dissociation of subliminal and supraliminal fear. Hum. Brain Mapp. 27, 652-661. doi: 10.1002/hbm.20208

Conflict of Interest Statement: The authors declare that the research was conducted in the absence of any commercial or financial relationships that could be construed as a potential conflict of interest.

Received: 19 May 2014; accepted: 13 August 2014; published online: 01 September 2014.

Citation: Iyengar U, Kim S, Martinez S, Fonagy P and Strathearn L (2014) Unresolved trauma in mothers: intergenerational effects and the role of reorganization. Front. Psychol. 5:966. doi: 10.3389/fpsyg.2014.00966

This article was submitted to Psychology for Clinical Settings, a section of the journal Frontiers in Psychology.

Copyright (c) 2014 Iyengar, Kim, Martinez, Fonagy and Strathearn. This is an openaccess article distributed under the terms of the Creative Commons Attribution License (CC BY). The use, distribution or reproduction in other forums is permitted, provided the original author(s) or licensor are credited and that the original publication in this journal is cited, in accordance with accepted academic practice. No use, distribution or reproduction is permitted which does not comply with these terms. 


\title{
Predictors of mother-child interaction quality and child attachment security in at-risk families
}

\author{
Simona De Falco* ${ }^{\dagger}$, Alessandra Emer ${ }^{\dagger}$, Laura Martini, Paola Rigo, Sonia Pruner and Paola Venuti \\ Università degli Studi di Trento, Rovereto, Italy
}

\section{Edited by:}

Silvia Salcuni, Università degli Studi di

Padova, Italy

Reviewed by:

Alessandra Simonelli, University of Padova, Italy

Vincenzo Paolo Senese, Second

University of Naples, Italy

\section{*Correspondence:}

Simona De Falco, Università degli

Studi di Trento, Rovereto, Italy

e-mail:simona.defalco@unitn.it

${ }^{+}$Simona De Falco and

Alessandra Emer have contributed equally to this work.
Child healthy development is largely influenced by parent-child interaction and a secure parent-child attachment is predictively associated with positive outcomes in numerous domains of child development. However, the parent-child relationship can be affected by several psychosocial and socio-demographic risk factors that undermine its quality and in turn play a negative role in short and long term child psychological health. Prevention and intervention programs that support parenting skills in at-risk families can efficiently reduce the impact of risk factors on mother and child psychological health. This study examines predictors of mother-child interaction quality and child attachment security in a sample of first-time mothers with psychosocial and/or socio-demographic risk factors. Forty primiparous women satisfying specific risk criteria participated in a longitudinal study with their children from pregnancy until 18 month of child age. A multiple psychological and socioeconomic assessment was performed. The Emotional Availability Scales were used to measure the quality of emotional exchanges between mother and child at 12 months and the Attachment Q-Sort served as a measure of child attachment security at 18 months. Results highlight both the effect of specific single factors, considered at a continuous level, and the cumulative risk effect of different co-occurring factors, considered at binary level, on mother-child interaction quality and child attachment security. Implication for the selection of inclusion criteria of intervention programs that support parenting skills in at-risk families are discussed.

\section{Keywords: attachment, emotional availability, psychosocial risk, parenting, psychosocial prevention}

\section{INTRODUCTION}

Child physical and psychological development is largely influenced by parent-child relationship (Bornstein, 2002). Through their caregiving, parents supply their children with the experiences and support they need for achieving their developmental milestones (Brinker et al., 1994). An extensive body of research on human parenting has provided evidence that quality of caregiving is essential in determining the level of children's social emotional as well as cognitive development (Bornstein and Tamis-LeMonda, 1989; Landry et al., 2006; Dexter et al., 2013). Specifically, sensitive and responsive parenting promotes a secure attachment relationship (De Wolff and van IJzendoorn, 1997; Nievar and Becker, 2008), which in turn is predictively associated with positive outcomes in numerous domains of child development (Bar-Haim et al., 2000; Vondra et al., 2001; Belsky and Pasco Fearon, 2002; Bernier and Meins, 2008; Dexter et al., 2013). However, the parentchild relationship can be affected by several psychosocial and socio-demographic risk factors that undermine its quality and in turn play a negative role in short and long term child psychological wellbeing (Sameroff, 1998, 2000; Choe et al., 2013). Classical research on the psychological development of children living in at risk families supports additive models according to which psychological problems are not the result of one specific risk factor but may be instead predicted by the combined presence of different factors (Greenberg et al., 1993; Lyons-Ruth et al., 1993; HubbsTait et al., 1996). Also, established models of parenting (Belsky,
1984) postulate that the quality of the parent-child relationship is the integrated result of three sets of factors: parent characteristics, infant characteristics, and context which can influence parenting in a supportive or stressful way. Accordingly, many studies have investigated to which extent attachment security can be explained by theoretically relevant risk factors, such as low family socio-economic status (SES), maternal depression and other psychological symptoms, young maternal age, single parenting. However, most studies concentrated on one specific risk factor at the time, or several co-occurring factors that could not be disentangled. The aim of the present study was to examine the influence on dyadic emotional availability (EA; Biringen and Robinson, 1991; Biringen, 2000), as an index of mother-child interaction quality, and on child attachment security of different psychosocial and socio-demographic risk factors in at-risk families living in Northern Italy. Results in this direction may guide the selection of inclusion criteria for effective intervention programs that promote sensitive and responsive parenting in at-risk families.

\section{ATTACHMENT SECURITY AND EMOTIONAL AVAILABILITY}

Secure attachment has been shown to positively influence child social emotional as well as cognitive adaptation beyond infancy (Bar-Haim et al., 2000; Vondra et al., 2001; Dexter et al., 2013). Secure mother-child attachment is the result of adequate maternal sensitivity, as postulated by Ainsworth etal. (1978) and 
demonstrated by a strong body of literature (NICHD Early Child Care Research Network, 1997, 2006). However, especially in high risk populations, the strength of this association may be modest and sensitivity may just partially explain child attachment security (Ward and Carlson, 1995; Seifer et al., 1996). Indeed, different risk factors can affect maternal sensitivity and child attachment security in many ways, complicating their associations. When studying the impact of risk factors on mother-child relationship, it may be appropriate to focus on more complex constructs within the theoretical attachment framework that expands that of maternal sensitivity. In this perspective, EA is a crucial construct (Biringen and Robinson, 1991; Aviezer et al., 1999; Bretherton, 2000; EA; Biringen and Robinson, 1991; Biringen, 2000) is a relationship construct based on attachment theory (Ainsworth et al., 1978) integrated with Emde's (1980) emotions perspective. It refers to the quality of emotional exchanges between parents and their children, focusing on the two partners' accessibility to each other and their ability to read and respond appropriately to one another's communications (Biringen and Robinson, 1991). Studies of EA suggest that the construct not only plays a role in the prediction of attachment (Easterbrooks and Biringen, 2000 , 2005) but also show significant and meaningful associations with many discrete affective indices of parent-child interaction (Robinson et al., 1993; Zimmerman and McDonald, 1995; Kogan and Carter, 1996), and can be considered a global index of the overall quality of the parent-child affective relationship (Biringen, 2000).

\section{PSYCHOSOCIAL RISK FACTORS FOR PARENT-CHILD RELATIONSHIP}

Among the most investigated factors thought to have a detrimental effect on parent-child relationship and child healthy development are low SES of the family and maternal psychopathology. SES influences physical and psychological health as well as the chances of social and cultural achievements during the all life span (Ensminger and Fothergill, 2003). Children born and raised in low SES families have higher chances of perinatal negative outcomes and fewer chances of receiving the appropriate physical cares and cognitive stimulation they need for their healthy development (Yoshikawa et al., 2012). Low parental SES has been predictively associated with lower children IQ and school achievements (Bradley and Corwyn, 2002; Gottfried et al., 2003; Clearfield and Niman, 2012). The effect of low SES on child development is partially mediated by reduced parenting quality (McLoyd and Wilson, 1991; Fish, 2001). Parenting quality is thought to be affected by the increased instability and stresses connected to low income and poor education conditions (Bronfenbrenner, 1979; Aber et al., 2000; Bradley and Corwyn, 2002; Lemelin et al., 2006; Seow, 2012). Low SES mothers are reported to show lower levels of synchronic and responsive behavior when interacting with their children (Tamis-LeMonda etal., 2001; Ammaniti et al., 2002; Steele et al., 2002; van Bakel and Riksen-Walraven, 2002; Aviezer et al., 2003; Evans etal., 2005; Tarabulsy et al., 2005; Shin etal., 2006) as well as more inconsistent, punitive, and coercive parenting (McLoyd and Wilson, 1991). Lower levels of attachment security and a higher rate of disorganized attachment have been clearly documented in studies on low SES and low income families (Lyons-Ruth et al., 1991; NICHD Early Child Care Research Network, 1997; van IJzendoorn et al., 1999). However, some level of inconsistency exists in this body of research and meta-analytic studies demonstrated comparable levels of attachment security between low SES and middle class children when isolated cases of neglect and maltreatment where excluded (Spieker and Booth, 1988).

A plethora of research has documented negative associations between maternal psychopathology and child psychological wellbeing (Downey and Coyne, 1990; Cummings and Davies, 1994; Seifer and Dickstein, 2000; Burstein etal., 2012). This field of research has been dominated by studies on maternal depression showing its detrimental effect on mother-child relationship and child healthy development (Downey and Coyne, 1990; Campbell et al., 1992, 1995; Beck, 1995; Murray et al., 1999; Edhborg et al., 2001; Nagata et al., 2004; Toth et al., 2009; McCabe, 2014). Maternal depression has been empirically linked to lower levels of attachment security (Lyons-Ruth et al., 1990; Lyons-Ruth et al., 1990; Murray, 1992; Teti et al., 1995; Goodman and Gotlib, 1999, 2002; Lyons- Martins and Gaffan, 2000) and diminished maternal sensitivity connected to the nature of depressive symptoms has been accounted to mediate this association (Ammaniti et al., 2007). However, the strength of this association has been found to be modest and maternal depression alone may not result in inadequate parenting quality or attachment insecurity for some children (van IJzendoorn et al., 1999; Atkinson et al., 2000; Toth et al., 2009).

\section{SOCIO-DEMOGRAPHIC RISK FACTORS FOR PARENT-CHILD RELATIONSHIP}

Other conditions that have been investigated as potential risk factors in the parenting literature are two socio-demographic factors, namely young maternal age, and, to a lower extent, single parenting. However, both factors are thought to affect parent-child relationship mainly when occurring together with psychosocial risk conditions, as those described above, which indeed are especially frequent among young and single mothers (Rosenkrantz Aronson and Huston, 2004; Letourneau et al., 2004; Svoboda et al., 2012).

Adverse health and psychological outcomes have been associated with adolescent pregnancy and parenting (Long, 2009) including gestational hypertension, preterm labor and delivery (Sieger and Renk, 2007), and children's cognitive and language delayed development (Keown et al., 2001; Rafferty et al., 2011). Being themselves in a process of "separation-individuation" and in a period of emotional and social changes during the transition to adulthood, adolescent mothers may find it difficult to face the challenges of parenthood. There is a strong body of research showing that compared to older mothers, adolescent mothers display less desirable childrearing attitudes, lower sensitivity and diminished (EA; Pomerleau et al., 2003; Easterbrooks et al., 2005; Bornstein and Putnick, 2007). Accordingly, researchers found that children of adolescent mothers are less likely to develop a secure attachment and more likely to develop behavioral problems (Madigan et al., 2006; Moran et al., 2008).

Raising a child without the help of a partner exposes the mothers to more challenges, stress and fatigue, leading to higher chances 
of psychological problems (Broussard et al., 2012). Children raised only by the mother show poorer outcomes in several areas of development. Research in this domain has demonstrated lower levels of social emotional adaptation, social competence, cognitive scores, school achievements as well as higher rates of anxiety disorders and deviant behaviors in children raised in single-mother compared to two-parents families (Carlson and Corcoran, 2001; Weinraub et al., 2002; Tremblay and Japel, 2003; Fergusson et al., 2007; Scharte and Bolte, 2011; Shaw et al., 2012). Studies on attachment relationship between single mothers and their children showed inconsistent results ranging from increased (Golombok et al., 1997) to slightly decreased children's attachment security (Rosenkrantz Aronson and Huston, 2004).

All the mentioned risk factors may negatively affect motherchild relationship quality and children's attachment security eventually affecting child healthy development. However, the predictive value of each risk factor appears to be moderated by the co-occurrence of other risk factors in a complex additive model. Nevertheless most of the studies within this body of literature took into account one risk factor at the time. Moreover, some inconsistency in the results might be related to the tendency to operationalize risk factors only in a dichotomic way by comparing families with and without a specific risk condition, disregarding factors' intensity that can be instead accounted by considering risk factors at a continuous level (McCabe, 2014). Starting from the above considerations, the present study aimed to assess the influence of psychosocial and socio-demographic risk factors on mother-child EA and on children's attachment security in a sample of at-risk families living in Northern Italy. In an attempt to identify the specific effect on mother-child relationship of each risk factor as well as the cumulative effect of their co-occurrence, low family SES, maternal psychopathology, maternal young age, and single parenting, were analyzed both as dichotomic and as continuous variables in a longitudinal design. We specifically hypothesized to find modest negative associations between continuous measures of risk factors and the EA and attachment measures. Also, we didn't expect differences in EA and attachment security measures between groups of dyads with or without single risk factors. Finally, we expected that EA and attachment security measures would be higher in dyads presenting socio-demographic factors alone compared to dyads presenting psychosocial risk factors alone or a combination of both. Results of this explorative study would be crucial for the identification of the families at higher risk for low relationship quality and attachment security who might profit of prevention intervention that promote emotionally available mother-child relationship and in turn reduce the risk of poor developmental outcomes.

\section{MATERIALS AND METHODS PARTICIPANTS}

This study involved 40 first-time mothers with specific psychosocial and/or socio-demographic risk factors and their healthy full term children living in three different areas (A, B, and C) of Northern Italy. At the time of recruitment mothers had a mean age of 27.32 years $(\mathrm{SD}=6.56)$ and they were in the third trimester of pregnancy. Measures for the present study were collected when children were aged $3,6,12$, and 18 months (with a 2-weeks flexibility interval). Participants were part of a broader intervention study on at-risk families in either the intervention or the control group (group assignment was controlled as appropriate in the analyses for the purposes of the present study, see "Materials and Methods" section). Participation in the project was proposed by midwifes, OB/GYN doctors and psychologists of the local public health centers who received specific information about the project and the inclusion criteria. After consensus was obtained, mothers were visited by a trained psychologist to verify through clinical interview and psychological assessment that at least one of the following inclusion criteria was satisfied: (1) age under 22 years; (2) single mother; (3) low family SES [family income under 13.125,90 euros (poverty threshold according to ISTAT for 2011); less than 10 years of education]; (3) high indexes of psychopathological symptoms assessed through standardized questionnaires [Global Severity Index, GSI $>1$ at the SymptomsChecklist 90-R, (SCL 90-R; Derogatis, 1994 ) and/or Edimburg Postnatal Depression Scale (EPDS; Cox et al., 1987) score >9] or being actually followed by the local public mental health services. Twenty-three mothers $(57,5 \%)$ satisfied criteria for only one of the risk factors: 15 for psychopathological symptoms $(37,5 \%)$, 3 for single parenting $(7,5 \%), 3$ for low family SES $3(7,5 \%)$, and 2 for young age $(5,0 \%)$. In the remaining sample, 14 mothers $(35,0 \%)$ satisfied criteria for two risk factors, and $3(7,5 \%)$ for 3 risk factors. Eighty-seven percent of the contacted mothers accepted to participate in the study and drop out was $12 \%$. Participants gave written informed consent for their participation in the study. The study protocol was approved by the local ethical committee.

\section{PROCEDURE}

The protocol of the broader longitudinal study in which the participants were involved included several home visits of a trained psychologist for test administration, mother-child interaction observation and video recording. Measures of maternal risk factors used for the present study were collected during home visits at pregnancy and at child age three and six Measures of motherchild relationship quality and child attachment security were taken during home visits at ages 12 and 18 months, respectively.

\section{Measures of psychosocial and socio-demographic risk factors}

Maternal risk factors were considered both at a dychotomic and at a continuous level. (A) Dychotomic classifications of the mothers for low family SES, maternal psychopathology, young age and single parenting are described in the Participants section where the inclusion criteria are defined. (B) As continuous measures of psychosocial risk factors the following questionnaire scores were considered: the Four-Factor Index of Social Status (Hollingshead, unpublished manuscript) as a measure of family SES; the GSI of the SCL 90-R (Derogatis, 1994) and the EPDS (Cox et al., 1987) score as measures of maternal psychopathological symptoms.

\section{Emotional availability measure}

Emotional availability in a subsample of 25 mother-child dyads was evaluated from 15 -min of free-play at home interaction videorecorded continuously by a female filmmaker. A standard set 
of age-appropriate toys was used and mothers were instructed to play with their children in their usual way, disregarding the observer presence. Observations were coded using the emotional availability scales (EAS): Infancy to Early Childhood Version (EAS 4th Edn; Biringen, 2008). These Scales consist of six dimensions concerned with emotional regulation in the parent-child dyad. Four dimensions address the EA of the parent in relation to the child (sensitivity, structuring, non-intrusiveness, and non-hostility), and two address the EA of the child in relation to the parent (responsiveness and involving). All scales range from 1 (highly emotional unavailable) to 7 (highly emotional available) points and scores are given based on seven subcategories. The Sensitivity scale assesses the parent's appropriate affectivity, acceptance, flexibility, clarity of perceptions, affect regulation, and variety and creativity in play displayed toward the child. Structuring assesses the degree to which the parent provides rules, regulations, and a supportive framework for interaction while appropriately scaffolding child play, exploration, or routine. Non-intrusiveness refers to the ability to be available for the child without being over-directive, over-stimulating, or overprotective. Non-hostility assesses the degree of hostility both in covert and overt forms. Responsiveness focuses on the child's interest in exploring on his or her own and in responding to the mother's bids (i.e., the balance between connection and autonomy) as well as on the extent of the child's enjoyment of the interaction. Involving of mother assesses the child's ability and willingness to engage the mother in interaction. The flexible nature of the Scales, which can be used with children from infancy to early childhood, and the choice of an ecological context of free-play with a standard toy set for pre-school children allowed us to use the same observational situation for all participants. Coding was carried out by two independent coders who were first trained on the EAS to obtain satisfactory interrater reliability with the codings the author of the EAS 4 th edition and then between themselves. Interrater reliability [Biringen, 2005 was assessed using average absolute agreement intraclass correlation coefficients (ICC); McGraw and Wong, 1996] on $15 \%$ of the interactions coded, and ICCs ranged from 0.81 to 0.93 .

\section{Attachment security measure}

Child attachment security was measured using the Italian version of the Attachment Q-Sort (AQS; Weters, 1987; Cassibba and D'Odorico, 2009) applied at 18 months of child age by a trained observer after 2-4 home visits lasting ca 1,5 h each. AQS is a Q-Sort method to evaluate child security in relation to the quality of child secure-base behavior (Vaughn and Waters, 1990). The Italian version includes 90 items describing child behavior that the observer has to sort into nine piles according to similarity with the infant's behavior (Vaughn and Waters, 1990; Cassibba et al., 2000). By comparing this sorting with a composite description of the "hypothetically most secure infant" provided by experts in the field of attachment theory, a score for attachment security is obtained (Cassibba et al., 2000) that is thought to reflect the degree of similarity of the target child to the prototypical securely attached child (Teti and Ablard, 1989; Bretherton et al., 1989; Howes and Hamilton, 1992).

\section{RESULTS}

\section{PRELIMINARY ANALYSIS AND ANALYTIC PLAN}

Distributions of the dependent variables were examined for normalcy which was confirmed for all EAS and for AQS scores. As the EAS and the AQS are measures of theoretically associated constructs, bivariate correlation analysis was performed between AQS score and EAS scores in order to verify that these measures were in fact empirically associated in this study. Results, highlighting positive association between the AQS and two scales of the EAS: mother nonintrusiveness $[r(36)=0.38, p<0.05]$, and child responsiveness $[r(36)=0.40, p<0.05]$, constitute relevant confirmation of the validity of the instruments used to measure the dependent variables.

Bivariate correlation analyses were performed to check associations of AQS and EAS scores with the risk factors measured as continuous variables. Then, risk factors were considered in binary fashion and for each of them (young maternal age, single parenting, maternal psychopathology, family SES), separate ANCOVAs were performed with AQS and EAS scores as dependent variables, and each risk factor (present or absent) as between factor. Finally, the risk factors were aggregated into a threelevel between factor (socio-demographic only, psychosocial only, both) which served as independent variable in further separate ANCOVAs with AQS and EAS scores as dependent variables. Participants were part of a broader intervention study either in the target or control group; as a precaution, group assignment was included as covariate in all the analyses of variance described above.

\section{DESCRIPTIVE STATISTICS}

Table 1 show the means and standard deviations of AQS and EAS scores for dyads with and without each risk factor and in the whole sample. Table 2 shows descriptive statistics of AQS and EAS scores for dyads with socio-demographic risk factors alone, psychosocial risk factors alone, and with both kind of risk factors.

\section{CORRELATIONAL ANALYSIS}

Results showed a positive correlation of mother's sensitivity $[r(36)=0.47, p<0.01]$, structuring $[r(36)=0.55, p<0.001]$, and non-hostility $[r(36)=0.38, p<0.05)$ with family SES. Correlation between family SES and AQS scores was within the moderate range but did not reach significance $[r(40)=0.33, p=0.09]$. AQS and EAS scores were not significantly associated with measures of maternal psychopathology, i.e., SCL 90-R GSI and EPDS scores (Table 3).

\section{GROUP COMPARISONS}

No significant differences were found in AQS and EAS scores of dyads differentiated according to the presence/absence of each of the risk factors as defined for the inclusion criteria. However, dyads presenting a low family SES had lower scores of maternal structuring and non-intrusiveness scores $[F(1,34)=3.13, p<0.062$ and $F(1,34)=2.98, p<0.07$, respectively], compared to dyads who did not meet the criteria for this risk factor, but the results did not reach statistical significance. 


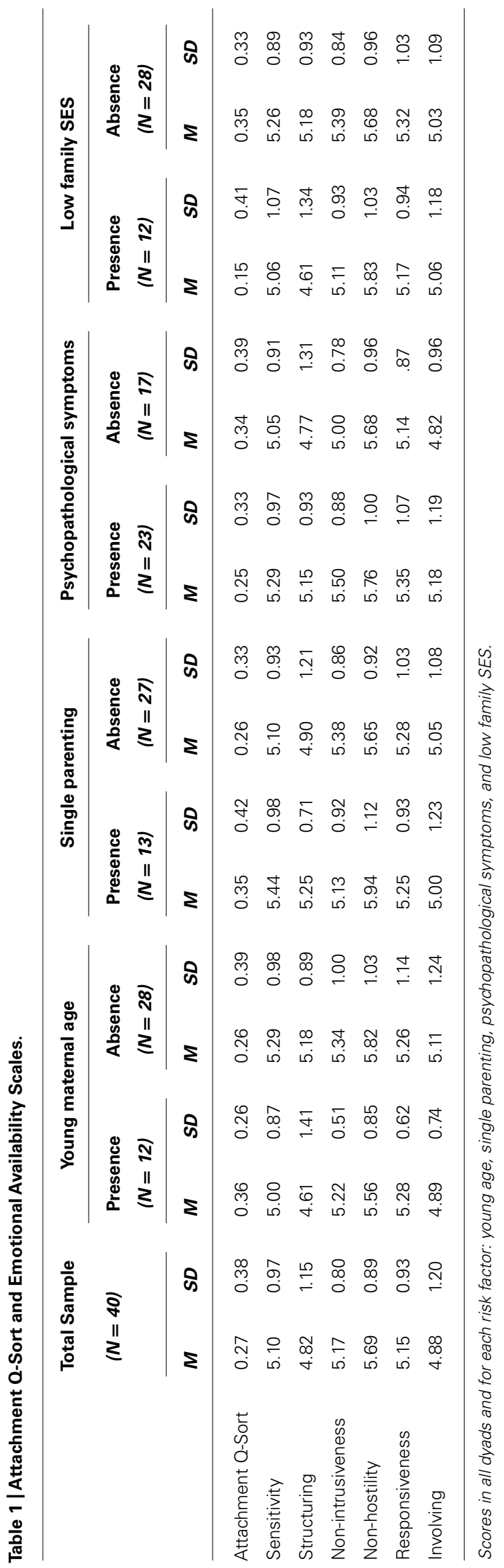


A significant difference was found between dyads with different type of risk factors (socio-demographic only, psychosocial only, both), $F(2,37)=3.26, p<0.05, \eta^{2}=0.31$. Post hoc test showed that attachment security was higher in dyads with demographic risk factor only compared to dyads with both demographic and sociopsychological fragilities, whereas attachment security of children in dyads presenting only psychosocial risk factor did not differ significantly from the other two groups. $(p<0.02$, Bonferroni Correction for multiple comparisons; Table 2).

\section{DISCUSSION}

Among several influential variables, parents can be considered the "final common pathway" for children development, growth and adaptation (Bornstein, 2002). Specifically, the quality of mother-child interaction and attachment are key determinants of child social emotional adaptation and cognitive development (Bowlby, 1969; Ainsworth et al., 1978; Belsky and Pasco Fearon, 2002; Bernier and Meins, 2008). Different risk factors can affect mother-child relationship resulting in negative children outcomes as demonstrated by a strong body of research (Sameroff, 1998; Choe et al., 2013). Psychosocial risk factors, such as low family SES and maternal psycopathology, and socio-demographic risk factors, such as very young maternal age and single parenting, are among the most theoretically relevant and empirically investigated risk conditions. Although results of this line of research are substantially coherent in identifying the detrimental effect of each factor, they also point out to a complex cumulative model of risk according to which a single factor may not be influential itself whereas its predictive value might be moderated by the association with other risk conditions or by its degree of intensity (Belsky, 1984; Greenberg et al., 1993; Lyons-Ruth et al., 1993; Hubbs-Tait et al., 1996). Several intervention programs have been developed for at-risk families and some have shown positive effect on motherchild relationship quality (Bakermans-Kranenburg et al., 2003) reducing the impact of risk factors on mother and child psychological health (Kohlhoff and Barnett, 2013). Starting from the above considerations, this study aimed at investigating the effect of psychosocial and socio-demographic risk factors on motherchild EA, measured with the EAS at 12 months of child age and child attachment security, measured with the AQS at 18 months of child age, in at risk dyads living in Northern Italy. Specifically, we focused on low family SES, maternal psycopathology, young maternal age and single parenting considered both at a continuous (where appropriate) and at a dichotomic level in order to investigate the contribution of each factor as well as the potential additive effect of more factors on mother-child relationship measures. We had a set of specific hypotheses: we expected 1) that intensity of each risk condition would show modest negative association with mother-child EA and child attachment security. Also, we hypothesized 2) to find no differences in our dependent variables between dyads differentiated according to the presence/absence of each of the risk factor, but we expected 3) socio-demographic risk factors to show a smaller effect on EA and child attachment security then psychosocial risk factors or the combination of the two type of fragility. Preliminary analyses of the selected measures validity verified positive association between some maternal and child EA scales and AQS score.
With respect to our first hypothesis, we found that in our sample the level of family SES was significantly positively associated with different dimensions of maternal EA, namely sensitivity, structuring and non-hostility. Mothers with a higher socioeconomic level recognize and respond more appropriately to child signals, structure the interaction in a way that better foster child play and exploration and are more able to limit their display of negative emotions during interaction. The positive association between SES and the quality of mother interactive behavior measured in similar and different ways has been observed in previous studies (Rosen et al., 2003; Aviezer et al., 2003; Evans et al., 2005; Tarabulsy et al., 2005) and attributed to higher cognitive, emotional, material, and social resources that characterize high compared to low SES families. The association between family SES and child attachment security at 18 months did not reach significance but the coefficient was in the moderate range and the small $n$ of our sample may have reduced the power of our analyses. Such association has been reported in previous studies (Lyons-Ruth et al., 1991; NICHD Early Child Care Research Network, 1997; van IJzendoorn et al., 1999) with some notable exceptions (Spieker and Booth, 1988). We also found maternal age to be positively associated with mother EA and specifically to mother structuring and non-hostility, in line with previous studies demonstrating that compared to older mothers, younger mothers show more limited knowledge about childrearing and child development, lower confidence in their parenting skills (Bornstein and Putnick, 2007) and a less emotionally available interactive style (Pomerleau et al., 2003; Gazzotti et al., 2010). Instead, no association was found between maternal age and child attachment security. Surprisingly, our measures of maternal psychopathology, i.e., SCL-90-R and EPDS (at 3 and 6 months of age respectively), showed no associations with either mother-child EA and child attachment security. Yet, psychopathological symptoms of the mother, and depression in particular, have been repeatedly reported to predict negative outcomes terms of maternal sensitivity and child attachment security though highlighting only moderate association (van IJzendoorn et al., 1999; Atkinson et al., 2000). Our findings might been explained by the small intersubject variability in questionnaire scores of a sample including only mothers at risk for socio-demographic and/or psychosocial risk factors.

As expected, according to our second hypotheses, in our sample of at-risk mother-child dyads we did not find any effect of the single risk factors considered in a binary fashion, i.e., in terms of presence or absence, on either EA and attachment security, with the exception of the tendency of mothers with low SES to display lower structuring and non-intrusiveness which, however, did not reach significance. With respect to our third hypothesis, when we explored the effect of the type of risk factors by aggregating them into a three level variable, i.e., comparing dyads with socio-demographic risk factors only (young maternal age and/or single parenting), those with psychosocial risk factors only (low family SES and/or maternal psychopathology) and those who had both type of risk factors, results highlighted higher attachment security in children of mothers with socio-demographic risk factors only compared to those with both kinds of risk conditions, with attachment security level of children with psychosocial risk 
Table 2 | Descriptive and inferential statistics for Attachment Q-Sort and Emotional Availability Scales scores for type of risk factors.

\begin{tabular}{|c|c|c|c|c|c|c|c|c|}
\hline & \multicolumn{2}{|c|}{$\begin{array}{c}\text { Socio-demographic } \\
\text { risk only }(N=10)\end{array}$} & \multicolumn{2}{|c|}{$\begin{array}{l}\text { Psychosocial risk only } \\
\qquad(N=19)\end{array}$} & \multicolumn{2}{|c|}{$\begin{array}{l}\text { Both risk factors } \\
\qquad(N=11)\end{array}$} & \multirow[b]{2}{*}{$F(2,37)$} & \multirow[b]{2}{*}{$p$} \\
\hline & $M$ & $S D$ & $M$ & $S D$ & $M$ & $S D$ & & \\
\hline Attachment Q-Sort & 0.35 & 0.40 & 0.24 & 0.38 & 0.06 & 0.37 & 3.26 & 0.03 \\
\hline Sensitivity & 5.42 & 0.86 & 5.21 & 0.89 & 5.00 & 1.13 & 1.46 & 0.25 \\
\hline Structuring & 5.33 & 0.88 & 5.18 & 0.91 & 4.44 & 1.40 & 2.09 & 0.13 \\
\hline Non-intrusiveness & 5.42 & 0.59 & 5.39 & 0.96 & 5.06 & 0.90 & 1.71 & 0.19 \\
\hline Non-hostility & 5.92 & 0.97 & 5.75 & 0.92 & 5.56 & 1.15 & 1.30 & 0.30 \\
\hline Responsiveness & 5.58 & 0.67 & 5.21 & 1.16 & 5.13 & 0.92 & 0.94 & 0.44 \\
\hline Involving & 5.17 & 0.75 & 5.07 & 1.19 & 4.88 & 1.25 & 1.39 & 0.27 \\
\hline
\end{tabular}

Table 3 | Bivariate correlations of AQS and Emotional Availability Scales scores with family SES, maternal age, SCL 90-R (GSI), EPDS.

\begin{tabular}{lccccrrr}
\hline & AQS & Sens. & Structure & Non-intr. & Non-host. & Resp. & Invol. \\
\hline Age & -0.10 & 0.33 & $0.50^{* *}$ & 0.25 & $0.35^{*}$ & 0.19 \\
SES & 0.33 & $0.47^{* *}$ & $0.55^{* *}$ & 0.30 & $0.38^{*}$ & 0.30 \\
SCL 90-R & 0.12 & 0.09 & 0.11 & 0.00 & -0.08 & -0.05 \\
EPDS & -0.13 & -0.16 & -0.25 & -0.04 & -0.08 & -0.22 \\
\end{tabular}

Significance: ${ }^{*} p<0.05,{ }^{* *} p<0.01$. Sens(itivity); Struct(uring); Non-intr(usiveness); Non-host(ility); Resp(onsiveness); Invol(ving).

factors only somehow in the middle. Although, AQS does not allow to classify secure vs. non-secure children, when looking at previous studies, it becomes evident that mean scores of children in dyads with socio-demographic risk only are surprisingly similar to those of the no-risk typical sample used in a study of AQS reliability and validity in the Italian population (Cassibba et al., 2000). Altogether these findings speak in favor of classical approaches to psychological development of children living in at-risk families according to which the predictive value of each factor is moderated by its intensity and by the co-occurrence of other specific risk conditions (Belsky, 1984; Greenberg et al., 1993; Lyons-Ruth et al., 1993). Also, these findings are consistent with theoretical models (Belsky, 1984) and psychometrics evidences (Markon et al., 2011) according to which considering risk variables in a binary, instead of continuous, fashion might lower the possibility to describe the risk conditions in a valid and complete way (McCabe, 2014).

A crucial limitation of the present study concerns the sample size and the small $n s$ of the subgroups of dyads satisfying each selected risk criterion or a specific association of criteria; a wider sample would allow more sophisticated and informative analyses to identify the contributing role of each single risk factors as well as their reciprocal additive effects. Moreover, the inclusion of other theoretically relevant variables, such as child temperament and maternal attachment security would enrich the study in terms of deepening our understanding of the effects of the selected risk factors on mother-child relationship and attachment. Nevertheless, the results of this study may have some important implications for the selection of inclusion criteria for prevention programs that promote emotionally available caregiving and secure attachment in at-risk families, at least within the target geographical area. In our sample, dyads with co-occurring socio-demographic and psychosocial risk factors show the lowest level of attachment security suggesting that they might be the most urgent targets for prevention intervention programs, whereas dyads with sociodemographic risk factors alone appear to be less in need of such intervention. Moreover, looking at risk factor intensity, we found that family SES and maternal age were positively associated with maternal EA, suggesting that mother child-dyads displaying low family SES or very young maternal age might deserve special attention for the risk of emotionally unavailable and undesirable interactive style.

\section{ACKNOWLEDGMENTS}

This study was granted by the Provincia Autonoma di Trento, Scommettiamo sui Giovani project. We thank the Dipartimento di Salute Mentale dell'Azienda Provinciale per i Servizi Sanitari di Trento for the valuable collaboration on the project.

\section{REFERENCES}

Aber, J. L., Jones, S., and Cohen, J. (2000). "The impact of poverty on the mental health and development of very young children" in Handbook of Infant Mental Health, ed. C. H. Zeanah (New York: Guilford Press), 113-128.

Ainsworth, M. D. S., Blehar, M. C., Waters, E., and Wall, S. (1978). Patterns of Attachment: A Psychological Study of the Strange Situation. Hillsdale, NJ: Lawrence Erlbaum.

Ammaniti, M., Cimino, S., and Trentini, C. (2007). Quando le Madri Non Sono Felici. La Depressione Post-Partum. Roma: Il Pensiero Scientifico Editore 
Ammaniti, M., Sergi, G., Speranza, A. M., Tambelli, R., and Vismara, L. (2002). Maternità a rischio, interazioni precoci e attaccamento infantile. Età Evol. 72, 61-67.

Atkinson, L., Paglia, A., Coolbear, J., Niccols, A., Parker, K. C., and Guger, S. (2000). Attachment security: a meta-analysis of maternal mental health correlates. Clin. Psychol. Rev. 20, 1019-1040. doi: 10.1016/S0272-7358(99)00023-9

Aviezer, O., Sagi, A., Joels, T., and Ziv, Y. (1999). Emotional availability and attachment representations in kibbutz infants and their mothers. Dev. Psychol. 35, 811-821. doi: 10.1037/0012-1649.35.3.811

Aviezer, O., Sagi-Schwartz, A., and Koren-Karie, N. (2003). Ecological constraints on the formation of infant-mother attachment relations: when maternal sensitivity becomes ineffective. Infant Behav. Dev. 26, 285-299. doi: 10.1016/S01636383(03)00032-8

Bakermans-Kranenburg, M. J., van IJzendoorn, M. H., and Juffer, F. (2003). Less is more: meta-analyses of sensitivity and attachment interventions in early childhood. Psychol. Bull. 129, 195-215. doi: 10.1037/0033-2909.129.2.195

Bar-Haim, Y., Sutton, D. B., Fox, N. A., and Marvin, R. S. (2000). Stability and change of attachment at 14, 24, and 58 months of age: behavior, representation, and life events. J. Child Psychol. Psychiatry 41, 381-388. doi: 10.1111/1469-7610. 00622

Beck, C. H. (1995). The effects of postpartum depression on maternal-infant interaction: meta-analysis. Nurs. Res. 44, 298-304. doi: 10.1097/00006199199509000-00007

Belsky, J. (1984). The determinants of parenting: a process model. Child Dev. 55 , 83-96. doi: 10.2307/1129836

Belsky, J., and Pasco Fearon, R. M. (2002). Infant-mother attachment security, contextual risk, and early development: a moderational analysis. Dev. Psychopathol. 14, 293-310. doi: 10.1017/S0954579402002067

Bernier, A., and Meins, E. (2008). A threshold approach to understanding the origins of attachment disorganization. Dev. Psychol. 44, 969-982. doi: 10.1037/00121649.44.4.969

Biringen, Z. (2000). Emotional availability: conceptualization and research findings. Am. J. Orthopsychiatry 70, 104-114. doi: 10.1037/h0087711

Biringen, Z. (2005). Training and reliability issues with the emotional availability scales. Infant Ment. Health J. 26, 404-405. doi: 10.1002/imhj.20060

Biringen, Z. (2008). Emotional Avalilability Scales, IV Edn, Unpublished manual, Department of Human Development and Family Studies, Colorado State University, Fort Collins, CO.

Biringen, Z., and Robinson, J. (1991). Emotional availability in mother-child interactions: a reconceptualization for research. Am. J. Orthopsychiatry 61, 258-271. doi: $10.1037 /$ h0079238

Bornstein, M. H., and Putnick, D. L. (2007). Chronological age, cognitions, and practices in European American mothers: a multivariate study of parenting. Dev. Psychol. 43, 850-864. doi: 10.1037/0012-1649.43.4.850

Bornstein, M., and Tamis-LeMonda, C. S. (1989). "Maternal responsiveness and cognitive development in children" in Maternal Responsiveness: Characteristics and Consequences, ed. M. H. Bornstein (San Francisco, CA: Jossey-Bass), 49-61. doi: $10.1002 / \mathrm{cd} .23219894306$

Bornstein, M. H. (2002). "Parenting infants," in Handbook of Parenting, Vol. 1, Children and Parenting, ed. M. H. Bornstein (Mahwah, NJ: Lawrence Erlbaum Associates), 3-43.

Bowlby, J. (1969). Attachment and Loss: Attachment, Vol 1. London: Hogarth Press. Bradley, R. H., and Corwyn, R. F. (2002). Socioeconomic status and child development. Annu. Rev. Psychol. 53, 371-399. doi 10.1146/annurev.psych.53.100901.135233

Bretherton, I. (2000). Emotional availability: an attachment perspective. Attach Hum. Dev. 2, 233-241. doi: 10.1080/14616730050085581

Bretherton, I., Biringen, Z., Ridgeway, D., Maslin, C., and Sherman, M. (1989). Attachment: the parental perspective. Infant Ment. Health J. 10, 203-221. doi: 10.1002/1097-0355(198923)10:3<203::AID-IMHJ2280100307>3.0.CO;2-8

Brinker, R. P., Seifer, R., and Sameroff, A. J. (1994). Relations among maternal stress, cognitive development, and early intervention in middle- and low-SES infants with developmental disabilities. Am. J. Mental Retard. 98, 463-480.

Bronfenbrenner, U. (1979). The Ecology of Human Development. Cambridge, MA: Harvard University Press.

Broussard, C. A., Joseph, A. L., and Thompson, M. (2012). Stressors and coping strategies used by single mothers living in poverty. Affilia 27, 190-204. doi: $10.1177 / 0886109912443884$
Burstein, M., Stanger, C., and Dumenci, L. (2012). Relations between parent psychopathology, family functioning, and adolescent problems in substance-abusing families: disaggregating the effects of parent gender. Child Psychiatry Hum. Dev. 44, 631-647. doi: 10.1007/s10578-012-0288-z

Campbell, S. B., Cohn, J. F., and Meyers, T. (1995). Depression in first time mothers: mother-infant interaction and depression chronicity. Dev. Psychol. 31, 349-357. doi: 10.1037/0012-1649.31.3.349

Campbell, S. B., Cohn, J. F., Flanagan, C., Popper, S., and Meyers, T. (1992). Course and correlates of postpartum depression during the transition to parenthood. Dev. Psychopathol. 4, 29-47. doi: 10.1017/S095457940000554X

Carlson, M. J., and Corcoran, M. E. (2001). Family structure and children's behavioral and cognitive uutcomes. J. Marriage Fam. 63, 779-792. doi: 10.1111/j.1741-3737.2001.00779.x

Cassibba, R., and D'Odorico, L. (2009). La Valutazione Dell'Attaccamento Nella Prima Infanzia. L'Adattamento Italiano Dell'Attachment Q-Sort (AQS) di Everett Waters. Milano: Franco Angeli.

Cassibba, R., van IJzendoorn, M. H., and D’Odorico, L. (2000). Attachment and play in child care centers: reliability and validity of the attachment Q-sort for mothers and professional caregivers in Italy. Int. J. Behav. Dev. 24, 241-255. doi: 10.1080/016502500383377

Choe, D. E., Olson, S. L., and Sameroff, A. J. (2013). Effects of early maternal distress and parenting on the development of children's self-regulation and externalizing behaviour. Dev. Psychopathol. 25, 2, 437-453. doi: 10.1017/S095457941 2001162

Clearfield, M. W., and Niman, L. C. (2012). SES affects infant cognitive flexibility. Infant Behav. Dev. 35, 29-35. doi: 10.1016/j.infbeh.2011.09.007

Cox, J. L., Holden, J. M., and Sagovsky, R. (1987). Detection of postnatal depression. Development of the 10-item Edinburgh Postnatal Depression Scale. Br. J. Psychiatry 150, 782-786. doi: 10.1192/bjp.150.6.782

Cummings, E. M., and Davies, P. T. (1994). Maternal depression and child development. J. Child Psychol. Psychiatry 35, 73-112. doi: 10.1111/j.14697610.1994.tb01133.x

De Wolff, M. S., and van IJzendoorn, M. H. (1997). Sensitivity and attachment: a meta-analysis on parental antecedents of infant attachment. Child Dev. 68, 571-591. doi: 10.1111/j.1467-8624.1997.tb04218.x

Derogatis, L. R. (1994). Symptom Checklist-90-R: Administration, Scoring, and Procedures Manual, 3rd edn. Minneapolis, MN: National Computer Systems.

Dexter, C. A., Wong, K., Stacks, A. M., Beeghly, M., and Barnett, D. (2013). Parenting and attachment among low-income African American and Caucasian preschoolers. J. Fam. Psychol. 27, 629-38. doi: 10.1037/a0033341

Downey, G., and Coyne, J. C. (1990). Children of depressed parents. Psychol. Bull. 108, 50-76. doi: 10.1037/0033-2909.108.1.50

Easterbrooks, M. A., and Biringen, Z. (2000). Guest editors' introduction to the special issue: mapping the terrain of emotional availability and attachment. Attach. Hum. Dev. 2, 123-129. doi: 10.1080/14616730050085518

Easterbrooks, M. A., and Biringen, Z. (2005). The emotional availability scales: methodological refinements of the construct and clinical implications related to gender and at-risk interactions. Infant Ment. Health J. 26, 291-294. doi: 10.1002/imhj.20053

Easterbrooks, M. A., Chaudhuri, J. H., and Cestsdottir, S. (2005). Patterns of emotional availability among young mothers and their infants: a dyadic, contextual analysis. Infant Ment. Health J. 26, 309-326. doi: 10.1002/imhj.20057

Edhborg, M., Lundh, W., Seimyr, L., and Widstrom, A. M. (2001). The longterm impact of postnatal depressed mood on mother-child interaction: a preliminary study. J. Reprod. Infant Psychol. 19, 61-71. doi: 10.1080/02646830 123255

Emde, R. N. (1980). "Emotional availability: a reciprocal reward system for infants and parents with implications for prevention of psychosocial disorders," in ParentInfant Relationships, ed. P. M. Taylor (Orlando, FL: Grune \& Stratton)

Ensminger, M. E., and Fothergill, K. E. (2003). "A decade of measuring SES: what it tells us and where to go from here," in Socioeconomic Status, Parenting, and Child Development, ed. M. H. Bornstein and R. H. Bradley (Mahvah, NJ: Lawrence Erlbaum Associates), 13-27.

Evans, G. W., Gonnella, C., Marcynyszyn, L. A., Gentile, L., and Salpekar, N. (2005). The role of chaos in poverty and children's socioemotional adjustment. Psychol. Sci. 16, 560-565. doi: 10.1111/j.0956-7976.2005.01575.x

Fergusson, D. M., Boden, J. M., and Horwood, L. J. (2007). Exposure to single parenthood in childhood and later mental health, educational, economic, 
and criminal behavior outcomes. Arch. Gen. Psychiatry 64, 1089-1095. doi: 10.1001/archpsyc.64.9.1089

Fish, M. (2001). Attachment in low-ses rural appalachian infants: contextual, infant, and maternal interaction risk and protective factors. Infant Ment. Health J. 22, 641-664. doi: 10.1002/imhj.1024

Gazzotti, S., Spinelli, M., Albizzati, A., and Riva Crugnola, C. (2010). Maternità in età adolescenziale: attaccamento materno, stili di interazione, stati affettivi, coordinazione affettiva madre-bambino. Età Evol. 96, 64-74.

Golombok, S., Tasker, F., and Murray, C. (1997). Children raised in fatherless families from infancy: family relationships and the socioemotional development of children of lesbian and single heterosexual mothers. J. Child Psychol. Psychiatry 38, 783-792. doi: 10.1111/j.1469-7610.1997.tb01596.x

Goodman, S. H., and Gotlib, I. H. (1999). Risk for psychopathology in the children of depressed mothers: a developmental model for understanding mechanisms of transmission. Psychol. Rev. 106, 458-490. doi: 10.1037/0033-295X.106. 3.458

Goodman, S. H., and Gotlib, I. H. (eds). (2002). Children of Depressed Parents: Mechanisms of Risk and Implications for Treatment. Washington, DC: American Psychological Association.

Gottfried, A. W., Gottfried, A. E., Bathurst, K., Guerin, D. W., and Parramore, M. M. (2003). Socioeconomic Status, Parenting, and Child Development. Mahwah, NJ: Laurence Erlbaum Associates, 189-207.

Greenberg, M. T., Spelts, M. L., and DeKlyen, M. (1993). The role of attachment in the early development of disruptive behavior problems. Dev. Psychopathol. 5, 191-213. doi: 10.1017/S095457940000434X

Howes, C., and Hamilton, C. E. (1992). Children's relationships with caregivers mothers and child care teachers. Child Dev. 63, 859-866. doi: 10.2307/1131238

Hubbs-Tait, L., Huges, K. P., Culp, A. M., Osofsky, J. D., Hann, D. M., Eberarhart-Wright, A., et al. (1996). Children of adolescent mothers: attachment representation, maternal depression, and later problems. Am. J. Orthopsychiatry 66, 416-426. doi: 10.1037/h0080192

Keown, L. J., Woodward, L. J., and Field, J. (2001). Language development of preschool children born to teenage mothers. Infant Child Dev. 10, 129-145. doi: 10.1002/icd.282

Kogan, N., and Carter, A. S. (1996). Mother-infant reengagement following the stillface: the role of maternal emotional availability in infant affect regulation. Infant Beh. Dev. 19, 359-370. doi: 10.1016/S0163-6383(96)90034-X

Kohlhoff, J., and Barnett, B. (2013). Parenting self-efficacy: links with maternal depression, infant behaviour and adult attachment. Early. Hum. Dev. 89, 249-256. doi: 10.1016/j.earlhumdev.2013.01.008

Landry, S. H., Smith, K. E., and Swank, P. R. (2006). Responsive parenting: Establishing early foundations for social communication and problem solving. Dev. Psychol. 42, 627-642. doi: 10.1037/0012-1649.42.4.627

Lemelin, J. P., Tarabulsy, G. M., and Provost, M. A. (2006). Preschool cognitive development from infant temperament, maternal sensitivity and psychosocial risk. Merrill Palmer Q. 52 , 779-806. doi: 10.1353/mpq.2006.0038

Letourneau, N. L., Stewart, M. J., and Barnfather, A. K. (2004). Adolescent mothers: support needs, resources, and support-education interventions. J. Adolesc. Health 35, 509-525. doi: 10.1016/j.jadohealth.2004.01.007

Long, M. S. (2009). Disorganized attachment relationships in infants of adolescent mothers and factors that may augment positive outcomes. Adolescence 44, 621-633.

Lyons-Ruth, K., Alpern, L., and Repacholi, B. (1993). Disorganized infant attachment classification and maternal psychosocial problems as predictors of hostile-aggressive behavior in the preschool classroom. Child Dev. 64, 572-585. doi: $10.2307 / 1131270$

Lyons-Ruth, K., Connell, D., Grunebaum, H., and Botein, S. (1990). Infants at social risk: maternal depression and family support services as mediators of infant development and security of attachment. Child Dev. 61, 85-98. doi: $10.2307 / 1131049$

Lyons-Ruth, K., Repacholi, B., McLeod, S., and Silva, E. (1991). Disorganized attachment behavior in infancy: short-term stability, maternal and infant correlates, and risk-related subtypes. Dev. Psychopathol. 3, 377-396. doi: 10.1017/S0954579400007586

Madigan, S., Morgan, G., and Pederson, D. R. (2006). Unresolved state of mind, disorganized attachment relationships, and disrupted interactions of adolescents mothers and their infants. Dev. Psychol. 42, 293-304. doi: 10.1037/00121649.42.2.293
Markon, K. E., Chmielewski, M., and Miller, C. J. (2011). The reliability and validity of discrete and continuous measures of psychopathology: a quantitative review. Psychol. Bull. 137, 856-879. doi: 10.1037/a0023678

Martins, C., and Gaffan, E. A. (2000). Effects of early maternal depression on patterns of infant-mother attachment: a meta-analytic investigation. J. Child Psychol. Psychiatry 41, 737-746. doi: 10.1111/1469-7610.00661

McCabe, J. E. (2014). Maternal personality and psychopathology as determinants of parenting behavior: a quantitative integration of two parenting literatures. Psychol. Bull. 140, 722-750. doi: 10.1037/a0034835

McGraw, K. O., and Wong, S. P. (1996). Forming inferences about some intraclass correlation coefficients. Psychol. Methods 1, 30-46. doi: 10.1037/1082989X.1.1.30

McLoyd, V. C., and Wilson, L. (1991). "The strain of living poor: parenting, social support, and child mental health," in Children in Poverty: Child Development and Public Policy, ed. A. C. Huston (Cambridge: Cambridge University Press), 105-135.

Moran, G., Forbes, L., Evans, E., Tarabulsy, G. M., and Madigan, S. (2008). Both maternal sensitivity and atypical maternal behavior independently predict attachment security and disorganization in adolescent mother-infant relationships. Infant Behav. Dev. 31, 321-325. doi: 10.1016/j.infbeh.2007.12.012

Murray, L. (1992). The impact of postnatal depression on infant development. J. Child Psychol. Psychiatry 33, 543-561. doi: 10.1111/j.1469-7610.1992.tb00890.x

Murray, L., Sinclair, D., Cooper, P., Ducoumau, P., and Turner, P. (1999). The socioemotional development of 5-year-old children of postnatally depressed mothers. J. Child Psychol. Psychiatry 40, 1259-1271.

Nagata, M., Nagai, Y., Sobajima, H., Ando, T., and Honjo, S. (2004). Depression in the early postpartum period and attachment to children - in mothers of NICU infants. Infant Child Dev. 13, 93-110. doi: 10.1002/icd.339

NICHD Early Child Care Research Network. (1997). The effects of infant child care on infant-mother attachment security: results of the NICHD study of early child care. Child Dev. 68, 860-879. doi: 10.1111/j.1467-8624.1997.tb01967.x

NICHD Early Child Care Research Network. (2006). Infant-mother attachment classification: risk and protection in relation to changing maternal caregiving quality. Dev. Psychol. 42, 38-58. doi: 10.1037/0012-1649.42.1.38

Nievar, M. A., and Becker, B. J. (2008). Sensitivity as a privileged predictor of attachment: a second perspective on De Wolff and van IJzendoorn's meta-analysis. Soc. Dev. 17, 102-114. doi: 10.1111/j.1467-9507.2007.00417.x

Pomerleau, A., Scuccimarri, C., and Malcuit, G. (2003). Mother-infant behavioral interactions in teenage and adult mothers during the first six months postpartum: relations with infant development. Infant Men. Health J. 24, 495-509. doi: 10.1002/imhj.10073

Rafferty, Y., Griffin, K. W., and Lodise, M. (2011). Adolescent motherhood and developmental outcomes of children in early head start: the influence of maternal parenting behaviors, well-being, and risk factors within the family setting. Am. J. Orthopsychiatry 81, 228-245. doi: 10.1111/j.1939-0025.2011.01092.x

Robinson, J. L., Little, C., and Biringen, Z. (1993). Emotional communication in mother-toddler relationships: evidence for early gender differentiation. Merrill Palmer Q. 39, 496-517.

Rosen, D., Spencer, M. S., Tolman, R. M., Williams, D. R., and Jackson, J. S. (2003). Psychiatric disorders and substance dependence among unmarried low-income mothers. Health Soc. Work 28, 157-165. doi: 10.1093/hsw/28.2.157

Rosenkrantz Aronson, S., and Huston, A. (2004). The mother-infant relationship in single, cohabiting, and married families: a case for marriage? J. Fam. Psychol. 18, 5-18. doi: 10.1037/0893-3200.18.1.5

Sameroff, A. J. (1998). Environmental risk factor in infancy. Pediatrics 102, 12871292.

Sameroff, A. J. (2000). “Ecological perspectives on developmental risk,” in WAIMH Handbook of Infant Mental Health: Vol. 5, Infant Mental Health in Groups at High Risk acura di, eds J. D. Osofsky and H. E. Fitzgerald (New York: Wiley), 1-33.

Scharte, M., and Bolte, G. (2011). Impact of socioeconomic and environmental factors on increased health risks of children with single mothers. Am. J. Epidemiol. 173, S218-S218.

Seifer, R., and Dickstein, S. (2000). "Parental mental illness and infant development," in Handbook of Infant Mental Health, ed. C. H. Zeanah (New York: Guilford Press), 145-160.

Seifer, R., Schiller, M., Sameroff, A. J., Resnick, S., and Riordan, K. (1996). Attachment, maternal sensitivity, and infant temperament during the first year of life. Dev. Psychol. 32, 12-25. doi: 10.1037/0012-1649.32.1.12 
Seow, W. K. (2012). Environmental, maternal, and child factors which contribute to early childhood caries: a unifying conceptual model. Int. J. Paediatr. Den. 22, 157-168. doi: 10.1111/j.1365-263X.2011.01186.x

Shaw, D., Hyde, L. V., and Brennan, L. L. (2012). Early predictors of boys' antisocial trajectories. Dev. Psychopathol. 24, 871-888. doi: 10.1017/S0954579412000429

Shin, H., Park, Y. J., and Kim, M. J. (2006). Predictors of maternal sensitivity during the early postpartum period. J. Adv. Nurs. 55, 425-434. doi: 10.1111/j.13652648.2006.03943.x

Sieger, K., and Renk, K. (2007). Pregnant and parenting adolescents: a study of ethnic identity, emotional and behavioral functioning, child characeristics, and social support. J. Youth Adolesc. 36, 567-581. doi: 10.1007/s10964-007-9182-6

Spieker, S. J., and Booth, C. L. (1988). “Maternal antecedents of attachment quality," in Clinical Implications of Attachment, eds J. Belsky and T. Nezworski (Hillsdale, NJ: Erlbaum), 95-135.

Steele, M., Steele, H., and Johansson, M. (2002). Maternal predictors of children social cognition: an attachment perspective. J. Child Psychol. Psychiatry 43, 861872. doi: 10.1111/1469-7610.00096

Svoboda, D. V., Shaw, T. V., Barth, R. P., and Bright, C. L. (2012). Pregnancy and parenting among youth in foster care: a review. Child Youth Serv. Rev. 34, 867-875. doi: 10.1016/j.childyouth.2012.01.023

Tamis-LeMonda, C. S., Bornstein, M. H., and Baumwell, L. (2001). Maternal responsiveness and children's achievement of language milestones. Child Dev. 72, 748-767. doi: 10.1111/1467-8624.00313

Tarabulsy, G. M., Bernier, A., Provost, M. A., Maranda, J., Larose, S., Moss, E., et al. (2005). Another look inside the gap: ecological contributions to the transmission of attachment in a sample of adolescent mother-infant dyads. Dev. Psychol. 41, 212-224. doi: 10.1037/0012-1649.41.1.212

Teti, D. M., Gelfand, D., Messinger, D., and Isabella, R. (1995). Maternal depression and the quality of early attachment: an examination of infants, preschoolers, and their mothers. Dev. Psychol. 31, 364-376. doi: 10.1037/0012-1649.31.3.364

Teti, D. M., and Ablard, K. E. (1989). Security of attachment and infant-sibling relationships: a laboratory study. Child Dev. 60, 1519-1528. doi: 10.2307/1130940

Toth, S. L., Rogosch, F. A., Sturge-Apple, M., and Cicchetti, D. (2009). Maternal depression, children's attachment security, and representational development: an organizational perspective. Child Dev. 80, 192-208. doi: 10.1111/j.14678624.2008.01254.x

Tremblay, R. E., and Japel, C. (2003). "Prevention during pregnancy, infancy and preschool years," in Early Prevention of Adult Antisocial Behaviour, eds D. P. Farrington and J. W. Coid (Cambridge: Cambridge University Press).

van Bakel, H. J. A., and Riksen-Walraven, J. M. (2002). Parenting and development of one-year-olds: links with parental, contextual and child characteristics. Child Dev. 73, 256-273. doi: 10.1111/1467-8624.00404 van IJzendoorn, M. H., Schuengel, C., and Bakersman-Kranenburg, M. J. (1999). Disorganized attachment in early childhood: meta-analyses of precursors, concomitants, and sequelae. Dev. Psychopathol. 11, 225-249. doi: 10.1017/S0954579499002035

Vaughn, B. E., and Waters, E. (1990). Attachment behavior at home and in laboratory: q-sort observations and Strange Situation classi cation of one-year-olds. Child Dev. 61, 1965-1973. doi: 10.2307/1130850

Vondra, J. I., Shaw, D. S., Swearingen, L., Cohen, M., and Owens, E. B. (2001). Attachment stability and emotional and behavioral regulation from infancy to preschool age. Dev. Psychopathol. 13, 13-33. doi: 10.1017/S095457940 $100102 \mathrm{X}$

Ward, M. J., and Carlson, E. A. (1995). Associations among adult attachment representations, maternal sensitivity, and infant-mother attachment in a sample of adolescent mothers. Child Dev. 66, 69-79. doi: 10.2307/ 1131191

Weinraub, M., Horvath, D. L., and Gringlas, M. B. (2002). "Single parenthood," in Handbook of Parenting: Being and Becoming a Parent, Vol. 3, ed. M. H. Bornstein (Mahwah, NJ: Lawrence Erlbaum Associates), 109-140.

Weters, E. (1987). Attachment Behaviour Q-Set (Revision 3.0). Manoscritto non Pubblicato. New York: State University of New York at Stony Brook.

Yoshikawa, H., Aber, J. L., and Beardslee, W. R. (2012). The effects of poverty on the mental, emotional, and behavioral health of children and youth implications for prevention. Am. Psychol. 67, 272-284. doi: 10.1037/a0028015

Zimmerman, L., and McDonald, L. (1995). Emotional availability in infants' relationships with multiple caregivers. Am. J. Orthopsychiatry 65, 147-152. doi: $10.1037 / \mathrm{h} 0079586$

Conflict of Interest Statement: The authors declare that the research was conducted in the absence of any commercial or financial relationships that could be construed as a potential conflict of interest.

Received: 05 June 2014; accepted: 29 July 2014; published online: 20 August 2014. Citation: De Falco S, Emer A, Martini L, Rigo P, Pruner S and Venuti P (2014) Predictors of mother-child interaction quality and child attachment security in at-risk families. Front. Psychol. 5:898. doi: 10.3389/fpsyg.2014.00898

This article was submitted to Psychology for Clinical Settings, a section of the journal Frontiers in Psychology.

Copyright (c) 2014 De Falco, Emer, Martini, Rigo, Pruner and Venuti. This is an openaccess article distributed under the terms of the Creative Commons Attribution License (CC BY). The use, distribution or reproduction in other forums is permitted, provided the original author(s) or licensor are credited and that the original publication in this journal is cited, in accordance with accepted academic practice. No use, distribution or reproduction is permitted which does not comply with these terms. 


\title{
Parenting quality in drug-addicted mothers in a therapeutic mother-child community: the contribution of attachment and personality assessment
}

\author{
Francesca De Palo ${ }^{1}$, Nicoletta Capra ${ }^{2}$, Alessandra Simonelli ${ }^{1}$, Silvia Salcuni ${ }^{1}{ }^{*}$ and Daniela Di Riso ${ }^{1}$ \\ ${ }^{1}$ Department of Developmental and Social Psychology, University of Padua, Padua, Italy \\ 2 Therapeutic Community "Casa Aurora" - Comunità di Venezia s.c.s., Venice, Italy
}

Edited by:

Angelo Compare, University of

Bergamo, Italy

Reviewed by:

Gabriele Roberto Cassullo, Università degli Studi di Torino, Italy

Mingna Liu, Northwestern University, USA

\section{*Correspondence:}

Silvia Salcuni, Department of Developmental and Social Psychology, University of Padua, Via Venezia 8, 35131 Padova, Italy e-mail: silvia.salcuni@unipd.it
Growing evidence shows that attachment is a key risk factor for the diagnosis and treatment of clinical diseases in Axis I, such as drug addiction. Recent literature regarding attachment, psychiatric pathology, and drug addiction demonstrates that there is a clear prevalence of insecure attachment patterns in clinical and drug addicted subjects. Specifically, some authors emphasize that the anxious-insecure attachment pattern is prevalent among drug-addicted women with double diagnosis (Fonagy etal., 1996). The construct of attachment as a risk factor in clinical samples of drug-addicted mothers needs to be studied more in depth though. The present explorative study focused on the evaluation of parenting quality in a therapeutic mother-child community using attachment and personality assessment tools able to outline drug-addicted mothers' profiles. This study involved 30 drug addicted mothers, inpatients of a therapeutic community (TC). Attachment representations were assessed via the Adult Attachment Interview; personality diagnosis and symptomatic profiles were performed using the Structured Clinical Interview of the DSM-IV (SCID-II) and the Symptom Check List-90-R (SCL-90-R), respectively. Both instruments were administered during the first six months of residence in a TC. Results confirmed the prevalence of insecure attachment representations (90\%), with a high presence of $U$ patterns, prevalently scored for dangerous and/or not protective experiences in infanthood. Very high values (>5) were found for some experience scales (i.e., neglect and rejection scales). Data also showed very low values (1-3) in metacognitive monitoring, coherence of transcript and coherence of mind scales. Patients' different profiles ( $U$ vs. $E$ vs. Ds) were linked to SCID-II diagnosis, providing insightful indications both for treatment planning and intervention on parenting functions and for deciding if to start foster care or adoption proceedings for children.

Keywords: adult attachment interview, psychiatric symptoms, mother-child relationship, therapeutic community, drug addiction

\section{INTRODUCTION}

In Italy, pregnant women or women who deliver under the influence of addictive substances receive a warning from the Substance Addiction Treatment Services (Ser.T) and the JuvenileLess-Protection Services (Social Services, Juvenile Court) with the aim to activate a protection protocol for the child's conditions, since its birth or the very first months of life. Basing their perspective on the protection protocol for child's conditions, health care services and Therapeutic Community's (TCs) might improve their ability to define personalized mother-child dyad evaluation and treatment as soon as possible, in order to reduce risk of failure or not-useful therapeutic planning (Stocco et al., 2012). The general aim of this paper is underlined the importance of the integration of contributions devised by attachment and personality assessment, to delineate clinical "mothers' profiles." Starting from the individual's affective-relational functioning, considering the quality of the state of mind in respect to attachment, and the clinical symptomatology, the definition of mothers' profile highlighted early indicators of risks and/or protection of the parental functioning, as well as indicators about the treatment compliance and outcomes for these patients.

\section{THEORETICAL BACKGROUND}

Attachment is a biological-based system with the goal of increasing protection from dangers and predation, comfort during times of stress, and social learning, through the manifestation of attachment-related behavior in infancy (e.g., clinging, crying, monitoring caregivers, and developing a preference for a few reliable caregivers; Davila et al., 2005). The process through which attachment patterns in childhood are stable overtime is given by the fact that early experiences with caregivers are transformed into internal mental representations of attachment during childhood and adolescence, the Internal Working Models (IWM; Bowlby, 1973, 1980). IWM are theorized as beliefs about the self and others from which rules are derived and used to guide behavior (Bowlby, 1973). IWM develop from repeated interactions with caregivers 
and their quality is linked to caretakers' responsiveness during episodes of distress (Thompson and Raikes, 2003; Marvin and Britner, 2008). These internal representations are hypothesized to act as filters for future relationships and experiences, affecting behaviors by influencing quality and regulation/dysregulation of emotional experience (Carlson et al., 2004). Bowlby $(1973,1980)$ suggested that negative representations of the self or others are due to the influence of strategies for processing attachment-related thoughts and feelings which compromise realistic appraisals: in such situation, the child and the adult become more vulnerable to psychopathology.

Attachment theory emerged as a useful developmental model, with several implications for psychopathology and clinical treatments, and provided clinicians and researchers with a method to examine the impact of early experiences on later adjustment (Sroufe, 2005; Slade, 2008). Infants' early attachment to their caregivers is considered a key developmental task which influences: (a) child's representations both of self and others, (b) the individual's strategies for processing attachment-related thoughts and feelings during the cycle of life (Dozier et al., 2008). Bowlby (1969, 1973, 1980), (c) the affective bonding between infants and their caregivers, and (d) the long-term effects of early attachment experiences on personality development, interpersonal functioning, and psychopathology in terms of behavioral systems (George et al., unpublished manuscript; Fonagy and Target, 1997).

Attachment insecurity, although originally defined as an adaptive set of strategies designed to manage distress (George and West, 2012), increases vulnerability to psychopathology. Moreover, recent findings in the literature about attachment and psychiatric pathology demonstrate more and more that there is a clear prevalence of insecure attachment patterns in clinical subjects as assessed by the Adult Attachment Interview (AAI; George et al., unpublished manuscript; Hesse, 2008). The classical metaanalytic study by Fonagy et al. (1996) as well as the meta-analytic findings in Bakermans-Kranenburg et al. (2008) highlighted the prevalence of insecure attachment, when the three-way classification system was used, and of the Unresolved with respect to loss and/or trauma (U) attachment, when the four-way classification system was used.

Recent studies linked attachment constructs with psychopathology, including depression, anxiety, eating disorders, and personality disorders. In respects with personality disorders, several studies investigated the association between attachment, assessed by the AAI, and incidence of Borderline Personality Disorder (BPD) in clinical samples (Davila et al., 2005; Levy, 2005; Dozier et al., 2008); Fonagy et al. (1996), using the three-way classification system, found that $75 \%$ of the subjects diagnosed with a BPD had a Preoccupied (E) state of mind and half of them belonged to the rarely used "fearful preoccupied with respect to trauma" (E3) sub-group. The same results were obtained by Patrick etal. (1994) and by Rosenstein and Horowitz (1996): authors found that the majority of BPD patients (64\%) were classified $\mathrm{E}$ at the AAI. Preoccupied attachment often co-occurs with unresolved status. Not surprisingly, when the four-way classification system was used, 89\% (Fonagy etal., 1996) and 75\% (Patrick et al., 1994) of BPD patients were classified as Unresolved with respect to a Loss and/or a Trauma (U). Brennan and Shaver
(1998) described persons with a fearful attachment as the most troubled ones, with a high prevalence of distortion of reality or negativity about others (Allen et al., 1998). Within the attachment theory framework, BPD adults could be considered the "product" of early dysfunctional parent-child relationships: BP subjects, with their pervasive needs for approval and acceptance and their difficulties in emotion regulation (Brennan and Shaver, 1998), generally grew up in a condition of inconsistent and unpredictable parents' responses; these parental attitudes induced an increase of attachment system activation, in spite of the explorative and assertive systems (George and West, 2012), leading to the development of an insecure self-image, an unreliable others' image, deficits in empathic attunement, social and relational maladjustment and affect dysregulation in children (Shorey and Snyder, 2006).

Many researchers found that BPD diagnosis (Axis II) is highly correlated with Substance Dependence Disorder (SDD, Axis I), especially for women (Gunderson, 2001; Gunderson et al., 2010). Women characterized by SDD and BPD are socially unsuccessful, emotionally instable and explosive, more likely to incur acting out and episodic psychotic experience, including intra-psychic experiences of splitting, identity diffusion, projective identification (Kernberg, 1977; Gunderson et al., 1981). To our knowledge, even if the correlation between BPD and insecure attachment was clearly demonstrated (see Fonagy etal., 1996; Ward etal., 2001 for a review), so far there is a paucity of research providing empirical support to the association between attachment and SDD. Moreover, studies conducted using the AAI (George et al., unpublished manuscript) suffered from a limited sample size or provided inconsistent results (Caspers et al., 2006). To the extent that substance abuse can be a self-medicating strategy intended to mitigate or protect against distress (Khantzian, 1985), insecure individuals may be more likely to abuse substances as a way of regulating negative feelings. For example, Rosenstein and Horowitz (1996) found a higher rate of substance abuse among adolescents classified as dismissing than among the ones classified as Preoccupied. Consistent with Rosenstein and Horowitz's (1996) findings, Allen et al. (1996) found a significant positive association between problematic substance use and those AAI scales which are usually attributed to a dismissing state of mind (e.g., derogation of caretakers), while a negative association was found between problematic substance use and those scales which are usually associated with Preoccupied attachment (e.g., involving anger). However, such studies failed to find a significant overall effect of attachment category on substance abuse. Similarly, one study found that a scale associated with dismissing attachment (i.e., derogation of attachment experiences) was related to current hard drug use among previously hospitalized adults (Allen et al., 1996). Support for these results came from Mickelson et al. (1997), who found significantly higher rates of alcohol and drug abuse among dismissing individuals when compared to Secure or Preoccupied subjects. Further support came from Borelli et al. (2010) who examined attachment-related differences among the four AAI groups and predicted that compared to secure women, dismissing, and unresolved women would be more likely to have a history of substance abuse and to have been incarcerated for drug related crimes. They also predicted that these drug-related variables would 
be associated with greater derogation of attachment and greater lack of resolution of loss or trauma as assessed by AAI. In line with these results, Ward et al. (2001) found a significant association between substance abuse and dismissing state of mind with respect to attachment. However, these data are in contrast with some authors who have emphasized that preoccupied attachment is the most frequent classification among drug-addicted women with double diagnosis (Fonagy et al., 1996). In contrary, when the four-way system of the AAI classification is considered, Fonagy et al. (1996) and Riggs and Jacobvitz's (2002) studies showed that substance abuse is more common among individuals with Unresolved attachment classifications.

Although different clinical groups assessed by means of the AAI showed a high proportion of insecure and unresolved attachment patterns, a clear association between a specific psychiatric clinical diagnosis (based on Axis I and Axis II) and a peculiar attachment pattern was never found. Moreover, data did not lead to a specific attachment indication about SDD (Caspers et al., 2006): the authors explain this gap referring to many limitations connected to the samples, which compromise the applicability of research designs. In addition, when considering research designs, several other factors need to be mentioned, such as the number of variables taken into consideration and the type of data analyses. Last but not least, such studies often failed to address the issue of the presence in the sample of subjects with double diagnosis. These may also be time parents at the same (in particular mothers), showing a psychic condition that might be made even more problematic by the presence of a child and by the necessity to exert a parenting function.

\section{AIM}

Many mother-child TCs are present on the whole national territory: they greatly differ from each other in terms of constituent aspects, which have recently been included into a complex and articulated regulation. This new regulation leaves space to autonomous choice for regional organization and definition (available places, internal arrangement, monthly fee, etc.). In the first place, TCs give hospitality to drug-addicted women (already detoxified or on methadone therapy and followed by the Ser.T.) and their children, to whom a comprehensive rehabilitation path is offered, including parenting support.

As for the intervention methods, a combined treatment (i.e., for both parent and child together) is carried out on an intensive basis (the dyads are in residential care): TCs typically offer a therapeutic rehabilitation program, which is centered on the individual-parent-child system taken as a whole (Meisels et al., 1993). Admitting the mother-child dyad into a TC means, on the one hand, the possibility of guaranteeing an adequate intervention for the adult while providing a protective environment for the child; on the other hand, it allows to monitor mother's mothering and parenting capacities of taking care of her child autonomously, and/or to learn how to do it in an adequate manner. This implies the risk for these mothers to be evaluated as incapable of caring for their children and, consequently, the risk of being separated from them (Stevens et al., 1989; National Institute on Drug Abuse, 1996), when a good outcomes in treatment programs will not reached.
The aim of the present paper was to investigate, in a very homogeneous diagnostic sample, the possible associations between the quality of state of mind in respect with attachment and psychopathological characteristics of SDD (Axis I) and BPD (Axis II) in mothers hosted with their children in an Italian TC, in order to suggest specific treatment methods able to obtain a more positive outcome with these addicted women, also taking into account the relationship with their children.

All mothers in our sample were clustered into four profiles, characterized by the same clinical diagnosis (SDD and BPD), but with differences in affective and relational attachment patterns (F - Ds - E - U) and in levels of symptomatology (SCL-90-R positive subscales): Warm, Cold, Hot, and Unpredictable mothers' profiles. Data were used in a clinical qualitative approach to delineate groups' affective-relational functioning, considering the quality of the state of mind in respect with attachment, and clinical symptomatology. Furthermore, in an intervention stance (Wallin, 2007), the paper aimed to individuate early indicators of risks and/or protection of the parental functioning, as well as indicators about treatment compliance and outcomes.

\section{MATERIALS AND METHODS PARTICIPANTS}

This study examined 30 mothers $(M=30 \text { years; } \mathrm{SD}=6.5)^{1}$. In our sample, the $43.3 \%$ of mothers was sent to TCs according to a court decree, whereas the remaining participants were volunteers. The main aim of accessing treatment was the detoxification from substances, in order to be able to take care of their children (i.e., rehabilitation path to parenting support).

Regarding substance abuse history, all mothers during the 12 months period before entrance in the community, showed a pathological pattern of abuse or use of substances which led to a significant impairment or distress: $22(73.3 \%)$ mothers used heroin, $5(16.7 \%)$ cocaine, and the $3(10.0 \%)$ alcohol. The mean age for the onset of the dependence was 17 years $(\mathrm{SD}=4.6)$, whereas the intoxication period lasted on average 12 years (from 3 to 24). Participants reported that during that time they were affected by a persistent desire to get substances, never considering physical or psychological problems, which may be related to the dependence; they recognized how substance abuse deeply influenced their type of social, occupational, and recreational activities.

Focusing on the medical history, 12 mothers (40\%) in this sample reported drug-related pathologies: in particular, $\operatorname{HIV}(N=1)$, $\operatorname{HBV}(N=1)$, and $\operatorname{HCV}(N=10)$. Moreover, the majority of them was subjected to a pharmacological treatment: 21 mothers $(70 \%)$ out of 30 used opioids (Methadone, Subotex, Naltrexone) to substitute or reduce addiction; 8 mothers $(27 \%)$ daily had antipsychotics (Seroquel, Talofen, Inpromen); 6 (20\%) had benzodiazepines, only $2(6 \%)$ out of 30 had anti-depressives. All mothers may have a set of diverse symptoms at the same time and for this reason they could follow more than one pharmacological treatment. Taking into consideration the social and environmental context, several aspects were analyzed: first of all, regarding education and work, 21 participants (70\%) ended the middle

\footnotetext{
${ }^{1}$ The children were 14 females and 16 males, from newborn to 7 years old.
} 
school and $9(30 \%)$ others attended a professional school. Before the access in service, $22(73.3 \%)$ mothers were unemployed and the rest were dependent employees. All mothers reported past trauma experiences: 21 (70\%) experienced maltreatments (eight physically, nine psychologically, and four sexually); 18 (60\%) participants suffered from an unresolved loss, 11 (37\%) attempted suicide, $9(30 \%)$ had an overdose experience, and $10(34 \%)$ were engaged in prostitution acts. As mentioned above, all participants were mothers who, generally, had pregnancy and parenting difficulties with consequences on child's development: 21 (70\%) of both mothers and their partners used drugs during pregnancy, and $9(30 \%)$ of children were born with Newborn Abstinence Syndrome.

\section{PROCEDURE AND INSTRUMENTS}

Therapeutic Community for drug-addicted women and their children offers residential care to the mother-child dyad and provides a comprehensive rehabilitation program, which takes place during a two-year stay ${ }^{2}$. During the first month in TC, participants underwent an assessment phase: specifically, the central issues were substance addiction and medical history, social-environmental influences and other psychiatric symptoms and adult attachment patterns (Stocco et al., 2012). All participants were administered a set of measures.

- The Structured Clinical Interview for DSM-III-R (SCID-II; First et al., 1997; Italian version by Mazzi et al., 2003) allows diagnostic evaluations of a potential personality disorder, such as the ones included on Axis II of DSM-IV, passive-aggressive, and depressive disorders (Appendix B of DSM-IV), and unspecified personality disorder.

- The SCL-90-R (Derogatis, 1983; Italian version by Sarno et al., 2011) was used in order to evaluate psychological problems and symptoms of psychopathology. This is a relatively brief self-report questionnaire published by the Clinical Assessment division of the Pearson Assessment \& Information group. It is designed to evaluate a broad range of psychological problems and symptoms of psychopathology. It consists of 90 items and takes $12-15$ min to be administered, yielding nine scores along primary symptom dimensions and three scores among global distress indices. The primary assessed symptom dimensions are somatization, obsessive-compulsive, interpersonal sensitivity, depression, anxiety, hostility, phobic anxiety, paranoid ideation, psychoticism, and a category of "additional items" which helps clinicians assessing other clients' symptoms. The three indices are Global Severity Index (GSI), considered to be a more sensitive single quantitative indicator, concerning respondent's psychological distress status; Positive Symptom Distress Index, considered to be an intensity measure, which may also provide information about respondent's distress style; Positive Symptom Total, which reveals the number of symptoms that the respondent has endorsed to any degree. Particularly, criteria to interpret the GSI score are: with $T<55$ subjects' general level

\footnotetext{
${ }^{2}$ The access in the community for addicted mothers and their children is applied by a decree of the Juvenile Court and it implies a coercive intervention for the mother; the risk is to be immediately separated from her child (Stevens et al., 1989; National Institute on Drug Abuse, 1996), unless she accepts treatment programs offered.
}

reported is normative, $55 \leq T \leq 65$ subject reports from moderate to high level of disease; $T>65$ subject reports a level of disease over the clinical cut-off.

- The AAI (George et al., unpublished manuscript). This semistructured interview aims to elicit information concerning an individual's current representation of his or her childhood experiences with the attachment figures. The interview consists of questions through which the participant is asked to recall and to reflect upon memories related to his/her attachment experiences with his/her caregivers during childhood. The AAI coding system is divided in two phases. First, the protocol is coded according to the Scales of Subjective Experience (Loving, Push to achieve, Rejection, Neglect, Role reversing) and Scales of the State of Mind (Coherence of transcript, Metacognitive monitoring; Idealization; Lack of memory; Passivity; Anger; Derogation; Coherence of mind; Fear of Loss; Unresolved Loss; Unresolved trauma) with respect to attachment, relying on both form and content. Each of these scales may receive a score based on a 1-9 Likert Scale: levels score were considered Low $(<4)$, Mild (4-7) and High ( > 7) (Main et al., unpublished manuscript). Secondly, interviews are considered as a whole and classified into the adult attachment categories: secure (F), Dismissing (Ds), EntangledPreoccupied (E), Unresolved with respect to a Loss and/or a Trauma (U). Interviews are audio taped and transcribed. Two raters, who were unfamiliar with the sample and who had no access to demographic and psychiatric information, rated the interviews independently. Both raters had been trained in conducting this coding, and had substantial experience with this instrument. The AAI interviews are rated either in respect to evaluation scales and to the general attachment category. The inter-rater reliabilities of the scales used by the present raters were all higher than 0.80 . The inter-rater reliabilities of raters in this study were consistent with values reported in the literature: $85 \%$ on major attachment classification (100\% agreement on insecure vs. secure classification), and between 70 and $80 \%$ on sub-classification categories (Bakermans-Kranenburg and van IJzendoorn, 1993).

\section{RESULTS}

Regarding the personality structure evaluated according to DSMIV-TR (American Psychiatric Association [APA], 2000), all participants reached SDD criteria in Axes I, BPD criteria in axes II according to the SCID-II (First et al., 1997), general medical conditions at risk (Axes III), and, psycho-social and environmental problems (Axes IV).

Focusing on SCL-90-R, a peculiar finding is that neither the means of subscales nor the means of GSI score ever overcame $T=65$ (i.e., cut-off for the clinical range). According to our perspective, this could be caused by a multiplicity of factors, which go beyond mothers' psychopathology. Their self-reported symptomatology could highlight their tendency to "underscore" psychiatric symptoms partially, in order to prevent negative evaluations and its consequences in TCs: they tend to show themselves in a better way as a consequence of their accessing the community due to an assessment purpose in order to maintain their relationship with their children. Depression scale was a common factor in all profiles. Regarding the prevalence 
of depressive symptoms, we firstly need to consider that these mothers have just accessed a mandatory residential treatment, have just been separated from their own life-context. Secondly, all our mothers are very likely living a hard period of abstinence from substances, when they are experiencing parenting with responsibility toward their children, and they know health care community employers are due to assess their parenting abilities. For these reasons, the presence of depressive aspects will not be discussed in the following profiles, because they are considered clinical characteristics, which are common to all subjects, thus not particularly significant for the main purpose of this categorization.

Furthermore, another common factor in all mothers is the positive Psychoticism scale: we hypothesize that aspects of hostility, sensation seeking, and impulsivity may be connected to the diagnosis of BPD.

As shown in Table 1, there was a highly significant proportion of insecure attachment categories in the three-way distribution of attachment patterns $[F=4(13,3 \%) ; D S=14(46,7 \%) ; E=12$ $(40 \%)]$ as well as in the four-way distribution of attachment patterns $[F=4(13,3 \%) ; \mathrm{DS}=9(30 \%) ; E=7(23,3 \%) ; \mathrm{U} / \mathrm{CC}=10$ $(33.3 \%)]:$ these data seemed in line with previous literature about AAI distribution of attachment patterns in clinical groups, confirming a prevalence of insecure models, independently from the considered diagnostic category (Bakermans-Kranenburg et al., 2008). However, when considering the 3-categories distribution, overlying values of DS and E attachment patterns emerged, consistently with data obtained from groups of subjects with BPD and with SDD (Dozier et al., 2008). Considering a 4-category distribution, higher percentage of the $U$ attachment pattern lead with the researches on subjects with substance dependence and double diagnosis (Fonagy et al., 1996).

From a qualitative clinical point of view, we define 4 "Mothers' profiles" (Warm, Cold, Hot, and Unpredictable profiles) starting from attachment patterns ( $\mathrm{F}-\mathrm{Ds}-\mathrm{E}-\mathrm{U}$, respectively), also evaluating AAI subscales, and their associations with level of psychiatric symptomatology (SCL-90-R subscales): indicators of risks or protection of parental functioning and of treatment compliance and outcome are discussed.

Warm profile characterized mothers with SDD and BPD, Secure pattern of attachment and few symptoms. In this profile, as regards psychopathologic features and considering only subscales in the range between 55 and 65, five scales out of nine emerge as significantly relevant. More specifically, interpersonal sensitivity shows the highest score, followed by psychoticism, depression, anxiety, and paranoid ideation, decreasingly. Overall, the GSI score highlights a normative amount of general distress. Subjects presented primary experiences with attachment figures characterized by loving relationship. Coherence of mind and metacognitive monitoring emerged as aspects of principal functioning related to their past attachment experiences. Furthermore, the mild use of defensive strategies, such as idealization, lack of memory, and passivity, remains. Generally, some affective-relational aspects have been observed in Warm profile mothers: even though they experienced both positive and negative relational experiences in infanthood, they are able to depict, describe, and meditate on the complexity they lived.
These mothers may be considered in some ways as "earned secure" subjects, that means those people who show secure states of mind in respect to attachment in adulthood, even if they did not live optimal experiences in childhood (George et al., unpublished manuscript). In other words, they processed a mental re-organization: from an unsecure attachment pattern in childhood, to a more balanced and judicious mental organization in adulthood. These women tend to be particularly acute and meditative, presenting a good reflection functioning, which enables them to integrate difficult memories, which are often threatening and discrepant. They are usually able to describe either the way in which their early experiences had contributed to make themselves the women they are, or the way in which their parents' parenting toward them had influenced their own parental functioning toward their children.

An example from an AAI is presented below:

AAI Question: Are there aspects of these early experiences in childhood that you think they might have been a disadvantage or that have obstructed your development?

Answer: yes, yes, because. They many times indeed. They always knew what was the best for me, and this took away from me the chance to choose by myself, didn't it? And. ... Because you say: "no!, for me this is not right, I think something else, I want to do something else," and then I did it, with no support though, and so it is easier for someone to make a mistake, because you start saying: "but I am doing something against. . with no blessing, and.. so it is more difficult," so, they supported less and less my real personality, they have always believed.. in a good way. But to know what was right for me"

With the increase of reflecting and auto-observation functioning, defensive mechanisms typical of BPD, such as defensive exclusion of bad memories (Lack of memories; George and West, 2012) and use of idealization, diminished. Being capable of reflecting on their own relationships allowed them to regain their contradicted memories, giving a more coherent picture of life experiences. This goes with a higher comprehension of their own actual problems and with a higher acceptation of a possible therapy. Overall, Warm profile mothers experienced both loving and not protective experiences in childhood; they have a state of mind able to use both defensive strategies (as idealization, lack of memory, and passivity) and, at the same time, reflective strategies (as, good ability in mentalization and coherence of mind). The latter allows modulating dysfunctional characteristic of the BPD. However, difficulties linked to interpersonal sensitivity, psychoticism, anxiety, and paranoid idealization persisted, in particular when left alone in stressful situations. Even when considering SDD, mothers belonging to the Warm profile seemed to be able to talk about drug abuse experiences, understanding the underneath needs that bring them to drugs assumption, and diminishing the necessity of drug consumption. They are not safe from the risk of relapse into drug addiction, but, overtime, they learn how to interpret that need.

A secure autonomous state of mind with respect to attachment provides parents with flexibility of thinking and ability to regulate their emotions, allowing them to respond with sensitivity and empathy to their infants' distress. On the other hand, women with BPD are characterized by intrusive insensitivity, based on 
Table 1 | Mothers profiles in respect with attachment patterns and SCL-90-R subscales.

\begin{tabular}{|c|c|c|c|c|c|}
\hline $\begin{array}{l}\text { SDD-BPD mother } \\
\text { profiles }\end{array}$ & $\begin{array}{l}\text { Attachment } \\
\text { pattern }\end{array}$ & $\begin{array}{l}\text { AAl } \\
\text { State of mind scales }{ }^{1}\end{array}$ & $\begin{array}{l}\text { AAI } \\
\text { Experience scales }{ }^{2}\end{array}$ & $\begin{array}{l}\text { SCL-90-R } \\
\text { Global symptom } \\
\text { index }^{3}\end{array}$ & $\begin{array}{l}\text { SCL-90-R Subscales } \\
55 \leq T \leq 65\end{array}$ \\
\hline WARM & $\begin{array}{l}\text { Secure (F) } \\
N=4\end{array}$ & $\begin{array}{l}\text { Coherence mind** } \\
\text { Coherence } \operatorname{Tr}^{* *} \\
\text { Metacognitive monitoring** } \\
\text { Idealization** } \\
\text { Lack of memory* } \\
\text { Passivity* } \\
\text { Anger* } \\
\text { Derogation* } \\
\text { Fear of loss* } \\
\text { Unresolved Loss* } \\
\text { Unresolved trauma* }\end{array}$ & $\begin{array}{l}\text { Loving** } \\
\text { Push toachieve* } \\
\text { Rejection* } \\
\text { Neglect* } \\
\text { Role } \\
\text { reversing* }\end{array}$ & $\begin{array}{l}T=51,25 \\
\text { Normal distress }\end{array}$ & $\begin{array}{l}\text { Interpersonal } \\
\text { Sensitivity } \\
\text { Psychoticism } \\
\text { Depression } \\
\text { Anxiety } \\
\text { Paranoid ideation }\end{array}$ \\
\hline HOT & $\begin{array}{l}\text { Preoccupied (E) } \\
N=7\end{array}$ & $\begin{array}{l}\text { Coherence mind* } \\
\text { Coherence } \text { Tr* }^{*} \\
\text { Metacognitive monitoring* } \\
\text { Passivity* } \\
\text { Idealization* } \\
\text { Anger** } \\
\text { Lack of memory* } \\
\text { Derogation* } \\
\text { Fear of loss* } \\
\text { Unresolved loss * } \\
\text { Unresolved trauma* }\end{array}$ & $\begin{array}{l}\text { Loving** } \\
\text { Role reversing** } \\
\text { Rejection* } \\
\text { Neglet* } \\
\text { Push to achieve* }\end{array}$ & $\begin{array}{l}T=58,29 \\
\text { Distress from } \\
\text { moderate to high }\end{array}$ & $\begin{array}{l}\text { Psychoticism } \\
\text { Depression } \\
\text { Anxiety } \\
\text { Interpersonal Sensitivity } \\
\text { Somatization } \\
\text { Paranoid ideation }\end{array}$ \\
\hline UNPREDICTABLE & $\begin{array}{l}\text { Unresolved } \\
\text { (U/CC) } \\
N=10\end{array}$ & $\begin{array}{l}\text { Coherence mind* } \\
\text { Coherence } \mathrm{Tr}^{*} \\
\text { Metacognitive monitoring* } \\
\text { Passivity** } \\
\text { Idealization** } \\
\text { Anger** } \\
\text { Derogation* } \\
\text { Lock of memory* } \\
\text { Fear of loss* } \\
\text { Unresolved loss* } \\
\text { Unresolved trauma** }\end{array}$ & $\begin{array}{l}\text { Loving* }^{*} \\
\text { Neglect** } \\
\text { Rejection** } \\
\text { Role reversing* } \\
\text { Push to achieve* }\end{array}$ & $\begin{array}{l}T=61,30 \\
\text { Distress from } \\
\text { moderate to high }\end{array}$ & $\begin{array}{l}\text { Psychoticism } \\
\text { Paranoid ideation } \\
\text { Interpersonal Sensitivity } \\
\text { Hostility } \\
\text { Anxiety } \\
\text { Obsessive-compulsive } \\
\text { Symptoms } \\
\text { Depression } \\
\text { Somatization }\end{array}$ \\
\hline
\end{tabular}

\footnotetext{
${ }^{1}$ The State of Mind Scales end the Experience Scales means score ranges: ${ }^{*}(<4),{ }^{*}(4-7),{ }^{* *}(>7)$ (Adult Attachment scoring and classification Systems, Main et al., unpublished manuscript).

2The State of Mind Scales end the Experience Scales means score ranges: ${ }^{*}(<4),{ }^{*}(4-7),{ }^{* * *}(>7)$ (Adult Attachment scoring and classification Systems, Main et al., unpublished manuscript).

${ }^{3}$ Criteria for the interpretation of scores: $T<55$ general level of distress in the normative range, $55 \leq T \leq 65$ subject reports from moderate to high general level of distress; $T>65$ subject reports a level of distress in the clinical range.

${ }^{4}$ Scales are decreasingly presented, from the one with the highest score to the one with the lowest.
} 
ratings of their speech and behavior, by displaying deregulated affective communication toward their infants, including critical and intrusive behaviors as well as the rejection they were subjected in childhood (Kiel et al., 2011; Stepp et al., 2012). The presence of both these patterns in the Warm profile resulted in a complex parenting style: they may express a responsive behavior, associated to an underneath state of fear, tension, or anxiety; then, being able to reflect on their own behaviors, they may solve this tension, detaching themselves from infants. These women may exhibit tension when intimately approaching their children, because proximity makes them vulnerable. However, this difficulty is only a feeble physical detachment, rather than an active and negative refuse of communicating with the infant.

Talking about compliance and therapeutic alliance during treatment, secure subjects are predisposed to consider the therapist as a secure base, using it to "tune" an attachment paradigm both in an operative and valuable way. Satterfield and Lyddon (1995) confirmed this hypothesis analyzing the therapeutic alliance: they observed that patients with a secure attachment style had a propensity to establish bonds and negotiate treatment goals with their mental health consultants. As mentioned above, secure attached patients are generally able to reveal their thoughts and their feelings, recognizing that their own relational models influence their life experiences. Because of the possibility to establish a therapeutic alliance with them, treatment toward Warm profile mothers had the purpose of remodeling the personality asset and of improving their global functioning, principally working mostly on aspects related on identity confusion, chronic feelings of emptiness and relational instability (Wallin, 2007).

Mothers belonging to the Warm profile, in line with their baggage of reflective abilities, resulted to be able to reach a significant therapeutic alliance and therapeutic change. However, a larger awareness of their own mistakes causes them more suffering. In particular, metacognition strategies lead to strong feelings of responsibility for what has been done in the past, and for being in TC at present. Thus, a good treatment program for these mothers would need to help them to forgive themselves for their faults and to believe in their own abilities. Awareness about the complexity of their life experiences and capacity of metacognitive monitoring permits them to conclude the therapeutic path remaining together with their children, in spite of their BPD dysregulation pattern. Besides therapeutic moments of reflection that would help patients to face their past history of childhood and the connection between this and caregiving toward their kids, therapists directly intervene on this relationship, providing educative strategies to enhance the quality of it in everyday life. Strategies that would allow mothers to comprehend positive and negative aspects of the relation, but, above all, to strengthen mechanisms of repairing. Providing a new baggage of abilities to repair relational ruptures and the elaboration of traumatic experiences allow these women to re-acquire their paternal responsibility. These women are able to understand their limits in parenting skills and capacities, learn how to handle them, applying new strategies of caring, then their outcome could be rather positive. These mothers maintain the relationship with their children more or less autonomously even after the end of the therapeutic pathway.
An example taken from an AAI of this women's modality to take care of their children is presented below:

AAI Question: Why do you think your parents behaved like you have described to me during your childhood?

Answer: Eh, surely because It was what they were subjected to in their childhood...yes, and then also because of the moment they were living in, so the moment between them and I believe it was fundamental to define in that moment their actions, and indeed this scares me thinking about Mark, I wouldn't being in this situation because I know how much it is important to define the rule in which you - as a parent - have to be in the formation... Because it's not that what you teach with words, but through the things people listen and see you are doing, so the proper example, so if you are peace$f u l$, if you are... in the most possible way peaceful, in the most possible way quiet, what you transmit to a child, if you may have problems with your husband... so those are significant things that you don't understand when you are experiencing them, no? And this scares me a lot.

The Cold profile characterized mothers with SDD and BPD, Dismissing pattern of attachment and, regarding psychopathological features, four subscales out of nine are relevant: depression presents the highest score, followed by psychoticism, obsessivecompulsive symptoms and hostility, decreasingly. Overall, the GSI underlines a normal level of distress. Subjects have primary experiences with attachment figures characterized by rejection and neglect. Regarding those characteristics of the state of mind, idealization, lack of memory, and derogation emerge as aspects of functioning related to their past attachment experiences. Not receiving comfort and experiencing refusals from attachment behaviors, a double defense mechanisms of affectivity are used: parents' qualities are split between positive and negative, but only the firsts are recognized, whereas the seconds are inhibited; through the second mechanism, instead, they remember bad experiences, but they excuse their parents for them. In this case, subjects take their parents' point of view, and, in line with this, they base their behavior on cognitive expectations and deny their attachment needs and feelings. An example from an AAI is presented below:

\section{AAI Question: Have you ever felt worried or frightened when you were child?}

Answer: Not frightened, but worried. . .but I don't remember exactly why probably because everything was going so bad and I was trying to let it roll right off my back, I didn't give any kind of satisfactions, even when my mom battered me I remember it hurt me but I forced myself not to cry

Cold profile mothers use thoughts and behaviors with the aim to defensively exclude painful feelings from awareness: from this perspective obsessive-compulsive symptoms focused on control of emotion, and BPD defense mechanisms are characterized by idealization and devaluation of self and others, which consistent with the constraint of affectivity and control.

In respect to the SDD, these women seem to deny their dependence from substances: as in the original attachment bond, they oscillate from an over-evaluation of their own abilities ("to not need it"), to endorsing downfall ("I can not live without it").

Mothers belonging to the Cold profile exhibited controlled and dismissing engagement toward their children, showing high levels of push to achieve and perfectionism, low levels of attention to feelings and emotions, scarce attention to physical contact and loving attitude. In particular, maladaptive parenting 
behaviors may emerge in response to children's emotional distress (Kim et al., 2009), interfering with their ability to respond adaptively to this distress, with negative emotional reactions (Leerkes and Crockenberg, 2009). Furthermore, Cold profile mothers may have increasing difficulty inhibiting insensitive behavior and/or displaying sensitive behavior as their infants' distress persists. In this case, mothers are more likely to be characterized as intrusively insensitive, based on ratings of their speech and behavior, displaying dysregulated affective communication toward their infants, including critical and intrusive behaviors as well as the same rejection they were subjected to in childhood (Crandell et al., 2003; Hobson et al., 2005; Newman et al., 2007).

As regards compliance and therapeutic alliance during treatment, Cold profile mothers showed difficulties in establishing a healing relationship: they tended to express a strong message of autonomy and independency, and to deny needs to be supported even to the therapist. This kind of dismissing patients diminished or ignored intimacy and attachment values (Holmes, 1996), and tended to use the supportive therapeutic secure base (Dozier et al., 2008) to talk about others but not about their own self or themes, using intellectualization and taking distance from a real chance of re-elaboration (Holmes, 1998). According to Wallin (2007), therapists must be very attentive in order to take narrow affective signals; although dismissing patients are reluctant to express their own feelings, even if not on purpose they evocate and provoke reactions in the therapist. Therapists, highlighting their own feelings toward the treatment, may help patients to integrate their owns, even if dissociated or denied. In order to reach a good outcome, treatment might "translate empathy in words" (Wallin, 2007), reducing patients' fear and their idea about therapist's controlling and refusing behavior, with all possible misunderstandings. In this way, these mothers may be supported during the elaboration of their carelessness and refusal experiences, acquiring the ability to trust others in the therapeutic-relational context, asking and accepting necessary support. Therapists should provide them suggestions and behavioral strategies mainly functional, in order to enhance the interaction with children in everyday life. Specifically, therapist could initially function as a sort of model for handling interactions and for managing the tuning with the child. Successively, their abilities to interiorize could take to a gradual relational autonomy, that could permit them to interact with their child adequately.

Dismissing parenting characteristics might be considered not completely dysfunctional, as far as they show up as stable modalities of taking care of children, reassuring functional basic care; on the other side, the therapy role as secure base may enhance the access to these women's affective sphere, increasing the possibility that they ask for help when child's requests make it necessary. In this direction, Cold profile mothers' prognosis might be better observed later in time, when they become able to do autonomously their own parental functioning, benefiting from the support of social and familiar networks in their life context. Indeed, mothers included in this profile may aspire to a total autonomy or, in case they are not able to overtake their dysfunctional patterns, maintain a central role of caring in their children's life, sustained by a familiar context of support.
An example from an AAI of this women's modality to take care of their children is presented below:

AAIQuestion: Thinking about how you talked, do you think there is something in particular that you have learned from your experience in childhood? I mean, what do you think you have got or understood, given the kind of infancy you had?

Answer: yes there would be that I will not do the same mistakes my mom did with me.. well it is not fucking true because sometimes things come up to mind so automatically that you can not even realize that, sometimes I should be sweeter to her but it is not automatic, fortunately I am here and there is someone who tells me that... I can learn...

Hot profile characterizes mothers with SDD and BPD, Preoccupied pattern of attachment and significant symptoms in six of the nine subscales of the SCL-90-R: the highest score is shown for psychoticism, then, decreasingly, depression, anxiety, interpersonal sensitivity, somatization, and paranoid ideation are significantly relevant. The GSI displays a general level of distress. Subjects included in this profile reported primary experiences with attachment figures characterized by the alternation of functional loving and role reversing behaviors; passivity and involving anger emerged at present in remembering their early attachment experiences.

Considering an affective-relational point of view, Hot profile mothers exhibited the inability to overpass their past history, and they still remained strongly linked to or worried about their own early attachment experiences. Affective status from their past influences actual narrative and thinking processes, making them vague and passive, creating confusion between perceptions of past, present and future. Self-concept appears as still trapped and involved in early negative relationships, which have not yet been elaborated. As a consequence, these women do not seem to be able to separate themselves from their own family identity, or from the inadequate experiences they lived (George et al., unpublished manuscript). Attachment experiences were lived as contradictory and incoherent (Shorey and Snyder, 2006): these women had partially positive experiences of functional loving care, alternated within adequate proximity situations and role reversing, in which parent "from taking care of someone, becomes the one who is taken care of" (George et al., unpublished manuscript). These experiences led to highly ambivalent IWM (Bowlby, 1973) in respect to self and others, defensively characterized by passivity, anger and cognitive disconnection (George and West, 2012) where no elaboration of thought is allowed.

AAI Question: Do you remember an episode, a memory that can explain why you think this relationship was confusing?

Answer: Ah because it could seem nearly that she adored me in a moment that she...would be happy and less after I don't know what for how but all the contrary, that I was a bother that she was not happy about me... This confuses.. because one moment it was one way, and after another.... Even if it was laughing and joking about something and for one word she didn't appreciate. . so, as you were laughing as you would have found yourself crying less after. Needed ehm like it needed just a little thing, it needed nothing for her to being annoyed. . .

The example above highlights how Hot profile mothers' states of mind are bound to an affective and relational dysregulation. This general distress status is manifested primarily through 
symptomatic aspects of psychoticism, anxiety, and interpersonal sensitivity. Given the strong negative feelings and the emotional over-involvement, substance abuse, and consumption seemed to be external mechanisms of regulation, which are activated when subjects experience uncontrollable and unmanageable painful emotions (Khantzian, 1985).

All these elements provided indications about Hot profile mothers' parenting dysfunctional model. These mothers displayed disrupted affective communications, characterized by intrusive and insensitive behaviors, similar to that has been observed in studies with BPD samples (Hobson et al., 2009). In the relationship with their children they appear over-involved and over-stimulating; an active but not synchronized pattern of behaviors emerged (George and West, 2012). Furthermore, they expressed difficulties in tuning with their children positive affects, in line with studies conducted both on mothers with preoccupied attachment pattern (Haft and Slade, 1989; Deoliveira et al., 2005) and on BPD mothers (Crandell et al., 2003; Newman et al., 2007). In particular, these women reported difficulties in sharing expressions of infant's happiness, linked to infant's aspects of autonomy. Additionally, these mothers may more likely engage in role confusion with their children, and encouraging them to assume the parent or friend role.

In psychotherapy, Hot profile mothers are able to use the therapist as a secure base for affective and emotional support, but, similarly to patients with a preoccupied attachment patterns, they present difficulties in exploring and experimenting new relational possibilities (Obegi, 2008). On the contrary, differently from women's of the previous profile, these patients may exaggerate their feelings, thoughts and physical disease, in order to get others' attention and support, showing the desire to access the therapeutic too promptly. This approach to treatment could lead to endless programs, without obtaining any true change: these mothers appeared able to explore their own feelings in the therapeutic room, but they could not do the same in their real life context, precluding themselves the possibility to live new life experiences.

According to Wallin (2007), these patients might be helped reaching an emotional balance and reinforcing their own selfesteem. The therapeutic relationship should provide them with new alternative strategies, with the aim to disable the overactivation that they commonly use. For these reasons, therapeutic programs might be planned to establish a stable and very modulated relationship, in which the patient may count on the therapist's emotional availability: the therapist might represent a sort of regulative and holding figure. Hot profile mothers tended to create a strong affective contact with their children. However, they could cause dysfunctional outcomes for infants' growth, due to overinvolvement, maladjusted emotional functioning, and to the great difficulties in handling child's natural drive to separation and autonomy. If not healed, these mothers may be really dysfunctional for their children's growth. A possible interactive intervention for these mothers led by the therapist regards the holding (building limits) of intrusive behaviors and the affective over-activation, which grow in contact with the child. Rarely, or with many difficulties, these mothers are able to interiorize these new relational strategies provided by the therapist: they are also predisposed to trust on and imitate it, using those strategies that these women interpret as more effective for the quality of the relationship with the child and the latter's well-being. When dealing with extremely serious cases, it is fundamental to keep in mind that dividing the dyad over the first year of child's age would be really dangerous since at that time the bond is so intense that, if broken, it would have more negative than positive effects.

In light of this, therapeutic outcomes include, on a side, a partial sharing of the parental responsibility with a "third" relational figure, as the foster home. This would be seen as an effective result, given the severity of these patients' pathology: indeed, children can maintain the bond with their mothers, not being affected by their pathological oscillations. At the same time, foster home would guarantee the constancy of caring, protecting children's development. On the other side, there are some situations in which, through distressing paths, women become aware of the chronicity of their pathology, taking them to choose to give their children up to adoption. Paradoxically, even these outcomes, if thought in light of child's well-being, may be interpret as positive, because maternal support makes this painful ruptures more tolerable for children. These adoptions have better long-term outcomes than others overtime.

An example from an AAI of these women's modality to be in relation with their children is presented below:

AAI Question: In general, how do you think experiences with your parents have influenced your personality as an adult?

Answer: Beh anyway even in her relationship, theirs, anyway I always said. I hope this does not happen to me... Yes no.. Well, because sometimes I felt guilty for being born, in the sense, talking to myself, yes and, if I were not there, maybe the two of them, they would not have been here fighting, all this kind of stuff, so then I thought, before having a child, in my life, I will think about it many times. And instead at the end, the exactly same thing happened to me, identical, in everything.. Either for age, because for example, even my parents have a twenty-year age difference and my boyfriend is twelve years older than me, so even for this, so for everything, seems that.. Everything I have ever said no I will never want something like that, [Smiles] And then instead, the contrary.

Unpredictable profile characterizes mothers with SDD and BPD, Unresolved and/or Cannot Classified patterns of attachment and significantly over the normative cut-off in eight SCL-90-R scales of psychiatric symptoms, with the only exclusion of the phobic anxiety scale. Overall, unpredictable mothers present a very severe symptomatic frame; psychoticism, specifically, reports a value $(T=65)$ which is just below the clinical range.

Unpredictable profile mothers' affective-relational history is characterized by frequent maltreatment from caregivers, and/or by the presence of unresolved loss or trauma in childhood. Subjects present also primary experiences with attachment figures characterized prevalently by neglect and rejection. These early experiences have been stored in memory in an unelaborated way; segregated contents pop up automatically (George and West, 2012) in daily life, without any possibility of control, following freeassociations with traumatic experiences experienced in childhood. When segregated traumatic contents emerged, these women manifest dissociative paths and disorganized thoughts, associated to 
absence of metacognition, and they consequently fall in a temporary condition of inability to employ control or to remedy on their thoughts.

AAI Question: In general, do you think that experiences with your parents, overall, might have influenced your personality as adult?

Answer: Yes, in a bad way. because I have lived in anxiety. I felt anxiety even when I was young, because it was not a peaceful environment, it was not a warm environment. It was an unpredictable environment. So I still feel anxiety from there. And I'm full of fears and fragilities. Because anyway when they were still alive I felt untouchable, now that they are not still here I feel like I'm a tiny point, even staying in, whatever, I have always thought that if they would be still alive probably I would not have been here. They would have done anything to figure things out. That they had always demonstrated to me, solving issue. Instead I know exactly more I feel alone, I don't know, and I have to make anything by myself. And I have to struggle, it is so hard for me... I can cope with this. . .ever..."

For these women, the attachment disorganization entails a multiple and separated representation of the self and the attachment figure leading to a metacognitive deficit that makes emotion regulation extremely difficult. These features interact with the most significant clinical aspects of the BPD (i.e., impulsivity, oscillations between idealization and devaluation of self and others, feeling of emptiness, unmotivated and intense anger, autodamaging behaviors, unstable and intense affective relationships) and in this way they amplify each other in a reciprocal manner. Overall, Unpredictable profile mothers present a highly compromised portrait, with persistent and disabling symptomatology, unresolved state of mind (characterized by feeble metacognitive abilities and strong dissociative mechanisms of thought), weak regulation of emotional experience, and a fragmented and diffused self. In this perspective, substance abuse and consumption seemed an extreme attempt of containment, through dissociative mechanisms, in order to approach the border between life and death, and to hold traumatic memories and experiences. However, these acting behaviors, especially in this case, expose individuals to high risk situations (overdose or suicidal behaviors).

In line with previous results, being subjected to traumatic unresolved experiences constitutes a risky condition for the undertaking of caregiving behaviors. Main and Hesse (1990) have posited that subjects whose mental statuses are immerged in painful unresolved memories - as for instance, memories of loss, incidents, diseases, maltreatment and violence - live in a pervasive condition of fear, that facilitates the assumption of caregiving behaviors of the threatening/timorous dissociated type. These caregiving behaviors appear out of the blue and with no contextual anchorage (Hesse and Main, 2006). Developing a mental condition of dissociation related to traumatic or loss experiences that have not yet been resolved, might be displayed by the attachment figures via a specific difficulty paying attention to infant's painful emotional status, blocking the ability to regulate and modulate painful memories.

Mothers who belong to the Unpredictable profile exhibit behavioral patterns characterized by unpredictable modalities of interaction, and by a deregulated affective communication toward their infants, including critical and intrusive behaviors, role confusion, and frightened/frightening behaviors. More specifically, their children seem to live in a paradox in which they look for help and protection from their mothers, who, due to their unresolved and distressing memories, are frightened and, in turn, frightening. As a consequence, infant understands this latent fear and, consequently, reacts to this getting frightened. Talking about treatment issues, these disorganized patients lack any stable attachment strategy, struggling for the establishment of the therapeutic alliance, which results to be highly swinging, full of continuous outbreaks, interruptions, and rapprochements. As Holmes (2001) highlighted, therapists must tolerate this and, if necessary, approach to patient avoiding the classical setting. The therapeutic process with these patients is very long, but extremely gratifying. Once established, the alliance will be subjected to tensions and ruptures, and reparations represent the crucial action of the therapeutic task. The patient needs to find coherence. With the majority of these patients, the relationship with the therapist is a relevant part of the therapy: in the unresolved attachment group, the therapeutic relationship represents the therapy itself (Wallin, 2007). The treatment core is the integration of memories and experiences. Therapists' mission is to provide different experiences and models of interaction, to create a relationship in which the patient can feel really safe. This is quite hard because these patients, although their willingness to cure themselves from their wounds, are often forced unconsciously to rebuild the well-known relational IWM with the therapist, in which there is no hope or possible help. It is important to underline that Unpredictable profile mothers must not be supported and led in therapy just to make them relive feelings linked to their traumas, but rather they need to recall those experiences and translate them into words, naming emotions and feelings. When patient is able to travel across these experiences again without being once more traumatized, at that moment memories are melt and changed, turning an omnipresent trauma omnipresent into one circumscribed in a specific time and place (Wallin, 2007). Given that these mothers' prevalent interactive strategy involves the unpredictability of behaviors and emotional reactions in the relationship with the child, the therapist's primary function could be to attempt to limit this modality, even substituting itself with the mother herself in taking care of the child, completely. In fact, considering that the interiorization and comprehension abilities are highly compromised, it is difficult for these women to acquire proper and functional models of interactions with their kids in absence of figures who could constantly give them behavioral and affective patterns to imitate and reproduce in everyday life.

Because of a particularly compromised clinical frame and a very long therapeutic work, Unpredictable profile mothers do not always reach the hoped therapeutic results. Situation gets worse when treatment outcome is considered in relation to children: these mothers scarcely come out from the TC program with their children autonomously. In the best case, a good outcome consists of being able to help these women to understand their limits in parental functioning, building together alternative pathways for the child, such as foster care or even adoption. In many cases, drop out occurs making it impossible to build anything good neither for themselves nor for their children. In these cases, mothers might leave the community or abandon infants, and professionals: given 
the impossibility of finding any openness in women, it may be compelled to separate the dyad, offering, a new, even if painful, way of life for children. In other cases, when there is a total closure toward the therapy of mothers, who boycott frequently therapeutic moments and interventions, equipe is compelled to separate the dyad forcedly, given that there is not a premise for a change.

\section{AAI Question: ok, what future would you like your daughter to have?}

Answer: not like mine..no, indeed, I will do everything for... because she would have a life. . .happy. Not like my mom said to me, "you never know it will make you freak out, that she would become like you who drove me crazy" she told me. And I said "I will not be the same mum as you were so she will not have reasons to do that." (Silence) because she may hurt me whenever she wants... I always have to shut up because I am scared to hurt her... no, stop, this story is over. I'm tired. . . because I didn't call her: " means that she does not love me if she didn't call me" she said to my boyfriend. So, you're fifteen, you talk as you would be seven, s, c'mon (Silence)... (grumble) ok

\section{DISCUSSION}

This study aimed at being a first attempt to organize a clinical model in an attachment framework, as to interpret multi-level assessment of SDD and BPD mothers, hosted in Health Care Services and TCs with their children. The main purpose is, so, improving and planning effective clinical and much more personalized interventions, in order to reduce risks of failure and useless therapeutic planning.

The present study deserves a reflection on the characteristics of the clinical population that follow a mandatory treatment in a residential mother-child TCs. The main purpose was to help clinicians and researchers to find more efficient models, in order to connect mother's health with child's well-being. This would allow to help both of them in the transition to foster care services and adoptive pathways when mother's relational and attachment diseases do not allow the possibility for them to stay together. All mothers are led to comprehend their difficulties in the parental functioning, but not all of them are able to solve and overtake their trauma and severe personality dysfunctions. Indeed, the majority of these mothers understands its limitations in parenting, learns how to handle them and applies new strategies of caring: in this sub-group we find women who, as outcomes of their therapeutic pathway, maintain the relationship with their children more or less autonomously (see Warm and Cold profiles). Another sub-group includes those mothers who are able to understand their limits, not completely overtaking them: here we find those who, in alliance with their therapists' thoughts, build pathways of custody or adoption. Finally, the last sub-group, which is fortunately rather small, includes those women who, because of their severe pathology, can not understand deeply their parental dysfunctions. For this reason, their kids are separated in a forced way from their mothers, against the latter's will (see Hot and Unpredictable profiles). Not all mothers who adhere to this program of intervention are able to take care of their children after the therapeutic pathway. We have seen how trauma, personality and attachment history represent central aspects in respect to the outcomes: for this reason we think they should be better and more deeply studied, in order to select dyads which could have more possibilities to benefit from intervention programs. In general, the complexity of these mothers' characteristics demands for an integrated model of intervention, which should include both representational and behavioral aspects connected to the attachment and to the general psychopathological functioning. In fact, each of the therapeutic accesses points will have to consider, on a side, the individual dysfunctionalities and, on another one, the quality of the interactions and of the relationship with the child.

We showed how the attachment framework (Bowlby, 1969; Wallin, 2007) offers a powerful model in which the quality of relational and attachment patterns help definitively to define mothers parenting profile. Whenever possible, paying attention to mothers' clinical diagnosis, evaluating deficits and resources in their personality structure (DSM-IV diagnosis in Axes I and II), level of psychiatric symptoms and maladjustment could help on planning centered parent-child rehabilitation program. Given that, our " 4 profiles-mother model" could be considered as a qualitative clinical pilot framework to plan treatment and to foresee outcome.

In conclusion, we hope that future research will employ larger samples as to validate our preliminary clinical findings.

The present paper presents a series of limitation that may provide new perspectives for future studies. The first limitation concerns the slenderness of the sample: 30 subjects do not constitute a representative group, and, for this reason, compromising the generalizability of results, even considering the homogeneity of the clinical population studied in our sample. Such small numbers do not allow neither for consistent statistical analysis about the influence of socio-demographic aspects on observed clinical and therapeutic characteristics, nor for the definition of an exhaustive and interpretative model of the connection between SDD, BPD, and distribution of attachment patterns, as evaluated by AAI.

Moreover, as for the applied methodology, two main points emerged. Firstly, SCL-90-R is a self-report measure that, when administered in mandatory conditions, could be influenced by social desirability. The possibility of adding another tool in which social desirability issues are taken into consideration could help in reducing the risk of obtaining biased scores on psychiatric scales (e.g., Millon Clinical Multiaxial Inventory-III, MCMI-III; Millon, 1983, 1997; Millon et al., 2008; Zennaro et al., 2008). Then, as regards the evaluation of mental representations linked to attachment, we consider that the AAI needs to be sustained with other tools, such as the Adult Attachment Projective Picture System (AAP; George and West, 2001). AAP specifically could allow for a deeper analysis of the disorganized attachment factors, the entity of traumatic experience and defensive mechanisms; these aspects could be highly useful given the complexity of these comorbid patients' traumatic early experiences. Last but not least, it would be useful to introduce some quantitative and multiple-informant evaluation of parenting style and efficacy, in order to investigate both women's perceptions of their skills in taking care of their children (e.g., using self-report questionnaires), and quality of real behaviors via observational measures (e.g., the Biringen Scales, EAS - Emotional Availability Scales; Biringen et al., unpublished manuscript). 


\section{REFERENCES}

Allen, J. G., Coyne, L., and Huntoon, J. (1998). Complex posttraumatic stress disorder in women from a psychometric perspective. J. Pers. Assess. 70, 277-298. doi: 10.1207/s15327752jpa7002_7

Allen, J. P., Hauser, S. T., and Borman-Spurrell, E. (1996). Attachment theory as a framework for understanding sequelae of severe adolescent psychopathology: an 11-year follow-up study. J. Consult. Clin. Psychol. 64, 254-263. doi: 10.1037/0022006x.64.2.254

American Psychiatric Association [APA] (ed.). (2000). Diagnostic, and Statistical Manual of Mental. (Disorders): DSM-IV-TR ${ }^{\circledR}$. Washington, DC: American Psychiatric Publication.

Bakermans-Kranenburg, M. J., and van IJzendoorn, M. H. (1993). A psychometric study of the Adult Attachment Interview: reliability and discriminant validity. Dev. Psychol. 29, 870-879. doi: 10.1037/0012-1649.29.5.870

Bakermans-Kranenburg, M. J., Van IJzendoorn, M. H., Mesman, J., Alink, L. R., and Juffer, F. (2008). Effects of an attachment-based intervention on daily cortisol moderated by dopamine receptor D4: a randomized control trial on 1-to 3-yearolds screened for externalizing behavior. Dev. Psychopathol. 20, 805-820. doi: 10.1017/S0954579408000382

Borelli, J. L., Goshin, L., Joestl, S., Clark, J., and Byrne, M. W. (2010). Attachment organization in a sample of incarcerated mothers: distribution of classifications and associations with substance abuse history, depressive symptoms, perceptions of parenting competency and social support. Attach. Hum. Dev. 12, 355-374. doi: $10.1080 / 14616730903416971$

Bowlby, J. (1969/1982). Attachment and Loss, Vol. 1. Attachment. New York: Basic Book.

Bowlby, J. (1973). Attachment and Loss, Vol. 2. Separation: Anxiety and Anger. New York: Basic Book.

Bowlby, J. (1980). Attachment and Loss, Vol. 3. Loss: Sadness and Depression. New York: Basic Book.

Brennan, K. A., and Shaver, P. R. (1998). Attachment styles and personality disorders: their connections to each other and to parental divorce, parental death, and perceptions of parental caregiving. J. Pers. 66, 835-878. doi: 10.1111/1467-6494.00034

Carlson, E. A., Sroufe, L. A., and Egeland, B. (2004). The construction of experience: a longitudinal study of representation and behavior. Child Dev. 75, 66-83. doi: 10.1111/j.1467-8624.2004.00654.x

Caspers, K. M., Yucuis, R., Troutman, B., and Spinks, R. (2006). Attachment as an organizer of behavior: implications for substance abuse problems and willingness to seek treatment. Subst. Abus. Treat. Prevent. Pol. 1:32. doi: 10.1186/1747597X-1-32

Crandell, L. E., Patrick, M. P. H., and Hobson, R. P. (2003). "Still-face" interactions between mothers with borderline personality disorder and their 2-month-old infants. Br. J. Psychiatry 83, 239-247. doi: 10.1192/bjp.183. 3.239

Davila, J., Ramsay, M., Stroud, K. B., and Steinberg, S. J. (2005). “Attachment," in Development of Psychopathology: A Vulnerability-Stress Perspective, eds B. Hankin and J. Abella (Thousand Oaks, CA: Sage), 215-242.

Deoliveira, C. A., Moran, G., and Pederson, D. R. (2005). Understanding the link between maternal adult attachment classifications and thoughts and feelings about emotion. Attach. Hum. Dev. 7, 153-170. doi: 10.1080/14616730500 135032

Derogatis, L. R. (1983). SCL-90-R Revised Manual. Baltimore, MA: John Hopkins School of Medicine.

Dozier, M., Stovall-McClough, K. C., and Albus, K. E. (2008). "Attachment and psychopathology in adulthood," in Handbook of Attachment: Theory, Research, and Clinical Applications, Vol. 19, 1020, 2nd Edn, eds J. Cassidy and P. R. Shaver (New York, NY: Guilford Press), 718-744.

First, M. B., Gibbon, M., Spitzer, R. L., Williams, J. B., and Benjamin, L. (1997). Structured Clinical Interview for DSM-IV Personality Disorders (SCID-II): Interview and Questionnaire. Washington, DC: American Psychological Association.

Fonagy, P., Leight, T., Steele, M., Steele, H., Kennedy, R., Mattoon, G., et al. (1996). The relation of attachment status, psychiatric classification and response to psychotherapy. J. Consult. Clin. Psychol. 64, 22-31. doi: 10.1037/0022-006x. 64.1.22

Fonagy, P., and Target, M. (1997). Attachment and reflective function: their role in self-organization. Dev. Psychopathol. 4, 679-700. doi: $10.1017 /$ S0954579497001399
George, C., and West, M. (2001). The development and preliminary validation of a new measure of adult attachment: the Adult Attachment Projective. Attach. Hum. Dev. 3, 30-61. doi: 10.1080/14616730010024771

George, C., and West, M. (2012). The Adult Attachment Projective Picture System. New York: Guilford Press.

Gunderson, J. (2001). Bordeline Personality Disorder. A Clinical Guide. Washington: American Psychiatric Publishing.

Gunderson, J. G., Kolb, J. E., and Austin, V. (1981). The diagnostic interview for borderline patients. Am. J. Psychiatry 138, 896-903.

Gunderson, J. G., Zanarini, M. C., Choi-Kain, L. W., and Hudson, J. (2010). Familiality of BPD's component phenotypes. Paper Presented at the 163rd Annual Meeting of the American Psychiatric Association, New Orleans, LA.

Haft, W., and Slade, A. (1989). "Sintonizzazione affettiva e attaccamento materno," in Trad. it. in La Comunicazione Affettiva tra il Bambino e i Suoi Partner, ed. C. R. Crugnola (a cura di) (Milano: Raffaello Cortina).

Hesse, E. (2008). "The Adult Attachment Interview: protocol, method of analysis, and empirical studies," in Handbook of Attachment: Theory, Research, and Clinical Applications, 2nd Edn, eds J. Cassidy and P. R. Shaver (New York: Guilford Press), 552-598.

Hesse, E., and Main, M. (2006). Frightened, threatening, and dissociative parental behavior in low-risk samples: description, discussion, and interpretations. Dev. Psychopathol. 18, 309-343. doi: 10.1017/SO954579406060172

Hobson, R. P., Patrick, M., Crandell, L., García-Pérez, R., and Lee, A. (2005). Personal relatedness and attachment in infants of mothers with borderline personality disorder. Dev. Psychopathol. 17, 329-347. doi: 10.1017/SO954579405 050169

Hobson, R. P., Patrick, M. P. H., Hobson, J. A., Crandell, L., Bronfman, E., and Lyons-Ruth, K. (2009). How mothers with borderline personality disorder relate to their year-old infants. Br. J. Psychiatry 195, 325-330. doi: 10.1192/bjp.bp.108. 060624

Holmes, J. (1996). Attachment, Intimacy and Autonomy: Using Attachment Theory in Adult Psychotherapy. Northvale, NJ: Jason Aronson.

Holmes, J. (1998). "Defensive and creative use of narrative in psychotherapy: an attachment perspective," in Narrative in Psychotherapy and Psychiatry, eds G. Roberts and J. Holmes (a cura di) (Oxford: Oxford University Press), 49-68.

Holmes, J. (2001). Psicoterapia Per una Base Sicura. Milano: Raffello Cortina Editore. Kernberg, O. E. (1977). "The structural diagnosis of borderline personality organization," in Borderline Personality Disorders: The Concept, the Syndrome, the Patient, ed. P. Hartocollis (NewYork: Jason Aronson), 87-121.

Khantzian, E. J. (1985). The self-medication hypothesis of addictive disorders: focus on heroin and cocaine dependence. Am. J. Psychiatry 142, 1259-1264.

Kiel, E. J., Gratz, K. L., Moore, S. A., Latzman, R. D., and Tull, M. T. (2011). The impact of borderline personality pathology on mothers' responses to infant distress. J. Fam. Psychol. 25, 907-918. doi: 10.1037/a0025474

Kim, H. K., Pears, K. C., Capaldi, D. M., and Owen, L. D. (2009). Emotion dysregulation in the intergenerational transmission of romantic relationship conflict. J. Fam. Psychol. 23, 585-595. doi: 10.1037/a0015935

Leerkes, E. M., and Crockenberg, S. C. (2009). Antecedents of mothers' emotional and cognitive responses to infant distress: the role of family, mother, and infant characteristics. Inf. Ment. Heal. J. 27, 405-428. doi: 10.1002/imhj.20099

Levy, K. N. (2005). The implications of attachment theory and research for understanding borderline personality disorder. Dev. Psychopathol. 17, 959-986. doi: $10.1017 /$ S0954579405050455

Main, M., and Hesse, E. (1990). "Parents' unresolved traumatic experiences are related to infant disorganized attachment status: is frightened and/or frightening parental behavior the linking mechanism?", in Attachment in the Preschool Years, eds M. T. Greenberg, D. Cicchetti, and E. M. Cummings (Chicago: Chicago University Press).

Marvin, R. S., and Britner, P. (2008). "Normative development: the ontogeny of attachment," in Handbook of Attachment: Theory, Research, and Clinical Applications, 2nd Edn, eds J. Cassidy and P. R. Shaver (New York: Guilford Press), 269-294.

Mazzi, F., Morosini, P., De Girolamo, G., and Guaraldi, G. P. (2003). Intervista Clinica Strutturata per i disturbi dell'Asse II del DSM-IV, Versione Clinica. Firenze: Organizzazioni Speciali.

Meisels, S. J., Dichtelmiller, M., and Liaw, F. (1993). "A multidimensional analysis of early childhood intervention programs," in Handbook of Infant Mental Health, ed. C. H. Zeanah (New York: Guilford Press), 361-385. 
Mickelson, K. D., Kessler, R. C., and Shaver, P. R. (1997). Adult attachment in a nationally representative sample. J. Pers. Soc. Psychol. 73, 1092-1106. doi: 10.1037/0022-3514.73.5.1092

Millon, T. (1983). Modern Psychopathology, Chap. 12. Prospect Heights, IL: Waveland.

Millon, T. (1997). Millon Clinical Multiaxial Inventory-II: Manual. Minneapolis, MN: National Computer Systems.

Millon, T., Krueger, R., and Simonsen, E. (eds). (2008). Contemporary Directions in Psychopathology: Toward the DSM-V and ICD-11. New York, NY: Guilford Press.

National Institute on Drug Abuse. (1996). Drug Abuse and Drug Abuse Research: The Fifth Triennial Report to Congress. Rockville, MD: National Institute on Drug Abuse.

Newman, L. K., Stevenson, C. S., Bergman, L. R., and Boyce, P. (2007). Borderline personality disorder, mother-infant interaction and parenting perceptions: preliminary findings. Aust. N. Z. J. Psychiatry 41, 598-605. doi: $10.1080 / 00048670701392833$

Obegi, J. H. (2008). The development of the client-therapist bond through the lens of attachment theory. Psychotherapy (Chic.) 45, 431-446. doi: 10.1037/a0014330

Patrick, M., Hobson, R. P., Castle, D., Howard, R., and Maughan, B. (1994). Personality disorder and the mental representation of early social experience. Dev. Psychopathol. 6, 375-388. doi: 10.1017/S09545794000 04648

Riggs, S. A., and Jacobvitz, D. (2002). Expectant parents' representations of early attachment relationships: associations with mental health and family history. J. Consult. Clin. Psychol. 70, 195-204. doi: 10.1037/0022-006x. 70.1 .195

Rosenstein, D. S., and Horowitz, H. A. (1996). Adolescent attachment and psychopathology. J. Consult. Clin. Psychol. 64, 244-253. doi: 10.1037/0022006x.64.2.244

Sarno, I., Preti, E., Prunas, A., and Madeddu, F. (2011). SCL-90-R Symptom Checklist-90-R Adattamento Italiano. Firenze: Giunti, Organizzazioni Speciali.

Satterfield, W. A., and Lyddon, W. J. (1995). Client attachment and perceptions of the working alliance with counselor trainees. J. Counsel. Psychol. 42, 187-189. doi: 10.1037/0022-0167.42.2.187

Shorey, H. S., and Snyder, C. R. (2006). The role of adult attachment styles in psychopathology and psychotherapy outcomes. Rev. Gen. Psychol. 10, 1-20. doi: 10.1037/1089-2680.10.1.1

Slade, A. (2008). "The implications of attachment theory and research for adult psychotherapy. research and clinical perspectives," in Handbook of Attachment: Theory, Research, and Clinical Applications, Vol. 19, 1020, 2nd Edn, eds J. Cassidy and P. R. Shaver (New York, NY: Guilford Press), 762-782.
Sroufe, L. A. (2005). Attachment and development: a prospective, longitudinal study from birth to adulthood. Attach. Hum. Dev. 7, 349-367. doi: $10.1080 / 14616730500365928$

Stepp, S. D., Whalen, D. J., Pilkonis, P. A., Hipwell, A. E., and Levine, M. D. (2012). Children of mothers with borderline personality disorder: identifying parenting behaviors as potential targets for intervention. Personal. Disord. 3:76. doi: 10.1037/a0023081

Stevens, S., Arbiter, N., and Glider, P. (1989). Women residents: expanding their role to increase treatment effectiveness in substance abuse programs. Int. J. Addict. 24, 425-434.

Stocco, P., Simonelli, A., Capra, N., and De Palo, F. (2012). "New perspectives of research and intervention for drug-addicted mothers and their children," in DrugAddictions: From Pathophysiology to Treatment, ed. Dr. D. Belin (Rijeka: InTech Open Access Publisher), 425-452.

Thompson, R. A., and Raikes, A. H. (2003). Toward the next quarter-century: conceptual and methodological challenges for attachment theory. Dev. Psychopathol. 15, 691-718. doi: 10.1017/S0954579403000348

Wallin, D. (2007). Attachment and Psychotherapy. New York: Guilford Press.

Ward, A., Ramsay, R., Turnbull, S., Steele, M., Steele, H., and Treasure, J. (2001). Attachment in anorexia nervosa: a transgenerational perspective. $\mathrm{Br}$. J. Med. Psychol. 74, 497-505. doi: 10.1348/000711201161145

Zennaro, A., Ferracuti, S., Lang, M., and Sanavio, E. (2008). L'adattamento Italiano del MCMI-III. Studi di Validazione. Firenze: Giunti O.S.

Conflict of Interest Statement: The authors declare that the research was conducted in the absence of any commercial or financial relationships that could be construed as a potential conflict of interest.

Received: 03 June 2014; accepted: 25 August 2014; published online: 10 September 2014.

Citation: De Palo F, Capra N, Simonelli A, Salcuni S and Di Riso D (2014) Parenting quality in drug-addicted mothers in a therapeutic mother-child community: the contribution of attachment and personality assessment. Front. Psychol. 5:1009. doi: 10.3389/fpsyg.2014.01009

This article was submitted to Psychology for Clinical Settings, a section of the journal Frontiers in Psychology.

Copyright (C) 2014 De Palo, Capra, Simonelli, Salcuni and Di Riso. This is an openaccess article distributed under the terms of the Creative Commons Attribution License (CC BY). The use, distribution or reproduction in other forums is permitted, provided the original author(s) or licensor are credited and that the original publication in this journal is cited, in accordance with accepted academic practice. No use, distribution or reproduction is permitted which does not comply with these terms. 


\title{
Anorexia and attachment: dysregulated defense and pathological mourning
}

\author{
Elisa Delvecchio ${ }^{1}$, Daniela Di Riso ${ }^{1}$, Silvia Salcuni ${ }^{1}$, Adriana Lis ${ }^{1}$ and Carol George ${ }^{2}$ \\ ${ }^{1}$ Dipartimento di Psicologia dello Sviluppo e della Socializzazione, Università di Padova, Padua, Italy \\ ${ }^{2}$ Department of Psychology, Mills College, Oakland, CA, USA
}

\author{
Edited by: \\ Sayyed Mohsen Fatemi, Harvard \\ University, USA \\ Reviewed by: \\ Gabriele Roberto Cassullo, Università \\ degli Studi di Torino, Italy \\ Mingna Liu, Northwestern University, \\ USA

\section{*Correspondence:} \\ Elisa Delvecchio, Dipartimento di \\ Psicologia dello Sviluppo e della \\ Socializzazione, Università di Padova, \\ Via Venezia 12, Padova 35100, Italy \\ e-mail: elisa_delvecchio@libero.it
}

\begin{abstract}
The role of defensive exclusion (Deactivation and Segregated Systems) in the development of early relationships and related to subsequent manifestations of symptoms of eating disorders was assessed using the Adult Attachment Projective Picture System (AAP). Fifty-one DSM-IV diagnosed women with anorexia participated in the study. Anorexic patients were primarily classified as dismissing or unresolved. Quantitative and qualitative analyses of defensive exclusion were carried out. Results showed potential benefits of using the AAP defense exclusion coding system, in addition to the main attachment classifications, in order to better understand the developmental issues involved in anorexia. Discussion concerned the processes, such as pathological mourning, that may underlie the associations between dismissing and unresolved attachment and anorexia. Implications for developmental research and clinical nosology are discussed.
\end{abstract}

Keywords: attachment, adult attachment projective picture system, anorexia nervosa, defense mechanisms, dysregulation

\section{INTRODUCTION}

Anorexia nervosa (AN) is a severe form of psychopathology which is difficult to treat (Steiner et al., 2003). Symptoms include refusal of maintaining a minimal body weight according to age and height (less than $85 \%$ of the expected), intense fear of gaining weight or becoming fat (even when the subject is underweight), exaggerated weight concerns, desperate attempts to prevent weight gain through self-induced vomiting, laxative abuse, or excessive dieting and exercise, and denial of the seriousness of current low body weight or wrong perception of body weight (dysmorphophobia; American Psychiatric Association [APA], 1994). The anorexic identity appears to be one of the most dangerous clinical conditions and has severe psychological implications (Fairburn and Brownell, 2002). It shows a high incidence of comorbid diagnoses and the highest mortality rate among all mental disorders (Attia, 2010). It is 10 times more frequent in females than in males (Woodside et al., 2001), and the highest incidence occurs in adolescent girls and young women (0.5-1\%; American Psychiatric Association [APA], 1994).

Researchers have identified biological, cognitive, family-related, and socio-cultural factors that contribute to and maintain eating disorders (e.g., Bruch, 1973; Kiang and Harter, 2006; Farber, 2008). Steiner etal. (2003) emphasized that a developmental psychopathological approach is needed to unify these different perspectives. They suggested that identifying developmental risks and buffering factors was essential to address etiology and treatment. One important developmental factor is attachment, intended as the foundation of emotional- and self-regulation. It concerns beliefs about the accessibility and worthiness of self and others, and capacities to review and reflect on interpersonal experience (e.g., Cassidy and Shaver, 2008; Zachrisson and Skårderud, 2010). Attachment insecurity is an established risk factor for eating disorders in general and, more specifically, for anorexia (e.g., Pierrehumbert et al., 2002; Troisi et al., 2005, 2006; Canetti et al., 2008; Dozier et al., 2008; Tereno et al., 2008; Zachrisson and Skårderud, 2010; Amianto et al., 2011). The prevalence of insecure attachment in eating disorders is estimated between 70 and 100\% (Ramacciotti et al., 2001; Zachrisson and Kulbotten, 2006). So far, researchers approached the study of eating disorders using two different research methodologies. Both of them are connected to attachment research, but differ as regards conceptual histories and forms of assessment (Waters et al., 2002; Crowell et al., 2008).

The majority of eating disorder studies was conducted following the romantic adult attachment perspective. This approach conceives attachment as a personality style related to satisfaction in romantic love and in adult relationships (i.e., marriage and dating; Hazan and Shaver, 1987; Kenny and Hart, 1992; Friedberg and Lyddon, 1996; Chassler, 1997; Sharpe et al., 1998; Ward et al., 2000; Broberg et al., 2001; Latzer et al., 2002; OrzolekKronner, 2002; Pierrehumbert et al., 2002; Tasca et al., 2004, 2006a,b; Evans and Wertheim, 2005; Troisi et al., 2005, 2006; Kiang and Harter, 2006; Eggert et al., 2007). In this perspective, attachment style was assessed using self-report questionnaires that identified secure, avoidant, ambivalent, and for some measures, fearful attachment styles. According to this perspective, insecure attachment style is significantly associated with eating disorders. However, results were mixed as to which particular insecure attachment style was the most prominent (e.g., Elgin and Pritchard, 2006; Kiang and Harter, 2006; Tasca et al., 2007; Tereno et al., 2008).

In the field of eating disorders, there are relatively few adult attachment studies adopting a developmental approach. Such approach evaluates an individual's state of mind on the basis of experiences with parental attachment figures during childhood. To our knowledge, all studies to date used a single 
assessment methodology, the Adult Attachment Interview (AAI; George et al., 1984; George et al., unpublished manuscript; Main et al., unpublished manuscript; Hesse, 2008). The AAI designates five adult attachment patterns - secure, dismissing, preoccupied, unresolved, and cannot classify. This last pattern is associated with abuse or other severe attachment threats (Hesse, 2008). According to this perspective, most of the existing studies reported a predominance of dismissing and unresolved attachment (Cole-Detke and Kobak, 1996; Fonagy et al., 1996; Ward et al., 2001; Ringer and Crittenden, 2007; Barone and Guiducci, 2009), with the exception of one study that reported a prevalence of dismissing and preoccupied attachment (Ramacciotti et al., 2001).

Establishing the distribution of attachment classifications has been the standard first step in investigating attachment correlates in psychopathology (Dozier et al., 2008). The predominance of dismissing and unresolved adult attachment and analogous personality style groups (avoidant, fearful) in eating disorder samples is striking, especially for anorexia. Distributions are different from those established for other psychopathological conditions or for control samples (van IJzendoorn and Bakermans-Kranenburg, 1996; Bakermans-Kranenburg and van IJzendoorn, 2009; Cassibba et al., 2013). However, distribution patterns do not adequately explain the underlying processes that contribute to the intense separation anxiety, fear of abandonment, and maladaptive behavior which are associated with this specific eating disorder. Several studies reported experience and state of mind rating scales more in detail, exploring different dynamics even in the same classification patterns, in an effort to better understand these processes.

From a developmental perspective, both behavioral control of attachment figures and dysregulated frightened states of mind define the disorganized attachment pattern (Main and Solomon, 1990; Solomon et al., 1995; Lyons-Ruth and Jacobvitz, 2008; Marvin and Britner, 2008). Unresolved attachment (unresolved for loss and abuse) is conceived as the adult analog of children's disorganized attachment pattern (Hesse, 2008). The prevalence of unresolved attachment in the eating disorder literature suggests that disorganization plays a strong etiological role. Solomon and George (2011, p. 4) argued that disorganization is not limited to behavior and broadly "represents dysregulation of co-adaptive processes (in attachment-caregiving relationships) at the level of behavior, physiology, and representation."

George and West (2012) argued that the predominant theory regarding disorganization in adulthood, although fruitful, needed to be updated, and primarily based on the model of attachment dysregulation. Many researchers reported the AAI approach as limiting in the study of risk factors (Schuengel and van Ijzendoorn, 2001; Steele, 2003; Hesse, 2008; Buchheim and George, 2011). In an attempt to broaden the conceptualization of trauma beyond loss and abuse (the only risk experience assessed by the AAI), George and West (2012) defined attachment trauma as to include all the experiences which represent a threat to personal safety and to the integrity of attachment relationships. This view would include a broader range of severe dysregulation risk factors, such as family experiences (e.g., parental conflict, even if not directed toward the child), alcoholism, and psychopathology (e.g., Solomon and George,
2011), community terrorism and violence (e.g., Almqvist and Broberg, 2003; De Haene et al., 2010), and institutionalization (e.g., Schuengel and van Ijzendoorn, 2001). George and West (2012) emphasized that all forms of attachment trauma constitute a loss, which, if not mourned, would lead to "the persistent and insatiable nature of the yearning for the lost attachment figure" (Bowlby, 1980, p. 26 - italics added) and to the dysregulation associated with feelings of fear, rage, helplessness, abandonment, and isolation (George and West, 2012)

Mourning requires re-organizing and integrating representations of self and attachment figures to match the reality of their inaccessibility (Bowlby, 1980; West and Sheldon-Keller, 1994). When mourning is complete, the individual accepts experience as truthful and permanent, and dismantles and transforms perceptions of the frightened, unprotected, and helpless self to begin anew (Bowlby, 1980; West and Sheldon-Keller, 1994; George and West, 2012). When mourning is incomplete, representational models of the self and attachment figures remain unchanged and persist (Bowlby, 1980; George and West, 2012). In this process, defenses play a central role (Bowlby, 1980). They refer to automatic and unconscious attention processes which select, exclude, and transform behavior, thought, and emotions so as to modulate attachment distress and prevent psychological breakdown. Adaptive use of defensive processes promotes healthy mourning, whereas maladaptive dependence on defenses compromises relatedness, incrementing the risk for "breakdowns in functioning." Such breakdowns, in turn, undermine the ability to cope with distress (Bowlby, 1980, p. 72). Bowlby (1980) defined three forms of defense: deactivation, cognitive disconnection, and segregated systems. Deactivation encompasses strategies that shift attention away from attachment events, memories, or feelings. Deactivation is associated with evaluations of self and others as not deserving care and with the rejection or neutralization of attachment needs (Solomon et al., 1995; George and Solomon, 2008). Normative forms of deactivation are the main organizing defense that defines the insecure-avoidant pattern in children and the dismissing attachment in adults (Solomon et al., 1995; George and West, 2001). Maladaptive forms of deactivation foster a form of pathological mourning which Bowlby (1980) called "failed mourning" or "prolonged absence of conscious grieving" (George and West, 2012).

Cognitive disconnection literally disconnects attachment distress from its source, undermining consistency, and the ability of holding in mind a unitary view of events and emotions which follow attachment activation (Bowlby, 1980). Disconnection results in confused evaluations of self and others that make it difficult to turn away from attachment (i.e., deactivate; Solomon et al., 1995; George and West, 2001). Normative forms of cognitive disconnection are the main organizing defense that defines ambivalent-resistant attachment in children and preoccupied attachment in adults (Solomon et al., 1995; George and West, 2001). This defensive process is highly present in most individuals and can be seen as a background "mental noise" that remains active in all individuals. However, individuals classified as preoccupied do not manage to keep such noise in the background and are therefore overwhelmed by this "mental noise." Maladaptive forms of 
cognitive disconnection are associated with a form of pathological mourning that Bowlby (1980) described as "preoccupation with personal reactions and sufferings." It refers to a chronic mourning state characterized by disorganized behavior pining, anger and endless search for attachment figures. Attachment state of mind is akin to "living in the war zone" and manifests on the AAI as a subgroup of the preoccupied classification, preoccupied with trauma (George and West, 2012).

Segregated systems encompass painful and threatening attachment experiences and affects which are blocked from consciousness, such as those associated with unbearable loss (Bowlby, 1980). Segregated systems can dysregulate attachment under conditions of stress or threat and are associated with behavioral and psychological hypervigilance (i.e., a fear response). Such hypervigilance manifests itself either via loss of control or constricted (i.e., frozen) forms (Solomon et al., 1995; George and West, 2001). Segregated systems are the building blocks of mourning (Bowlby, 1980). When experience and affect are modulated, transformed, and integrated they are what Bowlby considered as the residual "scars" of loss. On the contrary, when normative defense breaks down, dysregulated experience and affect define a disorganized form of chronic mourning (Bowlby, 1980). Dysregulated segregated systems are the underlying processes associated with disorganized attachment in children and with unresolved attachment on the AAI in adults (Solomon et al., 1995; George and West, 2001; George and Solomon, 2008).

In the present study we propose that defensive processes linked to attachment trauma and associated with maladaptive deactivation and pathological mourning may explain to some intent severe manifestations of eating disorders. More specifically, anorexia presents a distinct pattern of symptoms associated with a lack of attention or ability to discriminate inner feelings and distress cues, with the illusion of having control over feelings of emptiness, overwhelm, and fear (e.g., Bruch, 1973; Leon et al., 1993; Eggert et al., 2007). As previously mentioned, Fonagy et al. (1996) reported that $93 \%$ of their eating disorder patients were unresolved. In Ward et al.'s (2001) study, only 35\% of their anorexic sample was unresolved, however, $80 \%$ was assigned to a classification indicative of some form of dismissing/devaluing attachment (irrespective if unresolved or not). These patterns suggest that deactivating defenses shift attention away from personal distress. However, when fragile in the face of trauma, defensive breakdown can lead to dysregulation (i.e., unresolved).

The present study was designed to address the issue of attachment and defensive exclusion patterns (deactivation and segregated systems) in young adult women diagnosed with DSM-IV anorexia. In order to accomplish this goal, we used the Adult Attachment Projective Picture System (AAP), the only adult attachment measure that (1) provides AAI-based classifications, (2) evaluates defensive processing patterns, (3) makes a distinction between "normative" and "traumatic" segregated systems and (4) addresses pathological mourning, as assessed by three or more traumatic indicators of segregated systems in the same story.

Specifically, in light of these considerations, this study had the general aim to investigate patterns of attachment as rated in the main classification of the AAP coding system, examining the role of two typical forms of defensive exclusion in order to assess the dynamics underneath the attachment profile. Moreover, according to the pathological mourning perspective, specific forms of pathological mourning in the anorexia sample were explored.

Four sets of hypotheses were considered in the current work:

(1) It was expected the majority of anorexic patients to show an unresolved or dismissing attachment pattern (Ramacciotti et al., 2001; Zachrisson and Kulbotten, 2006).

(2) Differences were expected between the current sample and the non-clinical sample of similar age from van IJzendoorn and Bakermans-Kranenburg (1996), and from Cassibba et al.'s (2013) data on attachment classifications measured by the AAI (i.e., adolescents and young adults). Furthermore, anorexic patients' distribution of attachment classifications was expected to be significantly different from clinical samples (van IJzendoorn and Bakermans-Kranenburg, 1996; Cassibba et al., 2013), with a higher percentage of unresolved and dismissing patterns in the current sample.

(3) A more frequent use of traumatic segregated systems than normative ones was expected in the stories.

(4) The fourth hypothesis predicted that attachment in anorexia would be associated with pathological mourning. More specifically, high percentages of Ds profiles with failed mourning and $U$ profiles with chronic mourning were expected. As a consequence, we expected that anorexia would not be associated with the form of pathological mourning linked to chronic preoccupation with trauma (Buchheim and George, 2011; George and West, 2001, 2012).

\section{MATERIALS AND METHODS PARTICIPANTS}

Participants were 51 female patients with anorexia (AN) recruited in a mental health assessment and treatment center in Italy. Age in the sample ranged from 18 to 36 years $(M=24.82$; SD $=4.91)$. Patients were diagnosed according to DSM-IV criteria (American Psychiatric Association [APA], 1994) by expert psychiatrists. Thirteen (26\%) patients had co-morbid diagnoses: obsessivecompulsive disorder (12\%), major depressive disorder $(8 \%)$, and borderline personality disorder $(6 \%)$. The mean age at the onset of anorexia was 16.5 years. Forty seven $(92.5 \%)$ were single and three $(7.5 \%)$ were married. Thirty one $(77.5 \%)$ were full-time university students, seven (17.5\%) were employed, and two (5\%) were unemployed. The socioeconomic level of the sample was medium to high. Two-thirds of the sample came from intact families. Although the participants' mothers were well educated, the majority of them (63\%) did not work outside their home.

These demographics indicated that the patients from the current sample were similar to those in the majority of eating disorder studies with regard to socioeconomic status and educational level. The external sociological variables indicated that patients had a stable family constellation and considered their mother as their primary caregiver.

\section{PROCEDURE}

Attachment assessment was done prior to treatment; none of the participants was in any kind of psychotherapeutic treatment at 
the time of the study. The patients gave their informed consent to participate in the study. There were no dropouts from AAP testing.

\section{MEASURES}

The AAP (George et al., unpublished manuscript; George and West, 2001, 2012) is a free-response assessment of adult attachment based on the analysis of the "story" responses to a set of theoretically derived attachment-related drawings. The AAP stimulus set includes eight stimuli, a warm-up picture and seven attachment scenes ordered to progress from mildly to highly distressing situations (Buchheim et al., 2006). Participants are instructed to tell a story for each stimulus. The story elements include a description of how the situation began, the characters' actions, feelings, and thoughts, and how the situation ends. Each attachment stimulus response is coded for story content (agency, connectedness, and synchrony), defensive processes (deactivation, cognitive disconnection, segregated systems) and the inclusion of personal experience. Coding is completed using verbatim transcripts of audiotaped AAP responses. Attachment group classification is determined based on the patterns of content, defense, and personal experience codes demonstrated across the entire set of seven attachment stories. The AAP identifies the four standard adult attachment patterns: three organized patterns (secure-F, dismissing-Ds, preoccupied-E), and one disorganized pattern, named unresolved-U. For a description of AAP coding variables see George and West (2012). For the purpose of this paper, a more specific explanation of defensive processes will be provided. Deactivation attempts to shift attention away from attachment events, individuals, or feelings and is evidenced in story material that attempts to deflect and prevent the individual from becoming conscious of attendant attachment distress. Examples include references to social scripts (e.g., visiting a grave on the anniversary of the death), power (e.g., material wealth), achievement (e.g., intellectual pursuits), authority, or romance (diversion of attention from attachment needs to the sexual system). Deactivation is also evidenced by overt rejection, such as descriptions of characters as not deserving care, pushed away, or being punished for inconsequential transgressions. Cognitive disconnection, the splitting of attachment attention and affect, is evidenced when story elements are confusing or contradictory. Cognitive disconnection is also evidenced by themes of anger, withdrawal, or superficial sentimentality. Finally, segregated systems refer to the attempt to block painful distress, fear and rage, and are evidenced by descriptions of fear, isolation, abandonment, helplessness, and extreme vulnerability. "Normative" segregated systems are differentiated from "traumatic" forms. Normative segregated systems are story elements that have been empirically established as very common responses in community samples (e.g., fear of being hit by a ball while playing dodge ball). Traumatic segregated systems are defined as severe, eerie, evil, or surreal material (e.g., being beaten, disgust, rage, characters described as floating or as a statue - i.e., frozen). Traumatic segregated systems are also evident when individuals constrict and freeze in response to a stimulus, handing the picture back to the administrator or stating in a very firm way that they cannot provide a response. Pathological mourning for attachment trauma is designated when in a transcript three or more indicators of traumatic segregated systems are coded. Failed mourning for attachment trauma is designated when this pattern occurs for Ds cases. Preoccupation with attachment trauma is designated when this pattern occurs for E cases. Unresolved for attachment trauma is designated when this pattern occurs for $U$ cases. This pattern is rare when the classification is $\mathrm{F}$ and in this case it is not considered as pathological mourning.

Two trained reliable AAP judges coded independently 20 randomly selected protocols. Cohen's kappa on the AAP four-way classifications were $k=0.95$. Final classifications regarding cases with disagreements between judges were determined by consensus. Inter-judge agreement for the pathological mourning attachment groups was $k=0.91$, indicative of a nearly total agreement between observers (Viera and Garrett, 2005). The AAP demonstrated concurrent validity with the AAI (George and West, 2001; Buchheim and George, 2011). Predictive validity and interjudge reliability were demonstrated in a range of community and clinical studies (e.g., Béliveau and Moss, 2005; Van Ecke, 2005, 2006; Aikins et al., 2009; Webster et al., 2009).

\section{RESULTS}

The first hypothesis was that the most prevalent attachment classifications in the current sample would be $U$ and Ds. Results confirmed this expectation. The classification distribution is shown in Table 1. Twenty six (51\%) patients were classified U, $19(37 \%)$ patients were Ds, four were scored (8\%) E, and two patients (4\%) were classified secure (F). In summary, $88 \%$ of the sample showed an unresolved or dismissing attachment pattern.

In order to assess the second hypothesis, a series of Chi-square tests was performed to compare the current distribution to the community and clinical samples reported in van IJzendoorn and Bakermans-Kranenburg (1996) and Cassibba et al.'s (2013) metaanalyses.

Significant results were found for all comparisons $(p<0.05)$, suggesting that distributions were significantly different (Table 2 ). Patients with anorexia classified as unresolved in the current sample $(60 \%)$ clearly outnumbered individuals with the same classification in both van IJzendoorn and Bakermans-Kranenburg (1996) as well as Cassibba et al.'s (2013) meta-analyses, in which the highest percentage of individuals scored as unresolved was 40\% (van IJzendoorn and Bakermans-Kranenburg, 1996). In line with expectations, the percentage of dismissing classifications was higher in the current study than in both the above cited meta-analyses. Therefore, as expected, anorexic patients showed a significantly different distribution of attachment classifications in comparison to clinical samples recruited in previous studies.

Moving to the third aim, means and SDs of the AAP Deactivation and Segregated System processes are reported in Table 3. The mean of Deactivation defenses, in the overall sample, showed that patients used more than one Deactivation defense in each story $(M=9.54$; DS $=7.22)$, while the mean of segregated systems $(M=7.53 ; \mathrm{SD}=4.58)$ showed that patients reported at least one segregated system in each story. The frequency of traumatic SS was 
Table 1 | Frequency and percentage of attachment pattern classification in Anorexia nervosa (AN) current patients ( $n=51$ ), van IJzendoorn and Bakermans-Kranenburg's (1996) and Cassibba et al.'s (2013) samples.

\begin{tabular}{|c|c|c|c|c|c|c|c|c|c|c|}
\hline Classification & \multicolumn{2}{|c|}{$\begin{array}{l}\text { AN female } \\
(n=51)\end{array}$} & \multicolumn{2}{|c|}{$\begin{array}{l}\text { Adolescent and } \\
\text { young adults } \\
\text { ( } n=225 \text { ) }\end{array}$} & \multicolumn{2}{|c|}{$\begin{array}{l}\text { Clinical sample } \\
\text { (axis I and II) } \\
(n=350)\end{array}$} & \multicolumn{2}{|c|}{$\begin{array}{l}\text { Italian non-clinical } \\
\text { adolescents } \\
(n=336)\end{array}$} & \multicolumn{2}{|c|}{$\begin{array}{l}\text { Italian clinical } \\
\text { sample } \\
(n=260)\end{array}$} \\
\hline Ds & 19 & 37.3 & 47 & 21 & 43 & 26 & 80 & 24 & 79 & 30 \\
\hline $\mathrm{E}$ & 4 & 7.8 & 27 & 12 & 42 & 25 & 33 & 10 & 44 & 17 \\
\hline$U$ & 26 & 51.0 & 44 & 20 & 66 & 40 & 14 & 4 & 94 & 36 \\
\hline
\end{tabular}

F, Secure; Ds, Dismissing; E, preoccupied; U, Unresolved.

Table 2 | Chi-square test between the current sample $(n=51)$ and van IJzendoorn and Bakermans-Kranenburg's (1996) and Cassibba et al.'s (2013) samples.

\begin{tabular}{llll}
\hline & & $\chi^{2}$ & \multicolumn{1}{c}{$\boldsymbol{p}$} \\
\hline van IJzendoorn and & Adolescent and & $41.53<0.001$ \\
Bakermans-Kranenburg (1996) & $\begin{array}{l}\text { young adults (225) } \\
\text { Clinical sample (350) }\end{array}$ & 9.57 & 0.023 \\
Cassibba etal. (2013) & $\begin{array}{l}\text { Italian non-clinical } \\
\text { adolescents (336) }\end{array}$ & $124.78<0.001$ \\
& Italian clinical & 10.04 & 0.018 \\
& sample (260) & & \\
\hline
\end{tabular}

significantly higher than the frequency of normative SS (Wilcoxon test, $z=-1.74 ; p<0.05$, one tailed significance).

The very limited number of $\mathrm{F}$ and $\mathrm{E}$ patients did not allow to pursue statistical analysis on these two categories of patients, thus the following statistical analyses were carried out only on patients classified as Ds or U. No significant differences were found between Ds and $U$ patients as regards the frequency of total, normative, and traumatic segregated systems (Mann-Whitney test, respectively, $z=-0.49, p=0.62 ; z=-0.40, p=0.69 ; z=-0.39$, $p=0.69$ ). Ds patients showed a significant higher frequency of Deactivation defenses than $U$ patients (Wilcoxon test, $z=-2.95$; $p<0.01$, one tailed significance).

The last set of analyses focused on pathological mourning. Overall, 26 patients $(64.44 \%)$ showed a pathological mourning. Among them, $11(37.9 \%)$ were classified as DS (failed mourning), while the remaining subjects $(62.1 \%)$ were classified as $U$ (unresolved for attachment trauma). Nineteen out of $45(35.6 \%)$ patients showed only normative segregated systems $(17.8 \%)$ or reported less than three traumatic segregated systems $(17.8 \%)$.

A Chi-square test showed no significant differences in the distribution of pathological mourning versus normative mourning within the two considered attachment classifications $\left(\chi^{2}(1)=0.62\right.$, $p=0.43)$.

\section{DISCUSSION}

This study was firstly designed to replicate and extend existing literature concerning attachment classifications in anorexic patients. A second major aim was to provide an additional contribution to attachment-related issues in a sample of anorexic patients by means of a qualitative analysis and via the use of a conceptual model based on attachment trauma.

As expected, the distribution of attachment patterns in the current sample was significantly different from non-clinical samples (van IJzendoorn and Bakermans-Kranenburg, 1996; Cassibba et al., 2013), with an overrepresentation of the unresolveddisorganized attachment pattern, advocating for specificity in the link between attachment and AN.

The distribution of attachment patterns was in line with literature of clinical anorectic samples, showing that $U$ and Ds attachment classifications were the most prevalent (Ramacciotti et al., 2001; Zachrisson and Kulbotten, 2006). More specifically, $37 \%$ of the sample was classified as Ds. These patients tend to maintain an avoidant, detached, or distanced position in relation to attachment. Such attitude implies the use of deactivation strategies in order to keep distressing emotions under control after attachment activation (George et al., unpublished manuscript). This dismissing attitude represents a defensive turning away from potentially painful emotional material, similar to the anorexic's denial of hunger (Cole-Detke and Kobak, 1996; Dalgleish et al., 2001).

Most of AN patients ( $51 \%$ ) were classified as U, confirming both their inability to use deactivation and/or cognitive disconnection strategies and to refer to internal working models of attachment in order to block attachment stress (Solomon et al., 1995; George and Solomon, 2008). Results also showed that they were significantly less able to use deactivation defenses than Ds patients. These findings, in line with previous studies, suggested that $\mathrm{AN}$ is associated with dismissing as well as unresolved-disorganized attachment (Fonagy etal., 1996; Ward etal., 2001; Ringer and Crittenden, 2007). 
Table 3 | Mean and SD of Attachment Projective Picture System (AAP) defensive processes according to the four ways AAP classification.

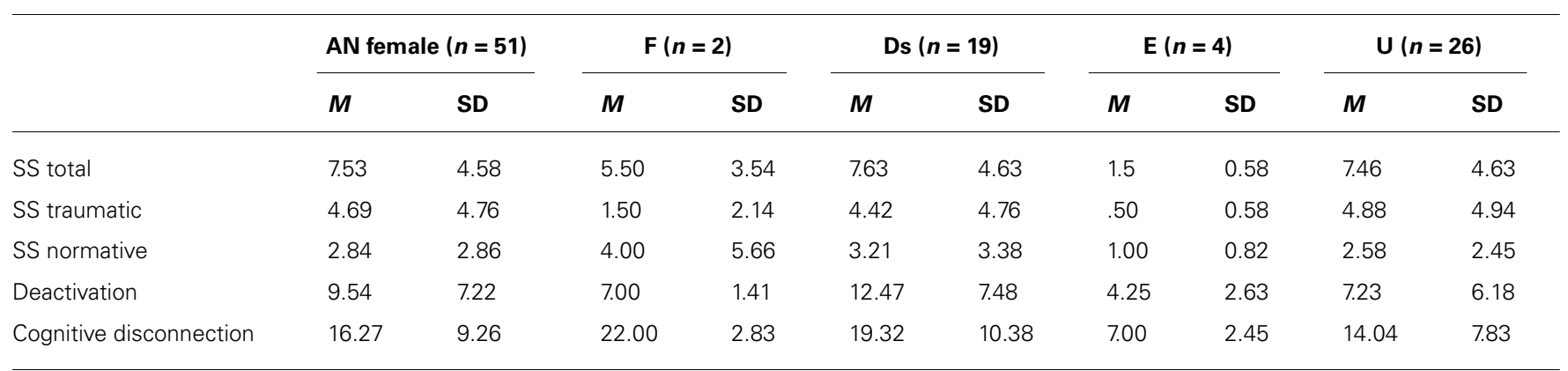

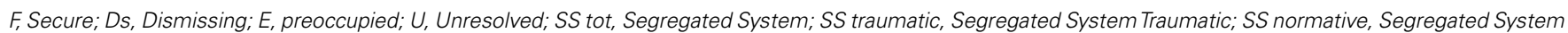
Normative; Ds tot, Deactivation.

Moving to the third hypothesis, focused on the comparison between traumatic and normative segregated systems, findings showed that severe, eerie, evil, or surreal material in response to AAP stimuli (i.e., traumatic segregated systems) was significantly overrepresented when compared to common fearful, dangerous story elements (the normative segregated systems). No significant differences were found between Ds and U patients neither in traumatic nor in normative segregated systems. In other words, dismissing AN patients were overwhelmed by the same amount of traumatic and normative segregated systems, which, as previously mentioned, represent the main processes associated with unresolved attachment.

Focusing more on the use of segregated systems, the overrepresented presence of failed mourning (58\%) in the Ds patients confirms the risk of a normative defense break-down due to dysregulated experience and affect. As a consequence, this leads to a disorganized form of chronic failed mourning (Bowlby, 1980). Similarly, the majority $(69 \%)$ of $U$ patients showed that normative defense break-down leads to a disorganized form of chronic pathological mourning (Bowlby, 1980). Qualitative analysis of the four patients classified as preoccupied confirmed the absence of pathological mourning.

Results of the present paper seem to support previous findings from neuropsychological studies on traumatic experience (Pearlman, 1995; Perry et al., 1995). Such research stressed how the unresolved attachment pattern could develop also through subtle and traumatic experiences of misattuned mothering, and not only via traumas-such as separation due to adoption, premature birth, or physical trauma. As a consequence of infants' affective dysregulation experience, states of body-mind link disintegration occur. In such situations, the infant may attempt to find comfort by means of a permanent dissociation from intolerable levels of anxiety via self-regulating behaviors, such as thumb sucking or demands for food. These self-regulatory mechanisms may be imprinted as primary comfort and self-care, replacing early attachment relationships, and mutual caring. In addition, Schore (2000) and other neuropsychiatric researchers suggested that these dissociative processes could be biochemically imprinted in the brain. As Perry et al. (1995) suggested "states become traits." Such psychobiological imprinting of early attachment disruptions would also explain why eating disorders are so often triggered by experiences of separation and loss or feared loss-puberty, leaving for college, breaking up with a boyfriend, or death of a loved one.

This study is not without limitations. First of all, the current study involved a small sample of anorexic girls who were in-patients in treatment at the time of the study, which underlines their severe health conditions. Thus, results from the current work may not be representative of the general anorexic population. Second, the AAP, differently from the AAI, does not give any autobiographical information about patients. In order to have a deeper knowledge of patients' personal story, future studies should use either AAP, and AAI together, or AAP and other measures to assesses traumatic experiences and pathological mourning. Third, this study lacks information about the relationship between symptom severity and attachment. Last but not least, the present research did not involve a communitybased control group sample or other psychiatric groups diagnosed with different eating disorders for comparison. Finally, our data do not address issues of causality. Future studies should use longitudinal prospective designs as to assess attachment strategies across time, starting before the emergence of any symptoms.

However, beside these limitations, the AAP, compared with the AAI, proved itself a useful tool in the evaluation of unconscious defensive processes and in the identification of segregated systems. It allowed the examination of new and unique constructbased features of attachment, overcoming limits of the AAI. The issue of unresolved attachment and of its internalization, via the analysis of the internal quality of segregated systems across AAP stories, was of interest as to understand the presence and the quality of pervasive dysregulation mechanisms and pathological mourning in AN patients. This issue has never been studied before in eating disorder patients, which highlights the importance of the present work. Given the interesting findings from this study, our model could be considered as a pilot framework for future research employing larger samples of eating disorder patients.

The developmental perspective in attachment research seems to offer a helpful contribution also to the clinical field, suggesting useful criteria for the choice of suitable treatment interventions with AN patients. Given the pilot nature of this study, we expect to expand these findings to get to a better understanding of the current data. Moreover, given the paucity of studies which 
have so far applied the AAP to analyze psychological functioning in AN patients, we hope that these pilot results will provide some valid reasons for improving the heuristic power of this method.

\section{REFERENCES}

Aikins, J. W., Howes, C., and Hamilton, C. (2009). Attachment stability and the emergence of unresolved representations during adolescence. Attach. Hum. Dev. 11, 491-512. doi: 10.1080/14616730903017019

Almqvist, K., and Broberg, A. G. (2003). Young children traumatized by organized violence together with their mothers: the critical effects of damaged internal representations. Attach. Hum. Dev. 5, 367-380. doi: 10.1080/14616730310001633447

American Psychiatric Association [APA]. (1994). Diagnostic, and Statistical Manual of Mental Disorders (DSM-IV). Available at: http://www.psychiatryonline.com/ DSMPDF/dsm-iv.pdf

Amianto, F., Abbate-Daga, G., Morando, S., Sobrero, C., and Fassino, S. (2011). Personality development characteristics of women with anorexia nervosa, their healthy siblings and healthy controls: what prevents and what relates to psychopathology? Psychiatry Res. 187, 401-408. doi: 10.1016/j.psychres.2010. 10.028

Attia, E. (2010). Anorexia nervosa: current status and future directions. Annu. Rev Med. 61, 425-435. doi: 10.1146/annurev.med.050208.200745

Bakermans-Kranenburg, M. J., and van IJzendoorn, M. H. (2009). The first 10,000 Adult Attachment Interviews: distributions of adult attachment representations in clinical and non-clinical groups. Attach. Hum. Dev. 11, 223-263. doi: 10.1080/14616730902814762

Barone, L., and Guiducci, V. (2009). Mental representations of attachment in eating disorders: a pilot study using the Adult Attachment Interview. Attach. Hum. Dev. 11, 405-417. doi: 10.1080/14616730902814770

Béliveau, M. J., and Moss, E. (2005). Validation du projectif de l'attachemen adulte (AAP): Contribution aux validités convergente et divergente du projectif de l'attachement adulte. La Rev. Int. Educ. Fam. 9, 29-50.

Bowlby, J. (1980). Attachment and Loss: Loss, Sadness and Depression, Vol. 3. New York: Basic Books Classics.

Broberg, A., Hjalmers, I., and Nevonen, L. (2001). Eating disorders, attachment and interpersonal difficulties: a comparison between 18- to 24-year-old patients and normal controls. Eur. Eat. Disord. Rev. 9, 381-396. doi: 10.1002/erv.421

Bruch, H. (1973). Eating Disorders. New York: Basic Books.

Buchheim, A., and George, C. (2011). "Attachment disorganization in borderline personality disorder and anxiety disorder," in Disorganization of Attachmen and Caregiving, eds J. Solomon and C. George (New York, NY: Guilford Press), 343-383.

Buchheim, A., George, C., Kaechele, H., Erk, S., and Walter, H. (2006). Measuring adult attachment representation in an fMRI environment: concepts and assessment. Psychopathology 39, 136-143. doi: 10.1159/000091799

Canetti, L., Kanyas, K., Lerer, B., Latzer, Y., and Bachar, E. (2008). Anorexia nervosa and parental bonding: the contribution of parent-grandparent relationships to eating disorder psychopathology. J. Clin. Psychol. 64, 703-716. doi: $10.1002 /$ jclp. 20482

Cassibba, R., Sette, G., Bakermans-Kranenburg, M. J., and van IJzendoorn, M. H (2013). Attachment the Italian Way. Eur. Psychol. 18, 47-58. doi: 10.1027/10169040/a000128

Cassidy, J., and Shaver, P. R. (eds). (2008). Handbook of Attachment: Theory, Research and Clinical Applications, 2nd Edn. New York: Guilford Publications.

Chassler, L. (1997). Understanding anorexia nervosa and bulimia nervosa from an attachment perspective. Clin. Soc. Work J. 25, 407-420. doi: 10.1023/A:1025796416594

Cole-Detke, H., and Kobak, R. (1996). Attachment processes in eating disorder and depression. J. Consult. Clin. Psychol. 64, 282-290. doi: 10.1037/0022 006X.64.2.282

Crowell, J. A., Fraley, R. C., and Shaver, P. R. (2008). "Measurement of individual differences in adolescent and adult attachment," in Handbook of Attachment: Theory, Research, and Clinical Applications (2nd ed.), eds J. Cassidy and P. R. Shaver (New York, NY: Guilford Press), 599-634.

Dalgleish, T., Tchanturia, K., Serpell, L., Hems, S., de Silva, P., and Treasure, J. (2001). Perceived control over events in the world in patients with eating disorders: a preliminary study. Pers. Individ. Dif. 31, 453-460. doi: 10.1016/S0191-8869(00)00150-1
De Haene, L., Grietens, H., and Verschueren, K. (2010). Holding harm: narrative methods in mental health research on refugee trauma. Qual. Health Res. 20, 1664-1676. doi: 10.1177/1049732310376521

Dozier, M., Stovall, C., and Albus, K. (2008). "Attachment and psychopathology in adulthood," in Handbook of Attachment: Theory, Research, and Clinical Applications, 2nd Edn, eds J. Cassidy and P. R. Shaver (New York, NY: Guilford Press), 718-744.

Eggert, M., Levendosky, A., and Klump, K. (2007). Relationships among attachment styles, personality characteristics, and disordered eating. Int. J. Eat. Disord. 40, 146-155. doi: 10.1002/eat.20351

Elgin, J., and Pritchard, M. (2006). Adult attachment and disordered eating in undergraduate men and women. J. College Stud. Psychother. 21, 25-40. doi: 10.1300/J035v21n02_05

Evans, L., and Wertheim, E. (2005). Attachment styles in adult intimate relationships: comparing women with bulimia nervosa symptoms, women with depression and women with no clinical symptoms. Eur. Eat. Disord. Rev. 13, 285-293. doi: 10.1002/erv.621

Fairburn, C. G., and Brownell, K. D. (eds). (2002). Eating Disorders and Obesity: A Comprehensive Handbook. New York: Guilford Press.

Farber, S. K. (2008). Dissociation, traumatic attachments, and self-harm: eating disorders and self-mutilation. Clin. Soc. Work J. 36, 63-72. doi: 10.1007/s10615007-0104-6

Fonagy, P., Leigh, T., Steele, M., Steele, H., Kennedy, R., Mattoon, G., et al. (1996). The relation of attachment status, psychiatric classification, and response to psychotherapy. J. Consult. Clin. Psychol. 1, 22-31. doi: 10.1037/0022-006X.64.1.22

Friedberg, N., and Lyddon, W. (1996). Self-other working models and eating disorders. J. Cogn. Psychother. 10, 193-203.

George, C., Kaplan, N., and Main, M. (1984). Adult Attachment Interview (AAI) Berkeley: University of California.

George, C., and Solomon, J. (2008). "The caregiving system: a behavioral systems approach to parenting," in Handbook of Attachment: Theory, Research, and Clinical Applications, 2nd Edn, eds J. Cassidy and P. R. Shaver (New York, NY: Guilford Press), 833-856.

George, C., and West, M. (2001). The development and preliminary validation of a new measure of adult attachment: the adult attachment projective. Attach. Hum. Dev. 3, 30-61. doi: 10.1080/14616730010024771

George, C., and West, M. (2012). The Adult Attachment Projective Picture System. New York: Guilford Press.

Hazan, C., and Shaver, P. R. (1987). Romantic love conceptualized as an attachment process. J. Pers. Soc. Psychol. 52, 511-24. doi: 10.1037/0022-3514.52.3.511

Hesse, E. (2008). "The adult attachment interview: historical and current perspectives," in Handbook of Attachment: Theory, Research, and Clinical Applications, 2nd Edn, eds J. Cassidy and P. R. Shaver (New York, NY, US: Guilford Press), 552-598.

Kenny, M., and Hart, K. (1992). Relationship between parental attachment and eating disorders in an inpatient and a college sample. J. Couns. Psychol. 4, 521-526. doi: 10.1037/0022-0167.39.4.521

Kiang, L., and Harter, S. (2006). Sociocultural values of appearance and attachment processes: an integrated model of eating disorder symptomatology. Eat. Behav. 7, 134-151. doi: 10.1016/i.eatbeh.2005.08.001

Latzer, Y., Hochdorf, Z., Bachar, E., and Canetti, L. (2002). Attachment style and family functioning as discriminating factors in eating disorders. Contemp. Fam. Ther. 24, 581-599. doi: 10.1023/A:1021273129664

Leon, G. R., Fulkerson, J. A., Perry, C. L., and Cudeck, R. (1993). Personality and behavioral vulnerabilities associated with risk status for eating disorders in adolescent girls. J. Abnorm. Psychol. 102, 438-444. doi: 10.1037/0021-843X.102.3.438

Lyons-Ruth, K., and Jacobvitz, D. (2008). "Attachment disorganization: genetic factors, parenting contexts, and developmental transformation from infancy to adulthood," in Handbook of Attachment: Theory, Research, and Clinical Applications, 2nd Edn, eds J. Cassidy and P. R. Shaver (New York, NY, US: Guilford Press), 666-697.

Main, M., and Solomon, J. (1990). "Procedures for identifying infants as disorganized/disoriented during the Ainsworth Strange Situation," in Attachment During the Preschool Years: Theory, Research and Intervention, eds M. T. Greenberg, D. Cicchetti, and E. M. Cummings (Chicago: University of Chicago Press), 121-160.

Marvin, R. S., and Britner, P. A. (2008). "Normative development," in Handbook of Attachment: Theory, Research, and Clinical Applications, 2nd Edn, eds J. Cassidy and P. R. Shaver (New York, NY: Guilford Press), 269-294. 
Orzolek-Kronner, D. (2002). The effect of attachment theory in the development of eating disorders: can symptoms be proximity-seeking? Child Adolesc. Soc. Work J. 19, 421-435. doi: 10.1023/A:1021141612634

Pearlman, L. A. (1995). "Self-care for trauma therapists: ameliorating vicarious traumatization," in Secondary Traumatic Stress: Self-care Issues for Clinicians, Researchers, and Educators, ed. S. B. Hudnall (Baltimore, MD: The Sidran Press) 51-64.

Perry, B. D., Pollard, R. A., Blakley, T. L., Baker, W. L., and Vigilante, D. (1995). Childhood trauma, the neurobiology of adaptation, and? use? dependent? development of the brain: how? states? become? traits? Infant Ment. Health J. 16, 271-291. doi: 10.1002/1097-0355(199524)16:4<271::AID-IMHJ2280160404>3.0.CO;2-B

Pierrehumbert, B., Bader, M., Miljkovitch, R., Mazet, P., Amar, M., and Halfon, O. (2002).Strategies of emotion regulation in adolescents and young adults with substance dependence or eating disorders. Clin. Psychol. Psychother. 9, 384-394. doi: 10.1002/cpp.339

Ramacciotti, A., Sorbello, M., Pazzagli, A., Vismara, L., Mancone, A., and Pallanti, S. (2001). Attachment processes in eating disorders. Eat. Weight Disord. 6, 166-170 doi: $10.1007 / \mathrm{BF} 03339766$

Ringer, F., and Crittenden, P. (2007). Eating disorders and attachment: the effects of hidden family processes on eating disorders. Eur. Eat. Disord. Rev. 15, 119-130. doi: 10.1002/erv.761

Schuengel, C., and van Ijzendoorn, M. H. (2001). Attachment in mental health institutions: a critical review of assumptions, clinical implications, and research strategies. Attach. Hum. Dev. 3, 304-323. doi: 10.1080/14616730110096906

Sharpe, T., Killen, J., Bryson, A., Shisslak, C., Estes, L., Gray, N., et al. (1998) Attachment style and weight concerns in preadolescent and adolescent girls. Int. J. Eat. Disord. 23, 39-44. doi: 10.1002/(SICI)1098-108X(199801)23:1<39::AIDEAT5 $>3.0 . \mathrm{CO} ; 2-2$

Schore, A. N. (2000). Attachment and the regulation of the right brain. Attach. Hum. Dev. 2, 23-47. doi: 10.1080/146167300361309

Solomon, J., and George, C. (2011). The Disorganized Attachment-Caregiving System. New York: Guilford Publications.

Solomon, J., George, C., and De Jong, A. (1995). Children classified as control- ling at age six: evidence of disorganized representational strategies and aggression at home and school. Dev. Psychopathol. 7, 447-464. doi $10.1017 /$ S0954579400006623

Steele, H. (2003). Holding therapy is not attachment therapy. Attach. Hum. Dev. 5, 219-220. doi: 10.1080/14616730310001594009

Steiner, H., Kwan, W., Shaffer, T. G., Walker, S., Miller, S., Sagar, A., et al. (2003). Risk and protective factors for juvenile eating disorders. Eur. Child Adolesc Psychiatry 12, i38-i46. doi: 10.1007/s00787-003-1106-8

Tasca, G., Kowal, J., Balfour, L., Ritchie, K., Virley, B., and Bissada, H. (2006a). An attachment insecurity model of negative affect among women seeking treatment for an eating disorder. Eat. Behav. 7, 252-257. doi: 10.1016/j.eatbeh.2005.09.004

Tasca, G., Ritchie, K., Conrad, G., Balfour, L., Gayton, J., Lybanon, V., et al. (2006b). Attachment scales predict outcome in a randomized controlled trial of two group therapies for binge eating disorder: an aptitude by treatment interaction. Psychother. Res. 16, 106-121. doi: 10.1080/10503300500090928

Tasca, G., Taylor, D., Bissada, H., Ritchie, K., and Balfour, L. (2004). Attachment predicts treatment completion in an eating disorders partial hospital program among women with anorexia nervosa. J. Pers. Assess. 83, 201-212. doi: 10.1207/s15327752jpa8303_04

Tasca, G. A., Balfour, L., Ritchie, K., and Bissada, H. (2007). The relationship between attachment scales and group therapy alliance growth differs by treatment type for women with binge-eating disorder. Group Dyn. Theory Res. Pract. 11, 1-14. doi: 10.1037/1089-2699.11.1.1

Tereno, S., Soares, I., Martins, C., Celani, M., and Sampaio, D. (2008). Attachment styles, memories of parental rearing and therapeutic bond: a study with eating disordered patients, their parents and therapists. Eur. Eat. Disord. Rev. 16, 49-58. doi: $10.1002 /$ erv.801
Troisi, A., Di Lorenzo, G., Alcini, S., Croce, N. R., Di Pasquale, C., and Siracusano, A. (2006). Body dissatisfaction in women with eating disorder: relationship to early separation anxiety and insecure attachment. Psychosom. Med. 68, 449-453. doi: 10.1097/01.psy.0000204923.09390.5b

Troisi, A., Massaroni, P., and Cuzzolaro, M. (2005). Early separation anxiety and adult attachment style in women with eating disorders. Br. J. Clin. Psychol. 44, 89-97. doi: 10.1348/014466504X20053

Van Ecke, Y. (2005). Immigration from an attachment perspective. Soc. Behav. Pers. Int. J. 33, 467-476. doi: 10.2224/sbp.2005.33.5.467

Van Ecke, Y. (2006). Unresolved attachment among immigrants: an analysis using the adult attachment projective. J. Gen. Psychol. 167, 433-442. doi: 10.3200/GNTP.167.4.433-442

van IJzendoorn, M. H., and Bakermans-Kranenburg, M. J. (1996). Attachment representations in mothers, fathers, adolescents, and clinical groups: a metaanalytic search for normative data. J. Consult. Clin. Psychol. 64, 8-21. doi: 10.1037/0022-006X.64.1.8

Viera, A. J., and Garrett, J. M. (2005). Understanding inter-observer agreement: the kappa statistic. Fam. Med. 37, 360-363.

Ward, A., Ramsay, R., and Treasure, J. (2000). Attachment research in eating disorders. Br. J. Med. Psychol. 73, 35-51. doi: 10.1348/000711 200160282

Ward, A., Ramsay, R., Turnbull, S., Steele, M., Steele, H., and Treasure, J. (2001). Attachment in anorexia nervosa: a transgenerational perspective. Br. J. Med. Psychol. 74, 497-505. doi: 10.1348/000711201161145

Waters, E., Crowell, J., Elliot, M., Corcoran, D., and Treboux, D. (2002). Bowlby's secure base theory and the social/personality psychology of attachment styles: work(s) in progress. Attach. Hum. Dev. 4, 223-229. doi: $10.1080 / 14616730210154216$

Webster, L., Hackett, R. K., and Joubert, D. (2009). The association of unresolved attachment status and cognitive processes in maltreated adolescents. Child Abuse Rev. 18, 6-23. doi: 10.1002/car.1053

West, M., and Sheldon-Keller, A. (1994). Patterns of Relating: An Adult Attachment Perspective. New York: Guilford Publications.

Woodside, D. B., Garfinkel, P. E., Lin, E., Goering, P., and Kaplan, A. S. (2001). Comparisons of men with full or partial eating disorders, men without eating disorders, and women with eating disorders in the community. Am. J. Psychiatry 158, 570-574. doi: 10.1176/appi.ajp.158.4.570

Zachrisson, H., and Kulbotten, G. (2006). Attachment in anorexia nervosa: an exploration of associations with eating disorder psychopathology and psychiatric symptoms. Eat. Weight Disord. 11, 163-170. doi: 10.1007/BF03327567

Zachrisson, H., and Skårderud, F. (2010). Feelings of insecurity: review of attachment and eating disorders. Eur. Eat. Disord. Rev. 18, 97-106. doi: 10.1002/erv.999

Conflict of Interest Statement: The authors declare that the research was conducted in the absence of any commercial or financial relationships that could be construed as a potential conflict of interest.

Received: 29 May 2014; accepted: 08 October 2014; published online: 28 October 2014. Citation: Delvecchio E, Di Riso D, Salcuni S, Lis A and George C (2014) Anorexia and attachment: dysregulated defense and pathological mourning. Front. Psychol. 5:1218. doi: $10.3389 /$ fpsyg.2014.01218

This article was submitted to Psychology for Clinical Settings, a section of the journal Frontiers in Psychology.

Copyright (C) 2014 Delvecchio, Di Riso, Salcuni, Lis and George. This is an openaccess article distributed under the terms of the Creative Commons Attribution License (CC BY). The use, distribution or reproduction in other forums is permitted, provided the original author(s) or licensor are credited and that the original publication in this journal is cited, in accordance with accepted academic practice. No use, distribution or reproduction is permitted which does not comply with these terms. 


\title{
The role of both parents' attachment pattern in understanding childhood obesity
}

\section{Claudia Mazzeschi ${ }^{1}$ *, Chiara Pazzagli ${ }^{1}$, Loredana Laghezza ${ }^{1}$, Giulia Radi ${ }^{1}$, Dalila Battistini ${ }^{2}$ and Pierpaolo De Feo ${ }^{3}$}

\author{
1 Department of Philosophy and Human Sciences, University of Perugia, Perugia, Italy \\ 2 Department of Psychiatry, School of Clinical Psychology and Psychiatric Rehabilitation, Perugia, Italy \\ ${ }^{3}$ Health Lifestyle Institute, Centro Universitario Ricerca Interdipartimentale per I'Attività Motoria, University of Perugia, Perugia, Italy
}

\section{Edited by:}

Silvia Salcuni, Dipartimento di

Psicologia dello Sviluppo e della

Socializzazione, Università degli Studi

di Padova, Italy

\section{Reviewed by:}

Michelle R. Lent, Geisinger Health System, USA

Gabriele Roberto Cassullo, Università degli Studi di Torino, Italy

*Correspondence:

Claudia Mazzeschi, Department of Philosophy and Human Sciences,

University of Perugia, Piazza Ermini 1, Perugia, Italy

e-mail: claudia.mazzeschi@unipg.it
Within the research area on the determinants of childhood obesity, a relatively new approach is the use of attachment theory to explore the mechanisms underlying children's obesity risk, especially considered as emotion regulation strategies in parent-child relationship. Few are the empirical researches that have addressed this issue. The empirical investigations have used self-report measures to assess adult attachment. In attachment studies, the use of interview methods and/or performance-based instruments is advised to evaluate the entire range of possible adult attachment patterns and comprehensively explain the emotional strategies, correlates, and consequences of individual differences in attachment system functioning. The aim of this study was to explore the extent to which both parents' attachment patterns serve as self-regulative mechanisms related to childhood overweight/obesity by the Adult Attachment Projective Picture System (AAP) in a sample of 44 mothers and fathers of children referred for obesity. Insecure attachment was found as a risk factor both for mothers and fathers. Also unresolved/disorganization was found to play a significant role in childhood obesity. The role of father's attachment was explored and findings suggested considering it in etiology and treatment of childhood obesity.

Keywords: parents' attachment, mother's attachment, father's attachment, childhood obesity, risk factor

\section{INTRODUCTION}

The need to deal with obesity at an early stage has become a priority due to the increasing prevalence of childhood obesity (Hollinghurst etal., 2014). The multifactorial nature of pediatric obesity, which is based on both genetic and environmental factors, requires a broad framework (Silventoinen etal., 2010; Harrison etal., 2011). Observational and experimental evidence reveals persistent effects of the early environment on eating behavior and obesity risk, highlighting the central role parents play in the onset of childhood obesity (Anzman et al., 2010).

At different levels of analysis, the literature on childhood obesity has recently begun to investigate the contribution of family factors in terms of the "neglect construct" (Hughes et al., 2005). These include variables with respect to both parental and family domains in etiology and treatment (Berge, 2009; Guilfoyle et al., 2010; Monasta et al., 2010; Lehto et al., 2012; Mazzeschi et al., 2013; Bost et al., 2014). To date, most studies have primarily focused on the consumption behaviors and parental feeding styles that characterize "obesogenic families" (Davison and Birch, 2002), although a number of research gaps have been identified (Zeller et al., 2007; Faith et al., 2011). Initial studies have predominantly focused on maternal factors rather than adopting a perspective that includes both mothers and fathers, and studies on the relationship between determinants of pediatric obesity and paternal role are very scarce (Wake et al., 2007; Freeman et al., 2010). It is critical to identify the relevant psychosocial/parental characteristics of both parents to extend our understanding of how parenting behaviors and interpersonal environments affect children (Lindsay et al., 2006; Harrison et al., 2011) and to explore the mechanisms that relate parenting variables to childhood obesity (Frankel et al., 2012; Bost et al., 2014).

From a theoretical point of view, a number of studies place obesity within the framework of attachment theory (Golan and Crow, 2004; Frankel et al., 2012) due to its power to relate parents' sensitivity in terms of the Internal Working Model (IWM) to the practice of feeding and regulating emotions in parents' relationships with their children (Fiese et al., 2012). Bost et al. (2014) has noted that insecure attached parents may use negative regulations strategies in response to children's distress, which has important consequences for interpersonal contexts involving food and the development of children's eating behaviors. Dyadic exchanges between the parent and child might affect food consumption through their effect on emotion regulation and parental feeding practices (Fiese et al., 2012). The classification of attachment patterns has identified two dimensions: secure vs insecure and organized vs disorganized attachment (Liotti, 2000; Rutter et al., 2009). The secure dimension enables us to distinguish individual differences in attachment patterns, identifying secure attachment and two types of insecure attachment (dismissing and preoccupied). The second dimension, which refers to the organization of the attachment pattern, distinguishes organized attachment (secure, dismissing and preoccupied) from disorganized one. In disorganized attachment, there is a lack of coherence and 
integration in attachment strategies in the face of separation. In the secure attachment pattern, the attachment figure provides emotional feedback and the parent's emotional availability enables the child to regulate his emotional experiences. Secure attached parents respond consistently and sensitively to the full range of infant emotions, thus allowing the infant to learn to self-regulate and develop strategies for managing increasing levels of arousal (Sloman et al., 2002). In contrast, insecure attached individuals tend to use regulatory strategies that are less flexible and adaptive. Insecure attached parents fail to regulate the children's emotional experiences and fail to protect their children and make them feel safe (Bowlby, 1980; Main and Hesse, 1990). Specifically, insecure attached dismissing individuals rely on deactivating strategies to regulate affect (Cassidy and Kobak, 1988). A deactivating emotional strategy leads dismissing parents to restrict their range of emotional expression and to detach from interactions that might trigger negative feelings (Magai, 1999). In contrast, insecure attached preoccupied individuals employ hyper-activating processes that elicit children's involvement (Mikulincer et al., 2003). In parenting, preoccupied parents inconsistently respond to their children's needs and provide few emotional anchors to assist their children in regulating their emotional states (Sloman et al., 2002; DeOliveira et al., 2005). Along the organized/disorganized dimension, the disorganized attachment pattern is characterized by the absence of a unitary or coherent pattern or strategy (Hesse and Main, 2000). The disorganized attachment pattern is associated with attachment-related experiences of unresolved loss or trauma/abuse (Solomon and George, 1999). Disorganized individuals use affective strategies in which painful attachment-related memories are isolated in segregated systems and blocked from conscious thought (Bowlby, 1980). The segregated systems are defined as unresolved when they are not integrated or contained at the representational level (George and West, 2001, 2011, 2012). Hesse and Main (2000) has hypothesized that the unresolved parent behaves in a frightened or frightening way toward the child, causing the infant to experience dysregulated fear in relation to the caregiver, which produces disorganization in the child's attachment strategy. Parental disorganized/unresolved attachment patterns are considered to be a strong risk factor for the child's development of maladaptive self-regulation strategies (Solomon and George, 1999; DeOliveira et al., 2005). The dysregulated emotional response of insecure or disorganized parents puts them at risk for ineffective parenting behaviors, which are frequently observed in studies of parental and familial functioning of overweight/obese children (Zeller et al., 2007; Moens et al., 2009; Sleddens et al., 2011; Lehto et al., 2012).

The few empirical studies focusing on the relationship between attachment and obesity have provided interesting data. Two studies investigated the association between the quality of early mother-child attachment and the later risk of child obesity. In a cohort study, Anderson and Whitaker (2011) assessed attachment with the Toddler Attachment Sort and examined the association between the attachment style observed in the mother-child relationship at 24 months of age and obesity at $4 \frac{1}{2}$; years of age. Results comparing secure to insecure attachment styles suggested that the insecure mother-child attachment style in early childhood was a risk factor for obesity. Similar findings emerged when insecure and disorganized attachment styles were combined and compared with the secure attachment style. In a later study, the observed poor quality of the early mother-child attachment relationship was also associated with a higher prevalence of obesity in adolescence (Anderson et al., 2012).

Only two studies have focused on the quality of parental attachment and the risk of childhood obesity. Using the Attachment Style Questionnaire, a significant prevalence of the insecure attachment style was found in the mothers of 30 children with obesity (Trombini et al., 2003). Recently, Bost et al. (2014) applied a mediation model to the investigation of the role of caregivers' attachment style on children's food consumption. The caregivers' attachment style was assessed with the Relationship Scales Questionnaire. The results indicated that insecure caregivers were more likely to report using negative emotion regulation strategies in response to their child's distress, planned mealtimes less often, and allowed their children to watch more television. Attachment was also correlated with feeding style; insecure parents reported using emotion-feeding pressure practices more often than secure parents.

Although these research studies have begun to provide empirical support for the theoretical proposal that insecurity of attachment is a risk factor for child obesity, they present a number of limitations. The reported studies have exclusively focused on the maternal contribution to the risk of pediatric obesity. Moreover, the two studies that assessed mothers' attachment patterns relied solely on self-report measures. In attachment studies, the use of interview methods and/or performancebased instruments is advised to evaluate the entire range of possible adult attachment patterns and comprehensively explain the emotional strategies, correlates, and consequences of individual differences in attachment system functioning. Jacobvitz et al. (2002) note that self-report measures of attachment elicit adults' conscious appraisals of themselves in attachment relationships. Adults' unconscious IWM and emotion-regulating processes, as well as the strategies developed by individuals to cope with the anxiety aroused by the narratives related to the attachment prompts, need to be explored to identify and overcome biases such as social desirability that can affect self-report results.

Based on the above considerations, the aim of this study was to explore the extent to which both parents' attachment patterns serve as self-regulative mechanisms related to childhood overweight/obesity. Paternal and maternal attachment was assessed by the Adult Attachment Projective Picture System (AAP; George and West, 2001), with other parental measures for anxiety and depressive symptoms. This performance-based measure was chosen because it is the instrument of choice for assessing adults' unconscious IWM and emotion-regulating processes. Maternal and paternal attachment patterns were analyzed separately to evaluate their different contributions to children's overweight/obesity. To date, no study has investigated the role of each parents' attachment pattern on child's obesity using narrative instruments or considered the specific characteristics of different types of attachment insecurity patterns and disorganization. Consequently, the specific aims of the present study were to: 
(1) investigate the role of both parents' secure/insecure organized and of disorganized/unresolved attachment patterns on child's overweight/obesity to extend the results of previous studies, which focused solely on the role of the mother's insecure attachment style; confronting parents' attachment pattern with data available from Italian normative sample

(2) analyze both parents' different attachment patterns to identify particular emotional regulation strategies; and

(3) explore the unique contribution of each parents' attachment pattern by employing both a two-way classification (secure vs insecure and organized/resolved vs disorganized/unresolved) and a four-way classification (secure, dismissing, preoccupied, and unresolved) to predict children's weight.

According to previous studies, we expect that mothers of overweight/obese children exhibit a predominantly insecure attachment. Because of the lack of studies regarding fathers' attachment and child obesity, no specific hypotheses are made. Considering attachment patterns as self-regulative mechanisms, we expect that mothers' and fathers' insecure attachment pattern predicts child BMI. Similarly, because of the fact that disorganized/unresolved attachment is a strong risk factor for dysregulation, we expect a prediction of the severity of child's BMI, both for mothers' and fathers' disorganized/unresolved attachment pattern.

\section{MATERIALS AND METHODS SUBJECT RECRUITMENT AND THE RESEARCH CONTEXT}

Data were collected at C.U.R.I.A.MO (Centro Universitario Ricerca Interdipartimentale per l'Attività Motoria), a center for childhood overweight-obesity treatment at the University of Perugia in Italy, approved by the local Ethics Committee (CEAS Umbria Region, HREC number 1/10/1633). The children, who ranged in age from 6 to 15 years, were referred to the center for overweight/obesity. Both caregivers provided written informed consent/assent after the families were briefed on the study; children provided verbal consent. The exclusion criteria were non-Italianspeaking caregivers, caregiver report of youth developmental delay or mental retardation or secondary overweight due to endocrinological diseases. Anthropometric measurement and psychological assessment were conducted by trained investigators, following standardized guidelines.

\section{SAMPLE}

The sample consisted of the mothers and fathers of 44 children referred for obesity/overweight to the CURIAMO. All the subjects were Caucasian. Parent's mean age was 42.2 years $(S D=4.7)$ for mothers and $45.6(\mathrm{SD}=4.7)$ for fathers. The socio-economic status of the families was medium-low (mean $=36.39$; $\mathrm{SD}=10.72$ ). The children mean age was 11.35 years $(\mathrm{SD}=2.9)$.

\section{MEASURES}

\section{Anthropometric measures}

To compute BMI, participants were measured for height and weight at the first medical examination. Weight was measured using a digital scale (BC-420S MA; Tanita, Sindelfingen, Germany); height was measured three times using a stadiometer, and the average height based on these readings was used.

\section{Parent measures}

State-Trait Anxiety Inventory Form Y. Anxiety was measured using the validated Italian version of the State-Trait Anxiety Inventory Form Y (STAI; Spielberger et al., 1970; Pedrabissi and Santinello, 1989). The STAI is a 40-item questionnaire measuring state (20 items) and trait (20 items) anxiety. Each scale consists of 20 items that are rated on a 4-point Likert scale ranging from 0 (none) to 4 (extremely high). The STAI assesses how respondents feel at the present moment (state) and how respondents generally feel (trait), indicating the extent to which the respondent experiences symptoms of anxiety. Total scores for trait and state anxiety range from 20 to 80 . The STAI has demonstrated good internal consistency, test-retest reliability for the STAI Trait, sensitivity to the detection of stress for the STAI State, and convergent and discriminant validity (Spielberger, 1989; Barnes et al., 2002; Vautier, 2004). The STAI State (mothers: $\alpha=0.90$; fathers: $\alpha=0.89$ ) and the STAI Trait (mothers: $\alpha=0.77$; fathers: $\alpha=0.81$ ) demonstrated good internal consistency in the present study.

Center for Epidemiologic Studies Depression Scale. This study used the Italian version of the Center for Epidemiologic Studies Depression Scale (CES-D; Fava, 1983), a 20-item, self-report measure originally designed for use in the general population that measures the frequency with which participants experienced specific symptoms of depression in the preceding week. The frequency of each symptom is rated on a scale ranging from 0 (rarely/none of the time, less than once a day) to 3 (most or all of the time, for 5-7 days). The CES-D test scores, which exhibit adequate internal consistency and test-retest reliability, correlate with clinical judgments and other self-report measures of depression, possess construct validity, and generate theoretically meaningful factors, such as depressed affect, somatic symptoms, and diminished positive affect (Radloff, 1977; Roberts, 1980; Fava, 1983; Iwata and Buka, 2002). The internal consistency of the scale in the present sample was good both for mothers $(\alpha=0.88)$ and fathers $(\alpha=0.86)$.

The Adult Attachment Projective Picture System. The AAP (George and West, 2001, 2011, 2012) is an adult attachment classification system based on the analysis of a set of projective stimuli. The AAP consists of a semi-structured interview procedure in which the client is asked to narrate a story for each of seven attachment picture stimuli (George and West, 2001, 2012). The stimuli portray scenes associated with attachment distress, such as the threat of separation, loss, illness, death, and solitude. The scenes represent children or adults alone (alone pictures) or in potential attachment-caregiving relationships (dyadic pictures). Individuals are asked to narrate a story for each image that refers to "what is happening in the situation, what led up to the scene, what the characters are thinking or feeling, and what might happen next." The AAP is audio-recorded and fully transcribed. Each AAP transcript is coded on seven scales grouped under the three major categories of discourse, content, and defensive processing. The AAP system identified also the individual's distinctive patterns of attachment defensive processes (Bowlby, 1980; George and Solomon, 2008). Two forms of defensive processing are regarded 
as normative or organizing forms of defensive exclusion. Deactivation is defined as attempts to dismiss, cool off, or shift attention away from attachment events, individuals, or feelings in response to the picture stimuli. The second organizing form of defensive exclusion, cognitive disconnection, disconnects the elements of attachment from their source, thus undermining consistency and the ability to maintain a unitary view of events, emotions, and the individuals associated with them. A third form of defensive processing, segregated systems, describes a mental state in which painful attachment-related memories rooted in experiences of trauma or loss through death are isolated and blocked from conscious thought (Bowlby, 1980). Segregated systems are identified in the AAP by content connoting fear, odd/disturbing material and emptiness. Segregated systems represent the failure of normative defenses and develop when attachment figures do not protect and comfort children when they are frightened or threatened, particularly in the context of attachment figure loss. The scoring of these dimensions by the classification system produces four adult attachment patterns: secure (F), dismissing (Ds), preoccupied (E), and unresolved (U; George and West, 2011; Lis et al., 2011). This is generally termed a four-way attachment classification. These four attachment patterns can be grouped into two two-way attachment classifications: secure vs organized insecure (dismissing and preoccupied); and resolved (secure, dismissing, and preoccupied) vs unresolved (George and West, 2012).

The AAP provides researchers and clinicians with a constructvalidated measure of attachment that preserves the emphasis on mental representation and defensive processes that is one of the primary features of attachment theory. For the purpose of establishing construct validity, the AAP has been validated using the Adult Attachment Interview (AAI; George et al., 1984/1985/1996), which exhibits a convergent agreement between the AAP and AAI for the four major attachment groups of 0.85 (kappa $=0.84, p<0.001$; George and West, 2001). The authors also found a strong inter-rater reliability of 0.86 (kappa $=0.79$, $p<0.001)$. The AAP provides good test-retest reliability. In one study, George and West (2001) found that $84 \%$ of the 69 participants were classified in the same category after 3 months (kappa $=0.78, p<0.001$ ). The most recent review of AAP reliability and validity results is presented in George and West (2012). In the present study, two highly trained AAP raters performed an independent and blind coding of 20 randomly selected protocols. Inter-rater reliability was assessed using the Cohen's (1990) kappa coefficient on AAP four-way attachment classification, and $\kappa=0.92$. The remaining protocols were then scored independently.

\section{DATA ANALYSIS}

Descriptive statistics for the samples were calculated as means and standard deviations or frequencies and percentages. Chi-square tests and Student's $t$-tests for paired samples were used to compare the mothers and fathers on the psychological features of anxiety, depression, and the distribution of attachment patterns. To investigate the unique contribution of mothers' and fathers' attachment to child BMI, three ANOVAs were separately performed for mothers and fathers: one for secure vs insecure organized (F vs $D s+E$ ), one for each of the four attachment patterns ( $F$ vs Ds vs $E$ vs
$\mathrm{U})$, and one for the resolved/organized vs disorganized/unresolved patterns $(\mathrm{F}+\mathrm{Ds}+\mathrm{E}$ vs $\mathrm{U})$. A Bonferroni post hoc analysis was performed due to the multiple comparisons of parent attachment patterns in the four-way ANOVA. Effect size was measured using partial eta-squares, with small, medium, and large effects of 0.0099, 0.0588, and 0.1379, respectively (Cohen, 1988). Pearson correlation coefficients were used to assess the association between child BMI and maternal/paternal anxiety and depression. To investigate the extent to which the attachment patterns of mothers and fathers predicted child BMI, three linear regression analyses were separately performed for mothers and fathers to test the effect of security, each attachment pattern ,and disorganization on child BMI. The data were analyzed using SPSS version 21.0 , and $p$-values of 0.05 or less were identified as statistically significant.

\section{RESULTS}

The mean child BMI was $26.61(\mathrm{SD}=4.6)$. Parent's mean BMI was 24.96 ( $\mathrm{SD}=3.79)$ for mothers and $27.27(\mathrm{SD}=3.45)$ for fathers. In terms of BMI classification (WHO), parents were overweight. With respect to anxiety and depressive mood, mothers' and the fathers' levels of state anxiety (mothers: $M=38.97$, $\mathrm{SD}=8.49$; fathers: $M=38.31, \mathrm{SD}=8.65$ ), trait anxiety (mothers: $M=40.88, \mathrm{SD}=6.20$; fathers: $M=40.38, \mathrm{SD}=6.69)$ and depressive mood (mothers: $M=14.35, \mathrm{SD}=10.03$; fathers: $M=12.30, \mathrm{SD}=9.16$ ) did not reach clinical level (cut-off $\geq 16$ ). Student's $t$-tests for paired samples revealed no significant differences between mothers and fathers for state anxiety $\left(t_{(44)}=0.183\right.$, $p=0.856)$, trait anxiety $\left(t_{(44)}=0.415, p=0.680\right)$ or depressive $\operatorname{mood}\left(t_{(44)}=0.234, p=0.324\right)$.

Frequencies and percentages were calculated for secure and insecure attachment, for the four attachment patterns, and for the resolved/organized vs unresolved/disorganized patterns between mothers and fathers (Table 1). Chi-square analyses revealed significant different distributions between parents for the secure and insecure attachment patterns $\left(\chi^{2}=5.236, d f=1\right.$, $p=0.022)$ and for the four attachment patterns $\left(\chi^{2}=18.17\right.$, $d f=9, p=0.032$ ). Qualitative analyses revealed that mothers exhibited significantly higher frequencies of the preoccupied attachment pattern compared to fathers, who exhibited higher frequencies of the dismissing pattern. There were no significant differences in the distribution of the resolved/organized and unresolved/disorganized patterns $\left(\chi^{2}=2.078, d f=1, p=0.14\right)$.

To compare mothers' and fathers' attachment patterns with a normative Italian sample, a Chi-square analysis was conducted using data from a meta-analysis (Cassibba et al., 2013). Findings revealed a significant different distribution for mothers $\left(\chi^{2}=24.49, d f=9, p=0.004\right)$ for the four-way pattern classification. Only the three-way distribution was available for fathers, and no significant association was found $\left(\chi^{2}=3.89, d f=4, p=0.421\right)$. The analyses of variance (ANOVAs) revealed that both mothers' and fathers' attachment patterns had a significant effect on child BMI that was different for the two AAP patterns (secure vs insecure: $F=36.806, p=0.001, \eta^{2}=0.429$ ) and the four AAP patterns $\left(F=23.139, p=0.001, \eta^{2}=0.547\right)$. The resolved/organized vs unresolved/disorganized pattern $(F=43.353, p=0.001$, $\left.\eta^{2}=0.386\right)$ also differentiated child BMI (Table 2 ). 
Table 1 | Frequencies and percentage for mothers and fathers on AAP attachment patterns.

\begin{tabular}{|c|c|c|c|c|c|c|c|c|c|}
\hline & & Secure & Insecure & $\boldsymbol{F}$ & $D s$ & $E$ & $U$ & Resolved & Unresolved \\
\hline \multirow[t]{2}{*}{ Mothers } & $N$ & 10 & 34 & 10 & 8 & 15 & 11 & 33 & 11 \\
\hline & $\%$ & $30.3 \%$ & $69.7 \%$ & $22.8 \%$ & $18.2 \%$ & $34 \%$ & $25 \%$ & $75 \%$ & $25 \%$ \\
\hline \multirow[t]{2}{*}{ Fathers } & $N$ & 7 & 36 & 7 & 19 & 5 & 12 & 32 & 12 \\
\hline & $\%$ & $24.3 \%$ & $75.7 \%$ & $16 \%$ & $42 \%$ & $13 \%$ & $29 \%$ & $72.7 \%$ & $27.3 \%$ \\
\hline
\end{tabular}

Children whose mothers exhibited a secure attachment pattern had lower BMIs than children whose mothers exhibited dismissing, preoccupied, or unresolved attachment patterns (Table 3). Based on the AAP classification, children whose mothers exhibited dismissing and preoccupied patterns had higher BMIs than children with secure attached mothers. The BMI of children with mothers who exhibited unresolved attachment was significantly higher than the BMI of children with secure attached mothers. The same trend was also found for fathers (Table 3).
The correlation analysis did not identify significant relationships between child BMI and parental state anxiety (mothers: $r=-0.041, p=0.718$; fathers: $r=-0.102, p=0.540)$, trait anxiety (mothers: $r=0.085, p=0.455$; fathers: $r=0.018, p=0.915$ ) or depressive mood (mothers: $r=-0.024, p=0.834$; fathers: $r=0.116, p=0.487)$. Study data were consistent with a recent systematic review and meta-analyses (Weng et al., 2012).

Three multivariate linear regressions were performed to measure the unique contribution of mothers' and fathers' attachment to child BMI (Table 4). In the first model, mothers $(F=16.41$,

Table 2 | Analysis of variance (ANOVA) for mothers' and fathers' attachment on child's BMI.

\begin{tabular}{|c|c|c|c|c|c|c|c|c|c|c|c|c|}
\hline & \multicolumn{12}{|c|}{ Mothers } \\
\hline & \multicolumn{4}{|c|}{$S$ vs $I$} & \multicolumn{4}{|c|}{ Four-way } & \multicolumn{4}{|c|}{$R$ vs $U$} \\
\hline BMI & 36.18 & 1 & 0.000 & 0.415 & 13.88 & 1 & 0.000 & 0.523 & 25.01 & 1 & 0.000 & 0.385 \\
\hline
\end{tabular}

Fathers

\begin{tabular}{|c|c|c|c|c|c|c|c|c|c|c|c|c|}
\hline & \multicolumn{4}{|c|}{$S$ vs $I$} & \multicolumn{4}{|c|}{ Four-way } & \multicolumn{4}{|c|}{$R$ vs $U$} \\
\hline & $F$ & $d f$ & $p$ & $\eta^{2}$ & $F$ & $d f$ & $p$ & $\eta^{2}$ & $F$ & $d f$ & $p$ & $\eta^{2}$ \\
\hline
\end{tabular}

Effect size measured using partial $\eta^{2}=0.001$ constitutes a small effect, 0.06 a medium effect, and 0.14 a large effect.

Table 3 | Means and standard deviations of child's BMI for mothers' and fathers' attachment.

\begin{tabular}{|c|c|c|c|c|c|c|}
\hline & \multicolumn{3}{|c|}{ Mothers } & \multicolumn{3}{|c|}{ Fathers } \\
\hline & $M$ & SD & Post hoc ${ }^{1}$ & $M$ & SD & Post hoc ${ }^{1}$ \\
\hline Secure & 23.47 & 2.35 & & 22.40 & 0.52 & \\
\hline Insecure & 28.10 & 2.55 & & 27.94 & 2.77 & \\
\hline Secure & 24.06 & 2.77 & $\mathrm{~F}<\mathrm{Ds}=\mathrm{E}<\mathrm{U}$ & 22.40 & 0.54 & $\mathrm{~F}<\mathrm{Ds}=\mathrm{E}<\mathrm{U}$ \\
\hline Dismissing & 27.57 & 3.04 & & 27.69 & 3.01 & \\
\hline Preoccupied & 28.53 & 1.92 & & 28.75 & 2.22 & \\
\hline Unresolved & 33.30 & 4.76 & & 33.30 & 4.76 & \\
\hline Resolved & 27.01 & 3.07 & & 26.68 & 3.42 & \\
\hline Unresolved & 33.30 & 4.77 & & 33.92 & 4.07 & \\
\hline
\end{tabular}

${ }^{1} F$, secure; Ds, dismissing; E, preoccupied; U, unresolved. 
Table 4 | Linear multivariate regression for mothers and fathers attachment patterns on child's BMI.

\begin{tabular}{llllll}
\hline & $\boldsymbol{R}$ & $\boldsymbol{R}^{\mathbf{2}}$ & $\boldsymbol{\beta}$ & $\boldsymbol{t}$ & $\boldsymbol{p}$ \\
\hline Mothers & & & & & \\
S vs I & 0.624 & 0.389 & -0.624 & -4.29 & 0.000 \\
Four-way & 0.671 & 0.450 & & & \\
Secure (F) & & & -0.578 & -4.84 & 0.000 \\
Unresolved (U) & & & 0.401 & 3.36 & 0.002 \\
$R$ vs U & 0.620 & 0.369 & 0.620 & 5.00 & 0.000 \\
\hline Fathers & & & & & \\
S vs I & 0.593 & 0.352 & -0.593 & -3.97 & 0.000 \\
Four-way & 0.770 & 0.593 & & & \\
Unresolved (U) & & & 0.505 & 5.82 & 0.000 \\
Secure (F) & & & -0.457 & -5.27 & 0.000 \\
$R$ vs $U$ & 0.629 & 0.375 & 0.629 & 4.35 & 0.000 \\
\hline
\end{tabular}

$p=0.000)$ and fathers $(F=14.19, p=0.000)$ attachment security both negatively predicted child BMI. In the second model, which included the four patterns, only the secure and the unresolved patterns made a significant contribution (mothers: $F=10.19$, $p=0.000$; fathers: $F=9.96, p=0.000$ ), while the dismissing and preoccupied patterns were excluded. In the third model, disorganized/unresolved attachment predicted child BMI for both mothers $(F=25.01, p=0.000)$ and fathers $(F=18.92$, $p=0.000)$.

\section{DISCUSSION}

This study contributes to the broader debate on the role of family factors in childhood obesity, specifically the role of parent attachment, by empirically investigating the characteristics and relationship of parent's attachment to child BMI in a sample of parents of children with overweight/obesity. As noted previously, few empirical papers have addressed this issue, and earlier findings, while promising, require further investigation. In this paper, the AAP was chosen for its power to capture attachment strategies and in order to overcome the limitations of the self-report measures (Jacobvitz et al., 2002) used in previous empirical research (Trombini et al., 2003; Bost et al., 2014). AAP produces four patterns (a four-way classification) near to secure vs insecure and organized/resolved vs disorganize/unresolved (George and West, 2012).

According to our hypothesis, mothers of overweight/obese children exhibit a predominantly insecure attachment as earlier literature showed (Trombini etal., 2003; Bost et al., 2014). This study also investigated fathers and found that they also exhibited insecure attachment patterns. To our knowledge, no previous studies had investigated the relationship between fathers' attachment and childhood obesity because the mother generally served as informant (Bost etal., 2014). In this sample of parents of overweight/obese children, attachment security was not the main feature neither for mothers nor for fathers. In the distribution of attachment of the Italian non-clinical mothers, the security emerges as the main feature (Cassibba et al., 2013).

With regard to the first aim, in the four specific patterns of attachment identified by the AAP, the mothers of the study were categorized as prevalently preoccupied, unresolved and secure, and fathers were categorized as dismissing, unresolved, and secure. The comparison of these patterns of parental attachment with the data available for both Italian normative samples and clinical/at risk samples (Cassibba et al., 2013) indicated that for the fourway classification, the mothers in the sample were more likely to exhibit the preoccupied and unresolved patterns compared to the non-clinical mothers. Moreover, this distribution was similar to the distribution of the clinical/at risk Italian normative sample, suggesting that mothers of overweight/obese children were more similar to mothers in the normative risk group than to mothers in the non-clinical normative sample. For the four-way classification, fathers were more likely to be classified as dismissing. The comparison of these findings with normative data indicates the need to also examine the role of the father and paternal attachment in childhood obesity.

With respect to the second aim, on the distinction between organized/resolved and disorganized/unresolved patterns of attachment, mothers and fathers in the study sample did not differ significantly. Mothers and fathers in the study were primarily classified as organized, although there was a higher prevalence of disorganized/unresolved attachment in the study sample compared to the normative sample (Cassibba et al., 2013). Findings indicated that parents of overweight/obese children differed from the non-clinical normative sample for the prevalence of disorganized/unresolved attachment and were more similar to the clinical/at risk normative sample. Moreover, the distribution of parental attachment categories was different for mothers and fathers.

According to George and West (2012), the preoccupied, dismissing, and unresolved patterns of attachment that were seen in the present study for mothers and fathers represent different ways of coping with attachment needs and intimacy. Shaver and Mikulincer's (2002) model claims that these three patterns represent different types of affect regulation in parenting. The preoccupied pattern of attachment relies on hyper-activating strategies (Cassidy and Kobak, 1988) at the cost of keeping the attachment system constantly activated and alert to the possibility of separation. Parents with this type of attachment pattern tend to respond inconsistently, be overprotective and interfere with their children's needs (Cassidy and Kobak, 1988). The dismissing strategy relies on deactivating processes that produce an emotional "distance" from attachment-activating experiences and emphasize self-reliance. Parents with this type of strategy keep the attachment system in check at the cost of emotional openness; they have low levels of emotional involvement in close relationships and deny basic needs. The disorganized/unresolved pattern lacks a coherent and unique strategy; parents with this type of pattern risk becoming deeply disturbed by their unresolved experiences and unable to alleviate their child's distress or develop their child's resources. Mothers and fathers of overweight/obese children exhibit affect regulation strategies that conflict with secure attachment patterns, which might be related to the child's level of overweight/obesity. 
The present study was able to identify some associations between parental attachment and childhood overweight/obesity. Mothers' and fathers' insecure attachment predicted child BMI. Children with insecure attached mothers exhibited higher BMIs. Similarly, fathers' insecure attachment was related to the severity of the problem. Consistent with the findings of Bost et al. (2014), insecurely attached parents may use negative regulation strategies in response to child distress, with important consequences for interpersonal contexts involving food and the development of children's eating behaviors. Findings for our sample indicated that secure attachment appeared to be a protective factor because children of secure mothers and fathers exhibited the lowest BMIs.

Regarding the role of the specific patterns of attachment to child BMI, study findings indicated that the dismissing and preoccupied patterns of attachment did not contribute differently to child BMI for either mothers or fathers. It was the overall aspect of insecure attachment that differentiated between mothers and fathers contribution to child BMI. The two insecure patterns (Ds and E) did not differentially contribute to the severity of the child's obesity. Moreover, according to our hypothesis, the unresolved/disorganized pattern contributed significantly to child obesity for both mothers and fathers and was related to the severity of the problem. Parents' unresolved attachment is held to be a strong risk factor for the child's development of maladaptive self-regulation strategies (Solomon and George, 1999; DeOliveira et al., 2005). This finding was confirmed by the comparison between child BMI and resolved/organized attachment, which found a significant difference in the severity of the child's overweight/obesity for both mothers and fathers. Moreover, both maternal and paternal disorganized attachment positively predicted the severity of the child's obesity. Study findings suggest that parental attachment potentially contributes to pediatric obesity, identifying an additional family component to the multiple sources of childhood obesity (Monasta et al., 2010). Specifically, study findings confirm evidence from earlier empirical research, which found that insecure and unresolved/disorganized parental attachment were risk factors for higher levels of childhood food intake. The present study provides the additional information that this relationship holds for both mothers and for fathers, although neither the dismissing nor preoccupied attachment patterns exerted a special or unique contribution to the severity of the child's weight problem. Another contribution was the finding that unresolved/disorganized attachment was a powerful risk factor for both mothers and fathers, confirming that the dysregulation of affect that characterizes this pattern of attachment might interfere with the parents' understanding of the child's needs and affect food intake.

Some limitations of the study should be noted. First, the sample size was not large and belonged to a medium-low socioeconomic status. Findings need to be used considering the small size of the sample and its socio-economical features. Because the specific focus of this paper was the investigation of the separate contribution of mothers' and fathers' attachment, parents' BMI was not used in the analysis. A previous work (Mazzeschi et al., 2013) showed the existence of a relationship between child and parent BMI. Further investigation are needed in order to put together, trough more complex model, the joint contribution of these variables in order to consider a broader range of possible factors influencing child BMI. A third limitation regards the fact that the study did not employ a normal weight control group, and comparisons were based on data from an Italian meta-analysis (Cassibba et al., 2013) that was primarily conducted using the distribution of categories derived from the use of AAI. If a high convergent agreement between AAP and AAI has been devised (George and West, 2012), some differences could be advocated with specific regard to the unresolved pattern of attachment and the possibility for AAP to assess different kinds of trauma or is severity (Delvecchio et al., 2013). More studies in this direction are needed, to better understand the separate and joint contributions of parents' attachment to childhood obesity. In spite of these limitations, findings from this study suggest how important is the role of parental attachment in child obesity and underline the need to be considered in order to develop effective treatment plans.

\section{AUTHOR CONTRIBUTIONS}

Claudia Mazzeschi: substantial contribution to the conception of the work, to the research design, to data collection and interpretation; drafting the work; final approval of the version. Agreement to be accountable for all aspects of the paper. Chiara Pazzagli: substantial contribution to the research design, to data interpretation; drafting the work; final approval of the version; agreement to be accountable for all aspects of the work. Agreement to be accountable for all aspects of the paper. Loredana Laghezza: contribution to data collection; substantial contribution to data analysis; drafting the paper; approval of the version to be published. Agreement to be accountable for all aspects of the paper. Giulia Radi: contribution to data collection. Agreement to be accountable for all aspects of the paper. Dalila Battistini: contribution to data collection. Agreement to be accountable for all aspects of the paper. Pierpaolo De Feo: contribution to data interpretation; revising the work; finally approval of the version. Agreement to be accountable for all aspects of the paper.

\section{ACKNOWLEDGMENTS}

The authors acknowledge the support of the EUROBIS project (www.eurobis.it), the C.U.R.I.A.MO project (www.unipg.it/ curiamo), and the Fondazione Cassa di Risparmio, Perugia.

\section{REFERENCES}

Anderson, S. E., Gooze, R. A., Lemeshow, S., and Whitaker, R. C. (2012). Quality of early maternal-child relationship and risk of adolescent obesity. Pediatrics 129, 132-140. doi: 10.1542/peds.2011-0972

Anderson, S. E., and Whitaker, R. C. (2011). Attachment security and obesity in US preschool-aged children. Arch. Pediatr. Adolesc. Med. 165, 235-242. doi: 10.1001/archpediatrics.2010.292

Anzman, S. L., Rollins, B. Y., and Birch, L. L. (2010). Parental influence on children's early eating environments and obesity risk: implications for prevention. Int. J. Obes. 34, 1116-1124. doi: 10.1038/ijo.2010.43

Barnes, L. L. B., Harp, D., and Jung, W. S. (2002). Reliability generalization of scores on the Spielberger State-Trait Anxiety Inventory. Educ. Psychol. Meas. 62, 603-618. doi: 10.1177/0013164402062004005

Berge, J. M. (2009). A review of familial correlates of child and adolescent obesity: what has the 21 st century taught us so far? Int. J. Adolesc. Med. Health 21, 457483. doi: 10.1515/IJAMH.2009.21.4.457 
Bost, K. K., Wiley, A. R., Fiese, B., Hammons, A., McBride, B., and STRONG KIDS Team. (2014). Associations between adult attachment style, emotion regulation, and preschool children's food consumption. J. Dev. Behav. Pediatr. 35, 50-61. doi: 10.1097/01.DBP.0000439103.29889.18

Bowlby, J. (1980). Attachment and Loss: Vol. 3. Sadness and Depression. New York: Basic Books.

Cassibba, R., Sette, G., Bakermans-Kranenburg, M. J., and Van IJzendoorn, M. H. (2013). Attachment the Italian way: in search of specific patterns of infant and adult attachments in Italian typical and atypical samples. Eur. Psychol. 181, 47-58. doi: 10.1027/1016-9040/a000128

Cassidy, J., and Kobak, R. R. (1988). "Avoidance and its relation to other defensive processes," in Clinical Implications of Attachment, eds J. Belsky and T. Nezworski (Hillsdale, NJ: Erlbaum), 300-323.

Cohen, J. (1988). Statistical Power Analysis for the Behavioral Sciences, 2nd Edn. Hillsdale, NJ: Lawrence Erlbaum.

Cohen, J. (1990). Things I have leatned (so far). Am. Psychol. 45, 1304-1312. doi: 10.1037/0003-066X.45.12.1304

Davison, K. K., and Birch, L. L. (2002). Obesigenic families: parents' physical activity and dietary intake patterns predict girls' risk of overweight. Int. J. Obes. Relat. Metab. Disord. 26, 1186-1193. doi: 10.1038/sj.ijo.0802071

Delvecchio, E., Pazzagli, C., Di Riso, D., Chessa, D., and Mazzeschi, C. (2013). Attachment pattern and cognitive skills: an exploratory study in an Italian nonclinical sample. Percept. Mot. Skills 116, 830-846. doi: 10.2466/03.10.PMS.116.3. 830-846

DeOliveira, C. A., Moran, G., and Pederson, D. R. (2005). Understanding the link between maternal adult attachment classifications and thoughts and feelings about emotions. Attach. Hum. Dev. 7, 153-170. doi: 10.1080/146167 30500135032

Faith, M. S., Butryn, M., Wadden, T. A., Fabricatore, A., Nguyen, A. M., and Heymsfield, S. B. (2011). Evidence for prospective associations among depression and obesity in population-based studies. Obes. Rev. 12, e438-e453. doi: 10.1111/j.1467-789X.2010.00843.x

Fava, G. A. (1983). Assessing depressive symptoms across cultures: Italian validation of the CES-D self-rating scale. J. Clin. Psychol. 39, 249-251. doi: 10.1002/10974679(198303)39:2<249::AID-JCLP2270390218>3.0.CO;2-Y

Fiese, B. H., Hammons, A., and Grigsby-Toussaint, D. (2012). Family mealtimes: a contextual approach to understanding childhood obesity. Econ. Hum. Biol. 10 365-374. doi: 10.1016/j.ehb.2012.04.004

Frankel, L. A., Hughes, S. O., O'Conner, T. M., Power, T. G., Fisher, J. O., and Hazen, N. L. (2012). Parental influences on children's self-regulation of energy intake: insights from developmental literature on emotion regulation. J. Obes. 2012, 327259. doi: 10.1155/2012/327259

Freeman, E., Fletcher, R., Collins, C. E., Morgan, P. J., Burrows, T., and Callister, R. (2010). Preventing and treating childhood obesity: time to target fathers. Int. J Obes. 36, 12-15. doi: 10.1038/ijo.2011.198

George, C., Kaplan, N., and Main, M. (1984/1985/1996). The Adult Attachment Interview. Berkeley: University of California.

George, C., and Solomon, J. (2008). "The caregiving system: a behavioral systems approach to parenting," in Handbook of Attachment: Theory, Research, and Clinical Applications, 2nd Edn, eds J. Cassidy and P. R. Shaver (New York, NY: Guilford Press), 833-856.

George, C., and West, M. (2001). The development and preliminary validation of a new measure of adult attachment: the adult attachment projective. Attach. Hum Dev. 3, 30-61. doi: 10.1080/14616730010024771

George, C., and West, M. (2011). The adult attachment projective picture system: integrating attachment into clinical assessment. J. Pers. Assess. 93, 407-416. doi: $10.1080 / 00223891.2011 .594133$

George, C., and West, M. (2012). The Adult Attachment Projective Picture System: Attachment Theory and Assessment in Adults. New York: Guilford.

Golan, M., and Crow, S. (2004). Parents are key players in the prevention and treatment of weight-related problems. Nutr. Rev. 62, 39-50. doi: 10.1111/j.17534887.2004.tb00005.x

Guilfoyle, S. M., Zeller, M. H., and Modi, A. C. (2010). Parenting stress impacts obesity-specific health-related quality of life in a pediatric obesity treatment-seeking sample. J. Dev. Behav. Pediatr. 31, 17-25. doi: 10.1097/DBP.0b013e3181c73641

Harrison, K., Kelly, K., Bost, K. K., McBride, B. A., Donovan, S. M., Grigsby-Toussaint, D. S., et al. (2011). Toward a developmental conceptualization of contributors to overweight and obesity in childhood: the six-Cs model. Child Dev. Perspect. 5, 50-58. doi: 10.1111/j.1750-8606.2010. 00150.x

Hesse, E., and Main, M. (2000). Disorganized infant, child, and adult attachment: collapse in behavioral and attentional strategies. J. Am. Psychoanal. Assoc. 48, 1097-1127. doi: 10.1177/00030651000 480041101

Hollinghurst, S., Hunt, L. P., Banks, J., Sharp, D. J., and Shield, J. P. (2014). Cost and effectiveness of treatment options for childhood obesity. Pediatr. Obes. 9, 26-34. doi: 10.1111/j.2047-6310.2013.00150.x

Hughes, S., Power, T., Fisher, J., Mueller, S., and Nicklas, T. A. (2005). Revisiting a neglected construct: parenting styles in a child-feeding context. Appetite 44, 83-92. doi: 10.1016/j.appet.2004.08.007

Iwata, N., and Buka, S. (2002). Race/ethnicity and depressive symptoms: a cross-cultural/ethnic comparison among university students in East Asia, North and South America. Soc. Sci. Med. 55, 2243-2252. doi: 10.1016/S02779536(02)00003-5

Jacobvitz, D., Curran, M., and Moller, N. (2002). Measurement of adult attachment: the place of self-report and interview methodologies. Attach. Hum. Dev. 4, 207215. doi: 10.1080/14616730210154225

Lehto, R., Ray, C., and Roos, E. (2012). Longitudinal associations between family characteristics and measures of childhood obesity. Int. J. Public Health 57, 495503. doi: 10.1007/s00038-011-0281-5

Lindsay, A. C., Sussner, K. M., Kim, J., and Gortmaker, S. (2006). The role of parents in preventing childhood obesity. Future Child. 16, 169-186. doi: $10.1353 /$ foc. 2006.0006

Liotti, G. (2000). Tipi e dimensioni dell'attaccamento nella terapia cognitiva. Psicobiettivo 20, 17-32.

Lis, A., Mazzeschi, C., Di Riso, D., and Salcuni, S. (2011). Attachment, assessment, and psychological intervention: a case study of anorexia. J. Pers. Assess 93, 434444. doi: 10.1080/00223891.2011.594125

Magai, C. (1999). "Affect, imagery, and attachment: working models of interpersonal affect and the socialization of emotion," in Handbook of Attachment: Theory, Research, and Clinical Application, eds J. Cassidy and P. R. Shaver (New York: Guilford Press), 787-802.

Main, M., and Hesse, E. (1990). "Parents' unresolved traumatic experiences are related to infant disorganized attachment status: is frightened and/or frightening parental behaviour the linking mechanism?," in Attachment in the Preschool Years, eds M. T. Greenberg, D. Cicchetti, and E. M. Cummings (Chicago: University of Chicago Press), 161-182.

Mazzeschi, C., Pazzagli, C., Laghezza, L., De Feo, P., Reboldi, P., and De Giorgi, G. (2013). Parental alliance and family functioning in pediatric obesity from both parents' perspectives. J. Dev. Behav. Pediatr. 34, 583-588. doi: 10.1097/DBP.0b013e3182a50a89

Mikulincer, M., Shaver, P. R., and Pereg, D. (2003). Attachment theory and affect regulation: the dynamics, development, and cognitive consequences of attachment-related strategies. Motiv. Emot. 27, 77-102. doi: 10.1023/A: 1024515519160

Moens, E., Braet, C., Bosmans, G., and Rosseel, Y. (2009). Unfavourable family characteristics and their associations with childhood obesity: a crosssectional study. Eur. Eat. Disord. Rev. 17, 315-323. doi: 10.1002/ erv.940

Monasta, L., Batty, G. D., Cattaneo, A., Lutje, V., Ronfani, L., Van Lenthe, F. J., et al. (2010). Early-life determinants of overweight and obesity: a review of systematic reviews. Obes. Rev. 11, 695-708. doi: 10.1111/j.1467-789X.2010. 00735.x

Pedrabissi, L., and Santinello, M. (1989). Manuale Ad. It. STAI-Y, Firenze: Organizzazioni Speciali.

Radloff, L. S. (1977). The CES-D scale: a self-report depression scale for research in the general population. Appl. Psychol. Meas. 1, 385-401. doi: $10.1177 / 014662167700100306$

Roberts, R. E. (1980). Reliability of the CES-D in different ethnic contexts. Psychiatry Res. 2, 125-134. doi: 10.1016/0165-1781(80) 90069-4

Rutter, M., Kreppner, J., and Sonuga-Barke, E. (2009). Emanuel Miller lecture: attachment insecurity disinhibited attachment, and attachment disorders: where do research findings leave the concepts? J. Child Psychol. Psychiatry 50, 529-543. doi: $10.1111 / j .1469-7610.2009 .02042 . x$ 
Shaver, P. R., and Mikulincer, M. (2002). Attachment-related psychodynamics. Attach. Hum. Dev. 4, 133-161. doi: 10.1080/14616730 210154171

Silventoinen, K., Rokholm, B., Kaprio, J., and Sørensen, T. I. (2010). The genetic and environmental influences on childhood obesity: a systematic review of twin and adoption studies. Int. J. Obes. 34, 29-40. doi: 10.1038/oby. 2011.304

Sleddens, E. F., Gerards, S. M., Thijs, C., de Vries, N. K., and Kremers, S. P. (2011). General parenting, childhood overweight and obesity-inducing behaviors: a review. Int. J. Pediatr. Obes. 6, 12-27. doi: 10.3109/17477166.2011. 566339

Sloman, L., Atkinson, L., Milligan, K., and Liotti, G. (2002). Attachment, social rank, and affect regulation: speculations on an ethological approach to family interaction. Fam. Process 41, 313-327. doi: 10.1111/j.1545-5300.2002. 41304.x

Solomon, J., and George, C. (1999). The caregiving system in mothers of infants: a comparison of divorcing and married mothers. Attach. Hum. Dev. 1, 171-190. doi: 10.1080/14616739900134221

Spielberger, C. D. (1989). State-Trait Anxiety Inventory: Bibliography, 2nd Edn. Palo Alto, CA: Consulting Psychologists Press.

Spielberger, C. D., Gorsuch, R. L., and Lushene, R. E. (eds). (1970). Manual for State-Trait Anxiety Inventory. California: Consulting Psychologist Press.

Trombini, E., Baldaro, B., Bertaccini, R., Mattei, C., Montebarocci, O., and Rossi, N. (2003). Maternal attitudes and attachment styles in mothers of obese children. Percept. Mot. Skills 97, 613-620. doi: 10.2466/pms.2003.97. 2.613

Vautier, S. (2004). A longitudinal SEM approach to STAI data: two comprehensive multitrait-multistate models. J. Pers. Assess. 83, 167-179. doi: 10.1207/s15327752jpa8302_11
Wake, M., Nicholson, J. M., Hardy, P., and Smith, K. (2007). Preschooler obesity and parenting styles of mothers and fathers: Australian national population study. Pediatrics 120, 1520-1527. doi: 10.1542/peds.2006-3707

Weng, S. F., Redsell, S. A., Swifth, J. A., Yang, M., and Glazebrook, C. P. (2012). Systematic review and meta-analyses of risk factors for childhood overweight identifiable during infancy. Arch. Dis. Child. 97, 1019-1026. doi: 10.1136/archdischild-2012-302263

Zeller, M. H., Reiter-Purtill, J., Modi, A. C., Gutzwiller, J., Vannatta, K., and Davies, W. H. (2007). Controlled study of critical parent and family factors on the obesigenic environment. Obesity 15, 126-136. doi: 10.1038/oby. 2007.517

Conflict of Interest Statement: The authors declare that the research was conducted in the absence of any commercial or financial relationships that could be construed as a potential conflict of interest.

Received: 13 May 2014; paper pending published: 09 June 2014; accepted: 05 July 2014; published online: 28 July 2014.

Citation: Mazzeschi C, Pazzagli C, Laghezza L, Radi G, Battistini D and De Feo P (2014) The role of both parents' attachment pattern in understanding childhood obesity. Front. Psychol. 5:791. doi: 10.3389/fpsyg.2014.00791

This article was submitted to Psychology for Clinical Settings, a section of the journal Frontiers in Psychology.

Copyright ( 2014 Mazzeschi, Pazzagli, Laghezza, Radi, Battistini and De Feo. This is an open-access article distributed under the terms of the Creative Commons Attribution License (CC BY). The use, distribution or reproduction in other forums is permitted, provided the original author(s) or licensor are credited and that the original publication in this journal is cited, in accordance with accepted academic practice. No use, distribution or reproduction is permitted which does not comply with these terms. 


\title{
The circle of security parenting and parental conflict: a single case study
}

\author{
Chiara Pazzagli ${ }^{1 *}$, Loredana Laghezza ${ }^{1}$, Francesca Manaresi ${ }^{2}$, Claudia Mazzeschi $^{1}$ and Bert Powell ${ }^{3}$ \\ 1 Department of Philosophy, Social and Human Sciences and Education, University of Perugia, Perugia, Italy \\ ${ }^{2}$ Astrea (Association for Therapy and Research in Developmental and Adult Psychopathology), Rome, Italy \\ ${ }^{3}$ Circle of Security International, Spokane, USA
}

\section{Edited by:}

Silvia Salcuni, Università degli Studi di Padova, Italy

Reviewed by:

Deborah Phillips, Harvard University, USA

Adriana Lis, University of Padova, Italy

\section{*Correspondence:}

Chiara Pazzagli, Department of Philosophy, Social and Human Sciences and Education. University of Perugia - Piazza G. Ermini 1, 06123 Perugia, Italy

e-mail: chiara.pazzagli@unipg.it
The Circle of Security Parenting (COS-P) is an early attachment based intervention that can be used with groups, dyads, and individuals. Created in the USA and now used in many countries, COS-P is a visually based approach that demonstrates its central principles through videos of parent/child interactions. The core purpose of the COS-P is to provide an opportunity for caregivers to reflect on their child's needs and on the challenges each parent faces in meeting those needs. Even though there is a wide range of clinical settings in which child/parent attachment is an important component of assessment there is limited empirical data on when and how attachment based interventions are appropriate for specific clinical profiles and contexts. The aim of this paper is to present a clinical application of COS-P in order to explore and reflect on some specific therapeutic tasks where it works and on some clinical indicators and contexts appropriate for its application. A single case study of a father, "M." (43 years old) in conflict for the custody of his 5 years old daughter is reported. The Adult Attachment Projective Picture System (AAP), the Parenting Stress Index, the Strengths and Difficulties Questionnaire, and the Parental Alliance Measure, were administered pre- and post-intervention. The clinical significance analysis method revealed that numerous changes occurred in the father. The AAP showed improvements in the level of agency of self. M. made gains in his capacity to use internal resources and to increase his agency of self. M. was classified as recovered in his perception of the child's functioning and as improved in his parenting stress and parenting alliance with the mother. Considerations on specific contexts and clinical indicators for the application of COS-P are proposed.

Keywords: attachment based intervention, support to parenting, single case study, secure base, pre-school age, parental conflict, circle of security parenting

\section{INTRODUCTION}

Numerous systematic intervention programs driven by attachment theory and research have been developed and early programs often involve problematic or at-risk parentschild relationships and are aimed to shift the developmental pathway in a more adaptive way (Van IJzendoorn et al., 1995; Zeanah et al., 2011). Parent's internal working models (IWMs), parenting behaviors, and the intervention process as an engine of therapeutic change are the three therapeutic tasks of attachment based interventions as defined by Berlin et al. (2008). The Circle of Security (COS; Marvin et al., 2002) intervention, and the Circle of Security Parenting (COS-P; Cooper et al., 2009) are directly derived from attachment theory and research, and are based on these three therapeutic tasks (Berlin et al., 2008). The COS intervention and the COS-P, have the same underlying model based on Ainsworth's idea of a Secure Base and a Haven of Safety (Ainsworth et al., 1978). The focus of both interventions is on helping parents develop reflective capacity regarding internal processes that drive problematic parent/child interactions as well as develop a coherent understanding of their child's attachment needs in order to break insecure parenting patterns.

In this article, we first discuss COS intervention characteristics in order to introduce the more recent COS-P, and then its clinical application through a single case study. The therapeutic tasks highlighted by Berlin et al. (2008) are used to identify the areas to be investigated by the use of a performance-based tool and self-reports. Finally, some clinical indications and contexts appropriate for COS-P application are discussed.

The COS intervention is an evidenced based intervention that joins psycho-educational, cognitive-behavioral, psychodynamic understanding and intervention techniques (Ramsauer et al., 2014). COS has been manualized as a time-limited group psychotherapy for parents of young children (aged 1-5). Intervention protocol is designed to promote: attachment security in early parent/child relationships through supporting and strengthening the caregiver's skills regarding perceptions and understanding of the child's needs; observational and inferential skills; reflective functioning; emotion regulation, and empathy for the distress that the caregiver's unregulated emotions cause in their children 
(Cooper et al., 2005; Powell et al., 2013). Increasing parental awareness of their child's exploratory and attachment needs helps the parent reflect and learn how their automatic maladaptive responses to those needs creates a problematic self-perpetuating feedback loop. That loop feeds painful unregulated parental affect that can lead to the triggering of their child's insecure attachment strategies (Marvin et al., 2002; Hoffman et al., 2006; Powell et al., 2009).

A central element of COS intervention is the use of multiple graphics and videos. The COS graphic is a map that allows parents to follow their child's relationship needs, helping the parent become more emotionally available to them. Using animated graphics, the alternating child's attachment and exploration needs in a "secure base" relationship are figuratively illustrated as a "circle of security."

Parents are invited to identify and reflect on the specific child's needs within the activation of the exploratory system, and within the activation of the attachment system, together with providing a supportive presence to respond to their child's needs (Page and Cain, 2009). Videotapes are used extensively to promote parental reflection on parent/child interactions. Review of selected video clips of parent/child interaction allows immediate feedback that enhances the parents' awareness of how interactive behaviors affects their child's responses. Highlighting positive moments in the parent/child interactions is used to facilitate the engagement of difficult-to-reach caregivers (McDonough, 2000, 2004).

In order to tailor the intervention for each dyad's needs (caregiver/child) a preliminary standardized assessment procedure is used to identify both the strengths and struggles in the dyadic relationship. A parent perception interview is used (Circle of Security Interview) to understand the parent's IWMs (Bowlby, 1973) that includes positive and negative child representations and a clinical model to organize treatment based on core defensive relationship strategies used by each parent. The assessment is also based on a systematic observation of parent/child interaction (Ainsworth et al., 1978; Cooper et al., 1999). Edited clips from the preliminary systematic observation of parent/child interaction are used to "individualize" videos of the participating dyads that will be shown during group intervention.

Relatively new is the creation of the COS-P which is a parenteducation program offering the core components of COS intervention protocol (Cooper et al., 2009). COS-P occurs in eight sessions that join education about attachment with an opportunity for caregivers to reflect on their child's needs and the challenges each parent faces in meeting those needs (Zeanah et al., 2011). COS-P aims to implement decades of attachment research in an accessible step-by-step process for use in group settings, home visitation, or individual counseling.

COS-P is implemented in eight sessions (Cooper et al., 2009). In the first sessions, the parent is introduced via animated graphics and video clips to the "Circle of Security" roadmap illustrating the child (and adult's) alternating needs for attachment and exploration, together with the need for a supportive parental presence. The parent is accompanied to individualized their child's attachment needs behind the child behavior, and the profound effect of experiences in which child's needs are met ("BeingWith") or unmet ("Being-Without") in the caregiver relationship.
In the central part of the program there is a shift from the child to the caregiver where caregiver proper functioning is depicted as being always bigger, stronger, wiser, and kind, take care of the child's needs when possible, and take charge when necessary. Limited circles are then introduced, both the insecure, where the caregiver is able to meet only the attachment or exploration needs of the child, and the disorganized circle, where parent is frightening/frightened being mean, weak or gone, i.e., mentally absent. After this the parent is encouraged to reflect on his own needs and vulnerabilities with the aid of music (i.e., "Shark Music"), illustrating how unregulated and perceived dangerous affects influences and shapes caregiving. When the completion of the limited circles is more possible, then parental reflective function on unregulated emotional responses to the child's behavior is enhanced. The parent is guided in a new way to stay with the child's needs as a solution to relationship struggles, and the experience of disruption and repair acquires a central role in the sessions. Lastly, key relationship challenges are reviewed and positive changes are highly remarked.

COS-P is designed to be more scalable and less intense than COS intervention. With COS-P preliminary standardized assessment is not performed, video is not tailored to each dyad's specific needs, and the number of weeks in which it takes place is less. Rather than "individualized" videos of the participating dyads and of the responses from the pre-intervention interview, COS-P uses DVDs of archived videotapes that are selected as prototypical examples of parent/child interactions. Those DVDs contain videos of secure and problematic parent/child interactions, healthy caregiving options and are used in conjunction with attachment related animated graphics designed to clarify the central principles of the intervention.

The COS-P has the advantage of being more flexible in terms of timing, practicality and more adaptable for community-based use while the COS intervention requires a significant investment in terms of space, video equipment, and preparation time. Hoffman et al. (2006) pointed out the need for research on the efficacy of COS-P and on the intervention on only one parent (or couple) at a time.

The present paper aimed to show a clinical application of COS$\mathrm{P}$ in order to reflect on some specific therapeutic tasks where it works and on some contexts and clinical indicators appropriate for its application. The case study presented involves a father in conflict for the custody of the 5 years old daughter. This case study was chosen because it involved a high level of parental conflict for child custody which is considered one of the four clinical contexts in which attachment perspective should have a central role (Zeanah et al., 2011) and because it might have been able to demonstrate change in long-term unresolved parental conflict.

With a pre/post-intervention design, a performance-based tool and self-report questionnaires were administered to the father. According to Berlin's et al. (2008) therapeutic tasks of attachment based interventions, parent's IWMs and parenting behavior were chosen to be assessed. Possible changes in parenting alliance were also assessed. The co-parenting relationship has been identified as having significant effects on parent/child relationship (Gable et al., 1994; McHale and Rasmussen, 1998; Frosch et al., 2000). Research has shown significant associations 
between higher parenting alliance and better parenting, less parenting stress and fewer attachment relationship difficulties with the child (Cohen and Weissman, 1984; Frank et al., 1991).

This study was designed to explore the presence of improvements into the following: (a) parental IWMs, particularly the underlying functioning dimensions of IWMs via a performancebased attachment tool; (b) parenting behaviors measured via a self-report that assessed parenting stress in child rearing. A selfreport regarding the child was also administered to evaluate changes in parental perception of child's behavioral adjustment, and positive and negative parent attributions of the child's characteristics; (c) parenting alliance measured with a self-report.

\section{MATERIALS AND METHODS CASE PRESENTATION}

M., a 43-year-old male, arrived at a private psychotherapist requesting help to improve his parenting capacities with his 5 years old daughter. His main goal was to demonstrate that he was a good father and to obtain the daughter's custody having a chronically unresolved conflict with the child's mother. M. lived with the mother of his daughter for one year and because of their high conflict they decided to not marry. He recounts that he didn't want children but that after his daughter's birth he became very involved in her caretaking. M. reported that the child's mother didn't want him to care their daughter and he was deeply convinced that the child's mother only wanted money from him. He described his daughter as difficult to manage and having severe behavioral and emotional problems such as concentration difficulties, impulsivity and nervousness. $M$. appeared highly distressed by the quality of his relationship with his daughter, but responsibility for all his daughter's difficulties were attributed exclusively to her mother or to specific intrinsic characteristics of the child. He showed low empathy and awareness of his child's needs and low reflective capacity regarding his own internal processes.

When M. started treatment, the situation was characterized by high levels of parental conflict for child custody as he and the child's mother each had an attorney and the level of antagonism and aggressiveness between the parents was increasing. The request to improve his parenting capacities seemed to be moved mainly by the conflict with the child's mother. M. seemed more motivated by the desire for revenge against the mother than to find new ways to connect with his daughter. The COS-P program was offered within the context of individual therapy with the aim of helping him shift his focus from parental conflict and management of the child's behavior to the improvement of the quality of his caregiving relationship with his child. Supporting his parenting capacities and self-reflection would help him recognize and respond more directly to his child's needs.

\section{PROCEDURE}

Pre- and post-intervention assessments were administered with M. before and 10 days after he completed the 8-week program. The clinician was a female psychologist-psychotherapist who completed the 4-day COS-P training and registered as a COS Parent Educator. The Italian version of COS-P program DVDs were used (COS-P Italian). With a pre/post-intervention design a series of measures were used to assess M.'s attachment status, parental behavior, parental perception of child's behavioral adjustment, and the level of co-parenting alliance. The performance-based tool and the self-report questionnaires were administered in two different sessions 1 week apart. The Adult Attachment Projective Picture System protocols were coded by two reliable judges qualified for coding.

\section{MEASURES}

\section{The Adult Attachment Projective Picture System (AAP; George and West, 2001)}

The AAP measures adult attachment status based on the analysis of a set of projective stimuli. It consists of eight cards with line drawings on them: a neutral warm-up scene and then seven scenes depicting increasingly difficult attachment threats. The scenes represent children or adults alone (Alone pictures) or in potential attachment-caregiving relationships (Dyadic pictures). Subjects are asked to tell stories related to the pictures in which they have to describe what is going on in the picture, what led up to the scene, what characters are thinking or feeling and what might happen next. The stories are recorded, transcribed verbatim, and rigorously coded. Coding include seven dimensions that evaluate patterns of responses and the attachment content story. On basis of this set of dimensions, the protocols are classified into four attachment groups: Secure (F), Dismissing (Ds), Preoccupied (P), and Unresolved (U). The seven dimensions are included in three major categories: story content, discourse, and defensive process. The story content related to the hypothetical characters portrayed in the stimuli, included agency of self and connectedness for alone stories and synchrony for dyadic pictures (George and West, 2011). The agency of self is the capacity to maintain the self-integrity and to preserve organized thought and behavior in stressful contexts (e.g., solitude, death, isolation). There are three degrees to which the self moved psychologically or behaviorally toward the empowerment or integration: (1) exploring own IWMs, through descriptions of genuine self-reflection or thoughtfulness; (2) using the relationships to re-establish attachment equilibrium and to assuage or calm the attachment system; (3) engaging in behaviors that produces change (West and George, 2002). The connectedness assesses the desire and ability of the individual to be connected to the other in intimate attachment, friendship, or partnered relationships. The synchrony assesses the degree to which the individual is able to describe reciprocal interaction. The discourse codes evaluate the ability to maintain the self-other boundaries, and personal experiences indicate a loss of distance from the tables. The defensive processes, protecting from attachment stressful stimulus, are: deactivation, cognitive disconnection, and segregated systems. Deactivation process produces a distance between the individual and the attachment-activating event and is coded for story themes that underline the importance of rules, social scripts, power, achievement, and authority. The cognitive disconnection processes disconnect the elements of attachment from their source, thus undermining consistency and the capability of holding in one's mind a unitary view of events, emotions, and the individuals associated with them (George and West, 2011). Cognitive disconnection describes a form of defensive exclusion associated 
with uncertainty, ambivalence, and mental preoccupation with experiences, individuals, or feelings. Finally, segregated system describes a mental state in which painful attachment-related memories are isolated and blocked from conscious thought.

The AAP provides to researchers and clinicians with a construct-validated measure of attachment that preserves the emphasis on mental representation and defensive processes that is one of the primary features of attachment theory. The AAP has been validated using the Adult Attachment Interview (AAI; George et al., 1996) classification, with a convergent agreement between both for the four major attachments groups was 0.85 (kappa $=0.84, p<0.001)$ (George and West, 2001, 2014). Studies have shown a strong inter-judge reliability of 0.86 (kappa $=0.79$, $p<0.001)$. The AAP has shown a good test-retest reliability as George and West (2001) found that with a sample of 69 participants after 3 months $84 \%$ were classified in the same categories $($ kappa $=0.78, p<0.001)$.

\section{The Parenting Stress Index-Short Form (PSI-SF; Abidin, 1995)}

The PSI-SF is a 36 -item self-report measure of parenting stress in the parent/child relationship and consists of 3 subscales, each with 12 five- point Likert scale that ranges from 1 (strongly agree) to 5 (strongly disagree). The "Parent-Child Dysfunctional Interaction" subscale reflects parent/child relationship difficulties (range 12-60) (e.g., My child smiles at me much less than I expected). The "Parental Distress" subscale reflects parental stress experienced when raising own child (range 12-60) (e.g., There are quite a few things that bother me about life) and the "Difficult Child" subscale (range 12-60) (e.g., I think my child is very moody and easily upset). PSI-SF has been validated with studies showing reduction in parenting stress following parent training (Abidin, 1995), positive correlation with child disruptive behaviors (Ross et al., 1998), positive relationship with maternal depression (Webster-Stratton, 1988), and negative association with parents' sense of competency (McBride, 1989). PSI-SF internal consistency is high $(\alpha=0.91)$, and test-retest reliability over a 6-month retest interval is good for the Total Stress score $(r=0.84)$ (Abidin, 1995). In this paper the Italian version was used and results compared with Italian normative data (Guarino et al., 2008).

The Strengths and Difficulties Questionnaire (SDQ; Goodman, 1997) SDQ is a brief behavioral screening questionnaire for emotional, relational, and behavioral disorders in children and adolescents aged 4-16 years (Goodman, 1999; Goodman and Scott, 1999; Mathai et al., 2002). The SDQ consists of 5 groups of 5 items each (25 items total): emotional symptoms, conduct problems, hyperactivity/inattention, peer relationship problems, and pro-social behavior. Responses to each of the 25 items consisted of 3 options: not true, somewhat true, or certainly true. For all scales, negatively worded items are assigned scores of 2 for certainly true, 1 for somewhat true, and 0 for not true. Response to all other questions scored $0,1,2$ so that a higher score indicated higher risk of emotional and behavioral problems. SDQ has been found to have good psychometric features both in clinical and non-clinical samples (Goodman and Scott, 1999; Goodman, 2001). The psychometric data indicated a mean internal consistency of 0.73 as measured with Chronbach's alpha (Goodman, 2001). The Italian version was used (Di Riso et al., 2010) and results compared with UK Normative data (Goodman, 2001) being Italian normative data for preschool children not available.

\section{The Parenting Alliance Measure (PAM; Konold and Abidin, 2001)}

The Italian version of PAM scale was used to evaluate the co-parenting alliance (Camisasca et al., 2013). The PAM is a 20 -item self-report instrument that assesses the strength of the perceived alliance between parents of children aged 1-19 years. This instrument assesses the parenting aspects of a couple's relationship (e.g., the levels of cooperation, communication, and mutual respect they exhibit with regard to their children's care). Parents respond to the items using a 5-point Likert scale that ranges from 1 (strongly disagree) to 5 (strongly agree), with a total possible range of 20-100, with higher scores indicating a stronger co-parenting alliance and greater reciprocity in the parental role. Previous studies have reported that PAM scores are positively correlated with marital quality and family functioning and negatively correlated with parenting stress and maladaptive family functioning (Feinberg et al., 2007). The PAM has demonstrated good psychometric characteristics with high degree of internal consistency $(\alpha=0.97)$ and a good test-retest reliability $(r=0.80)$ (Konold and Abidin, 2001). Results were compared with USA normative data (Konold and Abidin, 2001) because Italian normative data are not available.

\section{DATA ANALYSIS}

The clinical significance analysis method proposed by Jacobson and Truax (1991) ("JT method") for case studies using selfreport measures from pre to post-intervention was used. The JT method proposes a two-step criterion: (a) by the end of therapy, client should change from a dysfunctional range to a functional range; and (b) the magnitude of the change should be statistically reliable (McGlinchey et al., 2002). In order to evaluate the statistically reliable magnitude of the change, the reliable change index (RCI) was used (Jacobson et al., 1984). The $\mathrm{RCI}$ is the change in a client's pre- and post- treatment score divided by the standard error of the difference for the test being used. The RCI shows whether clients changed sufficiently such that the change exceeds measurement error. If the RCI is 1.96 or greater, the change in scores because of treatment is statistically significant (1.96 equates to the $95 \%$ confidence interval). Based on the two criteria, the JT method classifies individual as: recovered, if both criteria are passed; improved, if the RCI but not the cut-off criteria is passed; unchanged, if neither criteria are passed; and deteriorated, if the RCI criteria is passed but the direction of change is toward dysfunction (Carlson et al., 2012).

\section{RESULTS}

\section{THE ADULT ATTACHMENT PROJECTIVE PICTURE SYSTEM (AAP; George and West, 2001)}

General AAP attachment classification is discussed below. M.'s responses to some AAP pictures are then presented followed by a description of the story's unique feature of attachment interpreted using the AAP coding system. Pictures presented were selected as 
examples of significant changes in the underlying dimension of IWMs functioning.

\section{ATTACHMENT CLASSIFICATION DISCUSSION}

M.'s AAP pre and post were both coded and classified as insecure, specifically as Dismissing (Ds), because of his prominent use of the deactivation defense that allowed him to maintain distance in relationships. Stories often shifted attention away from distress to focus only on achievement or exploration. When distress was evident, he was quite able in describing what appeared on the surface, but the focus was typically superficial and not on the attachment relationship. Deactivation remained the principal way in which he minimized the influence of attachment stimuli, keeping strict self-other boundaries in relationships. M.'s modality to solve problems was modified from the exclusive use of action (agency $=$ capacity to act) to the use of thoughtful and selfexploration to manage distress evoked to the attachment stimulus (i.e., internalized secure base). Some stories of the post intervention phase suggested that M. began to display sufficient personal resources to allow him to better mentalize internal conflicts and build stable, cohesive internal representations of attachment figures. These can be considered as signal of a potential change and constitutes a positive sign of his ability to utilize the intervention for self-reflection and personal growth. Attachment figures are portrayed generally as providing functional care, but the level of synchrony was little bit improved from pre to post intervention. In the first protocol, the characters were described in a functional relationship and there was no mutually reciprocal interaction. In the second protocol with the bed pictures, the characters were portrayed in a reciprocal and mutually engaging relationship. M. showed gradual improvements in his capacity to identify and respond to his own and other's attachment-related needs.

\section{Bench}

Pre: A person ...mh ...a little bit ... a little bit preoccupied ... maybe she had to loose her home or she is preoccupied because she had received a bad break... relative's death or a economic loss or home's loss...I don't know if she is outside or if she is indoors ...perhaps in a closed room, she refuses help ... the bench is in a closed room and she stays there perhaps because she had a problem and she is waiting to be moved to another place more comfortable (What might happen next?) She could be better and she gets up and goes out (Anything else?) No.

Post: A woman staying on a bench in front of wall but... Initially it looks like a prison but then I see the grass and so I think that she outside in a garden. She sleeps and she thinks. She reflects and thinks about her life, about her projects, her difficulties, what she wants to do... then she can also sleep. (What might happen next?). She will wake up and she will go for a walk. (Anything else?) No.

In the first story, the loneliness of the bench picture triggered segregated feelings of emptiness, isolation, and danger (lost, death). M. could only describe the segregated system and he was unable to envisage being connected to attachment figures or any other human beings at this moment. He demonstrated a capacity for reorganization through the girl's ability to make a decision, to take action and go out. This representational action designates a shift in the mindset that prevents him from becoming completely disorganized. In the post-intervention story, the bench picture stimulus has given the first indication of his ability to use solitude for self-exploration and inner reflection. Although he didn't articulate what the problem was about, the character in the scene was portrayed as using a self-reflective activity in an autonomous way, on his own initiative. Here M.'s change in managing the source of distress is noted as he shifted from a functional solution, to the use of a thoughtful and self-exploration solution.

\section{Bed}

Pre: I see very clearly me and $C$. when she did not want to sleep and I stayed with her for a long time, I prepared all things in a comfortable way, for example the computer for the cartoons. I said "good night" to her and after a while she calls me and I stay close to her ... to give her a hug and to caress her...It's a story of a boy that doesn't want to go bed. He needs his parent to be close to him because he is upset and he isn't relaxed... The parent tries to explains to him that it is time to sleep and then he gives him a hug... could be the scene before that the parent stays more close to his son or the scene when the son calls the parent or the scene after the hug when the child is ready to sleep... In reality I must go to my daughter again four times before she falls asleep... I get up, I get the glass of water and I take it to her and then she wants chocolate ... this scene is very similar to what happen with C. (Anything else?) No.

Post: A mother with her child ... the child asks her for a hug or to take himself in her arms. He is awake and with open arms. When he looks at his mother he wants to take her in his arms. She is a caring mother and she hugs her son. (What are they thinking and feeling?) The child wants to be hugged and the mother has a pain in her hand but she will be a good mother and be there. (What might happen next?) They prepare themselves and then go out. (Anything else?) No.

In the pre-intervention story, material about the father's own experience was present. M. is being consciously reminded of events from his own life. The second story was free from M.'s personal experience as he was able to tell a story about hypothetical characters and events without autobiographical elements. In father's second stories, the mother responds promptly and appropriately to the child's need. This suggests a healthy capacity to appeal to attachment relationships for comfort, with the clear expectation that it will be provided. However, there was also an attempt to shift attention away from attachment events: the child's need of care was neutralized by deactivating defenses with a theme that emphasized the importance of a social rule (the mother has a duty to perform).

\section{Cemetery}

Pre: $\mathrm{He}$ is a man that reads an inscription on the gravestone of his relative or friend or stranger... I'm not able to find a link between him and the gravestone but at the same time I think that there's neither a close parent nor a stranger...I think that it is a person known in books... it's a gravestone of an author, a historic character.. The man remembers the cultural and philosophic message of this writer (What might happen next?). Then the man returns home. (Anything else?) No.

Post: A man stands in front of a gravestone... he is a little bit sad and he remembers a friend or a particular person for him. It's a classic 
Sunday visit to the cemetery. The man thinks about the peculiarities of his friend and about the beautiful things they did together. (What might happen next?) and then he prays and returns home and he is satisfied with this moment. (Anything else?) No.

In the two stories, this picture stimuli evokes in M. feelings of loss, a common theme, thus suggesting that the attachment conflict is recognized. In both stories, he attempted to neutralize feelings through deactivation by invoking concepts of social roles. In the post-intervention story, he referenced his IWMs of attachment by thinking about the deceased. The story regarded a deceased person with whom the character has had a relationship and who influenced the character in some way. The description involved genuine self-reflection and thoughtfulness. M. became more able to refer to internal state in which security and selfintegrity are derived from his internalized relationship to the attachment figure.

\section{THE PARENT STRESS INDEX-SHORT FORM (PSI-SF; Abidin, 1995)}

In the pre-intervention phase, $M$. experienced more stress than the average parent and scored in a clinical range (Total Stress Score $=95^{\circ}$ percentile). His score indicated that he was very distressed in his parenting abilities and he felt that he was not able to respond to parenting tasks (Parental Distress $=90^{\circ}$ percentile). He was also highly distressed by the quality of his relationship with his daughter. M.'s daughter didn't meet his expectations. M. felt alienated from his child and felt to some degree rejected by the child's behavior (Parent Child Dysfunctional Interaction $=90^{\circ}$ percentile). He perceived his daughter's behavior as excessively disruptive or destructive to their relationship (Difficult Child $=$ $95^{\circ}$ percentile).

After participating in COS-P, using to JT method, M.'s results had significantly changed resulting recovered in parenting stress for the Parental Distress subscale and improved for the Total Score and Child Dysfunctional Interaction subscale. The scale for the Difficult Child subscale remained unchanged. In the postintervention phase, M.'s level of parenting stress significantly improved and at this time, it fell in the borderline range (Total Stress Score $=84^{\circ}$ percentile). He perceived that his lower distress was linked to his features as a parent and he felt that he was more able to manage his child's needs and requests with the score in the average range (Parental Distress $=60^{\circ}$ percentile). In addition, significant improvement was observed in the father-child relationship. M. appeared more attuned with his child and their interaction and the dyad demonstrate increased mutual involvement (Parent Child Dysfunctional Interaction $=$ $70^{\circ}$ percentile). No changes in the perception of child problems was found (Difficult Child $=90^{\circ}$ percentile) $($ Table $\mathbf{1}$ ).

\section{THE STRENGTHS AND DIFFICULTIES QUESTIONNAIRE (SDQ; Goodman, 1997)}

The Total Difficulties Score indicated a high risk of clinically significant problems. Difficulties were in the behavioral and social areas. M. rated his child as having severe difficulties of attention, concentration, and hyperactivity problems. He also indicated that his daughter had problematic relationship with peers. M. described her as solitary, not having many friends and getting along better with adults than with other children. He observed
Table 1 | Father's self reports scores pre- and post-intervention.

\begin{tabular}{lccc}
\hline Measures & Pre-intervention & Post-intervention & RCI \\
\hline PSI-SF total stress score & 101 & 84 & $\geq 1.96$ \\
PSI-SF parental distress & 35 & 25 & $\geq 1.96$ \\
$\begin{array}{l}\text { PSI-SF parent-child } \\
\text { dysfunctional interaction }\end{array}$ & 29 & 24 & $\geq 1.96$ \\
PSI-SF difficult child & 37 & & \\
SDQ total score & 19 & 35 & $<1.96$ \\
SDQ emotional & 2 & 10 & $\geq 1.96$ \\
symptoms & 3 & 1 & $<1.96$ \\
SDQ conduct problems & 8 & 3 & $<1.96$ \\
SDQ & & 4 & $\geq 1.96$ \\
hyperactivity/inattention & 6 & & \\
SDQ peer relationship & & 2 & $\geq 1.96$ \\
problems & 5 & 8 & $\geq 1.96$ \\
SDO prosocial behavior & 52 & 71 & $\geq 1.96$ \\
PAM & & & \\
\hline
\end{tabular}

PSI-SF, Parenting Stress Index-Short Form; SDQ, Strengths and Difficulties Questionnaire; PAM, Parenting Alliance Measure.

a low level of pro-social behaviors in the daughter that included difficulties in helping others (both children and adults). After participation in the parenting program, M.'s profile ameliorated with respect to the assessment phase (Total Score $=10$ ). The score was close to average and unlikely to be clinically significant. M. reported good behavioral and emotionally functioning for the daughter. Relevant changes were reported for hyperactive problems (Hyperactivity/Inattention $=4$ ) and relationship with peers (Peer Relationship Problems $=2$ ). He perceived improvement in his daughter's pro-social abilities (Prosocial behavior $=8$ ): she was described as more able to be considerate and to share personal belongings with other children. Both the total score and the subscales resulted as recovered according to JT method (Table 1).

\section{THE PARENTING ALLIANCE MEASURE (PAM; Konold and Abidin, 2001)}

In the pre-intervention phase, $M$. reported very low level of parenting alliance $\left(6^{\circ}\right.$ percentile) and the score fell well within the clinical range. He showed a problematic perspective of being cooperative, communicative, and mutually respectful with regard to his child's caregiving. High levels of couple conflict have influenced M.'s capacity to cooperate with partner in meeting the needs of the child. In the post-intervention phase, the level of parenting alliances lightly ameliorate $\left(17^{\circ}\right.$ percentile). However, remaining in the clinical range, it shifted from problematic to a marginal quality of parenting alliance. According to JT method, the father crossed only one of the two-step criterions, the RCI but not the cut-off criteria, and he resulted as improved in parenting alliance. M. showed changes in his capacity to provide support to his daughter's mother in her role as a parent and he was more respectful of her opinions and appeared more able to communicate with her about their child. He seemed to invest more in his child, to be more involved in parenthood and childrearing. M. was more able to cooperate with the child's mother by nurturing the developmental needs of the daughter (Table 1). 


\section{DISCUSSION}

The research presented in this paper was designed to show a clinical application of COS-P in order to reflect on some specific therapeutic tasks and on some contexts and clinical indicators appropriate for its application. Whereas preliminary data on the efficacy of COS intervention has been published, no studies have yet investigated the efficacy of COS-P. From the overall research data of this single case study, it seems that COS-P worked making $\mathrm{M}$. feel more competent as a parent in the management of his daughter's needs and in his interaction with her, thus moving psychologically in the direction of integration and understanding. Slight improvements were also present at the level of parenting alliance.

Specifically, with regard to the first aim on the parent's IWMs, M.'s attachment pattern was classified as Dismissing before and after the parenting program intervention. He showed he relied heavily on a deactivation form of defensive exclusion in telling the stories, thus producing a representational "distance" between himself and the attachment-activating event and neutralizing the attachment related distress (Lis et al., 2011; Delvecchio et al., 2013). When describing interpersonal themes M. often failed to represent a reciprocal and mutually engaging relationship. Previous studies on the efficacy of COS intervention reported significant increase in the proportions of securely attached children after parents' participation to the intervention (Marvin et al., 2002; Hoffman et al., 2006). No studies on the COS intervention has yet investigated changes in the parent's attachment model. Recently a study protocol was published in which it will assess parent's state of mind by a pre/post administration of the Adult Attachment Interview (Ramsauer et al., 2014). Even though the parent's attachment pattern didn't change, M. showed an important increase in the agency of self, defined as the degree to which the self is moving psychologically or behaviorally in the direction of integration or understanding (George and West, 2001). He moved from an initial lower level of an external manifestation of agency of self, called capacity to act, to an upper level called internalized secure base. This change indicates the passage from the tendency to engage in behavior in order to cope with attachment distress, to the capacity to draw upon internal resources to gain a sense of security and to use more self-reflection. Gaining an increase in agency of self can be considered a change in the mechanisms that are underpinning his attachment organization and thus showing the activation of a process that could lead to the acquisition of increased attachment's security (Fonagy and Target, 1997; Pazzagli, 2011). The capacity to use thoughtful and self exploration in response to stressful attachment situation constitutes one of the main purposes of the COS-P, that is to help parents have more reflective capacity on internal processes that guide problematic patterns of parent/child interactions.

With regard to the second aim concerning improvements expected in parenting behaviors, data showed changes, statistically classified as improved in parenting stress and as recovered in perception of the child's functioning. Results highlighted important ameliorations at the level of parenting stress perceived by $\mathrm{M}$. In particular, the improvements in the parent domain are related to the perception of less stress in some functioning aspects like sense of competence (confidence in the ability to control child's behavior and knowledge of child development) and attachment (sense of closeness) (Abidin, 1995). For M., the source of stress appeared to be relevantly decreased: he seemed to perceive lower distress linked to his role as parent and to feel himself more able to manage his child needs and requests. Differently, he still reported some source of stress caused by some salient daughter characteristics that make it difficult for him to manage her. This data are in line with the results assessing changes in parent's perception of child positive and negative attributes before and after the parenting program. Although his perception of the daughter's difficulties remains high, he reported relevant changes in describing the child's behaviors, emotions and relationship difficulties. Relevant changes occurred not only in the reported reduction of the child's difficulties, but also in his increased perception of her strengths. M. also reported improvements in the daughter's prosocial behavior, depicting the child's behaviors as more considerate and available to the needs of others.

These results agreed with the aim of COS-P to provide parents with new ways to connect with their child by enhancing the caregivers' appropriate and sensitive responses to the child's emotions while developing the capacity to recognize their child's needs. At the beginning, M. perceived all the aspects assessed in parenting and child functioning as highly problematic. After participating in COS-P he seemed more balanced in his descriptions by reporting both challenging and functional aspects of their relationship. COS-P works on helping the caregiver understand the attachment's needs behind the child's behavior thus reducing the tendency to target negative attributions of the child. Positive changes in parenting behaviors goes in the expected direction of COS-P. Research has showed significant associations between caregiver's experience of parenting stress while performing parenting responsibilities and increased risk of child maltreatment and, ultimately, the development of childhood psychological and behavioral disorders (Abidin, 1992; Abidin and Jenkins, 1992). Furthermore, the capacity to recognize aspects of strength in the daughter shows that the COS model works through valuing participants and highlighting positive child/parent interactions.

Finally, the third aim concerned an expected improvement in parental alliance. This change is consistent with previous research that suggests increased alliance is associated with the quality of parenting. Parental alliance refers to the quality of the alliance between the two parents with regards to communication and teamwork (Konold and Abidin, 2001). After participating in COS-P, M. reported a change in the co-parenting relationship from problematic to one with marginal quality. This improvement was statistically significant. For Zeanah et al. (2011) high levels of parental conflict increase the likelihood of attachment disturbances in children, perhaps through a reduced sensitivity in parents who are worried about their own concerns. In this case study, the amelioration of the parental alliance could explain M.'s greater capacity to recognize his daughter's attachment needs. The narratives of father's AAP also showed enhanced recognition of the child's needs for proximity and care from both parents. To the table called "bed," showing a baby on bed that stretches out his hand to a stylized female figure, at the beginning M. narrowed his difficult experience with the daughter when going to sleep, after the participation to COS-P he depicted a mother-child 
interaction, without showing the need to replace himself to the female figure. Higher strength of childrearing alliance between parents provides an improved attachment outcome for child at risk for insecure attachment (Castellano et al., 2013).

The overall improvements showed by this research data agreed with M.'s comments of satisfaction and appreciation with participation in the COS-P. He described the experience as highly positive with particular emphasis on two aspects. M. declared that, despite having always imagined that his childhood history would have an influence in his life in general and his relationship with the daughter in particular, COS-P helped him to identify problematic areas and specific mechanisms related to those influences, allowing him to be more aware of the quality and characteristics of the relationship with his daughter and thus helping him to implement reparative behaviors. Another element that really struck $M$. was related to working through the parental role characteristics (being always bigger stronger, wiser and kind, to content needs when possible, and take charge when necessary). His reflection on his role allowed him to more clearly identify the times in which he pushed his daughter to provide care for him and seek her support and reinforcement. After the intervention, he described his relationship with his daughter as not only having some difficulties but also as having more moments of enjoyment and sharing. Furthermore, he started thinking about beginning an individual psychotherapy.

\section{CONCLUSION}

The present study is the first to show a clinical application of COS-P. A single case-study was presented of a father's treatment in a high parental conflict levels. As pointed out by Zeanah et al. (2011) in similar situations attachment perspectives should have a central role in interventions aimed at restoring interpersonal connections and establishing a safe and secure living situation for the child. M.'s initial motivation was characterized by a low will to work on relational struggles and parenting functions through a psychotherapy treatment. Instead it seemed that M.'s motivation was mostly characterized by extrinsic factors instrumental to the achievement of a pre-established outcome (e.g., seek revenge with the child's mother via applying for daughter's custody). After COS-P participation, father/child's mother antagonism diminished as they became more cooperative, conflict for child custody decreased as the judicial conflict on daughter's custody eclipsed.

The COS-P, differs from other visually based attachment approaches, as it uses materials and archived videotapes of parent/child interactions selected as examples of core COS model components without the aid of "individualized" video-feedback. For these reasons, COS-P has the advantage of being more flexible in terms of timing and practicality. In the case study presented, empirical data and clinical issues showed a trend toward increased capacity for integration and understanding in term of agency of self, along with a increased capacity to recognize the child's needs. Participation in COS-P allows participants to face personal relational struggles in a less direct and immediate way with respect to more individualized interventions. The intervention activated a process of involvement and self reflection that led to an increased capacity to recognize M.'s personal relational dynamic role as well as an increased motivation to pursue a deeper personal psychotherapy. A difficult-to-reach caregiver with low intrinsic motivation was an appropriate candidate for the application of COS-P.

The current study adds to the literature on attachment-based interventions by providing preliminary data from a single casestudy on the efficacy of COS-P. The article concerned a single case pilot study and this has implications for the generalizability of the results. Yet the fact that it involved a single case study, didn't evaluate the process therapeutic alliance between therapist and caregiver, and didn't assess the father/child's interaction by systematic observations are three core limitations. Randomized controlled trial on COS-P are needed in order to expand the preliminary research data on COS-P and to better individualize the clinical indications and contexts appropriate for its application.

\section{AUTHOR CONTRIBUTIONS}

Chiara Pazzagli: Substantial contributions to the conception and design of the work and to the interpretation of data; Drafting the work; Final approval of the version to be published; Agreement to be accountable for all aspects of the work. Loredana Laghezza: Substantial contributions to the design of the work and to the analysis of data; Drafting the work; Final approval of the version to be published; Agreement to be accountable for all aspects of the work. Francesca Manaresi: Acquisition of data for the work; Revising the work critically; Final approval of the version to be published; Agreement to be accountable for all aspects of the work. Claudia Mazzeschi: Substantial contributions to the design of the work and interpretation of data; Revising the work critically; Final approval of the version to be published; Agreement to be accountable for all aspects of the work. Bert Powell: Substantial contributions to the conception of the work; Revising the work critically; Final approval of the version to be published; Agreement to be accountable for all aspects of the work.

\section{REFERENCES}

Abidin, R. (1992). The determinants of parenting behavior. J. Clin. Psychol. 21, 407-412.

Abidin, R. (1995). Parenting Stress Index: Professional Manual, 3rd Edn. Odessa, FL: Psychological Assessment Resources, Inc.

Abidin, R., and Jenkins, C. (1992). The relationship of early family variables to children's subsequent behavioral adjustment. J. Clin. Child Psychol. 21, 60-69. doi: 10.1207/s15374424jccp2101_9

Ainsworth, M. S., Blehar, M. C., Waters, E., and Wall, S. (1978). Patterns of Attachment: a Psychological Study of the Strange Situation. Hillsdale, NJ: Erlbaum.

Berlin, L. J., Zeanah, C. H., and Lieberman, A. F. (2008). "Prevention and intervention programs for supporting early attachment security," in Handbook of Attachment, 2nd Edn., eds J. Cassidy and P. R. Shaver (New York, NY: Guilford Press), 745-761.

Bowlby, J. (1973). Attachment and Loss: Separation: Anxiety and Anger, Vol. 2, London: Hogarth

Camisasca, E., Miragoli, S., and Di Blasio, P. (2013). Is the relationship between marital adjustment and parenting stress mediated or moderated by parenting alliance? Eur. J. Psychol. 10, 235-254. doi: 10.5964/ejop.v10i2.724

Carlson, C. I., Ross, S. G., and Stark, K. H. (2012). Bridging system research and practice: evidence-based case study research in couple and family psychology. Couple Fam. Psychol. 1, 48-60. doi: 10.1037/ a0027511

Castellano, R., Velotti, P., Crowell, J., and Zavattini, G. C. (2013). The role of parents' attachment configurations at childbirth on marital satisfaction and conflict strategies. J. Child Fam. Stud. 23, 1011-1026. doi: 10.1007/s10826-013-9757-7 
Cohen, R. S., and Weissman, S. H. (1984). "The parenting alliance," in Parenthood: a Psychodynamic Perspective, eds R. Cohen, B. Cohler, and S. Weissman (New York, NY: Guilford), 33-49.

Cooper, G., Hoffman, K. T., Marvin, R. S., and Powell, B. (1999). The Circle of Security Interview. Spokane, WA: Marycliff Institute.

Cooper, G., Hoffman, K. T., and Powell, B. (2009). Circle of Security: COS-P Facilitator DVD Manual 5.0. Spokane, WA: Marycliff Institute.

Cooper, G., Hoffman, K. T., Powell, B., and Marvin, R. S. (2005). "The circle of security intervention: differential diagnosis and differential treatment," in Enhancing Early Attachments: Theory, Research, Intervention, and Policy, eds L. J. Berlin, Y. Ziv, L. M. Amaya-Jackson, and M. T. Greenberg (New York, NY: Guilford Press), 127-151.

Delvecchio, E., Pazzagli, C., Di Riso, D., Chessa, D., and Mazzeschi, C. (2013). Attachment pattern and cognitive skills: an exploratory study in an Italian non-clinical sample. Percept. Mot. Skills 116, 830-846. doi: 10.2466/03.10.PMS.116.3.830-846

Di Riso, D., Salcuni, S., Chessa, D., Raudino, A., Lis, A., and Altoè, G. (2010). The Strenght and Difficulties Questionniare (SDQ): early evidence of its reliability and validity in a community sample of Italian children. Pers. Indiv. Differ. 49, 570-575. doi: 10.1016/j.paid.2010.05.005

Feinberg, M. E., Greenberg, M. T., Osgood, D. W., Sartorius, J., and Bontempo, D. (2007). Effects of the communities that care model in Pennsylvania on youth risk and problem behaviors. Prev. Sci. 8, 180-191. doi: 10.1007/s11121-0070073-6

Fonagy, P., and Target, M. (1997). Attachment and reflective function: their role in self-organization. Dev. Psychopathol. 9, 679-700. doi: $10.1017 /$ S0954579497001399

Frank, S. J., Olmstead, C. L., Wagner, A. E., Laub, A. C., Freeark, K., Breizter, G. M., et al. (1991). Child illness, the parenting alliance and parenting stress. J. Pediatr. Psychol. 16, 361-371. doi: 10.1093/jpepsy/16.3.361

Frosch, C. A., McHale, J. L., and Mangelsdorf, S. C. (2000). Marital behavior and the security of preschooler-parent attachment relationships. J. Fam. Psychol. 14, 144-161. doi: 10.1037/0893-3200.14.1.144

Gable, S., Crnic, K., and Belsky, J. (1994). Coparenting within the family system: influences on children's development. Fam. Relat. 43, 380-386. doi: $10.2307 / 585368$

George, C., Kaplan, N., and Main, M. (1996). Adult Attachment Interview, 3rd Edn. Berkeley, CA: University of California.

George, C., and West, M. (2001). The development and preliminary validation of a new measure of adult attachment: the adult attachment projective. Attach. Hum. Dev. 3, 30-61. doi: 10.1080/14616730010024771

George, C., and West, M. (2011). The adult attachment projective picture system: integrating attachment into clinical assessment. J. Pers. Assess. 93, 407-416. doi: $10.1080 / 00223891.2011 .594133$

George, C., and West, M. (2014). The Adult Attachment Projective Picture System. New York, NY: Guilford.

Goodman, R. (1997). The strengths and difficulties questionnaire: a research note. J. Child Psychol. Psychiatry. 38, 581-586. doi: 10.1111/j.1469-7610.1997.tb01545.x

Goodman, R. (1999). The extended version of the strengths and difficulties questionnaire as a guide to child psychiatric caseness and consequent burden. J. Child Psychol. Psychiatry. 40, 791-799. doi: 10.1111/1469-7610.00494

Goodman, R. (2001). Psychometric properties of the Strengths and Difficulties Questionnaire (SDQ). J. Am. Acad. Child Adolesc. 40, 1337-1345. doi: 10.1097/00004583-200111000-00015

Goodman, R., and Scott, S. (1999). Comparing the strengths and difficulties questionnaire and the child behavior checklist: is small beautiful? J. Abnorm. Child Psychol. 27, 17-24. doi: 10.1023/A:1022658222914

Guarino, A., Di Blasio, P., D’Alessio, M., Camisasca, E., and Serantoni, G. (2008). Parenting Stress Index. Adattamento Italiano. Firenze: Giunti O.S. Organizzazioni Speciali.

Hoffman, K. T., Marvin, R. S., Cooper, G., and Powell, B. (2006). Changing toddlers' and preschoolers' attachment classifications: the circle of security interventions. J. Consult. Clin. Psychol. 74, 1017-1026. doi: 10.1037/0022006X.74.6.1017

Jacobson, N. S., Follette, W. C., Revenstorf, D., Baucom, D. H., Hahlweg, K., and Margolin, G. (1984). Variability in outcome and clinical significance of behavioral marital therapy: a reanalysis of outcome data. J. Consult. Clin. Psychol. 52, 499-504. doi: 10.1037/0022-006X.52.4.497
Jacobson, N. S., and Truax, P. (1991). Clinical significance: a statistical approach to defining meaningful change in psychotherapy research. J. Consult. Clin. Psychol. 59, 12-19. doi: 10.1037/0022-006X.59.1.12

Konold, T. R., and Abidin, R. R. (2001). Parenting alliance: a multifactor perspective. Assessment 8, 47-65. doi: 10.1177/1073191101008 00105

Lis, A., Mazzeschi, C., Di Riso, D., and Salcuni, S. (2011). Attachment, assessment, and psychological intervention: a case study of anorexia. J. Pers. Assess. 93, 434-444. doi: 10.1080/00223891.2011.594125

Marvin, R., Cooper, G., Hoffman, K., and Powell, B. (2002). The circle of security project: attachment-based intervention with caregiver-pre-school child dyads. Attach. Hum. Dev. 4, 107-124. doi: 10.1080/146167302529 82491

Mathai, J., Anderson, P., and Bourne, A. (2002). The Strengths and Difficulties Questionnaire (SDQ) as a screening measure prior to admission to a Child and Adolescent Mental Health Service (CAMHS). AeJAMH. 1, 1-12. doi: 10.5172/jamh.1.3.235

McBride, B. A. (1989). Stress and fathers' parental competence: implications for family life and parent educators. Fam. Relat. 38, 385-389. doi: 10.2307/ 585742

McDonough, S. C. (2000). "Interaction guidance: an approach for difficult-toengage families," Handbook of Infant Mental Health, 2nd Edn., ed C. H. Zeanah (New York, NY: Guilford Press), 485-493.

McDonough, S. C. (2004). "Interaction guidance: promoting and nurturing the caregiving relationship," in Treating Parent-Infant Relationship Problems: Strategies for Intervention, eds A. Sameroff, S. C. McDonough, and K. L. Rosenblum (New York, NY: Guilford Press), 79-96.

McGlinchey, J. B., Atkins, D. C., and Jacobson, N. S. (2002). Clinical significance methods: which one touse and how useful are they? Behav. Ther. 33, 529-550. doi: 10.1016/S0005-7894(02)80015-6

McHale, J. P., and Rasmussen, J. L. (1998). Coparental and family grouplevel dynamics during infancy: early family precursors of child and family functioning during preschool. Dev. Psychopathol. 10, 39-59. doi: $10.1017 /$ S0954579498001527

Page, T. F., and Cain, D. S. (2009). "Why don't you just tell me how you feel?": a case study of a young mother in an attachment-based group intervention. Child Adolesc. Soc. Work J. 26, 333-350. doi: 10.1007/s10560-0090166-0

Pazzagli, C. (2011). Quale contributo del paradigma dell'attaccamento alla psicopatologia? J. Psychol. 4, 823-828. doi: 10.1421/36111

Powell, B., Cooper, G., Hoffman, K., and Marvin, R. (2009). "The circle of security," in Handbook of Infant Mental Health, 3rd Edn., ed C. Zeanah (New York, NY: Guilford Press), 450-467.

Powell, B., Cooper, G., Hoffman, K., and Marvin, B. (2013). The Circle of Security Intervention: Enhancing Attachment in Early Parent-Child Relationships. New York, NY: Guilford Press.

Ramsauer, B., Lotzin, A., Mühlhan, C., Romer, G., Nolte, T., Fonagy, P., et al. (2014). A randomized controlled trial comparing circle of security intervention and treatment as usual as interventions to increase attachment security in infants of mentally ill mothers: study protocol. BMC Psychiatry 14:24-35. doi: 10.1186/1471-244X-14-24

Ross, C. N., Blanc, H. M., McNeil, C. B., Eyberg, S. M., and Hembree-Kigin, T. L. (1998). Parenting stress in mothers of young children with oppositional defiant disorder and other severe behavior problems. Child Study J. 28, 93-110.

Van IJzendoorn, M. H., Juffer, F., and Duyvesteyn, M. G. F. (1995). Breaking the intergenerational cycle of insecure attachment: a review of the effects of attachment-based interventions on maternal sensitivity and infant security. J. Child Psychol. Psychiatry 36, 225-248. doi: 10.1111/j.14697610.1995.tb01822.x

Webster-Stratton, C. (1988). Mothers' and fathers' perceptions of child deviance. J. Consult. Clin. Psychol. 56, 909-915. doi: 10.1037/0022-006X.56.6.909

West, M., and George, C. (2002). Attachment and dysthymia: the contributions of preoccupied attachment and agency of self to depression in women. Attach. Hum. Dev. 4, 278-293. doi: 10.1080/14616730210167258

Zeanah, C. H., Berlin, L. J., and Boris, N. W. (2011), Practitioner review: clinical applications of attachment theory and research for infants and young children. J. Child Psychol. Psychiatry 52, 819-833. doi: 10.1111/j.1469-7610.2011. 02399.x 
Conflict of Interest Statement: The authors declare that the research was conducted in the absence of any commercial or financial relationships that could be construed as a potential conflict of interest.

Received: 11 May 2014; accepted: 25 July 2014; published online: 12 August 2014. Citation: Pazzagli C, Laghezza L, Manaresi F, Mazzeschi C and Powell B (2014) The circle of security parenting and parental conflict: a single case study. Front. Psychol. 5:887. doi: 10.3389/fpsyg.2014.00887
This article was submitted to Psychology for Clinical Settings, a section of the journal Frontiers in Psychology.

Copyright (c) 2014 Pazzagli, Laghezza, Manaresi, Mazzeschi and Powell. This is an open-access article distributed under the terms of the Creative Commons Attribution License (CC BY). The use, distribution or reproduction in other forums is permitted, provided the original author(s) or licensor are credited and that the original publication in this journal is cited, in accordance with accepted academic practice. No use, distribution or reproduction is permitted which does not comply with these terms. 


\title{
Use of the adult attachment projective picture system in psychodynamic psychotherapy with a severely traumatized patient
}

\author{
Carol George ${ }^{1 *}$ and Anna Buchheim ${ }^{2}$ \\ ' Department of Psychology, Mills College, Oakland, CA, USA \\ 2 Institute of Psychology, University of Innsbruck, Innsbruck, Austria
}

\section{Edited by:}

Silvia Salcuni, Università degli Studi di

Padova, Italy

\section{Reviewed by:}

Rita B. Ardito, University of Turin, Italy Silvia Salcuni, Università degli Studi di Padova, Italy

\section{*Correspondence:}

Carol George, Department of

Psychology, Mills College,

5000 MacArthur Blvd., Oakland,

CA 94613, USA

e-mail: george@mills.edu
The following case study is presented to facilitate an understanding of how the attachment information evident from Adult Attachment Projective Picture System (AAP) assessment can be integrated into a psychodynamic perspective in making therapeutic recommendations that integrate an attachment perspective. The Adult Attachment Projective Picture System (AAP) is a valid representational measure of internal representations of attachment based on the analysis of a set of free response picture stimuli designed to systematically activate the attachment system (George and West, 2012). The AAP provides a fruitful diagnostic tool for psychodynamic-oriented clinicians to identify attachment-based deficits and resources for an individual patient in therapy. This paper considers the use of the AAP with a traumatized patient in an inpatient setting and uses a case study to illustrate the components of the AAP that are particularly relevant to a psychodynamic conceptualization. The paper discusses also attachment-based recommendations for intervention.

Keywords: Adult Attachment Projective Picture System, psychoanalysis, psychotherapy, trauma, adult attachment

\section{INTRODUCTION PRESENTING SYMPTOMS}

Gloria, a mid-aged patient, appeared restless and somewhat distrustful initially during her diagnostic clinical interview; she gained trust during the interview because the therapist's open and direct approach seemed to defuse the patient's fear of a discussing trauma therapy. She reported during this interview that 5 years ago she had a gruesome experience with a therapist who had suggested immediately at their first meeting that she begin trauma therapy for her rape experience. Gloria was terrified and she quit therapy.

When the second author first saw Gloria for the attachment assessment, her symptoms indicated a strong dissociative avoidance disorder, which also included headaches, fainting in stress situations, and memory loss. She had been in a car accident about 1 year prior to this time and, as a result, she felt for the first time in her life that treatment would be appropriate and she contacted a psychosomatic hospital. Gloria was diagnosed with post-traumatic stress disorder (PTSD; DSM-IV) with high dissociative states (amnesia) and a pain disorder.

\section{HISTORY OF RELATIONSHIP TRAUMA AND COURSE OF ILLNESS}

Gloria lived in an intact family with her parents and three younger siblings until her parents divorced at age 5, but she provided no details about her childhood before this time and would not speak at all about her biological father. Gloria and her siblings lived predominantly with their mother after the divorce. Her mother remarried 5 years later when Gloria was 10 years old and she viewed her stepfather as her "actual" father. She described him as being humorous, loved, and trusted, but she also described him impulsive, irascible, and argumentative. Gloria seemed insecure about her stepfather's acceptance, wondering how far she could push him before he would break. Would he accept her even if she acted like a wild child? Gloria stated that "once a week I pushed him until he burst," and she told how she tested him with "mischievousness" so as to push her stepfather into beating her. Gloria's deliberate misbehavior and her stepfather's beatings were central to their relationship.

Gloria's first major traumatic experience as a sadistic rape in late adolescence. The only details that she provided about her rape was that it occurred during daytime and that she did not know the rapist. After the rape, she began around 3 weeks later to have sudden headache and fainting attacks, fainting as much as three times a day. She also developed chronic dissociation experiences. Gloria's symptoms appeared to be associated with feeling of being exposed and to school or performance-related pressure. Although these problems persisted, she did not seek psychological treatment. Her symptoms, especially fainting, diminished when she studied abroad. Her symptoms reoccurred after returning home 2 years later, however, and she decided to go back abroad.

Gloria's second major traumatic experience was at 30 years old when her boyfriend of 2 years died in an accident. Gloria had separated from him shortly before his death, the reason being that she was no longer able to tolerate physical closeness. She felt severely guilty about his death and her guilt had masochistic qualities. As a result, she did not have another intimate relationship for many years.

Gloria had recently experienced a third trauma prior to her decision to seek treatment. She had been in a serious accident in which she had been thrown out of her car and into the air rendering her unconscious. She was thought at first to be dead. Her physical 
injuries included three spinal discs and a strain on the cervical spine and her fainting episodes increased to many episodes a day. Although Gloria reported in her initial interview, almost proudly, saying "I survived this," and she had since was unable to work.

Gloria felt that her symptoms had become debilitating, and she noticed that her fainting spells seemed related to stress. Her headaches had become so severe that she risked becoming unconscious. She was not able to recall what preceded the headaches and she could not remember any indicators associated with their onset, such as less debilitating headaches or other physical warning signs. Gloria described herself as being on autopilot. This "defensive mechanism" had saved her life more than 20 years ago, but now this automatic mechanism was out of her control.

Gloria had not allowed herself to think about this until she entered treatment and her treatment goal was "to get rid of it." She had a stiff commitment to being strong and carrying on. "I want to function. I will get through this. I want to be able to work. I have worked for many years to wipe out the traumatic event, to get rid of it, to repress it." This perspective had dominated her life and kept her moving forward. She was frightened of not being able to be in control of her symptoms and the prospect of becoming dependent on the pain medication prescribed to combat her severe headaches.

\section{BACKGROUND}

\section{ATTACHMENT AND PSYCHOANALYSIS}

Bowlby (1969) was a prominent psychoanalyst to use ethological concepts to describe the infant's biologically predisposed attachment to a primary caregiver. He viewed relatedness in early childhood as a primary and independent developmental goal that is not subservient to a physiological needs (e.g., hunger) or psychoanalytically defined primary processes. The infant is perceived from an interactional perspective, with a focus on the relationships with primary attachment figures. Attachment theory maintained some foundations of psychoanalytic theory (e.g., the developmental point of view) and there is a strong literature that discusses the divergences and convergences of psychoanalysis and attachment theory (e.g., Diamond and Blatt, 1999; Fonagy, 1999, 2001; Slade, 2000; Gullestad, 2001; Steele and Steele, 2008; Eagle, 2013) and also developed some aspects further, particularly the delineation of the internal world (Diamond and Blatt, 1999). Fonagy's (1999, 2001) overview of the intersection of these two approaches demonstrated that the relationship between attachment theory and psychoanalysis is more complex than adherents of either community have generally recognized. This paper addresses some of these complexities by integrating attachment assessment using the Adult Attachment Projective Picture System (AAP) in psychodynamic psychotherapy in an adult traumatized patient.

George and Solomon (1999) proposed that one major difference between psychoanalysis and attachment theory falls in the description of forms of defensive processes. Traditional psychoanalytic models provide a complex constellation of defenses to interpret a broad range of intrapsychic phenomenon, including phantasy, dream, wish, and impulse (e.g., Horowitz, 1988;
Kernberg, 1994). Attachment theory delineates two basic processes that manifest in three forms. According to George and Solomon (1999, 2008), Bowlby defined defense as forms exclusion directed to modulating difficult and anxious experiences with attachment figures, and the child's experiences with incomplete or failed bids for parental protection, care, and comfort. He defined defenses in terms of two qualitatively distinct processes: deactivation (retaining elements of intellectualization and denial) and cognitive disconnection (retaining elements of splitting). George and Solomon $(1999,2008)$ pointed out that under normal circumstances these two exclusion processes are associated with goals to maintain physical and psychological proximity in the attachment-caregiving relationship under conditions when the child's experiences with the attachment figure are less than satisfying. George and Solomon refined Bowlby's (1980) model suggesting that deactivation and cognitive disconnection organized and supported at least minimal forms of representational, behavioral, and emotional regulation. Bowlby (1980) proposed that these forms defensive exclusion functioned to segregate (akin to repression) memory, affect, and experience when the attachment figure was not available, conceiving of an extreme process he termed "segregated systems." Segregated systems were thought as associated with the painful and chronic distress experiences, such as those that accompany loss. Bowlby posited that segregated systems were the intrapsychic root of symptoms related pathological mourning and severe psychopathology. Attachment theorists have since demonstrated that segregated systems are associated with experiences of failed protection, attachment trauma, and disorganized/dysregulated attachment behavior and representation (Solomon and George, 2000, 2011; George and West, 2012).

Consistent with a psychoanalytic approach, some attachment theorists have suggested that utilization of defensive process models is needed to provide a complete picture of the emotional and behavioral regulation processes individuals develop from their childhood relationships with attachment figures (Cassidy and Kobak, 1988; George and Solomon, 1999; George and West, 2012). Further, George and West (1999) concluded, "In order to understand the relationship between adult attachment and mental health risk we need to examine the attachment concepts of defense and segregated systems, the mental processes that define disorganization" (p. 295). These theorists operationally defined Bowlby (1980) basic defense scheme as a central element for evaluating representational patterns of attachment using the Adult Attachment Projective Picture System (George etal., 1997, 1999; George and West, 2012). Suggesting that these representational structures have developed under conditions of attachment trauma (abuse, loss, failed protection), the concept of segregated systems is fruitful to explain some forms of relationship-based psychopathology in adults (George and West, 2012).

The discussion that follows provides some ideas about using attachment concepts in clinical work by showing how the perspectives of a psychoanalyst and attachment assessment may improve the understanding of an individual case of a traumatized patient with the diagnosis of a PTSD with dissociative states (e.g., fainting in response to stressful situations). 


\section{POSTTRAUMATIC STRESS DISORDER}

The lifetime prevalence of PTSD in Germany has been found to be $1.3 \%$ with a female-to-male ratio of 3.25-1. Traumatized patients are frequently misdiagnosed and mistreated in the mental health system. The number and complexity of the symptoms lead to fragmented and incomplete treatment. PTSD patients are vulnerable to become re-victimized by caregivers because of their difficulties with close relationships. Severely traumatized PTSD patients (complex trauma) develop difficulties in modulating arousal and show signs of severe affect dysregulation (e.g., aggression against self and other, and problems with social attachment and dissociative states).

Dissociation, defined as a deficit of the integrative functions of memory, consciousness and identity, is often related to traumatic experiences and traumatic memories (Liotti, 2004; Kihlstrom, 2005). During clinical interviews, dissociation is suggested either by such a degree of unwitting absorption in mental states that ordinary attention to the outside environment is seriously hampered. Dissociation can be accompanied by a sudden lack of continuity in discourse, thought or behavior of which the person is unaware (supposedly due to intrusion of dissociated mental contents in the flow of consciousness). Thus, for instance, a dissociative patient may suddenly interrupt her speech during a therapeutic session, stare into the void for minutes, and become unresponsive to the therapist's queries as to what is happening to her. Or a patient suffering from PTSD may suddenly utter fragmented and incoherent comments on intrusive mental images (usually related to traumatic memories) that surface in consciousness and hamper the continuity of the preceding dialog with the therapist. In the most extreme variety of dissociation (Dissociative Identity Disorder), an alternate ego state may appear during the clinical dialog, reporting (sometimes with an unusual tone of voice, e.g., like a child) memories of childhood abuse of which the patient has previously been totally unaware, or expressing attitudes and beliefs quite extraneous to the patients' personality (Liotti, 2004).

Furthermore, shattered meaning propositions predominate. Trust, hope and sense of agency is accompanied by social avoidance, with loss of meaningful attachment and therefore lack of participation in preparing for future (van der Kolk et al., 1996).

\section{DISORGANIZED-DYSREGULATED ATTACHMENT AND DISSOCIATIVE SYMPTOMS}

The founding premise of attachment theory is that stress, especially traumatic stress, produces a strong desire for proximity to and comfort by attachment figures; this desire is built into human biology as a survival safety mechanism and the mechanism is functions unchanged throughout the life span (Bowlby, 1969). Attachment experience shapes the ways in which individuals manage stress and are especially important when individuals experience a traumatic event (Bowlby, 1973, 1980; Schore, 2001). When attachment is secure, individuals know how and when to seek attachment figures and develop internal representations of self as deserving of care. Attachment security fosters confidence and trust that figures are available, empathic, and sensitive to their needs; security is a buffer or resilience factor that supports recovery from trauma (Bowlby, 1980; Schore, 2001).
When attachment is insecure, emotional and behavioral reactions when distressed may be made even more painful by unconscious evaluations that wishes for comfort are illegitimate. Insecurity may result in additional painful interactions with the attachment figures rather than the functional comfort and protection for which attachment was intended (Bowlby, 1980). Insecurity fosters anxiety, anger, and fear, and increases the risk of developing trauma-related emotional disorders (Bowlby, 1980; Adam et al., 1995; Dozier et al., 2008; George and West, 2012). Extreme forms of insecurity are associated with the breakdown of attachment and caregiving regulatory mechanisms risk emotional and homeostatic dysregulation, often termed disorganized attachment (Solomon and George, 2011). The risk of dysregulation is heightened when attachment relationships are threatened or threatening, such as parental loss or psychiatric debilitation or maltreatment (Lyons-Ruth and Jacobvitz, 2008). George and West (2012) defined events such as these as attachment traumas, events that involve terrifying threats to the integrity of self or attachment relationships. Attachment disorganization, conceived in terms of mechanisms of dysregulation and attachment trauma, has been shown to predict vulnerability to severe psychiatric symptomology, including dissociative symptoms (Lyons-Ruth and Jacobvitz, 2008; Weinfield etal., 2008; Solomon and George, 2011).

Liotti (2004) found the metaphor of a "drama triangle" useful in thinking about the intersection between dissociation and disorganized attachment. The dissociation triangle addresses how disorganized attachment fosters dissociative mechanisms that create incompatible and separate representations of self as victim, rescuer, and persecutor. The child's representation of the attachment figure is represented in a conflicting manifold way. On the one side, the attachment figure is represented as source of the child's fear, the self as a victim of attachment figure as persecutor. On the other side, the attachment figure by virtue of being the child's biological protector is viewed as the child's source of safety and protection (rescuer). In the child's mind, representation of self and attachment figure shift among these three incompatible models that are too complex to be synthesized into an integrated model of self. Liotti's model provides us with an integrated psychodynamic and attachment approach to our first questions concerning Gloria's illness, questions regarding the childhood origins of her episodes of near unconsciousness and her inability to ask for help following traumatic assault.

Fearon and Mansell (2001) examined cognitive perspectives on unresolved attachment in patients diagnosed with PTSD. They proposed that unresolved loss, as defined in attachment assessment during interview, involves intrusion avoidance phenomena similar to those of PTSD. Specifically, they develop a model based on unresolved loss that involves the failure to integrate representations of self and the world following a loss. The features of unresolved loss can be understood as emerging as a result of the activation of unintegrated representations of the loss experience and cognitive and behavioral avoidance processes. In this model, the sudden intrusion of memories, cognitions, and emotions associated with the loss automatically captures attention and initiates behavioral dispositions that are incompatible. With regard to attachment, the authors suggested that this was the mechanism that interfered 
with caregiving behavior. Lack of attentional resources and incompatible response tendencies can also result from safety behaviors directed at avoiding the perceived negative consequences of activating trauma memory. The authors proposed that these processes offer a novel way of understanding the disturbances in behavior and speech that are evident in mothers who are designated as unresolved with respect to loss.

This suggests that representational attachment measures, like the AAP, can provide a good understanding of the movement that the client might be making toward empowerment, integration, or understanding. Thus, even if a patient's overall attachment is unresolved (i.e., dysregulated), there may be indications in their responses to the AAP stimuli that suggest they are moving toward mental organization. Given the negative outcomes that are associated with abuse, focusing on resources and defensive strategies is arguably important for therapeutic recommendations.

\section{DISCUSSION}

Looking at this case from both a psychodynamic and attachment point of view, we ask a complex set of questions seeking to understand how childhood attachment experience and trauma were related to the patient's symptoms and her refusal to seek treatment. Were Gloria's experiences with childhood attachment figures traumatic and how might early experience block her from seeking help? Was Gloria's chronic denial of emotional pain related to her rape? Why were somatic symptoms - severe headaches and fainting - her only way to express pain? And finally, why had Gloria retreated with her ailments and refused to address her trauma?

The discrepancy in Gloria's descriptions is noteworthy. She idealized her stepfather by saying how much she loved him, while simultaneously describing his repetitive harsh spankings. From a psychodynamic viewpoint, these two object-representations are split and unintegrated. We speculated, therefore, that her stepfather's beatings were the answer she was looking for to confirm her experience as being recognized and loved.

The attachment perspective contributes added depth to this observation. The juxtaposition of love with dysregulating painful parental rage are the foundation of segregated systems (i.e., repressed and dissociated experience), defined as unconscious representational processes that become obstacles to grieving trauma and foster psychosomatic symptoms (Bowlby, 1980; George and West, 2012). According to attachment theory, attachment figure proximity, even proximity involving pain, is a better attachment solution than feeling isolated or abandoned (Bowlby, 1973; George and West, 2012). This thinking then permits us to better understand Gloria's representation of self in terms of the dissociation triangle described earlier. The quality of this daughter-stepfather relationship would be described as punitive-controlling attachment, a dysregulated form of attachment in which children seek to conquer feelings of abandonment and helplessness through parent-child combat (George and Solomon, 2008). The child in a punitive attachment relationship reciprocally plays out the roles of persecutor and victim.

Gloria's description of her mother is limited. She described her mother as distant and busy with her family and job. Her mother would "let things go" but also punished her. Unlike her stepfather's beatings, her mother used the "silent treatment," interpreted as withdrawal of maternal love and engagement. Gloria recalled, "She simply did not talk with me for many days." Once again, attachment theory provides additional depth to Gloria's experience with her mother. This form of parental withdrawal has been shown to be a reaction to parental feelings of being out of control and helpless; the child's experience is for the parent to inexplicably become psychologically invisible and vulnerable (George and Solomon, 2008). Faced with psychological abandonment, the silent treatment fosters a relationship in which the child must be very careful not to instigate the parent's withdrawal. Gloria would know quickly that her misbehavior-enraged script with her father was a dangerous script with her mother. Children in these situations develop precocious sensitivity and caregiving skills toward the parent; feelings of helpless abandonment are regulated by role reversal (George and Solomon, 2008). The child becomes a skilled caregiver, hypervigilant and seeking to rescue the parent from her pain. Gloria likely assumed the role of rescuer with her mother, completing the disorganized attachment-dissociation triangle.

In describing her life story, Gloria remembers how she enjoyed her parents' busy work schedule. Busy with their own life, she told how it provided her with a sense of freedom and independence. "If they are not caring, then at least I can do what I want." Her independence often fostered dangerous or senseless recklessness. Rebelling against and refusing to accept her parents' rules, she described herself as wild and out of control. She did what she wanted, including dangerous things that she now thought were stupid (e.g., climbing up the chimney, jumping on to the train tracks). When her parents sent to her to her room and forbade her to go out, she had climbed out of the window. She endured her punishment bravely and punishment did not deter her from doing these things again. According to attachment theory, Gloria's dangerous and defiant behavior in adolescence is viewed as attachment behavior (Allen, 2008); and indeed, even though her parents' response was punishment, Gloria achieved the connection to attachment figures she craved.

In her quest to be strong and rid herself of her symptoms, Gloria did not understand that her fainting was a defense mechanism. Fainting means survival and it was very likely that her trauma and fainting attacks were intertwined. The intersection of psychoanalysis and attachment theory is survival. From an attachment perspective, confronting her pain would threaten her fundamental ability to survive. From a psychoanalytic perspective, confronting these symptoms could mean her inner death and threatened survival may explain her resistance to the former therapist who had suggested trauma therapy.

\section{ADULT ATTACHMENT PROJECTIVE PICTURE SYSTEM: GLORIA'S ADULT REPRESENTATION OF ATTACHMENT}

The AAP was administered after Gloria had been in inpatient treatment for 2 weeks. Her adult attachment classification was judged to be pathological mourning for unresolved trauma. Pathological mourning is a state of chronic mourning that endures for years because trauma produced segregated systems block completion of the mourning, Mourning in attachment theory is defined 
by conscious awareness and re-organization of memories and feelings related to trauma, which leads to a representation of self that integrates current reality with the past (Bowlby, 1980; George and West, 2012). Gloria's AAP responses demonstrate the prominent role of attachment trauma in her representation of self and attachment relationships. The unresolved designation associated with her classification group signifies that she is not able to maintain regulatory processes to manage pain and fear. In Gloria's case, we see her attempt to keep attachment trauma walled off or segregated as fortified by defensive deactivation. When working well, this form of defensive exclusion neutralizes and shift attention away from distress and pain (George and West, 2012). The wall breaks though and Gloria succumbs to dysregulation.

The AAP assesses attachment by asking individuals to respond to two kinds of attachment situations. One situation portrays individuals alone. The alone stimuli provide evidence of the capacity to develop strategies to cope with stress in the absence of any visual cues for potential solutions, including no visible portrayal of potential attachment figures (George and West, 2012). Alone responses are evaluated for potential agency of self (capacity for internal integration or constructive action) and connectedness to others, especially attachment figures. The other situation portrays individuals in potential attachment-caregiving dyads. These scenes are evaluated for synchrony, evidence relationship of reciprocity, sensitivity, and mutuality. We first discuss Gloria's representation of self in response to alone AAP stimuli and then describe representations associated with the AAP dyadic stimuli.

It was Gloria's representation of the alone self in Bench, the fourth AAP picture stimulus, in which she becomes dysregulated and attachment representation is "unresolved." The stimulus figure is typically interpreted as an adolescent, drawn with legs and barefoot feet pulled up off the ground and arms loosely wrapped around the legs. The isolated vulnerability of this figure dysregulated her beyond repair. She told the following story, trauma designated in italics:

\begin{abstract}
"Uh, a young woman, she is sitting on a bench and is very sad and unhappy. She is desperate and doesn't know how to help herself. She sees no way out and feels that no one helps her. Feels left alone. Helpless, stranded and lonely. I don't know. I have no idea. But I don't know if it ends well, she is very sad. She may have the strength to pull herself out somehow. But if she has bad luck, then not. And then she will, she will suffer further."
\end{abstract}

The young woman (projected self) is desperate, helpless, and suffering. She is confused and cannot envision life without suffering. The references to desperation, helplessness, and suffering are AAP indicators of severe traumatic content and emotional dysregulation. Gloria demonstrates no clear agency of self, unable to describe change or moving forward. Her representational self is void of a sense of connection to others. She succumbs to despair.

One common deactivation strategy in the AAP is evidenced by descriptions of sleep. Representational (and real) sleep is effective in that events can neither be detected nor processed. Sleep represents a deactivating defensive posture that filters out the details of distressing experiences from consciousness. Deactivation is central to maintaining segregated systems (Bowlby, 1980). We see how
Gloria segregates images of stress-related dissociation (italics) with deactivation (underlined) in her Window response. Window, the first stimulus in the AAP set, portrays a rear view of a girl looking out a picture window.

\begin{abstract}
"It is night time and the child is awakened, that is why she doesn't have shoes on and is standing at the window and looking out. She is sad. Yes, she wishes I think that there actually was someone there with her but there is no one there now and that's why she looks outside, so as if to say, yes, there is certainly someone outside that cares for me. She feels lonely and perhaps looks toward the stars because they are comforting. But there are no stars above, or at least one can simply not recognize them. At some point the child goes away and goes back to sleep, but I think when she grows up then she will go somewhere out in the world in order to find something."
\end{abstract}

The most common responses to this scene are non-threatening descriptions of a child awakening in the morning to go outside to play or go to school (George and West, 2012). By contrast, Gloria's response is a representation of self as desperately alone and without comfort. The child wishes for somebody, anybody, to care for her. Attachment theory views the girl's "yearning and searching" as a natural response to separation and being alone; it is also associated with the initial phase of mourning loss of an attachment figure (Bowlby, 1980). In the absence of agency and connectedness, Gloria describes the girl's solution with the haunting image of looking for comfort in galaxy beyond. This image is surreal and is evaluated in the AAP as a form of derealization. George (2013) found such AAP images were found in the AAP responses of individuals with severe childhood trauma. Gloria copes by returning to a deactivated mental state. By going back to sleep, the girl re-orients her attention away from just enough to create the image of being able to move forward in life. Although it contains Gloria's dysregulated mind state, this image is fragile because Gloria fails to describe any concrete coping actions.

The last stimulus in the AAP set is an alone scene that portrays a child in the corner, drawn with solid lines that designate perceptual boundaries that potentially confine the child. The child is turned askew into the corner with one arm reaching outward away from the corner. Gloria told a story of trauma and self-protection, with trauma (in italics), personal agency (underlined), and her interpretation (in brackets) designated in her response:

\footnotetext{
"A small child stands in a corner and cannot get away. He defends, fends off with his hands. And he looks to the side and down because he tries in this way to protect his face or also not see what is coming next. ... he only thinks, hopefully it will not be so bad. Afterward? He will be beaten. [It doesn't help him that he fends against it. . . he should not have tried to avoid it because then he will be even more severely punished.] Yes, the scene repeats itself again and again. Until the child is someday simply big enough and can run away. And he will surely never do that because he knows what it feels like to stands in the corner and not be able to return and get away. So, he will have to get over it."
}

Gloria's final alone response describes the helplessness of abuse, the defining quality of her relationship with her stepfather. She describes a child who is helplessly trapped in the cycle of abuse. Important in her response, however, is the description of self has having the personal agency of protection. In those moments of abuse, this child was able to protect himself, a capacity to act. This 
was likely the source of Gloria's capacity to go forward in life. What we see too though is that she currently sees the uselessness of the trying to protect one's self. This may have been the impetus for seeking therapy. Unable to escape, she has not been able to "get over it." The child's agency in Corner did not change anything and Gloria's overall representation of self in the alone stories demonstrates that she caught in a cycle of pathological chronic mourning for attachment trauma.

Gloria's dyadic attachment representations demonstrated some sense of self as finding functional care from attachment figures. Her response to $\mathrm{Bed}$, however, describes how the absence of functional care that leads to relationship failure. The Bed scene portrays a child sitting up in bed reaching toward the opposite end of the bed where the mother is seated. Gloria's Bed story describes the sequelae of consistent maternal rejection. She told the following story in response to Bed; rejection is indicated by underline:

"That is clearly a night situation. The child has been sent to bed. The mother sits with him and the child wants very much like to be embraced, but the mother can probably not do that. She doesn't make any sort of preparation to take the child into her arms. She is probably not in the position to do so. She loves her child but she can simply not be so, so loving or express her love so. With physical contact or something like that. And the child does not yet understand that and would very much like to be embraced. And over time he will feel cast off and will react similarly himself. The child simply thinks that he would like to be held by the mother. The mother thinks, I don't want to do that. Or I can't do that, it isn't necessary. You have everything that you need. The child, so the relationship between the mother and the child will be in time one where the child doesn't ask for it anymore. But I remain an optimist. The child will at some time find someone that can offer this loving and can also express it. And then he will be fine. But that all still takes time."

This response evidences the process of how rejecting a child's attachment bids creates distance in the relationships and extinguishes the child's capacity to express its attachment needs. Bedtime signals separation for a child and naturally activates the need for comfort or at least a functional connection with the attachment figure (Bowlby, 1973). Gloria describes her need very clearly. She also "sees" how the mother's withdrawal fosters rejection over time and extinguishes the child's ability to ask. The need remains, as indicated by the suggesting that the boy will find a loving person who can provide what he needs. Feelings of intimacy and real connection, however, are sacrificed as it is only through mutual enjoyment and sensitivity that a child comes to know real intimacy (Bowlby, 1969). The relationship distance that results from rejection helps deactivate the distress of failed intimacy. It is like this experience that contributed to Gloria's decision to leave her boyfriend.

Gloria's overall AAP response patterns demonstrated a representation of self as helpless, desperate, abandoned, managed by deactivating defenses that created representational and relationship distance to shift her attention away from her pain. It is notable that none of these stories mirrored the independent or rebellious self she described during her clinical interview. Her AAP responses get beyond her desperate attempts to "get rid of" her feelings and demonstrate how frightened and helpless she really is. Gloria is caught in what seemed to be an endless cycle of trauma. Without protective and caring attachment figures, representational distance (deactivation), blurred by a positive smoke screen (hope to grow out of her circumstances), her only regulating mechanism is selfprotection, "fending off" distress. We can see how dysregulation and chronic mourning have played out in her life. Adolescent and adult trauma combined with the threat of feared addiction to medication seemed to have rendered her helpless, likely because they were out of her control and she was helpless to draw on the control strategies she had developed during childhood with her parents. On a positive note, Gloria's hope that she will someday find a caring relationship may finally support a commitment to developing a therapeutic relationship.

\section{THE PSYCHODYNAMIC VIEW}

Attachment and psychodynamic perspectives are mutually informing. From a psychodynamic perspective, Gloria had learned early on to repress negative feelings, not to be noticed, to be "independent," and to be outwardly "in control" when she was frightened. This coincided with her primary response mode - to endure and to pass over painful physical or emotional signs.

After her rape, a friend convinced Gloria to go to the police and to make a statement against the perpetrator. Ashamed and feeling that the police officer was insensitive to her situation, Gloria said that she was attacked but was able to get away, but she later retracted that statement. This retraction coincided with the onset of her severe headaches and the dissociative fainting episodes. She denied the severity of the trauma by not talking about it to anybody and suffered the consequences.

Freud (1920) defined "trauma" (Jenseits des Lustprinzips) as an overwhelming stimulus experience in response to which a healthy psyche cannot defend itself. The feeling of total helplessness compared with the traumatic experience sets the point of crystallization for further trauma. Helplessness is a difficult feeling to endure. This is presumably the reason why the psyche is not able to easily become peaceful after an overwhelming occurrence. Instead it tries on the one hand to hinder the return of the memory of the trauma in order to protect itself from further traumatization. On the other hand, there is a type of pressure to often deal with the incident in order to be able to find the fault of this threatening experience at least in thought, and perhaps in that to reach a process whereby the helplessness of the experience could be conquered through a new security or certitude. The traumatized person rocks back and forth between two opposite conditions - the "renunciation" (avoidance, dissociation) of the occurrence and the pressure of having to constantly remember it (intrusion). From the psychoanalytic viewpoint, these two opposite motivations deal in the classical sense with an intrapsychic conflict. Modern psychodynamic theory is derived from this trauma model.

The model emphasizes the effects of early development, especially physical and sexual trauma, with the simultaneous lack of protection of the child on psychic development. Up to now, research has shown that early traumatization is associated with deficits in the ability to steer intense affects highly unsettled by their attachment abilities (analogous to dysregulation risk associated with attachment disorganization). The effects of early traumatization often include attention and concentration deficits, antisocial behavior, the presence of physical symptoms as substitute 
expressions of emotional problems (somatization), as well as deep seeded hopelessness and a lack of basic trust. Early trauma has the most debilitating the consequences because, traumatic experience threatens the stability and the differentiation of the personality structure. The development of its affects, self confidence and trust requires a constant environment that supports stable and positive relationships to the parents.

This perspective suggests that it is reasonable to believe that the origin of Gloria's vulnerability was her repeated beating by her stepfather combined with maternal psychological absence. She had learned at an early age to internalize this experience and interpret beating as the deserved and expected consequence of mischief. She could neither acknowledge nor speak about trauma under these conditions. Instead, she blamed herself and rendered these experiences taboo for a long time.

\section{TREATMENT SUGGESTIONS}

Gloria's response to starting trauma therapy was traumatic in itself. She did not want to look inside and remember the rape that she has tried to repress for more than 20 years. Since the fainting attacks are probably strongly connected to the trauma, an avoidance of treatment of the trauma would probably not improve her disease. A premature treatment of the trauma without an established working alliance would however be contraindicated, because of Gloria's "gruesome" previous experience.

We would suggest the following key tasks in a psychodynamic treatment plan for this patient based on the AAP:

1. Establish a secure base for this patient. This would mean not being intrusive and postpone delving into the rape experience until an alliance was established. Gloria's unresolvedpathological chronic mourning classification on the AAP is also supports delaying exploring trauma and parenting failures because they are disorganizing and she is not able to contain feeling desperate, stranded, and helpless. She could not trust others to help her, and this would extend to an inability to trust her therapist. Rather, building on the hope Gloria alluded to in the Bed response bodes well for beginning the therapeutic relationship to build an alliance.

Part of the secure base therapist position would include helping Gloria develop a more integrated self-object representation. Gloria's chronic representation of self as embodied the classic contradictory themes, as evidenced on the AAP. Her representation of self juxtaposes self-protective capacity with helplessness. One view was the self as frightened and helpless: I am frightened and helpless and cannot tolerate or verbalize it. The corollary theme was the self as having the capacity for protection: "I can protect myself and survive." What becomes clear is that deactivation defenses neutralize and turn her attention away from her pain, thus maintaining trauma segregation and prevent her from understanding why she becomes dysregulated, "I dissociate and don't know why."

Other feature of the secure base position would help Gloria change her representation of object; that is, change the idealization of the stepfather to become more realistic. She would also need to accept the fact that, in attachment theory terms, her mother rejected her and did not protect her enough, which is why she had to learn to protect herself. Her avoidance, facilitated by deactivating defenses, is a reasonable response to her experience but is a maladaptive.

2. Diminish deactivating defenses. Strengthen Gloria's ability to tolerate negative feelings. This can help her face and accept the physical signs of distress in order to reduce the autopilot autonomic reactions. This can also help mitigate feelings of blame and foster increased ability for affect tolerance.

3. Re-organize attachment dysregulation that is strengthened by deactivation. Help Gloria not reject and be frightened intimacy and closeness, and accept relationships with an authentic self who has weaknesses.

The therapist should be careful of being silent and appearing anonymous, since, for Gloria who is already neutralized and deactivated, this behavior would mean rejection. With this patient, it would be expected that the silence of the analyst could activate the previous mode with the mother, as shown in the Bed story and described in her childhood as her mother's withdrawal of love: "She did not speak to me for days." One can readily expect also that this relationship pattern will probably appear in the transference. Therapeutic abstinence in the sense of being silent and non-responding may instill more tension and anxiety. Technical neutrality in a modified way (e.g., Kernberg et al., 2008) and a warm, accepting and in general empathetic position at the right moment seems to be the most useful technique recommendation until the danger of a retraumatization is attenuated. According to Kernberg et al. (2008) technical neutrality might be an ideal point of departure within the treatment of traumatized patients, like Borderline patients, at large and within each session because it counters patients' tendency to externalize their intrapsychic conflicts. However, at times it needs to be disrupted because of the urgent requirement for limit-setting and even in connection with the introduction of a major life problem of the patient that, at such point, would seem a non-neutral intervention of the therapist. Such deviation from technical neutrality may be indispensable in order to protect the boundaries of the treatment situation, and the patient from severe suicidal and other self-destructive behavior, and requires a particular approach in order to restore technical neutrality once it has been abandoned.

\section{CONCLUDING REMARKS}

Our goal in this paper was to demonstrate the complexity of trauma-related disorders as informed by attachment theory and psychodynamic perspectives for the purpose of psychotherapy. The response to trauma is embedded in patients' interpersonal difficulties and representations of self and attachment figures. Attachment representations should receive at least as much attention as their traumatic memories and symptoms (i.e., dissociative experiences dissociative defenses). The knowledge of the mental processes linked to traumatic dysregulation and disorganization of attachment should guide the therapist's understanding of these difficulties. Some patients are frozen in a state of chronic pathological mourning, such as the case described here. Responses in other patients may take other forms, including other forms of mourning, such as preoccupation with personal suffering or failed mourning (Bowlby, 1980; George and West, 2012). The case analysis of Gloria, integrating 
the AAP with psychodynamic interpretation, demonstrates the phenomenological overlap and the developmental continuity between childhood attachment behavior and the behavior of adult dissociative patients within the therapeutic relationship (Liotti, 1993, 1995; Fonagy, 1999; Muscetta et al., 1999; Liotti and Intreccialagli, 2003). Correction of patients' representations of attachment should become an important aim of the treatment.

One of the advantages of attachment assessment using the AAP is that the pictures scenes serve as stimuli for individual narratives. This means frightening memories can show up in a story without necessarily being articulated as one's own experiences. Gloria's predominant fear at the beginning of treatment was having to describe her trauma. She was so terrified that she abandoned therapy for quite a long time. Using the AAP in the context of an initial clinical assessment, the clinician gains specific knowledge about what kind of words might be eerie and traumatic for the patient due to his or her individual story. The clinician can then be more aware and careful in pursuing the details associated with a patient's fear, which certainly will be reactivated in the therapeutic dyad. With the help of an understanding of individual traumatic dysregulation and defensive structure as provided by the AAP, therapeutic interventions can focus step by step on helping patients to understand their intense emotional reactions of helplessness in the context of the treatment setting. According to Fonagy and Bateman (2006), the patient must be helped to consider who engendered the feeling and how, and to explore whether the feelings have occurred or are connected to events either in the immediate or longer term past.

Gloria presented herself as a very strong and autonomous person. There was no evidence of this person in the AAP, which demonstrated that she did not truly view herself as autonomous. Gloria's outward "strength" was controlling others, a strategy developed to manage frightening feelings of helplessness, abandonment, and isolation in the context of maltreatment and rejection (Solomon and George, 2011). Her strength was constructed from a disorganizing dissociation triangle and she knew and played out the script for each of its roles.

In thinking about the benefits of using the AAP in clinical settings, we must also discuss cautions and limitations. Developmental attachment assessments as designed to be stressful in order to be able to capture patterns of attachment representation and defensive processes. Using a picture set for assessment is a benefit of the AAP methodology, but the picture stimuli may become triggers, especially for individuals with PTSD. Because PTSD patients may be in a state of severe traumatization, it is possible that they may not be able to encode and respond to the task, which is called "constriction" (e.g., the person says that he or she is unable to create a story or hands the picture back to the interviewer saying they cannot or do not want to tell a story). Taking that into account, we stress that it would be very important to complete the AAP assessment in a supportive and caring clinical environment. Although more research is needed on the use of the AAP with disturbed patients, it is a promising instrument that has the potential to formulate psychodynamic hypotheses and treatment goals (see also Finn, 2011).

\section{ACKNOWLEDGMENTS}

We acknowledge the cooperation of the patient, her therapist, and the collaboration of Dr. Markus Pawelzik in making this case available.

\section{REFERENCES}

Adam, K. S., Keller, A. E., and West, M. (1995). "Attachment organization and vulnerability to loss, separation and abuse in disturbed adolescents," in Attachment Theory: Social, Developmental and Clinical Perspectives, eds S. Goldberg, R. Muir, and J. Kerr (Hillsdale, NJ: Analytic Press), 309-341.

Allen, J. P. (2008). “The attachment system in adolescence," in Handbook of Attachment: Theory, Research, and Clinical Applications, 2nd Edn, eds J. Cassidy and P. R. Shaver (New York, NY: Guilford Press), 419-435.

Bowlby, J. (1969). Attachment and Loss: Vol. 1 Attachment. New York, NY: Basic Books.

Bowlby, J. (1973). Attachment and Loss. Vol. 2 Separation: Anxiety and Anger. New York, NY: Basic Books.

Bowlby, J. (1980). Attachment and Loss. Vol. 3 Loss: Sadness and Depression. New York, NY: Basic Books.

Cassidy, J., and Kobak, R. R. (1988). "Avoidance and its relation to other defensive processes," in Clinical Implications of Attachment, eds J. Belsky and T. Nezworski (Hillsdale, NJ: Lawrence Erlbaum), 300-323.

Diamond, D., and Blatt, S. (1999). Prologue: attachment research and psychoanalysis. Psychoanal. Inq. 19, 424-447. doi: 10.1080/0735169990 9534263

Dozier, M., Stovall, K. C., and Albus, K. E. (2008). "Attachment and psychopathology in adulthood," in Handbook of Attachment, 2nd Edn, eds J. Cassidy and P. R. Shaver (New York, NY: Guilford Press), 718-744.

Eagle, M. (2013). Attachment and Psychoanalysis. New York, NY: Guilford Press.

Fearon, R. M. P., and Mansell, W. (2001). Cognitive perspectives on unresolved loss: insights from the study of PTSD. Bull. Menninger Clin. 65, 380-396. doi: 10.1521/bumc.65.3.380.19845

Finn, S. E. (2011). Use of the Adult Attachment Projective Picture System (AAP) in the middle of a long-term psychotherapy. J. Pers. Assess. 95, 427-433. doi: 10.1080/00223891.2011.595744

Fonagy, P. (1999). The transgenerational transmission of holocaust trauma: lessons learned from the analysis of an adolescent with obsessive-compulsive disorder. Attach. Hum. Dev. 1, 92-114. doi: 10.1080/14616739900134041

Fonagy, P. (2001). Attachment Theory and Psychoanalysis. New York, NY: Other Press.

Fonagy, P., and Bateman, A. (2006). Progress in the treatment of borderline personality disorder. Br. J. Psychiatry 188, 1-3. doi: 10.1192/bjp.bp.105.012088

Freud, S. (1920). Jenseits des Lustprinzips. G.W. 13, 1-69.

George, C. (2013). Pathological grief: attachment and risk. Paper Presented at the Annual Meeting of the Society for Personality Assessment. Chicago, IL.

George, C., and Solomon, J. (1999). The development of caregiving: a comparison of attachment and psychoanalytic approaches to mothering. Psychoanal. Inq. 19, 618-646. doi: 10.1080/07351699909534268

George, C., and Solomon, J. (2008). "The caregiving system: A behavioral systems approach to parenting," in Handbook of Attachment: Theory, Research, and Clinical Applications, 2nd Edn, eds J. Cassidy and P. R. Shaver (New York, NY: Guilford Press), 833-856.

George, C., and West, M. (1999). Developmental vs. social personality models of adult attachment and mental ill health. Br. J. Med. Psychol. 72, 285-303. doi: $10.1348 / 000711299159998$

George, C., and West, M. (2012). The Adult Attachment Projective Picture System: Attachment Theory and Assessment in Adults. New York, NY: Guilford Press.

George, C., West, M., and Pettem, O. (1997). The Adult Attachment Projective. Oakland, CA: Mills College.

George, C., West, M., and Pettem, O. (1999). "The adult attachment projective: disorganization of adult attachment at the level of representation," in Attachment Disorganization, eds J. Solomon and C. George (New York, NY: Guilford Press), 462-507.

Gullestad, S. E. (2001). Attachment theory and controversial issues: controversial issues. Scand. Psychoanal. Rev. 24, 3-16. doi: 10.1080/01062301.2001.10592610

Horowitz, M. J. (1988). Formulation of states of mind in psychotherapy. Am. J. Psychother. 42, 514-520. 
Kernberg, O. (1994). Review of pathological organizations in psychotic, neurotic, and borderline patients. Int. J. Psychoanal. 75, 159-162. doi: 10.1037/h00 85218

Kernberg, O. F., Jeomans, F. E., Clarkin, J. F., and Levy, K. N. (2008). Transference focused psychotherapy: overview and update. Int. J. Psychoanal. 89, 601-620. doi: 10.1111/j.1745-8315.2008.00046.x

Kihlstrom, J. F. (2005). Dissociative disorders. Annu. Rev. Clin. Psychol. 1, 227-253. doi: 10.1146/annurev.clinpsy.1.102803.143925

Liotti, G. (1993). "Disorganized attachment and dissociative experiences: an illustration of the developmental-ethological approach to cognitive therapy," in Cognitive Therapies in Action, eds K. T. Kuehlvein and H. Rosen (San Francisco, CA: Jossey-Bass), 213-239.

Liotti, G. (1995). "Disorganized/disoriented attachment in the psychotherapy of the dissociative disorders," in Attachment Theory: Social, Developmental and Clinical Perspectives, eds S. Goldberg, R. Muir, and J. Kerr (Hillsdale, NJ: Analytic Press), 343-363.

Liotti, G. (2004). Trauma, dissociation, and disorganized attachment: three strands of a single braid. Psychotherapy 41, 472-486. doi: 10.1037/0033-3204.41. 4.472

Liotti, G., and Intreccialagli, B. (2003). "Disorganized attachment, motivational systems and metacognitive monitoring in the treatment of a patient with borderline syndrome," in Attachment Theory and the Psychoanalytic Process, eds M. Cortina and M. Marrone (London: Whurr), 356-381.

Lyons-Ruth, K., and Jacobvitz, D. (2008). "Attachment disorganization, unresolved loss, relational violence, and lapses in behavioral and attentional strategies," in Handbook of Attachment: Theory, Research, and Clinical Applications, 2nd Edn, eds J. Cassidy and P. R. Shaver (New York, NY: Guilford Press), 666-697.

Muscetta, S., Dazzi, N., DeCoro, A., Ortu, F., and Speranza, A. M. (1999). States of mind with respect to attachment and change in a psychotherapeutic relationship. A study of the coherence of transcript in a short-term psychotherapy with an adolescent. Psychoanal. Inq. 19, 885-921. doi: 10.1080/073516999 09534279

Schore, A. N. (2001). The effects of early relational trauma on right brain development, affect regulation, and infant mental health. Infant Ment. Health J. 22, 201-269. doi: 10.1002/1097-0355(200101/04)22:1<201::AID-IMHJ8> 3.0.CO; $2-9$
Slade, A. (2000). The development and organization of attachment: implications for psychoanalysis. J. Am. Psychoanal. Assoc. 48, 1147-1174. doi 10.1177/00030651000480042301

Solomon, J., and George, C. (2000). “Toward an integrated theory of caregiving," in WAIMH Handbook of Infant Mental Health, eds J. Osofsky and H. Fitzgerald (New York, NY: Wiley), 323-368.

Solomon, J., and George, C. (2011). "The disorganized attachment-caregiving system: Dysregulation of adaptive processes at multiple levels," in Disorganized Attachment and Caregiving, eds J. Solomon and C. George (New York, NY: Guilford Press), 3-24.

Steele, H., and Steele, M. (2008). Clinical Applications of the Adult Attachment Interview. New York, NY: Guilford Press.

van der Kolk, B. A., van der Hart, O., and Marmar, C. R. (1996). "Dissociation and information processing in posttraumatic stress disorder," in Traumatic Stress: The Effects of Overwhelming Experience on Mind, Body, and Society, eds B. A. van der Kolk, A. C. McFarlane, and L. Weisaeth (New York, NY: Guilford Press), 303-327. Weinfield, N. S., Sroufe, L. A., Egeland, B., and Carlson, E. (2008). "Individual differences in infant-caregiver attachment," in Handbook of Attachment: Theory, Research, and Clinical Applications, 2nd Edn, eds J. Cassidy and P. R. Shaver (New York, NY: Guilford Press), 78-101.

Conflict of Interest Statement: The authors declare that the research was conducted in the absence of any commercial or financial relationships that could be construed as a potential conflict of interest.

Received: 01 May 2014; accepted: 20 July 2014; published online: 05 August 2014. Citation: George $C$ and Buchheim A (2014) Use of the adult attachment projective picture system in psychodynamic psychotherapy with a severely traumatized patient. Front. Psychol. 5:865. doi: 10.3389/fpsyg.2014.00865

This article was submitted to Psychology for Clinical Settings, a section of the journal Frontiers in Psychology.

Copyright (C) 2014 George and Buchheim. This is an open-access article distributed under the terms of the Creative Commons Attribution License (CC BY). The use, distribution or reproduction in other forums is permitted, provided the original author(s) or licensor are credited and that the original publication in this journal is cited, in accordance with accepted academic practice. No use, distribution or reproduction is permitted which does not comply with these terms. 


\title{
"A child's nightmare. Mum comes and comforts her child." Attachment evaluation as a guide in the assessment and treatment in a clinical case study
}

\author{
Silvia Salcuni*, Daniela Di Riso and Adriana Lis \\ Department of Developmental and Socialization Psychology, University of Padova, Padova, Italy
}

\section{Edited by:}

Osmano Oasi, Catholic University of

Sacred Heart, Italy

Reviewed by:

Osmano Oasi, Catholic University of

Sacred Heart, Italy

Raffaella Calati, IRCCS Centro S.

Giovanni di Dio, Fatebenefratelli, Italy

\section{*Correspondence:}

Silvia Salcuni, Department of

Developmental and Socialization

Psychology, University of Padua,

via Venezia 12, 35100 Padova, Italy

e-mail: silvia.salcuni@unipd.it
There is a gap between proposed theoretical attachment theory frameworks, measures of attachment in the assessment phase and their relationship with changes in outcome after a psychodynamic oriented psychotherapy. Based on a clinical case study of a young woman with Panic Attack Disorder, this paper examined psychotherapy outcome findings comparing initial and post-treatment assessments, according to the mental functioning in $S$ and $M$-axis of the psychodynamic diagnostic manual. Treatment planning and posttreatment changes were described with the main aim to illustrate from a clinical point of view why a psycho-dynamic approach, with specific attention to an "attachment theory stance," was considered the treatment of choice for this patient. The Symptom Check List 90 Revised (SCL-90-R) and the Shedler-Westen Assessment Procedure (SWAP-200) were administered to detect patient's symptomatic perception and clinician's diagnostic points of view, respectively; the Adult Attachment Interview and the Adult Attachment Projective Picture System (AAP) were also administered as to pay attention to patient's unconscious internal organization and changes in defense processes. A qualitative description of how the treatment unfolded was included. Findings highlight the important contribution of attachment theory in a 22-month psychodynamic psychotherapy framework, promoting resolution of patient's symptoms and adjustment.

Keywords: assessment, attachment, psychodynamic supportive therapy, outcome research, clinical case study

\section{INTRODUCTION}

Attachment theory in Bowlby's $(1969 / 1982,1973,1980,1988)$ and Ainsworth's $(1963,1967)$ tradition postulates that an individual's experience of early parental care contributes to the development of internal representations of self and others as safe and available. This theory offered the clinicians a scientific grounded model, which postulated and empirically demonstrated the origin of psychopathology in early separation experiences and in adverse emotional experiences (Oppenheim and Goldsmith, 2007; Cassidy and Shaver, 2008). The most recent literature endorses that attachment theory is consonant with all assessment and treatment approaches which evaluate childhood experiences as an important contributor to adult functioning (e.g., Wallis and Steele, 2001; Blatt and Levy, 2003; Diamond, 2004; BakermansKranenburg et al., 2005; Buchheim et al., 2007; Zegers et al., 2008; Buchheim and George, 2011). Throughout the case formulation and the planning of treatment, attachment theory has also the potential to provide-at least-a useful foundation for defining the target of change in psychotherapy (e.g., features of internal working models or attachment patterns), understanding the processes through which change occurs (e.g., through the development of a secure base and exploration of working models; e.g., Fonagy, 1999, 2001; Cozzolino, 2002; Parish and Eagle, 2003; Mallinckrodt et al., 2005; Wallin, 2007; Fosha, 2009; Holmes, 2010; Siegel, 2010). As Bowlby originally stated, while reconsidering classical attachment theory, Davila and Levy 2006, p. 990) stressed "five key tasks for psychotherapy: (a) establishing a secure base, which involves providing patients with a secure base from which they can explore the painful aspects of their life; (b) exploring past attachments, which involves helping patients explore past and present relationships, including their expectations, feelings, and behaviors; (c) exploring the therapeutic relationship, which involves helping the patient examine the relationship with the therapist and how it may relate to relationships or experiences outside of therapy; (d) linking past experiences to present ones, which involves encouraging awareness of how current relationship experiences may be related to past ones; and (e) revising internal working models, which involves helping patients to feel, think, and act in new ways that are unlike past relationship." Despite the increasing interest in the relevance of attachment theory as a framework to understand the unfolding of psychodynamic treatment, there is a gap between the proposed theoretical frameworks and the empirical measures of attachment used in the assessment, and only few studies addressed the interplay between attachment pattern measures, and their implication for unfolding and outcome in a psychoanalytic oriented treatment (Buchheim and Kachele, 2001; Dahlbender et al., 2004; Buchheim, 2005; Lis et al., 2008, 2011; Isaacs et al., 2009).

Interpersonal problems, adult attachment, and emotion regulation have been increasingly studied across adult anxiety disorders. Literature linked attachment and separation in infants and preschool children to separation anxiety disorder, 
agoraphobia, and panic attacks later in life, underlining how insecure attachment can lead to an increased risk for attachment psychopathology and subsequent social and emotional maladjustment/attachment and separation anxiety/school or work phobia/attachment correlations (Routh and Bernholtz, 1991). Of all the forms of anxiety, separation anxiety seems to be the one which is most likely to be associated with an anxious attachment style, because sufferers are by definition highly sensitive to real or perceived threats to relationships (Main et al., 1985). Separation anxiety would appear to be a core form of anxiety associated with panic attack disorder and with attachment problems (Hazan and Shaver, 1987; Bartholomew and Horowitz, 1991; Eng et al., 2001). Dysfunctional and not good-enough parenting and hereditary factors appear to play a role in generating early separation anxiety. However, the child's anxiety itself may generate overprotective parenting (Manicavasagar et al., 1999, 2009) which, in turn, could make children approach their caregivers both in response to dangerous external stimuli and to caregiver's permanent monitoring availability and attentiveness; moreover, overprotecting or over responsive parents could obstacle the expression of the explorative system, even when a "secure base" is provided (Pacchierotti et al., 2002). Although attachment theory suggests that anxious attachment styles are mostly associated with risks of developing anxiety disorders, neither all anxious attached patients develop panic attack disorder, nor all secure attached patients do not develop it: the latter is a weird and rare condition because, theoretically, secure early relationships with adults are the basis for the development of a sense of control and predictability accounting for normal subjects' tendency not to interpret ambiguous internal stimuli as threatening (Shear, 1991).

Based on a clinical case study of a young woman with Panic Attack Disorder- Matilde-, this paper examined psychotherapy outcome findings comparing initial and post-treatment assessments, according to the mental functioning in $S$ and $M$-axis of the Psychodynamic Diagnostic Manual (PDM; PDM Task Force, 2006) $)^{1}$. The patient's choice is motivated by this "rare combination": a PAD patient with secure attachment. The first aim of this paper was to provide incremental usefulness to the picture of the patient's idiographic and intra-subjective features, using a multi- method assessment based on (1) two performance-based attachment measures - the Adult Attachment Interview (AAI; George et al., 1984/1985/1996), and The Adult Attachment Projective Picture System (AAP; George and West, 2001, 2012), (2) the Shedler-Westen Assessment Procedure (SWAP-200; Westen and Shedler, 1999a,b), and (3) a self-report symptom scale, the Symptom Checklist 90 Revised (SCL-90-R; Derogatis, 1983; Funder, 1997; Meyer et al., 1999; Ozer, 1999).The second aim was to describe how Matilde's assessment findings - and more specifically attachment pattern analysis - could represent useful guidelines

\footnotetext{
${ }^{1}$ The PDM was developed to describe "the depth as well as the surface of emotional, cognitive, and social patterns" (p. 1) of an individual's functioning, as to improve the diagnosis and treatment of psychological disorders. PDM comprises three areas: personality patterns (Axis $P$ ), mental functioning ( $M$-axis), and symptoms ( $S$-axis). Our attention focused mainly on mental functioning or $M$-axis, "a microscopic look at mental life" (p. 8), although some attention was paid to symptoms and concerns or $S$-axis.
}

for the unfolding of a psychoanalytic therapy with a supportive approach, in an attachment theory framework (Misch, 2000).

We hypothesized that the AAI, the AAP, the SCL-90-R, and the SWAP-200 would help in focusing on the most relevant dimensions of patient's psychological functioning which make a meaningful diagnosis (Barron, 1998; Shedler and Westen, 2007) at the beginning and at the end of treatment. Attention was directed to the interplay between modification of overt symptoms and behaviors, and changes in personality functioning and adaptation; more specifically, we focused on patterns and complexities in the patient's internal organization and interpersonal functioning (Shectman and Harty, 1986; Peebles-Kleiger, 2002; Bram, 2010). A reduction in psychopathological symptoms and an improvement in mental functioning according to the PDM $M$-axis and $S$-axis were expected at the end of the therapy.

\section{CLINICAL CASE PRESENTATION: MATILDE}

Matilde was a pleasant 20-year-old young woman, who looked younger than her age. She was a self-referred patient, and was assessed for a high level of anxiety at a university-based psychology-training clinic ${ }^{2}$. Matilde had a diagnosis of Panic Attack Disorder in Axis I (DSM-IV; American Psychiatric Association [APA], 1994), and no diagnosis in Axis II. Although she was a 2-year student at the Medical School with outstanding results, she felt "anxious, confused, and insecure," "I do not know if this Faculty is good for me, maybe Biology would be better, or Pharmacy... I do not know really, I am so confused; I do not understand what is happening to me.... I am no more sure about anything." Insecurity caused her quite severe crying crises, pervasive anxiety, and some physical symptoms, such as psychomotor agitation and tachycardia. She had taken light tranquilizers in the last 3 months. She felt unable to control or understand her present distress. Since she started University, her life had been totally busy with studying, leaving no time or desire to engage in social relationships. She did not talk about any actual satisfying relationships. The only "friends" she kept in touch with were schoolmates from high school, with whom she shared school topics. She had never had a boyfriend, and felt very uncomfortable talking about romantic or sexual topics. Matilde moved away from her small native town to attend University, and she was sharing an apartment with other students next to the Medical School. She went back home to her family during University vacations. She came from an intact family, which she was very proud of. She had a 10-year-old sister, Sarah, to whom she was very attached. Sarah was described as very different from Matilde: very funny, an ironic with a lot of energy. They spent a lot of time playing together, and Matilde was unconcerned about her worries when she was with Sarah. Matilde describes her childhood with some enjoyment and unconcern while her present appears very worrying, uncertain and without any source of protection and soothing. Matilde supports a good relation with her mother, although the father is described as rigid and very involved in practical duties.

\footnotetext{
${ }^{2}$ The patient self-referred to a psychodynamic service, where therapists are trained to use an Operationalized Psychodynamic Diagnosis approach during consultation sessions, preferring free or "per area" clinical sessions to interviews (e.g., SCID).
} 


\section{APPROACH TO THE CASE: PROCEDURE AND INSTRUMENTS}

At the initial assessment phase Matilde underwent three interview sessions, two test sessions and one feedback session. In particular, Matilde's evaluation involved the administration of the AAI and the AAP, the SCL-90-R, and the SWAP-200. All results were integrated with clinical interview contents to formulate a case conceptualization, according to specific dimensions of the PDM. In the feedback session, a once-a-week psychodynamic psychotherapy with a supportive approach was proposed to and accepted by Matilde. The therapy lasted 22 months. At treatment conclusion Matilde accepted to be re-administered the AAP and the SCL90-R. Based on the last three sessions also the SWAP-200 was re-administered. All the tools administered were scored and interpreted by independent judges ${ }^{3}$. A brief description of used tools follows after timetable of administration (Table 1).

Symptom Checklist 90 Revised (Derogatis, 1983) is a 90-item self-report questionnaire scored on a five-point Likert scale of distress from 0 (none) to 4 (extreme), indicating the rate of occurrence of symptoms during the time reference (Derogatis et al., 1973). It is intended to measure symptom intensity on 10 different dimensions: somatization (SOM), obsessive-compulsive (O-C), interpersonal sensitivity (I-S), depression (DEP), anxiety (ANX, hostility (HOS), phobic anxiety (PHOB), paranoid ideation (PAR), psychoticism (PSY), and sleep difficulties (SLEEP). A Global Severity Index (GSI) of distress is calculated. According to the Italian Manual, an intensity raw score higher than one was qualified as penetrating in the clinical range. The internal consistency coefficient alphas for the nine symptom dimensions ranged from 0.77 for Psychoticism, to 0.90 for Depression. Test-retest reliability coefficients ranged between 0.80 and 0.90 after 1 week of therapy. The few validity studies of the SCL-90-R demonstrate levels of concurrent, convergent, discriminant, and construct validity comparable to other self-report inventories (Derogatis, 1983).

The Shedler-Westen Assessment Procedure (Westen and Shedler, 1999 a,b) is a set of 200 personality-descriptive statements developed for clinicians to assess adult personality traits and pathologies (Shedler and Westen, 1998). Starting from clinical interviews, the

\footnotetext{
${ }^{3}$ The self report SCL-90-R was digitally computed. Inter-reliability reached Cohen's $k=1$ for AAI and AAPs final classifications; 0.93 for AAI subscales; 0.85 for AAP codings; 0.72 for SWAP-200 final scales.
}

assessor is asked to describe the patient by arranging the statements into eight categories, from those that are not descriptive (assigned a value of " 0 ") to those that are highly descriptive (assigned a value of " 7 ") for each of the 200 personalitydescriptive variables. The instrument is based on the Q-sort method that requires clinicians to arrange items into a fixed distribution (Block, 1978). The SWAP-200 could be interpreted at a nomothetic as well as at an idiographic level. Nomothetic interpretations are carried out following two profiles. The first is the PD-T score profile of the 10 Personality Disorders included in DSM-IV (paranoid, schizoid, schizotypal, antisocial, borderline, histrionic, narcissistic, avoidant, dependent, obsessive); the Q-T profile covers 11 dimensions (psychological health, dysphoric, antisocial, schizoid, paranoid, obsessive, histrionic, narcissistic, avoidant, depressive high functioning, emotional dysregulation, dependent, hostile). Both PD-T and Q-T profiles include a score on a Healthy Functioning scale. Inter-rater reliability coefficients range from 0.70 to 0.80 . Support for the validity of the SWAP-200 is derived from its ability to predict relevant variables in expected ways, including family psychiatric history, history of abuse, social, and school functioning, violence, suicidal behaviors and attempts, attachment status, and eating disorder diagnostic groups (Westen and Muderrisoglu, 2003a,b). Idiographic narrative case description is also included in the SWAP-200 (e.g., Lingiardi et al., 2006). Both levels were used to assess Matilde. Moreover, the SWAP-200 (Westen and Shedler, $1999 a, b)$ is one of the instruments listed by PDM work-group members to be used to measure the dimensions of the $M$ axis.

The Adult Attachment Interview (George et al., 1984, 1985, 1996; Hesse, 2008) is an about $1 \mathrm{~h}$ audio-recorded semi-structured interview that explores an adult's mental representations of attachment, guiding the individual through a series of questions about past and present relationships with each parent and attachment-relevant events during childhood. The AAI focuses on the assessment of the attachment internal working model (Bowlby, 1969/1982) and assumes developmental continuity of the attachment system along life. AAI final attachment classification is evaluated on two different set of scales (1) Experience Scales that evaluate for example Loving, Rejecting, Neglect, Role Reversal, Pressure to achieve and (2) State of Mind Scales that assess Coherence, Metacognitive Processes, Lack of Recall, Passivity of Discourse, Idealization, Anger,

Table 1 | Timetable of administered tools.

\begin{tabular}{|c|c|c|c|c|c|}
\hline Administered ltime & T1 & T2 & T3 & T4 & T5 \\
\hline Patient with therapist & Three interview sessions & $\begin{array}{l}\text { Two test } \\
\text { session }\end{array}$ & Two feedback session & Therapy (lasted 22 months) & $\begin{array}{l}\text { Follow-up } \\
\text { assessment }\end{array}$ \\
\hline Patient & & $\begin{array}{l}\text { SCL90R } \\
\text { AAI } \\
\text { AAP }\end{array}$ & & & $\begin{array}{l}\text { SCL90R } \\
\text { AAP }\end{array}$ \\
\hline Therapist & & $\begin{array}{l}\text { SWAP-200 } \\
\text { PMD profile }\end{array}$ & & & $\begin{array}{l}\text { SWAP-200 } \\
\text { PMD profile }\end{array}$ \\
\hline
\end{tabular}


Derogation attitudes toward caregivers, Unresolved mourning or trauma, Feared loss of one's own child. Starting from these scales, each interview is classified in one of the primary attachment patterns: secure/autonomous, dismissing/avoidant, and preoccupied/entangled or "cannot classify." Where applicable, the "unresolved" pattern with respect to loss, trauma, or abuse could be scored. Multiple scoring is allowed (e.g., F/DS). AAI validation rests on more than 25 years of developmental and clinical research (van IJzendoorn and Bakermans-Kranenburg, 2008). Rigorous psychometric testing and meta-analyses of the AAI demonstrate its stability, and discriminant and predictive validity in both clinical and non-clinical populations. In a recent meta-analysis of 61 clinical samples (van IJzendoorn and Bakermans-Kranenburg, 2008), strong associations were found between psychiatric diagnoses (i.e., anxiety disorders, borderline personality disorder) and attachment insecurity.

The Adult Attachment Projective Picture System (George and West, 2001) is based on a standardized set of seven drawn pictures divided in Alone and Dyadic stimuli ${ }^{4}$. The pictures describe major attachment events, potential threat of separation, illness, solitude, death, and abuse. The stimuli are: child at window (window); departure; bench; bed; ambulance; cemetery; and child at corner (corner). Individuals are asked to make up a story for each image in which they describe what is going on in the picture, what led up to the scene, what the characters are thinking or feeling and what might happen next. The responses are audiotaped for transcription and verbatim analysis. The AAP assesses attachment in the Bowlby-Ainsworth tradition (West and George, 2002; George and West, 2012). The AAP Coding System, leads to four adult attachment classification patterns, - secure/autonomous, dismissing, preoccupied, unresolved - as they were traditionally assessed in the AAI, even if no multiple scoring is allowed. The AAP also assesses

${ }^{4}(1)$ Neutral (children playing ball); (2) child at window (alone); (3) departure (dyad); (4) bench (alone); (5) bed (dyad); (6) ambulance (dyad); (7) cemetery (alone); (8) child in corner (alone).

Table 2 | Results from SCL-90-R and SWAP-200 in assessment phase.

\begin{tabular}{ll}
\hline Diagnosis & Assessment \\
\hline DSM-IV & Axis I: panic attack disorder \\
SCL-90-R & GSI $=1.14$ \\
& SOM $=1.20$ \\
& O-C $=1.40$ \\
& DEP $=1.85$ \\
& ANX $=1.70$ \\
SWAP-200 & PD Factor \\
& Obsessive-compulsive (68) \\
& Schizoid (60) \\
& Q Factor Avoidant style (60.69) \\
& High Functioning (55.40) \\
\end{tabular}

For descriptive purposes, we report only meaningful values of the different instruments, using SCL-90-R clinical cut off $=1.20$, and SWAP-200 cut off of $50<T \leq 60$ (some evidence) and $T>60$ (high evidence). attachment personal elements that individuals may exclude from conscious awareness. Attachment classification using the AAP is determined by evaluating patterns of responses using a set of seven scales grouped under three major categories: discourse, content, and defensive processing. These dimensions evaluate the attachment story content related to the hypothetical characters portrayed in the stimuli, to defenses, and to self-other boundaries in narrative discourse (George and West, 2001, 2012). Discourse codes evaluate personal experience. Content codes include agency of self and connectedness for alone pictures, and Synchrony for dyadic pictures. Finally, the AAP codes for defensive exclusion, segregated systems, deactivation, and cognitive disconnection (Bowlby, 1980). They represent different degrees of "protection" from dangerous distressful events. Segregated systems describe a mental state in which painful attachment-related memories are isolated and blocked from conscious thought and rooted in experiences of trauma or loss through death (Bowlby, 1980). Deactivating defensive processes are defined as attempts to dismiss, cool off, or shift attention away from attachment events, individuals, or feelings in response to the picture stimuli. Cognitive disconnection processes literally disconnect the elements of attachment from their source, thus undermining consistency and the capability of holding in one's mind a unitary view of events, emotions, and the individuals associated with them. The most recent review of AAP reliability and validity was published in George and West (2012). AAP-AAI convergence for secure versus insecure classifications was 0.95 ( $\kappa=0.75, p=0.000)$; convergence for the four major attachment groups was $0.89(\kappa=0.84, p=0.000$; George and West, 2001, 2012; West and George, 2002). The AAP has also been shown to be useful in studying the neurobiological and emotional expression correlates of attachment in non-clinical and clinical samples (Buchheim and Benecke, 2007; Buchheim et al., 2007, 2008, 2009; Fraedrich etal., 2010) as well as in single case studies (Lis et al., 2011).

Both AAI and AAP show individual strengths in measuring attachment patterns, but their combined use increments their overall usefulness. The AAI, the golden standard measure of adult attachment (Bakermans-Kranenburg and van Ijzendoorn, 1993), focuses on the assessment of the representational model and coherence of mind, and assumes developmental continuity of the attachment system, evaluating abuse and loss in one's personal history. The AAP, based on the Bowlby-Ainsworth tradition (West and George, 2002; George and West, 2012), assesses current views of self, attachment figures, and expectations about the productiveness of attachment relationships, elucidating how current experience activates attachment accomplishment, disappointment, and trauma from the past (West et al., 1995; George and West, 2012). The AAP is also more trauma sensitive and underscores defense patterns (e.g., Hesse, 2008; George and West, 2012). The combined use of the AAI and the AAP gives the chance to portray a complex image of the patient's attachment pattern, providing a detailed narrative about life attachment activators such as separation, fear, solitude, and danger, shedding light on the unconscious defensive mechanisms and exploring the accessibility of attachment figures during the life-span (e.g., Hesse, 2008; George and West, 2012). The SCL-90-R contributed to get Matilde's self-evaluation of symptoms. 


\section{ASSESSMENT FINDINGS}

Results from DSM-IV diagnosis, SCL-90-R and SWAP-200 during the assessment phases are described in Table 2. Results from attachment tools are reported below and AAI subscales are shown in Tables 3 and 4.

Matilde's AAI was scored F2/Ds3, secure with features of dismissing or some restriction in feelings of attachment $(\mathrm{F} 2=$ free somewhat dismissing or restricted in attachment; DS3 = dismissing restricted in feelings with some evidences of Lack of Memories; George and Solomon, 1996; see Tables 3 and 4). Matilde secure pattern was so defined because she was able to explore his or her thoughts and feelings about childhood experiences, with fresh speech, humor and forgiveness, without becoming angrily or passively overwhelmed while discussing them. Generally, Matilde appeared to be aware of the nature of experiences with her parents and of the effects of such experiences on her present state of mind and on her personality. Nevertheless, she remained a little bit restricted in her emotional expressions, preferring to rationalize. State of mind scales tapped a dismissing feature, showing a slight tendency to idealize parents and some lack of memories. Further information about Matilde derived from a qualitative analysis of the AAI. She did not report any severe illness, traumatic or abuse experience. However, separations caused her some distress, but she felt always supported and listened by her mother.

Table 3 | AAl experience scales.

\begin{tabular}{lll}
\hline & Experience scales & \\
\hline & Mother & Father \\
\hline Loving & 7.0 & 5.5 \\
Neglect & 1.0 & 1.5 \\
Rejection & 1.5 & 1.5 \\
Pressure to achieve & 1.0 & 3.0 \\
Role Reversing & 1.0 & 1.0 \\
\hline
\end{tabular}

AAl State of Mind Scales end Experience Scales range from 1 to 9 (1-3 very low: 4-6 medium; 7-9 very high).

Table 4 | AAI state of mind scales.

\begin{tabular}{lllll}
\hline \multicolumn{5}{c}{ State of Mind } \\
\hline & Mother & Father \\
\hline Idealization & 2.5 & 2.0 & Lack of memory & 4.0 \\
Derogation & 2.0 & 3.0 & Preoccupied anger & 1.0 \\
& & Passivity & 1.0 \\
& & Fear of loss & 3.0 \\
& & Metacognitive & 4.0 \\
& & Coherency transcript & 6.0 \\
& & & Coherency mind & 6.0 \\
\end{tabular}

AAI State of Mind Scales end Experience Scales range from 1 to 9 (1-3 very low; 4-6 medium; 7-9 very high).
She described herself as a very calm girl but, during early childhood, she was very shy and very worried about separation: "I became very agitated when I did not see my parents, when they were not there, when they were away from home," "Once we were at the lake. I was on the one side of the road and my parents were on the other side. Some people passed and so I could not see my parents anymore. I did not see them anymore and I began to scream." However, she remembered that during her summer camp experience, when there were no well-known friends or schoolmates: "I felt the distance from home, I felt lost and confused ... I was very happy to go back home. The bus journey to go back home was very stressful," "I do not like changes. I am worried about changes."

She described the relationship with her mother as: affectionate, playful, reciprocal, supportive, and protective. When she was asked to recall a specific example in respect with "supportive relationship" she reported that "I gulped a small toy and it remained caught in my throat. I had to be taken to the hospital. I was very agitated, I screamed that I was frightened of dying. Mammy was very supporting... I mean comforting." She was able to identify a specific episode, but in a superficial and not qualitative consistent manner (Grice's qualitative maxim): the adjective-descriptor (supportive) of relationship with her mother was supported with a second generalized positive descriptor (comforting). The adjectives she chose to describe the relationship with her father were: always affectionate, playful, formal ("home rules had to be respected, for instance times for lunch and dinner"), respectful ("Nothing escaped from him; his words had always a weight"), and important. Such aspects were more linked to father's role as a parent and to school achievement: "I felt very bad about his criticism." Matilde felt closer to her mother than to her father, from whom she felt more detached. Moreover, during school years she always felt a little bit anxious and agitated about school achievement and completion. Beside all these difficulties, she always felt supported and sustained by her mother, and at the end she demonstrated herself as very forgiving toward her father's severity. When asked to imagine the possibility of being separated from her child, Matilde reported to feel " $a$ big void, a big feeling of lost, of mourning, a big pain, an absence of being complete" and the three wishes about this child when he would be 20-years old were: "to be able to choose, to have a clear reasoning, not being confused, and to be able to be autonomous."

Matilde was judged as secure on the AAP (F): she showed, at the representational level, a flexible and organized thinking about attachment situations and relationships (Bowlby, 1969/1982). She was confident that she could rely on attachment figures to achieve care, safety and protection and, when alone, she could access internalized attachment relationships (George and Solomon, 1996, 1999). In response to two of the alone stimuli - Window and Cemetery- as a secure individual, she demonstrated the ability to think (i.e., Internalized Secure Base) and to take constructive action. She also used flexible defensive processes to integrate attachment feelings and events. Using these resources she was able to re-organize her attachment-related feelings, also in the few cases (Bed and Cemetery Stories) when she became disorganized by feelings of loss and danger. From the pattern of story responses it appears that Matilde, above all other response qualities, genuinely valued and represented the capacity for integration of self and 
relationships. The responses to the Alone pictures demonstrated Matilde's internal resources, such as the potential availability and responsiveness of attachment figures. As a representative example of this attitude the Cemetery picture (a man stands by a gravesite headstone) story is reported.

"A gentleman who had a bad day or felt sad or depressed or undervalued because of an episode that happened during the day and goes and visits his father... he feels reassured because he found a place where to think about his life by himself and then he will go back home and will be able to reconsider what happened from a different point of view."

In Cemetery, Matilde reveals the intensity of feelings of pain associated with loss: she tries to deal with them through some form of uncertainty and desire to withdraw (cognitive disconnection). These forms of organized defensive mechanisms keep Matilde's attachment system activated but they cannot prevent her from becoming dysregulated, as evidenced by painful attachmentrelated feelings of loss represented by the appearance of a them where no clear distinction is made between life and death ("he goes and visit his father"). A segregated system (spectral domain) was activated by the picture features, which portray a man visiting a grave. However, Matilde was able to depict the man as engaged in some kind of "thinking." The man is able to "reconsider what happened from a different point of view." This process belongs to Internalized Secure Base, and portrays Matilde's ability to clearly differentiate between the living and the dead. The Dyadic picture stimuli portray attachment-caregiving dyads. The responses to Dyadic picture stimuli demonstrate Matilde's representation of the self and other in attachment situations when attachment figures are present and accessible, but they also demonstrate the use of attachment figures to quell the attachment anxiety aroused in the scenes depicted in the cards. Bed picture (a child and woman sit opposite to each other on the child's bed) could be a representative example.

"A boy had a nightmare during the night and his mother woke up eh... now he is scared and he would like to be close to his mum ... the mum is trying to soothe him and she will be able to do it ... the boy will come back to sleep quietly... (Anything else?) no.. maybe the bad dream was... was about the fact of staying alone without his mom ... and now... he wants his mom first!"

In Matilde's story, the child signals his attachment need after a "nightmare" (segregated system in AAP) and the mother is able to provide a contingent and soothing answer, containing the potential breakdown of the attachment system and resolving the segregated system. Both AAI and AAP classified Matilde as secure with somewhat dismissing or restricted feelings in attachment without elements of unresolved abuse or trauma. However, both tools detected some shortcomings about fears of separation and danger. The AAI was not able to draw attention in an exhaustive way to how Matilde experienced abandonment fears and felt scared without the presence of her parents. Instead the AAP clearly depicted this nuance, under a secure pattern, showing that her attachment was threatened by painful attachment-related feelings of loss, and by a nightmare (in Bed picture), a signal of danger. In both tools she demonstrated her ability to re-organize herself, but these disturbing feelings kept being alive underneath her reorganized secure pattern.

\section{CASE FORMULATION BASED ON PDM AXES}

$S$-axis - Matilde had a diagnosis of DSM-IV (American Psychiatric Association [APA], 1994), and showed a slightly High Functioning profile with Obsessive, Schizoid-Avoidant and Dysphoric characteristics, in both PD and Q factors in SWAP-200. Matilde's SCL90-R symptom profile revealed depression, anxiety, obsessivecompulsive, and somatization scores in the clinical range (Table 2).

$M$-axis - this Axis describes nine dimensions, which systematize the capacities that contribute to an individual's personality and overall level of psychological health or pathology.

\section{Capacity for regulation, attention, and learning}

In the clinical interview, she said, "I lost control of my body and thinking." She appeared in a profound state of crisis and she appeared to be unable to cope with it and with connected feelings of anxiety and distress. She (a) adhered rigidly to daily routines and became anxious or uncomfortable when they were altered, (b) had trouble making decisions and was indecisive or vacillated when faced with choices, (c) was overly concerned with rules, procedures, order, organization, and schedules: all obsessive strategies which would interfere with processes that support attention and learning from experience. However, according to Bowlby, being secure at both AAI and AAP means that Matilde had basic capacities for regulation. Matilde appeared to believe in the seeking of proximity and support as effective ways in regulating distress, in particular in AAP Dyadic pictures. However, at the moment of assessment, she was not able to recur to her internalized security patterns, showing how an emotional regressive crisis was rising up. Although Matilde subjectively felt unable to cope with it and was very frightened by it, according to the AAP and AAI, the dysregulation appeared momentary and not prolonged. It seems she was still functioning as she described herself in the early childhood memory, when she could not see her parents and she got anxious at the thought of being lost. However, her basic secure attachment suggests that, thanks to the therapy, she could re-establish her capacity of self-regulation, a secure person's basic characteristic.

\section{Capacity for interpersonal relationships}

Although she was excessively devoted to work and productivity, compromising leisure and relationships, her secure attachment pattern at the AAI and AAP indicated that Matilde had a positive representation of available adults who can offer protection, support, care, and comfort in threatening and stressful situations. The AAP supported also her potential ability to be connected with other relational systems such as partners and peers, almost in a concrete manner, since she was able to tell stories in which she described specific connections with friends and other people in general. However, her agency, connectedness, and synchrony were at the moment "quite silent" in her everyday life. She needed help to regain these resources.

\section{Quality of internal experiences}

In AAI and AAP she felt reassured by (her) mother's proximity, soothing, and comfort. However, episode and story plots clearly indicated some separation anxieties and worries in respect to changes, which she faced using dismissing defense mechanisms. AAP clearly depicted how under a secure pattern, her attachment 
was threatened by painful attachment-related feelings of loss and danger. Until that moment, such feelings were isolated and blocked from conscious thought. Even if she was able to deal with these experiences in childhood thanks to her mother's comfort, her fear of loss connected to the fear of being alone and unprotected seem to re-emerge We hypothesized that she was having trouble in coping with new adolescence-through-young adulthood tasks, such as the adult separation-individuation process. According to the SWAP-200, she experienced a sense of personal dissatisfaction, poor self-regard, low self-esteem, lack of confidence, and chronic self-criticism. Her unrealistically high standards together with her expectation of being "perfect" above all in her achievements, made her feel guilty, depressed and despondent, with negative self-regard toward others, and the world at large.

\section{Affective experience, expression, and communication}

According to the SWAP-200, Matilde tended to defend herself via the inhibition of emotion expression, by means of abstract thinking and intellectualized terms, and appeared unable to recognize her wishes and impulses. Apparently, intellectualization and disavowal defenses (above all rationalization) led her to the avoidance of expressed conflict and emotions - both positive and painful. This emotional constriction resulted in a bottled up affect being channeled into panic attacks. The SWAP-200 stressed the risk of recurrent episodes of overt anxiety, tension, nervousness, and irritability and difficulty in acknowledging or expressing underlying feelings of anger and resentment. The AAP and AAI confirmed that underneath this block of affection there was a rich and positive affective state she had internalized during childhood life experiences. However, although not so rigid, her present affective state of constriction and inhibition was consistent with the rigid attempt to neutralize affect using deactivating defenses in the AAP. The emotions, which were bottled up in the segregated system, surely carried a negative and overwhelming emotional tone, which at the moment she was unable to deal with.

\section{Defensive patterns and capacities}

The SWAP-200 indicated the extent to which Matilde tended to defend her from expressing emotions, by abstract thinking and intellectualized terms. Although her defenses were at a matureneurotic level, they were not solid enough to allow her to avoid the recourse to symptoms and anxiety. From an attachment viewpoint-AAP-Matilde shows a different picture underneath. Here defenses appeared organized and flexible, but in order to keep a regulated attachment she relied more on deactivation than on cognitive disconnection (George and West, 2012).

\section{Capacity to form internal representations}

Matilde was able to form internal representations of self and others, and her experiences were symbolized mentally. However, in the current state of distress, some emotions and conflicts were expressed somatically through her somatic symptoms and panic attack episodes.

Capacity for differentiation and integration (ego strength, selfcohesion, stability of reality testing). Overall, her AAP stories and her narrative in the AAI revealed that she was able to look realistically at herself, people, and relationships. Also during the clinical interview, a solid, stable and good child image emerged, but was not integrated with an adolescent and adult image: Matilde's ego was fragile and was shattered by a large number of symptoms, her self-image was damaged and not well integrated; moreover, she looked younger than her age and never talked about sexuality or intimate relationships.

\section{Self-observing capacities}

Matilde did not demonstrate good self-observation capacities. Her level of current distress, extension of intellectualization and rationalization defenses, avoidant and constricted emotional style did not allow for an adult and mature emotional insight.

Capacity to construct or use internal standards and ideals. SWAP-200 showed how she currently set unrealistically and childish high standards for herself and how she appeared intolerant of her own human defects.

\section{THERAPEUTIC STANCE AND THERAPY GUIDING CONCEPTION}

Matilde looked younger than her age and did not talk about sexuality or intimate relationships and we supposed that she did not undergo a true adolescent process. Looking at her secure attachment pattern, the therapist hypothesized that the present state of dysregulation and symptomatic picture is transitory and derived from the new young adulthood tasks she has now to deal with during her transition toward adulthood, such as moving to University. From a psychoanalytic as well as an attachment-oriented viewpoint, we hypothesized she was not able to face adolescent and adult separation-individuation processes. According to attachment theory, attachment relationships foster integration of attachment with relationships in peer behavioral systems during adolescence and adulthood: these include friendships and romantic relationships (West and George, 1999; Allen, 2008; George and Solomon, 2008; George and West, 2012). Psychoanalytic theories also agree that the individual needs to face adolescence as a separation-individuation process, where adolescents need to acquire an individual separate self-identity through identification with parents and separation from childhood ties. The AAP and AAI were taken into account, making the therapist sensible to specific topics concerning separation, loss, and loneliness, able to reactivate and unleash childhood attachment-related memories of fear of being lost and completely alone during treatment itself. Matilde needed to explore this topic with a therapist who would represent for her, in the transference, a secure parent similar to the one she had already experienced in her life via her mother's supporting stance. In particular, the therapist expected that supportive psychotherapy would integrate the "segregated" themes locked in Matilde's experience: she might then be able to consciously accept and deal with her blocked emotions and affects, as to regainenjoyment of life and satisfaction in the relationship with significant figures, re-finding the haven of safety of self and others that she had experienced in her childhood.

The clinical case formulation suggested for Matilde a therapeutic approach in the context of a "partial rapprochement" between attachment theory and psychoanalytic individual psychotherapies as the best solution (Skean, 2005; Slade, 2008; Steele et al., 2009). This intervention would include: (a) The use of therapeutic relationship and alliance as vehicles for a "secure base" 
constitution, in order to observe and understand the client's interpersonal behavior (Spence, 1982; Binder et al., 1987; Dozier et al., 1994; Slade, 2008; Steele et al., 2009); (b) Relationships with the self and others (internal and external), in terms of personality functioning but also from client's transference and therapist's counter-transference points of view of (McWilliams, 1999; Skean, 2005); moreover, patient's real or transferential relationships and past-present pattern of emotional responses and behaviors were examined (Gabbard, 2009). However, a particular emphasis was put on the supportive versus insight-oriented modes of therapy (Skean, 2005), because Matilde needed: (a) to reduce physical and psychical symptoms (S-Axis; Gabbard, 2009), and reestablish a consistent level of functioning (Dewald, 1971; Ursano and Silberman, 1996; Douglas, 2008); (b) to strengthen her fragile ego. Her defenses were at a mature-neurotic level, but were not solid enough to stop the recourse to symptoms and anxiety (PDM: Defenses; Capacity for Differentiation and Integration), (c) to change her self-definition, improving self-esteem, and getting a more integrated perception of the self, (PDM: Qualiy of internal experiences; Capacity for Differentiation and Integration); (d) To function better in everyday life investing lessin achievements and study matters (Dewald, 1971; Ursano and Silberman, 1996; PDM: Rehabilitation); (e) to improve her coping skills and to learn consistent strategies to manage her painful internalized feelings (PDM: Capacity for regulation, attention, and learning); (f) to increase her capacity to express affects both on the positive and negative aspects evidenced by AAI and that were consciously often inhibited and not acknowledged (PDM: Affective Experience, Expression, and Communication); (g) to encourage more consistent ways of relating to others (PDM: Capacity for Intepersonal Relationships; Misch, 2000). In addition, her concrete and intellectualized thinking (SWAP-200) made also difficult for her to deal with interpretations, suggesting again the need of a more supportive approach.

\section{BRIEF OUTLINE OF THE THERAPY UNFOLDING}

As expected, during the first months of therapy Matilde showed a high symptomatic picture. She appeared very distressed and confused, with a sense of failure, of inability to reach her standards. Long boring and intellectualized descriptions of daily routines and of University achievement, anxiety, uncertainties and doubts about her achievements were her main topics. The therapist acted as a secure attachment figure (Parish and Eagle, 2003; Mallinckrodt et al., 2005), as a caregiver who offered security and soothing to Matilde's distress. She worked actively helping Matilde to contain anxiety, shame, and anger (Winston et al., 2004). The therapist, very slowly and respecting her defenses, tried to reduce Matilde's anxiety, to increase her self-esteem and hope, and to make her more aware about herself as a person, and not only as a student who had to achieve some standards. She begun anyway to talk about how she could count on her mother, the only person that always helped her when she felt anxious and distressed. This finally opened a window on her family and her separation difficulties during childhood, and she started to tellhow she felt alone and how much she needed her mother's soothing, how much difficult it was to face her first experience of a 2-week summer camp, as well as to begin elementary school, middle school, and high school. She also admitted that anyway with her mother's help she was able to face these separations. She began to recognize, following therapist's verbalizations, that at that time she was beginning a new kind of "school-experience," similarly to the situation at present. In parallel with this initial understanding of her fear of facing changes and separation, all symptoms increased, especially anxiety symptoms. "It is a nightmare" were her words. She told the therapist that she called mommy every morning and evening but it was not enough. She felt lost and alone. The episodes reported by Matilde at this phase of the therapy were very similar to the ones she reported in the AAI, and the ways she dealt with the present separation from her mother were similar to the ones she previously used during her childhood: going concretely to her mother to be soothed and supported. Moreover, she used the same words she previously used in the two AAP stories where segregated systems were unleashed but resolved. It could be hypothesized that in the transference with the therapist Matilde's attachment system was activated and "seen in action" (George and West, 2012). As she said during the AAI, it was always difficult for her to deal with changes. Now in the transference with the therapist she was reliving her fears, the same fears she experiencedin childhood, the ones that were unleashed at the beginning of the University andthat she was able to face only through anxiety and obsessive symptoms. It was difficult for her to connect this experience with the new separation experience from home and from herself as a child, now that she had to face University and all the complex processes connected with entering adulthood. In the transference with the therapist she was reviving an acute separation anxiety and she was also unconsciously angry at the therapist's impossibility to help her. The therapist tried unsuccessfully to interpret and to connect this profound regression with Matilde's previous separation anxieties. Words were not useful. Wallin (2007) supports that "what patients are unable to explain with words, tends to be evocated, enacted or incorporated" (Zaccagnini and Zavattini, 2009). The working alliance showed for the first time some ruptures, and the risk of treatment disruption itself became a subject of discussion (Appelbaum, 2005; Colli and Lingiardi, 2009). Matilde's alliance rupture style was characterized by the presence of withdrawal maneuvers: emotional disengagement from the therapist, skipping from topic to topic, responding in an overly intellectualized fashion, and very short answers (Safran and Muran, 2000). In such a moment of regression, she really needed a concrete comfort and physical contact with her mother. The therapeutic stance was not enough for her; she decided that the best way to deal with the situation was to go back home. Matilde went home, "to be near to her family." Coming back to her parents represented for her the haven of safety she described in her AAP. Parents were still used as attachment figures during early, middle and late adolescence and also during young adulthood (Fraley and Davis, 1997), especially under conditions of extreme stress (Huntsinger and Luecken, 2004; Kamkar et al., 2012). She stayed home with her family for 3 weeks. When she came back, she appeared less anxious and more integrated: little by little, Matilde was more able to feel the setting as a place where exploration of her personal life and new experiences could be initiated, shared, and enjoyed. She was able to develop positive feelings toward the therapist (Misch, 2000). She began to integrate positive and negative feelings in life events, becoming more 
and more flexible, increasing her ability to tolerate changes and learning to find new solutions to life schedule. She reached some goals toward adulthood and began to find real friends, also far from home, and to spend energy in different activities (e.g., organization, church, neighborhood, etc.). She loved challenges and she felt pleasure in realizing her goals and in pursuing long-term ambitions. A boyfriend appeared. The symptoms disappeared. She continued to use a great amount of razionalization in order to explain some affective aspect of her experiences. from the point of view of attachment, she mantained a tendency to change the topic when she approached emotional issues using displacement defenses in order not to deal with her core difficulties. The therapeutic goal of accomplishing a true adolescent process was also achieved. A solid and good child image was now more integrated with an adolescent and adult image. Some developmental tasks were reached on the way toward adultood (friendship and romantic relationship). The therapist discussed with Matilde the fact that some shortcomings were still present in her personality functioning, but both agreed that she wished now to try to go on with her life by herself. As Freud (1966) suggested, the aim of psychotherapy at a developmental age is to help the patient to proceed along his or her developmental lines. Now Matilde managed to integrate some issues concerning the developmental step of adolescence and young adulthood and she wished to try new experiences by herself.

\section{FOLLOW-UP FINDINGS}

Results from DSM-IV diagnosis, SCL-90-R, and SWAP-200 in the follow-up phase are described in Table 5.

The AAP was scored secure, but without any segregated systems. As a representative example of some new attitudes, Matilde's stories for Window and Departure pictures are reported.

Window (a child looks out a window): a girl who woke up eh... parents are not there, they are at work and she knows she is alone at home. She is quiet. She is looking out of the window thinking about her mom and the fact she will come back home in the afternoon. She is thinking about who she can invite in ... who can ... can keep ... her company. She is quiet, excited by the day without parents (What

Table 5 | Results from SCL-90-R and SWAP-200 in follow-up phase.

\begin{tabular}{ll}
\hline DIAGNOSIS & Follow up \\
\hline DSM-IV & Axis I: No diagnosis \\
SCL-90R & GSI $=0.69$ \\
& SOM $=1.10$ \\
& O-C $=1.10$ \\
& DEP $=0.77$ \\
& ANX $=1.10$ \\
& PD factor \\
SWAP-200 & Obsessive-compulsive (62.82) \\
& O factor \\
& Obsessive style (70.50) \\
& High functioning (66.25)
\end{tabular}

High functioning (66.25) might happen next?) she will find someone . . a . . a friend . . a neighbor ... finally she will have fun (Anything else?) No.

Matilde tells one of the most common AAP stories for the Window picture: a typical home-related scenario in which a little girl needs to manage her solitude. The girl is "quiet" although she is alone home. So, Matilde is not threatened by the girl's loneliness, but she is somehow able to enjoy the possibility of being alone. The absence of segregated systems demonstrates the absence of dysregulating events, which could have led to her being alone (her parents are just working) and of girl's traumatic reactions. More specifically, the girl is depicted "thinking about her mom," activating her ability to internalize the secure base and being "content in solitude." In fact, this connection with the thought of her mother's coming back in the afternoon keeps the girl regulated and lets her also think about something specific to do alone: "she looks out of the window thinking about who she can invite in ... who can keep ... her company." The little girl can recall the affiliative system ("friend") to handle her loneliness. Her ability to think makes Matilde confident and envisages the possibility of changing things in the immediate future ("she invited friends"). From a developmental point of view, Matilde is now a late adolescent-young adult: she is prone to consider also peers and friends as a secure base to refer to in moderately distressful situations.

Departure (an adult man and woman stand facing each other with suitcases positioned nearby): a woman is going to leave for a business trip and she is saying goodbye to her husband... he took her to the station ... she was already planning what she needed to do during the trip ... yes during this period of work... he is quiet and he thinks about their relationship, about how they enjoy to be together, what he would do without ... in these few days without his wife...however... she will leave and he will spend a few dull days ... (Anything else?) No.

In Departure, Matilde is able to tell a typical AAP story, which portrays a couple at the train station. The husband thinks about their relationship and he feels that his days will be dull without his wife. Matilde's story suggests togetherness and a goal-corrected partnership. She portrays the husband as involved in a contingent, reciprocal and mutually engaging relationship.

\section{QUALITATIVE CLINICAL EVALUATION AT THE END OF THERAPY}

Matilde did not have any DSM-IV diagnosis in Axis I and her personality functioning resulted carachterized by obsessive high functioning features (PDM S-axes, SWAP-200). She had no more panic attacks accompanied by strong physical arousal, and her experiences were now more mentally symbolized. Her SCL90-R final symptom profile revealed a magnitude within the normal range. Only two symptomatic distress levels, obsessivecompulsive, and anxiety, still penetrated the clinical range, but their intensity had diminished compared to the assessment phase.

Her self-image improved: she now experienced a sense of personal satisfaction, sufficient self-esteem and self-confidence (PDM $M$-axes). The "negative-stressful" components of her affective world were still present but the level of self-blame, and emotional constriction greatly diminished. She was now less inhibited and became more spontaneous in expressing emotions, and also anger. Matilde still showed a pattern of Mature-Neurotic defenses and an 
absence of primitive defenses. Rationalization, intellectualization, undoing, and displacement were the mostly used defenses, but were now more flexible, less pervasive and she was able to avoid recourring to symptoms and anxiety. The AAP confirmed a flexible use of defenses and reduction in thereliance on dectivation defenses; however, her kind of defense structure still did not allow neither an emotional insight about her motivations and behaviors, or psychological mindedness.

Matilde remained secure in her attachment pattern, changing her defensive approach through a more integrated and coherent one, in which no more segregated systems or disregulation were present: she was now able to use again her self-regulation capacities autonomously (PDM $M$-axes). Her attachment adolescent crisis was resolved; she was out of her "nightmare." She still seemed naïve and used an excessive part of her mental energy to keep emotions and feelings at bay, showing a limited ability to appreciate metaphor, analogy, or nuance. In the context of a supportive stance, comprising a secure and holding environment and an atmosphere based on emotional safety, she was able to work on her fear of loss and changes allowing her internalized attachment status to reach an adult structure. She was now able to deal with adult tasks using her internalized parental figures, thinking about how they could protect her. Matilde now found pleasure, satisfaction, and enjoyment in everyday-life activities. Her underneath security pattern now re-emerged allowing her to maintain a loving relationship, and to engage and keep long-standing and intimate friendships and relationships (PDM $M$-axes). She now set less unrealistically high personal standards and she was now able to find meaning in belonging and contributing to a wider community (e.g., organization, church, neighborhood, etc.). Table 6 shows Matilde's qualitative picture at baseline and at follow up.

\section{DISCUSSION}

This clinical case study highlighted the importance of assessing patient's idiographic and intra-subjective features (Hilliard, 1993). The nature of the clinical case perspective requires a rich diagnostic process that includes both a nosographic approach (such as DSM-IV) and a more multifaceted point of view to assess the specific patient's psychological functioning (Barron, 1998; Shedler and Westen, 2007). There have been few studies investigating the psychotherapy process in supportive therapies (Orlinsky et al.,
2004), and very few studies were devoted to inserting also the contribution of validated measures of attachment. Slade (2008) endorsed that, although attachment theory terms have been incorporated in the present psychoanalytic theory, only few therapists have really integrated core elements of the attachment perspective in their clinical thought. Above all, few of them inserted measures of attachment and their strategies to understand the therapy unfolding (Rockland, 1989; Porcerelli et al., 2011). Assessing attachment means more than just determining a patient's attachment classification status. The benefit from the inclusion of attachment assessment to a multi-method approach is the chance of using results to elucidate the patient's representational and defensive patterns related to attachment activation (Bowlby, 1980).

This paper tried to illustrate a clinical case where results from attachment tools together with PDM assessment could help to give a more integrate picture and to form and inform the unfolding of the therapy. The incremented validity about symptoms and attachment internal working models evaluation added a specific qualitative contribution to each tool (e.g., SCL-90-R gave the self perception of symptomatology and SWAP-200 the clinical perception of it; AAI and AAP increased biographical information and defense mechanism, respectively). The paper presented a case formulation in which a psychodynamic approach was integrated with an attachment theory framework both in the assessment and post-assessment phases and with a "supportive psychotherapy approach." The secure attachment status, as derived from the AAI and the AAP, helped to structure Matilde's therapy, adding information to the therapeutic intervention: Matilde's secure attachment resulted helpful to establish a therapeutic plan, to facilitate the therapeutic alliance and the answer to the therapy, and to help her to face her symptoms and internal difficulties (Douglas, 2008; Steele and Steele, 2008). The AAP and AAI were taken into account, making the therapist sensible to the specific topics concerning separation and loss, which were reactivated throughout treatment. Matilde needed to explore them in the context of a "safe haven," the same context she had previously experienced in her life with her mother's supporting stance. On her side, the therapist recreated and maintained a well knownholding environment, affective mirroring and personal warmth (Markowitz, 2008) and an atmosphere based on emotional safety

Table 6 | Qualitative Matilde's picture of features at baseline and at the end of psychotherapy.

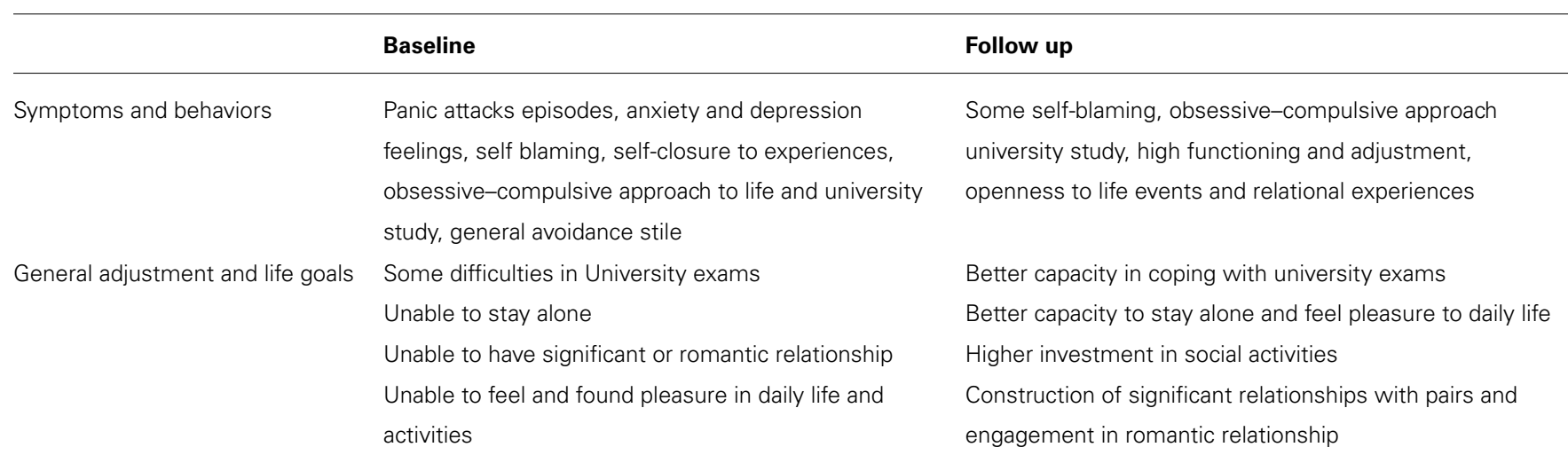


(Crits-Christoph and Connolly, 1999; Skean, 2005). She provided Matilde with the secure base she temporary lost, a starting point from where the exploration of painful experiences in her present life could finally begin. This gave her the possibility to recall some hidden memories, leading to self-exploration (Parish and Eagle, 2003; Mallinckrodt et al., 2005; Holmes, 2010). The "supportive approach" and the role of attachment framework turned out to be a key factor in the assessment and in the development of an effective therapeutic relationship with Matilde. Within a psychoanalytic framework, through the unfolding relationship with the therapist, Matilde brought her interpersonal world into the treatment room and allowed the therapist to experience aspects of her structuring of reality (Crits-Christoph and Connolly, 1999; Skean, 2005). The conclusion of the therapy showed a more integrated picture, where symptoms were no more outstanding and Matilde seemed to be out of her big "nightmare" and ready to face her life tasks in a more integrated and young-adult way. The post-treatment AAP confirmed that Matilde was able to integrate these issues of separation and loss. She was a very defensive neurotic patient blocked at latency, and showed some shortcomings related to the separation-individuation process (Mahler et al., 1975) both from a psychoanalytic and from an attachment point of view.

The treatment helped Matilde to make a developmental step toward maturity: "from childish features to adolescent ones, reaching the capacity of (emotionally) exploring the possibility of living independently from parents $(. .$.$) because they know that they can$ turn to parents in case of real need" (Allen and Land, 1999, p. 322). The therapist was both an "attachment figure" that helped Matilde to face new experiences, as well as a transference object (Dozier et al., 1994). Matilde's development resulted in increased abilities in managing the goal-corrected partnership with each parent, in which behavior is not determined only by adolescent's current needs and wishes, but also by recognition of the need to manage certain set goals for the partnership (Bowlby, 1973).

As all clinical case studies, this study suffered from some limitations (Hodkinson and Hodkinson, 2001): results are not generalizable in the conventional sense; it looks expensive, if attempted on a large scale and the complexity examined is difficult to represent simply and briefly. Furthermore, clinical case studies results stronger when researchers' expertise and intuition are maximized, but this raises doubts about their "objectivity": this type of research is easily subjected to criticisms by those who do not like the messages that they contain; and finally it cannot answer a large number of relevant and appropriate research questions that future studies could address (e.g., in this sense, it could be highly valuable for future research to compare PAD patients with different attachment styles). However, this particular case study could be considered an original and extremely valuable one, because it is grounded in "lived reality." This helps us to understand complex inter-relationships between diagnosis, measures and their clinical application, facilitating the development of conceptual/theoretical issues and the exploration of unexpected and unusual situations, such as PAD in a secure attached patient. As regards the choice of this patient, the present paper can provide "provisional truths, in a Popperian sense" (Hodkinson and Hodkinson, 2001): it represents the best account of such assessment and treatment in the current literature, and it should stand, until contradictory findings or better theories are developed.

\section{REFERENCES}

Ainsworth, M. D. (1963). "The development of infant-mother interaction among the Ganda," in Determinants of Infant Behavioral, ed. B. M. Foss (New York: Wiley), 67-104.

Ainsworth, M. D. (1967). Infancy in Uganda: Infant Care and the Growth of Love. Baltimore, MD: Johns Hopkins University Press.

Allen, J. P. (2008). “The attachment system in adolescence," in Handbook of Attachment: Theory, Research and Clinical Applications, 2nd Edn, eds J. Cassidy and P. R. Shaver (New York: Guilford Press), 419-435.

Allen, J. P., and Land, D. (1999). "Attachment in adolescence," in Handbook of Attachment Theory Research and Clinical Application, eds J. Cassidy and P. R. Shaver (New York: Guilford), 319-335.

American Psychiatric Association [APA] (1994). Diagnostic and Statistical Manual of Mental Disorders, 4th Edn, Washington, DC: American Psychiatric Association.

Appelbaum, A. H. (2005). Supportive Psychotherapy. Arlington, VA: American Psychiatric Publishing, Inc.

Bakermans-Kranenburg, M. J., and van Ijzendoorn, M. H. (1993). A psychometric study of the adult attachment interview: reliability and discriminant validity. Dev. Psychol. 29, 870-879. doi: 10.1037/0012-1649.29. 5.870

Bakermans-Kranenburg, M. J., Van Ijzendoorn, M. H., and Juffer, F. (2005). Disorganized infant attachment and preventive interventions: a review and meta-analysis. Infant Ment. Health J. 23, 191-216. doi: 10.1002/imhj.20046

Barron, W. J. (1998). Marking Diagnosis Meaningful. Enhancing Evaluation and Treatment of Psychological Disorders. Washington, DC: American Psychological Association. doi: 10.1037/10307-000

Bartholomew, K., and Horowitz, L. M. (1991). Attachment styles among young adults: a test of a four-category model. J. Pers. Soc. Psychol. 61, 226-244. doi: 10.1037/0022-3514.61.2.226

Binder, J. L., Henry, W. P., and Strupp, H. H. (1987). An appraisal of selection criteria for dynamic psychotherapies and implications for setting time limits. Psychiatry 50, 154-166.

Blatt, S. J., and Levy, K. N. (2003). Attachment theory, psychoanalysis, personality development, and psychopathology. Psychanal. Inq. 23, 102-150. doi: 10.1080/07351692309349028

Block, J. (1978). The Q-Sort Method in Personality Assessment and Psychiatric Research. Palo Alto, CA: Consulting Psychologist Press.

Bowlby, J. (1969/1982). Attachment and Loss, Vol. 1, Attachment. New York: Basic Books.

Bowlby, J. (1973). Attachment and Loss, Vol. 2, Separation: Anxiety and Anger. New York: Basic Books.

Bowlby, J. (1980). Attachment and Loss, Vol. 3, Loss: Sadness and Depression. New York: Basic Books.

Bowlby, J. (1988). A Secure Base. New York: Basic Books.

Bram, A. D. (2010). The relevance of the rorschach and patient-examiner relationship in treatment planning and outcome assessment. J. Pers. Assess. 92, 91-115. doi: 10.1080/00223890903508112

Buchheim, A. (2005). Inaccessible attachment: a paradox? Personlinch. Theor. Therap. 9, 155-164.

Buchheim, A., and Benecke, C. (2007). Mimisch-affektives verrhalten bei patientinnen mit angststörungen während des adult attachment interviews: Eine pilotstudie. Psychother. Psychol. Med. 57, 343-347. doi: 10.1055/s-2006-952030

Buchheim, A., Erk, S., George, C., Kächele, H., Kircher, T., Martius, P., et al. (2008). Neural correlates of attachment trauma in borderline personality disorders: a functional magnetic resonance image study. Psychiatry Res. 30, 223-235. doi: 10.1016/j.pscychresns.2007.07.001

Buchheim, A., and George, C. (2011). "Attachment disorganization in borderline personality disorder and anxiety disorder," in Disorganization of Attachment and Caregiving, eds J. Solomon and V. George (New York: Guilford Press), 343-383.

Buchheim, A., George, C., and Kächele, H. (2007). "My dog is dying today: attachment narratives and psychoanalytic interpretation of an initial interview," in Attachment and Sexuality, eds D. Diamond, S. J. Blatt, and J. D. Lichtenberg (Hillsdale, NJ: The Analytic Press), 161-178. 
Buchheim, A., Heinrichs, M., George, C., Pokorny, D., Koops, E., Henningsen, P., etal. (2009). Oxytocin enhances the experience of attachment security. Psychoneuroendocrinology 34, 1417-1422. doi: 10.1016/j.psyneuen.2009. 04.002

Buchheim, A., and Kachele, H. (2001). Adult attachment interview of a patient with a borderline personality organization: a single case study integrating attachmen and psychoanalytic perspective. Personlich. Theor. Therap. 5, 113-130.

Cassidy, J., and Shaver, P. R. (Eds.). (2008). Handbook of Attachment: Theory, Research, and Clinical Applications, 2nd Edn, New York: Guilford Press, 3-27.

Colli, A., and Lingiardi, V. (2009). The collaborative interactions scale: a new transcript-based method for the assessment of therapeutic alliance ruptures and resolutions in psychotherapy. Psychother. Res. 19, 718-734. doi: 10.1080/10503300903121098

Cozzolino, L. (2002). The Neuroscience of Psychotherapy: Building and Rebuilding the Human Brain. New York: Norton \& Company.

Crits-Christoph, P., and Connolly, M. B. (1999). Alliance and technique in shortterm dynamic therapy. Clin. Psychol. Rev. 19, 687-704. doi: 10.1016/S02727358(98)00079-8

Dahlbender, R. W., Buchheim, A., and Doering, S. (2004). OPD and AAI: integrative diagnostics of structure, conflict and attachment representation. Personlinch Theor. Therap. 8, 251-261.

Davila, J., and Levy, K. N. (2006). Introduction to the special section on attachment theory and psychotherapy. J. Consult. Clin. Psychol. 74, 989-993. doi: 10.1037/0022-006x.74.6.989

Derogatis, L. R. (1983). SCL-90-R Administration, Scoring Procedures Manual-I. Towson, MD: Clinical Psychometric Research, 14-15.

Derogatis, L. R., Lipman, R. S., and Covi, L. (1973). The SCL-90: an outpatient psychiatric rating scale-preliminary report. Psychopharmacol. Bull. 9, 13-28.

Dewald, P. A. (1971). Psychotherapy: A Dynamic Approach. New York: Basic Books, Inc.

Diamond, D. (2004). Attachment disorganization: the reunion of attachment theory and psychoanalysis. Psychoanal. Psychol. 21, 276-299. doi: 10.1037/07369735.21.2.276

Douglas, C. J. (2008). Teaching supportive psychotherapy to psychiatric resident. Am. J. Psychiatry 165, 445-452. doi: 10.1176/appi.ajp.2007.07121907

Dozier, M., Cue, K. L., and Barnett, L. (1994). Clinicians as caregivers: the role of attachment organization in treatment. J. Consult. Clin. Psychol. 62, 93-800. doi: 10.1037/0022-006x.62.4.793

Eng, W., Heimberg, R. G., Hart, T. A., Schneier, F. R., and Liebowitz, M. R. (2001). Attachment in individuals with social anxiety disorder: the relationship among adult attachment styles, social anxiety, and depression. Emotion 1, 365-380. doi: 10.1037/1528-3542.1.4.365

Fonagy, P. (1999). Pathological attachments and therapeutic action. Paper to the Developmental and Psychoanalytic Discussion Group, American Psychoanalytic Association Meeting, Washington, DC.

Fonagy, P. (2001). Attachment Theory and Psychoanalysis. New York: Other Press.

Fosha, D. (2009). "Healing attachment trauma with attachment (... and then some!)," in Clinical Pearls of Wisdom: 21 Leading Therapists Offer their Keyinsights, ed. M. Kerman (New York: Norton), 43-56.

Fraedrich, E., Lakatos, K., and Spangler, G. (2010). Brain activity during emotion perception: the role of attachment representation. Attach. Hum. Dev.12, 231-248. doi: $10.1080 / 14616731003759724$

Fraley, R. C., and Davis, K. E. (1997). Attachment formation and transfer in young adults' close friendships and romantic relationships. Pers. Relat. 4, 131-144. doi: 10.1111/j.1475-6811.1997.tb00135.x

Freud, A. (1966). Normality and Pathology in Childhood. London: Hogart Press.

Funder, D. C. (1997). The Personality Puzzle. New York: W. Norton.

Gabbard, G. O. (2009). Textbook of Psychotherapeutic Treatments. Arlington, VA: American Psychiatric Publishing, Inc. doi: 10.1176/appi.books.9781585623648

George, C., Kaplan, N., and Main, M. (1984). Adult Attachment Interview (Unpublished manuscript). Berkeley: University of California.

George, C., Kaplan, N., and Main, M. (1985). Adult Attachment Interview, 2nd Edn (Unpublished manuscript). Berkeley: University of California.

George, C., Kaplan, N., and Main, M. (1996). Adult Attachment Interview, 3nd Edn (Unpublished manuscript). Berkeley: University of California

George, C., and Solomon, J. (1996). Representational models of relationships: links between caregiving and attachment. Infant Ment. Health J. 17, 198-216. doi: 10.1002/(SICI)1097-0355(199623)17:3 < 198::AID-IMHJ2>3.0.CO;2-L
George, C., and Solomon, J. (1999). Attachment Disorganization. New York: Guilford Publications.

George, C., and Solomon, J. (2008). "The caregiving system: a behavioral systems approach to parenting," in Handbook of Attachment: Theory, Research, and Clinical Applications, 2nd Edn, eds J. Cassidy and P. R. Shaver (New York: Guilford Press), 833-856.

George, C., and West, M. (2001). The development and preliminary validation of a new measure of adult attachment: the adult attachment projective. Attach. Hum. Dev. 3, 30-61. doi: 10.1080/14616730010024771

George, C., and West, M. (2012). The Adult Attachment Projective Picture System. New York: Guilford Press.

Hazan, C., and Shaver, P. (1987). Romantic love conceptualized as an attachment process. J. Pers. Soc. Psychol. 52, 511-524. doi: 10.1037/0022-3514.52.3.511

Hesse, E. (2008). "The adult attachment interview: protocol, methods of analysis, and empirical studies," in Handbook of Attachment: Theory, Research, and Clinical Applications, 2nd Edn, eds J. Cassidy and P. R. Shaver (New York: Guilford Press), 552-598.

Hilliard, R. B. (1993). Single-case methodology in psychotherapy process and outcome research. J. Consult. Clin. Psychol. 61, 373-380. doi: 10.1037/0022006x.61.3.373

Hodkinson, P., and Hodkinson, H. (2001). The Strengths and Limitations of Case Study Research. Paper Presented to the Learning and Skills Development Agency Conference. Making an Impact on Policy and Practice, Cambridge.

Holmes, J. (2010). Exploring in Security: Towards an Attachment-Informed Psychoanalytic Psychotherapy. New York: Routledge.

Huntsinger, E. T., and Luecken, L. J. (2004). Attachment relationships and health behavior: the mediational role of self-esteem. Psychol. Health 19, 515-526. doi: 10.1080/0887044042000196728

Isaacs, M. B., George, C., and Marvin, R. S. (2009). Utilizing attachment measures in child custody evaluations: incremental validity. J. Child Cusotdy 6, 139-162. doi: 10.1080/15379410902894882

Kamkar, K., Doyle, A., and Markiewicz, D. (2012). Insecure attachment to parents and depressive symptoms in early adolescence: mediating roles of attributions and self-esteem. Int. J. Psychol. Stud. 4, 3-18. doi: 10.5539/ijps. v4n 2 p3

Lingiardi, V., Shedler, J., and Gazzillo, F. (2006). Assessing personality change in psychotherapy with the SWAP-200: a case study. J. Pers. Assess. 86, 23-32. doi: 10.1207/s15327752jpa8601-04

Lis, A., Mazzeschi, C., Di Riso, D., and Salcuni, S. (2011). Attachment, assessment and psychological intervention: a case study of anorexia. J. Pers. Assess. 93, 434444. doi: 10.1080/00223891.2011.594125

Lis, A., Mazzeschi, C., Salcuni, S., and Di Riso, D. (2008). Attachment and Personality in Clinical Settings: Assessment and Treatment Issues. Madrid: Editorial Psimàtic.

Mahler, M. S., Pine, F., and Bergman, A. (1975). The Psychological Birth of the Human Infant: Symbiosis and Individuation. New York: Basic Books.

Main, M., Kaplan, N., and Cassidy, J. (1985). Security in infancy, childhood, and adulthood: a move to the level of representation. Monogr. Soc. Res. Child Dev. 50, 66-104. doi: 10.2307/3333827

Mallinckrodt, B., Porter, M. J., and Kivlighan, D. M. Jr. (2005). Client attachment to therapist, depth of in-session exploration, and object relations in brief psychotherapy. Psychother. Theory Res. Pract. Train. 42, 85-100. doi: 10.1037/0033-3204.42.1.85

Manicavasagar, V., Silove, D., Marnane, C., and Wagner, R. (2009). Adult attachment styles in panic disorder with and without comorbid adult separation anxiety disorder. Aust. N. Z. J. Psychiatry 43, 167-172. doi: 10.1080/00048670802607139

Manicavasagar, V., Silove, D., Wagner, R., and Hadzi-Pavlovic, D. (1999). Parental representations associated with adult separation anxiety and panic disorder-agoraphobia. Aust. N. Z. J. Psychiatry 33, 422-428. doi: 10.1046/j.14401614.1999.00566.x

Markowitz, J. C. (2008). How "supportive" is internet-based supportive psychotherapy? Am. J. Psychiatry 165, 534. doi: 10.1176/appi.ajp.2007.07121853

McWilliams, N. (1999). Psychoanalytic Case Formulation. New York: Guilford Pubblications, Inc.

Meyer, G. J., Finn, S. E., Eyde, L. D., Kay, G. G., Kubiszyn, T. W., Moreland, K. L., et al. (1999). Benefits and Cost of Psychological Assessment in Healthcare Delivery: Report of the Board of Professional Affairs Psychological Assessment Work Group, Part I. Washington, DC: American Psychological Association. 
Misch, D. A. (2000). Basic strategies of dynamic supportive therapy. J. Psychother. Pract. Res. 9, 173-189.

Oppenheim, D., and Goldsmith, D. F. (2007). Attachment Theory in Clinical Work with Children. New York: Guilford Press.

Orlinsky, D. E., Ronnestad, M. H., and Willutzki, U. (2004). Fifty years of psychotherapy process-outcome research: Continuity and Change, in Bergin and Garfield's handbook of psychotherapy and behavior change, 5th Edn, ed. M. Laambert (New York: John Wiley and Sons).

Ozer, D. J. (1999). "Four principles for personality assessment," in Handbook of Personality: Theory and Research, 2nd Edn, eds O. P. John and L. A. Pervin (New York: Guilford Press), 671-686.

Pacchierotti, C., Bossini, L., Castrogiovanni, A., Pieraccini, F., Soreca, I., and Castrogiovanni, P. (2002). Attachment and panic disorder. Psychopathology 35, 347-335. doi: $10.1159 / 000068597$

Parish, M., and Eagle, M. N. (2003). Attachment to the therapist. Psychoanal. Psychol. 20, 271-286. doi: 10.1037/0736-9735.20.2.271

PDM Task Force. (2006). Psychodynamic Diagnostic Manual (PDM). Silver Spring, MD: Alliance of Psychoanalytic Organizations.

Peebles-Kleiger, M. J. (2002). Beginnings: The Art and Science of Planning Psychotherapy. Hillsdale, NJ: The Analytic Press.

Porcerelli, J. H., Cogan, R., and Bambery, M. J. (2011). The mental functioning axis of the Psychodynamic diagnostic manual: an adolescent case study. J. Pers. Assess. 93, 177-184. doi: 10.1080/00223891.2011.542724

Rockland, L. H. (1989). Psychoanalytically oriented supportive therapy. J. Am. Acad. Psychoanal. 17, 451-462.

Routh, D. K., and Bernholtz, J. E. (1991). “Attachment, separation and phobias," in Intersections with Attachment, eds J. L. Gewirtz, W. M. Kurtines, and J. L. Lamb (Hove: Psychology Press), 295-310.

Safran, J. D., and Muran, J. C. (2000). Negotiating the Therapeutic Alliance: A Relational Treatment Guide. New York: Guilford Press.

Shear, M. K. (1991). The concept of uncontrollability. Psychol. Inq. 2, 88-93. doi: 10.1207/s15327965pli0201-23

Shectman, F., and Harty, M. K. (1986). "Treatment implications of object relationships as they unfold during the diagnostic interaction," in Assessing Object Relations Phenomena, ed. M. Kissen (Madison, CT: International Universities Press), 279-303.

Shedler, J., and Westen, D. (1998). Refining the measurement of Axis II: a Qsort procedure for assessing personality pathology. Assessment 5, 333-353. doi: $10.1177 / 107319119800500403$

Shedler, J., and Westen, D. (2007). The Shedler-Westen assessment procedures (SWAP): making personality diagnosis clinically meaningful. J. Pers. Assess. 89, 41-55. doi: 10.1080/00223890701357092

Siegel, D. J. (2010). The Mindful Therapist: A Clinician's Guide to Mind Sight and Neural Integration. New York: W. W. Norton \& Company.

Skean, K. R. (2005). The case of "CG": balancing supportive and insight-oriented, psychodynamic therapy with a client undergoing intense life stresses. Prag. Case Stud. Psychother. 1, 1-18. doi: 10.14713/pcsp.v1i3.860

Slade, A. (2008). The Implications of Attachment Theory and Research for Adult Psychotherapy: Research and Clinical Perspectives. New York: Guilford Press.

Spence, D. P. (1982). Narrative Truth and Historical Truth. New York: Norton.

Steele, H., and Steele, M. (2008). Clinical Applications of the Adult Attachment Interview. New York: Guilford Press, 69-96.

Steele, H., Steele, M., and Murphy, A. (2009). The adult attachment interview: a clinical tool for facilitating and measuring process and change in psychotherapy. Psychother. Res. 19, 633-643. doi: 10.1080/10503300802609698

Ursano, R. J., and Silberman, E. K. (1996). "Psychoanalysis, psychoanalytic psychotherapy, and supportive psychotherapy," in The American Psychiatric Press
Synopsis of Psychiatry, eds R. E. Hales and S. C. Yudofsky (Washington, DC: American Psychiatric Association), 969-989.

van IJzendoorn, M. H., and Bakermans-Kranenburg, M. J. (2008). “The distribution of adult attachment representations in clinical groups: a meta-analytic search for patterns of attachment in 105 AAI studies," in Clinical Applications of the Adult Attachment Interview, eds H. Steele and M. Steele (New York: Guilford Press), 69-96.

Wallin, D. J. (2007). Attachment in Psychotherapy. New York: Guilford Press.

Wallis, P., and Steele, H. (2001). Attachment representations in adolescence: further evidence from psychiatric residential settings. Attach. Hum. Dev. 3, 259-269. doi: $10.1080 / 14616730110096870$

West, M., and George, C. (1999). Abuse and violence in intimate adult relationship: new perspectives from attachment theory. Attach. Hum. Dev. 1, 137-156. doi: $10.1080 / 14616739900134201$

West, M., and George, C. (2002). Attachment and dysthymia: the contributions of preoccupied attachment and agency of self to depression in women. Attach. Hum. Dev. 4, 278-293. doi: 10.1080/14616730210167258

West, M., Rose, S. M., and Sheldon-Keller, A. (1995). Interpersonal disorders in schizoid and avoidant personality disorders: an attachment perspective. Can. J. Psychiatry 40, 411-414.

Westen, D., and Muderrisoglu, S. (2003a). Assessing personality disorders using a systematic clinical interview: evaluation of an alternative to structured interviews. J. Pers. Disord. 17, 351-369. doi: 10.1521/pedi.17.4.351. 23967

Westen, D., and Muderrisoglu, S. (2003b). Reliability and validity of personality disorders assessment using a systematic clinical interview: evaluation of an alternative to structured interviews. J. Pers. Disord. 17, 350-368.

Westen, D., and Shedler, J. (1999a). Revising and assessing Axis II: I. Developing a clinically and empirical valid assessment method. Am. J. Psychiatry 156, 258-272.

Westen, D., and Shedler, J. (1999b). Revising and assessing Axis II: II. Toward an empirically based and clinically useful classification of personality disorderds. Am. J. Psychiatry 156, 273-285.

Winston, M. D., Rosenthal, R. N., and Pinsker, H. (2004). Introduction to Supportive Psychotherapy. Arlington, VA: American Psychiatric Publishing, Inc.

Zaccagnini, C., and Zavattini, G. C. (2009). Introduzione a D. J. Wallin, Psicoterapia $e$ Teoria dell'Attaccamento. Bologna, Il Mulino, 7-21.

Zegers, M. A., Schuengel, C., Van, I. M. H., and Janssens, J. M. (2008). Attachment and problem behavior of adolescents during residential treatment. Attach. Hum. Dev. 10, 91-103. doi: 10.1080/14616730701868621

Conflict of Interest Statement: The authors declare that the research was conducted in the absence of any commercial or financial relationships that could be construed as a potential conflict of interest.

Received: 21 May 2014; accepted: 30 July 2014; published online: 20 August 2014. Citation: Salcuni S, Di Riso D and Lis A (2014) "A child's nightmare. Mum comes and comforts her child." Attachment evaluation as a guide in the assessment and treatment in a clinical case study. Front. Psychol. 5:912. doi: 10.3389/fpsyg.2014.00912

This article was submitted to Psychology for Clinical Settings, a section of the journal Frontiers in Psychology.

Copyright (c) 2014 Salcuni, Di Riso and Lis. This is an open-access article distributed under the terms of the Creative Commons Attribution License (CC BY). The use, distribution or reproduction in other forums is permitted, provided the original author(s) or licensor are credited and that the original publication in this journal is cited, in accordance with accepted academic practice. No use, distribution or reproduction is permitted which does not comply with these terms. 


\title{
Assessing attachment representations among adoptees during middle childhood and adolescence with the Friend and Family Interview (FFI): clinical and research perspectives
}

\author{
Cecilia Serena Pace* \\ *Correspondence: cecilia.pace@unige.it \\ Edited by: \\ Silvia Salcuni, Università degli Studi di Padova, Italy \\ Reviewed by: \\ Chiara Pazzagli, University of Perugia, Italy
}

Department of Educational Science, University of Genoa, Genoa, Italy

Keywords: attachment, adoption, friend and family interview, middle childhood, adolescence, Internal Working Models (IWMs)

\section{ADOPTION AND ATTACHMENT THEORY BEYOND INFANCY AND EARLY CHILDHOOD}

Three trends of attachment research could be identified in the adoption field. The first was focused on the comparisons between attachment patterns of adopted children and those of their non-adopted peers. It indicates a higher probability of insecure and disorganized patterns among the adoptees (Van den Dries et al., 2009). The second highlighted a significant intergenerational concordance of attachment Internal Working Models (IWMs) between adoptive parents and their adopted children (Steele et al., 2003; Barone and Lionetti, 2012). The third revealedthrough longitudinal design - the increasing security of adopted children which is positively affected by the parental attachment security, especially maternal one (Beijersbergen et al., 2012). This trend suggests that adopted children have the ability to generate new relationships of attachment with adoptive parents, although the impact of their previous adverse experiences has not completely disappeared (Steele et al., 2008; Pace and Zavattini, 2011).

Recently, a new research trend has been emerging: the assessment of adoptees' IWMs in the course of middle childhood and adolescence, not exclusively focused on their relationship with parents. Many important changes happen at the emotional, cognitive and behavioral level during these stages which are related to attachment systems (Steele and Steele, 2005; Allen, 2008). Adolescents develop the meta-cognitive skills to check their mental states, as well as the ability to recognize positive or negative aspects in their relationships with parents. Moreover, they seek greater independence, greater autonomy and differentiation from their primary caregivers. Relationships with other people outside the family (friends, etc.) become much more important than they had ever been before (Allen, 2008). Due to these changes, middle childhood and adolescence could be considered periods of potential transformations at level of attachment representations. Therefore, they become relevant in the study of adoptees behavior (Palacios and Brodzinsky, 2010).

\section{THE FRIEND AND FAMILY INTERVIEW (FFI)}

The evaluation of attachment representations during middle childhood and adolescence is done using narrative tools, such as story-completion tasks or interviews (e.g., Attachment Interview for Childhood and Adolescence; Riva Crugnola et al., 2009). These tools allow us to go more in-depth into the adolescent's story and obtain a more extensive study of the richness of his or her experiences with regard to attachment relationships. The Friends and Family Interview (FFI, Steele and Steele, 2005; Steele et al., 2009) is an increasingly used narrative method with adopted samples (see below). The FFI is a semi-structured interview, informed by but distinct from the Adult Attachment Interview (AAI, Main et al., 2008) which is considered the "golden standard" method to assess attachment states of mind of adults. As the AAI, the FFI is aimed at capturing the individual differences of attachment representations (secure, dismissing, preoccupied, and disorganized). It focuses on the coherence of the narrative leaning heavily toward Grice's (1975) maxims of "good conversation," i.e., being truthful, relevant, economical and conventionally polite. Therefore, the core of the coding system is based on the "style of discourse," rather then its-positive or negative-content. Two main differences have emerged between the FFI and the AAI: (1) the questions of the FFI focus, in turn, on self, peers (best friend), siblings and parents, not exclusively on the interviewee-parents relationships (like the AAI), (2) the FFI is a way of systematically inquiring about the young person's view-supported by episodes-of the complex and often conflicting emotions arising in one's closest relationships, rather than comparing semantic (adjectives) and episodic memory (episodes) of the past experiences with attachment figures (like the AAI). Although the AAI was developed in the area of development research, it has revealed precious clinical applications, i.e., facilitating therapeutic alliance, assessing therapeutic outcomes, indentifying defensive processes, etc. (Steele and Steele, 2008). My question 
is whether the FFI could possibly have relevant clinical applications (as the AAI had) specifically in the adoption context. In addressing this question, I will briefly review literature that analyzed attachment models of adopted children and adolescents with the FFI, discuss questions left unanswered by the current literature, and set the path for future clinical applications and research concerns.

\section{CAPTURING ATTACHMENT REPRESENTATIONS AMONG ADOPTEES BY THE FFI: RESEARCH TO DATE}

I identified three research groups who analyzed the attachment representations of adoptees from middle childhood to adolescence using the FFI (Steele et al., 2009). In Table 1 see the distribution of attachment classifications among adoption studies using the FFI.

The first research group focused on the correlations between attachment security/insecurity and several features of children's psychological functioning. Abrines et al. (2012) found that internationally adopted children with a secure attachment showed significantly less attention problems and a trend toward less hyperactivity. Barcons et al. (2012) highlighted a significantly better interpersonal and parental relationships among adoptees classified as secure by the FFI. Lastly, Barcons et al. (2014) indicated that a secure attachment representation facilitates the development of adaptive skills (adaptability, social skills and leadership skills) of adoptees. From the second group, the Attachment Adoption Adolescents Research Network (AAARN), Stievenart et al. (2012) demonstrated-through a psychometric study-the measurement invariance of the FFI from Belgian and Romanian adopted adolescents. This study showed that the FFI coherence was similar across the two samples and correlated with the attachment categories. Among domestically adopted Romanian children, Groza et al. (2012) found that little more than the half had secure attachment representations and none showed disorganized ones. Lastly, Escobar and Santelices (2013) pointed out that in Chile nationally adopted adolescents showed more insecure attachment-mostly dismissing-than their non-adopted peers. The third research group found a significant concordance between secure/insecure attachment classifications of mothers by the AAI and late-adopted adolescents by the FFI (Pace et al., 2013a). In addition, Pace et al. (2013b) highlighted a significant change of attachment classifications. Growing from beginning of adoption to adolescence children moved from insecurity toward security through a long-term longitudinal research design.

\section{CLINICAL AND RESEARCH ISSUES REFLECTIVE FUNCTIONING (RF)}

The link between poor mentalization skills-often operationalized in terms of RF-and severe difficulties in the early parent-child relationships is widely acknowledged. Much less it is known regarding mentalization skills of adoptees, even if low RF was strongly associated with early relational traumas which are common in their pre-adoption lives. On one hand, traumatic experiences — such as abuse and maltreatment perpetuated by original attachment figure during infancy and childhood-can inhibit the development of RF: thinking of the other's mind for traumatized becomes a very dangerous experience. On the other hand, high RF in individuals who have experienced early adversities seems to represent a resilience factor. It can reduce both intergenerational transmission of insecurity and the probability of onset of borderline personality disorder (Fonagy and Bateman, 2006). One of the merit of the FFI's coding system is that RF is operationalized across three sub-domains: (1) developmental perspective that represents the interviewee's capacity to contrast his/her current thoughts and feelings concerning important relationships or his/her self-view with past attitudes; (2) theory of mind, intended as the ability to assume the mental or emotional perspective of another person; (3) diversity of feelings, defined as the ability to show an understanding of diverse (negative and positive) feelings being present in significant relationships involving self and other people (Kriss et al., 2012). Despite the importance of RF, none of the abovementioned adoption studies reported data on it. I suggest that the assessment of the RF through the FFI of adopted children and adolescents could be relevant: (1) from a clinical perspective, because it can help adoption workers to individuate a vulnerable factor (low RF) that needs to be enhanced; (2) from a research perspective, in order to analyze the precursors, concomitants and sequelae of RF of adoptees.

\section{DISORGANIZATION}

Disorganized IWMs are considered connected both with early maltreatments and later long-term psychopathological outcomes (Steele and Steele, 2008). Studies on late-adopted children (aged 3-8) showed-in line with their early adverse experiences - a consistent presence of disorganization among them (over $30 \%$ ) assessed through attachment completion tasks (Steele et al., 2003, 2008; Barone and Lionetti, 2012; Pace et al., 2012, 2013c). Surprisingly, disorganized IWMs appear rather under-represented in the adoption studies with FFI showing a percentage from 0 to $3 \%$. A lower result compared to non-clinical adolescent populations assessed by the AAI (around $11 \%$, Bakermans-Kranenburg and Van Ijzendoorn, 2009). I suppose that it would be rather difficult to think that disorganized representations, revealed among adopted children at previous stages, tend to "disappear" at later stages. The FFI coding system may not capture subtle cues of disorganization at a narrative level as both attachment completion task (e.g., catastrophic fantasy, bizarre/atypical material, child parents/controls, extreme aggression, etc.) and the AAI (e.g., lapses of monitoring of reasoning/discourse about loss/trauma) can do. However, I suggest the hypothesis that the FFI should include the evaluation of two non-verbal codes which could be connected with disorganized classifications: (1) distress and fear, (2) frustration and anger. These non-verbal codes capture specific signs of distress such as freezing behavior, stereotypic movements, verbal and non-verbal aggression toward the interviewer, etc. which are usually considered indexes of disorganization (Steele et al., 2009). Up today, none of the FFIrelated adoption studies have explicitly taken into consideration these codes. I suppose that the inclusion of the nonverbal codes could be useful with adoptees for two reasons: (1) from a clinical perspective, because it can help clinicians 
Table 1 | The distribution of attachment classifications among adoption studies using the FFI.

\begin{tabular}{|c|c|c|c|c|c|c|c|c|}
\hline Studies with FFI & $N$ & Type of adoption & Age & $\begin{array}{c}\text { Non-adopted } \\
\text { controls }\end{array}$ & \multicolumn{4}{|c|}{ Attachment classifications } \\
\hline Abrines et al., 2012 & 58 & Only international & $7-8(M=7.48)$ & no & 60 & 26 & 12 & 2 \\
\hline Barcons et al., 2012 & 116 & Only international & $8-11(M=8.92)$ & no & 60.3 & 25 & 12.9 & 1.7 \\
\hline Barcons et al., 2014 & 168 & Only international & $7-11(M=8.33)$ & no & 58.9 & 25 & 13.1 & 3 \\
\hline Groza et al., 2012 & 39 & $\begin{array}{l}\text { Only domestic } \\
\text { (Romanian) }\end{array}$ & $11-16(M=13.1)$ & no & 51.3 & & 8.7 & 0 \\
\hline $\begin{array}{l}\text { Escobar and Santelices, } \\
2013\end{array}$ & 25 & Only domestic (Chilean) & $11-18(M=12.9)$ & yes & 32 & 52 & 16 & 0 \\
\hline Pace et al., 2013a & 22 & $\begin{array}{l}\text { International and } \\
\text { domestic (Italian) }\end{array}$ & $12-16(M=14)$ & no & 64 & 27 & 9 & 0 \\
\hline
\end{tabular}

to understand adoptee's level of integration/non integration among behavioral and somatic vs. cognitive and affective expressions of self (e.g., an adolescent describing very violent fights with his father, but these are referred with a cool detachment), (2) from a research perspective, to explore whether they were correlated with disorganized classifications and, in turn, whether disorganization develops throughout longitudinal research design.

\section{REFLECTIONS ON SOME FFI QUESTIONS}

In the FFI the child/adolescent is asked to think back to his earliest memory of separation from caregivers, first in terms of his own behavior, thoughts, and feelings. Subsequently in terms of how he imagines his caregivers might have felt at the time (n. 21). Then he/she is asked to speak about his/her relationships with his/her brother and sister (n. 22).

I argue that these specific questions could often assume a unique meaning for adoptees. Indeed late-adopted children often had spent long time with their biological parents and siblings and they have lively and clear memories of them. For examples, it happen that adopted speaker asks to the interviewer "Separation from who? My biological parents or my adoptive parents?," or he/she can say "I have not sibling now here. But I had four older brothers in Brazil, where I was born. Would you like that I speak about them?". I suggest that leaving these questions open (without any limitation like: "I want you to speak about separation from your adoptive parents/your living-with sibling") could provide interesting and relevant information about adopted population. From a clinical perspective, the answers to these questions can assume a great importance during treatment of adoptive families, because they help to understand how the process of integration of past and present representations has been working in the inner world of the adoptees. From a research perspective, maybe it could be useful to capture this information in specific codes for adopted samples and explore whether they are connected with individual and familiar factors.

\section{CONCLUSIONS AND RECOMMENDATIONS}

In conclusion, the FFI is a novel method developed to assess the IWMs of individuals that range from 9 to 17 years of age and it was often used with adopted samples. A small but emerging adoption literature highlighted that adoptees with secure attachment representations measured by the FFI showed significantly less psychological problems and more competences compared to insecure ones. In addition significant associations between adoptees secure IWMs and maternal secure attachment states of mind were detected. However, the FFI, and its coding system, shows some limits—such as a lower skill of detecting disorganization compared with other measures - that need to be taken into consideration. Future research needs to consider not only the global attachment classifications (secure, dismissing, preoccupied and disorganized), but also other dimensions coded through the FFI (coherence, reflective function, evidence of secure base, etc.) that could offer more relevant information about the inner world of the adoptees. In addition, the FFI could be an attachment measurement (as yet it happened with the AAI) useful to yield valuable insights into the emotional and relational difficulties of adopted children/adolescents, facilitating case formulation and treatment planning of post-adoption services.

\section{REFERENCES}

Abrines, N., Barcons, N., Marre, D., Brun, C., Fornieles, A., and Fumadó, V. (2012). ADHDlike symptoms and attachment in internationally adopted children. Attach. Hum. Dev. 14, 405-423. doi: 10.1080/14616734.2012.691656

Allen, J. (2008). "The attachment system in adolescence," in Handbook of Attachment. Theory, Research, and Clinical Applications, eds J. Cassidy and P. Shaver (New York, NY: The Guildford PressBarcons), 419-435.

Bakermans-Kranenburg, M. J., and Van Ijzendoorn, M. H. (2009). The first 10,000 adult attachment interviews: distribution of adult attachment representations in clinical and non- clinical groups. Attach. Hum. Dev. 11, 223-263. doi: 10.1080/14616730902814762

Barcons, N., Abrines, N., Brun, C., Sartini, C. Fumadó, V., and Marre, D. (2012). Social relationships in children from intercountry adoption. Child. Youth Serv. Rev. 34, 955. doi: 10.1016/j.childyouth.2012.01.028

Barcons, N., Abrines, N., Brun, C., Sartini, C., Fumadó, V., and Marre, D. (2014). Attachment 
and adaptive skills in children of international adoption. Child Family Soc. Work 19, 89-98. doi: 10.1111/j.1365-2206.2012.00883.x

Barone, L., and Lionetti, F. (2012). Attachment and emotional understanding: a study on lateadopted pre-schoolers and their parents. Child Health Care Dev. 38, 690-696. doi: 10.1111/j.13652214.2011.01296.x

Beijersbergen, M., Juffer, F., Bakermans-Kranenburg, M., and van IJzendoorn, M. (2012). Remaining or becoming secure: parental sensitive support predicts attachment continuity from infancy to adolescence in a longitudinal adoption study. Dev. Psychol. 48, 1277-1282. doi: 10.1037/a0027442

Escobar, M. J., and Santelices, M. P. (2013). Attachment in adopted adolescents. National adoption in Chile. Child. Youth Serv. Rev. 35, 488-492. doi: 10.1016/j.childyouth.2012.12.011

Fonagy, P., and Bateman, A. W. (2006). Mechanisms of change in mentalization-based treatment of BPD. J. Clin. Psychol. 62, 411-430. doi: 10.1002/jclp.20241

Grice, H. (1975). "Logic and conversation," in Syntax and Semantics, Vol. 3, eds P. Cole and J. Moran (New York, NY: Academic Press), 41-58.

Groza, V., Muntean, A., and Ungureanu, R. (2012). The adoptive family within the romanian cultural context: an exploratory study. Adopt. Q. 15, 1-17. doi: 10.1080/10926755.2012.661327

Kriss, A., Steele, H., and Steele, M. (2012). Measuring attachment and reflective functioning in early adolescence: an introduction to the friends and family interview. Res. Psychother. Psychopathol. Process Outcome 15, 87-95. doi: 10.7411/RP.2012.009

Main, M., Goldwyn, R., and Hesse, E. (2008). Adult Attachment Scoring and Classification System. Unpublished manuscript, Department of Psychology, University of California at Berkeley.

Pace, C. S., Di Folco, S., Guerriero, V., and Zavattini, G. C. (2013b). "Attachment models of late-adopted children and their adoptive mothers during adolescence: a long-term follow-up," in Medimond International Proceedings, (Bologna), 151-154.

Pace, C. S., Di Folco, S., Zavattini, G. C., Santona, A., Guerriero, V., and D'Onofrio, E. (2013a). "Association between attachment representation of late-adopted adolescents and attachment state of mind of their adoptive mothers: a pilot-study. SYMPOSIUM: mental representations of attachment: development and sources of influence," in 4th International Conference on Adoption Research (ICAR4), (Bilbao), 35-36.

Pace, C. S., and Zavattini, G. C. (2011). 'Adoption and attachment theory' The attachment models of adoptive mothers and the revision of attachment patterns of their late-adopted children. Child Care Health Dev. 37, 82-88. doi: 10.1111/j.13652214.2010.01135.x

Pace, C. S., Zavattini, G. C., and D'Alessio, M. (2012). Continuity and discontinuity of attachment patterns: a short-term longitudinal pilot-study of late-adopted children and their adoptive mothers. Attach. Hum. Dev. 14, 45-61. doi: 10.1080/14616734.2012.636658

Pace, C. S., Zavattini, G. C., and Tambelli, R. (2013c). Does family drawing assess attachment representations of late-adopted children? A preliminary report. Child Adolesc. Mental Health. doi: 10.1111/camh.12042. [Epub ahead of print].

Palacios, J., and Brodzinsky, D. (2010). Adoption research: trends, topics, outcomes. Int. J. Behav. Dev. 34, 270-284. doi: 10.1177/0165025410362837

Riva Crugnola, C., Sagliaschi, S., and Rancati, I. (2009). Qualità dell'attaccamento ed elaborazione delle esperienze infantili avverse in preadolescenti adottati [Attachment's quality and processing of adverse childhood experiences in preadolescents adopted]. Psicol. Clin. Dello Sviluppo 3, 515-542.

Steele, H., and Steele, M. (2005). "The construct of coherence as an indicator of attachment security in middle childhood. the friends and family interview," in Attachment in Middle Childhood, eds K. A. Kerns and R. A. Richardson (New York, NY: Guilford Press), 137-160.

Steele, H., and Steele, M., (eds.). (2008). Clinical Applications of the Adult Attachment Interview. New York, NY: Guilford Press.

Steele, H., Steele, M., and Kriss, A. (2009). FFI Scoring System. New York, NY: Unpublished document, Center for Attachment Research, New School for Social Research.

Steele, M., Hodges, J., Kaniuk, J., Hillman, S., and Henderson, K. (2003). Attachment representations and adoption: associations between maternal states of mind and emotion narratives in previously maltreated children. J. Child Psychother. 29, 187-205. doi: 10.1080/0075417031000138442

Steele, M., Hodges, J., Kaniuk, J., Steele, H., Hillman, S., and Asquith, K. (2008). "Forecasting outcomes in previously maltreated children. The use of the AAI in a longitudinal adoption study," in Clinical Applications of the Adult Attachment Interview, eds H. Steele and M. Steele (New York, NY: Guilford Press), 427-451.

Stievenart, M., Casonato, M., Muntean, A., and van de Schoot, R. (2012). The friends and family interview: measurement invariance across Belgium and Romania. Eur. J. Dev. Psychol. 9, 737-743. doi: 10.1080/17405629.2012.689822

Van den Dries, L., Juffer, F., Van IJzendoorn, M. H., and Bakermans-Kranenburg, M. (2009). Fostering security? A meta-analysis of attachment in adopted children. Child. Youth Serv. Rev. 31, 410-421. doi: 10.1016/j.childyouth.2008. 09.008

Conflict of Interest Statement: The author declares that the research was conducted in the absence of any commercial or financial relationships that could be construed as a potential conflict of interest.

Received: 16 May 2014; accepted: 15 September 2014; published online: 01 October 2014.

Citation: Pace CS (2014) Assessing attachment representations among adoptees during middle childhood and adolescence with the Friend and Family Interview (FFI): clinical and research perspectives. Front. Psychol. 5:1114. doi: 10.3389/fpsyg.2014.01114

This article was submitted to Psychology for Clinical Settings, a section of the journal Frontiers in Psychology. Copyright (c) 2014 Pace. This is an open-access article distributed under the terms of the Creative Commons Attribution License (CC BY). The use, distribution or reproduction in other forums is permitted, provided the original author(s) or licensor are credited and that the original publication in this journal is cited, in accordance with accepted academic practice. No use, distribution or reproduction is permitted which does not comply with these terms. 